\title{
OCT1-mediated cellular drug uptake and interactions between drug transport and drug metabolism
}

\author{
Doctoral Thesis \\ In partial fulfillment of the requirements for the degree \\ "Doctor rerum naturalium (Dr. rer. nat.)" \\ in the Molecular Medicine Study Program \\ at the Georg-August University Göttingen
}

submitted by

\section{Ali Reza Saadatmand}

born in September 1977

Göttingen 2012 


\section{Members of the Thesis Committee:}

Supervisor

Name, Institute: Prof. Dr. med. Jürgen Brockmöller, Department of Clinical Pharmacology, Georg-August University Göttingen

Second member of the thesis committee

Name, Institute: Prof. Dr. med. Gerhard Burckhardt, Department of Systemic Physiology and Pathophysiology, Georg-August University Göttingen

Third member of the thesis committee

Name, Institute: Prof. Dr. med. Nicolas von Ahsen, Department of Clinical Chemistry, Georg-August University Göttingen

Date of Disputation: 25.10.2012 


\section{AFFIDAVIT}

Here I declare that my doctoral thesis entitled "OCT1-mediated cellular drug uptake and interactions between drug transport and drug metabolism" has been written independently with no other sources and aids than quoted.

Ali Reza Saadatmand

Göttingen, September 2012 


\section{List of Publications}

1) Saadatmand, A. R., Tadjerpisheh S., Jurgen Brockmoller, and Mladen V. Tzvetkov. Debrisoquine as a model substrate of the highly genetically variable organic cation transporter OCT1. Biochemical Pharmacology, 83: 1427-34 (2012)

2) Tzvetkov, M.V., Saadatmand, A.R., Lötsch, J., Tegeder, I., Sting, JC., and Brockmöller, J. Genetically Polymorphic OCT1: Another Piece in the Puzzle of the Variable Pharmacokinetics and Pharmacodynamics of the Opioidergic Drug Tramadol. Clinical pharmacology \& Therapeutics, 90: 143-150 (2011).

3) Tzvetkov, M.V., Saadatmand, A.R., Bokelmann, K., Meineke, I., Kaiser, R. \& Brockmöller, J.Effects of OCT1 polymorphisms on the cellular uptake, plasma concentrations and efficacy of the 5-HT(3) antagonists tropisetron and ondansetron. Pharmacogenomics J, 12: 22-29 (2010). 
Dedicated to my beloved wife Kateryna... 


\section{Table of contents}

TABLE OF CONTENTS. I

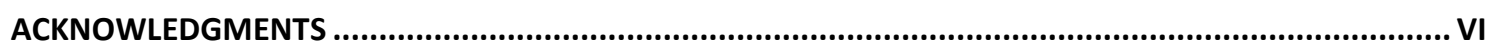

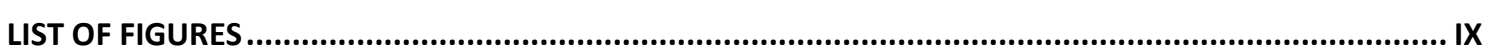

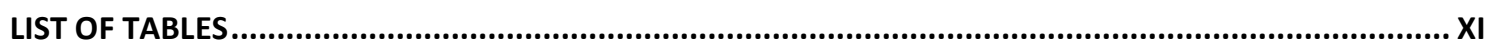

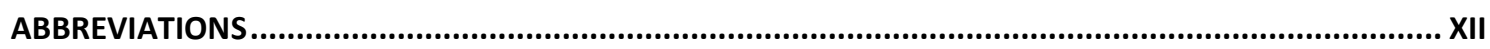

1 INTRODUCTION

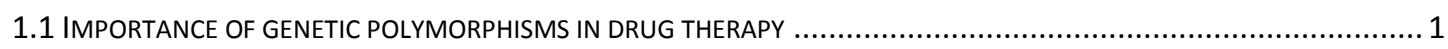

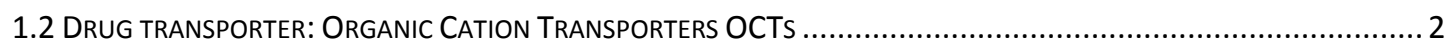

1.2.1 Tissue distribution and subcellular localization of the human OCT homologs.......................... 5

1.2.2 Substrate and Inhibitor Specificities of OCTs .................................................................... 6

1.2.3 Functions of polyspecific OCTs in various organs................................................................... 7

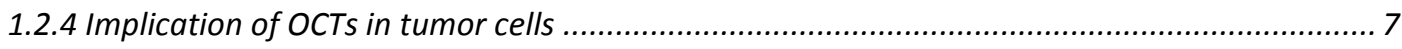

1.2.5 Genetic variation in the SLC22A1 gene coding for OCT1 …............................................. 8

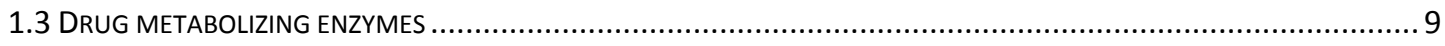

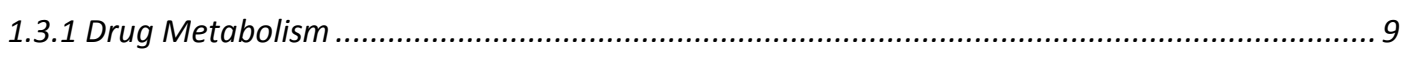

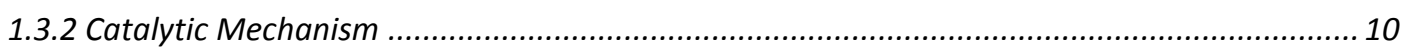

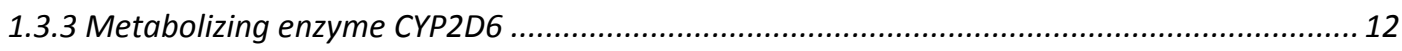

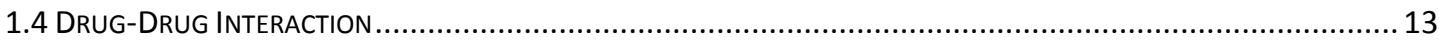

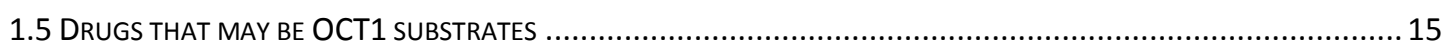

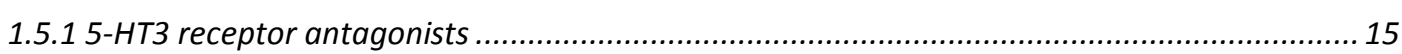

1.5.2 The analgesic drugs tramadol and O-desmethyl tramadol .................................................. 17

1.5.3 The CYP2D6 model drug debrisoquine ............................................................................ 18

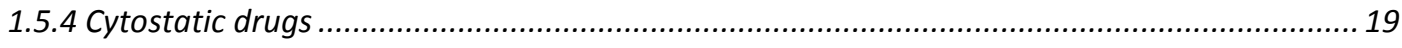

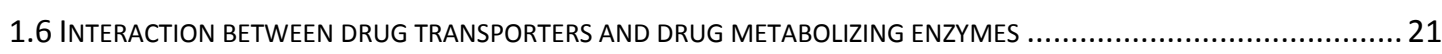

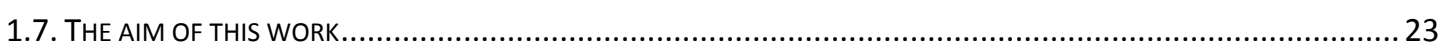

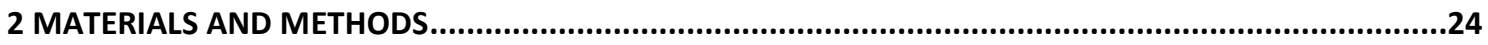

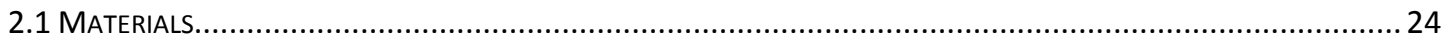

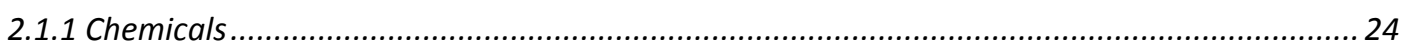

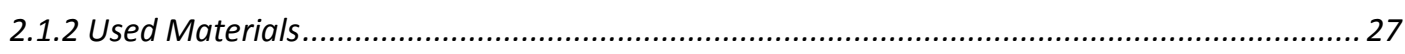

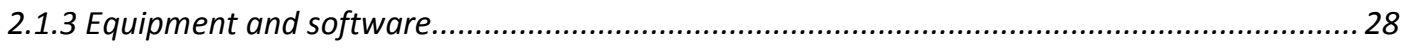

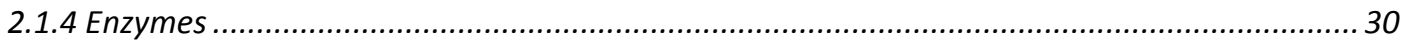

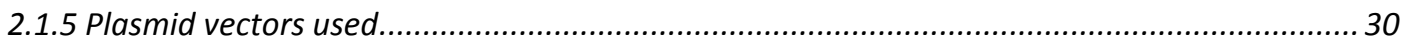

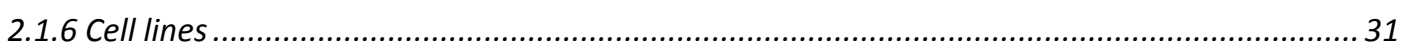

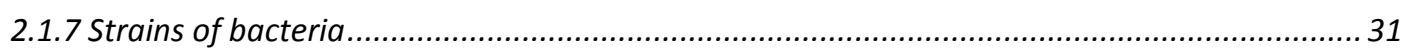




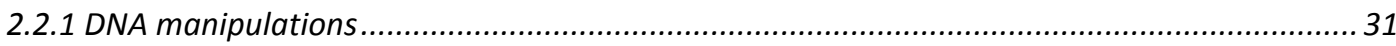

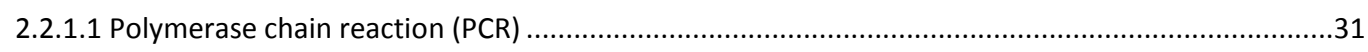

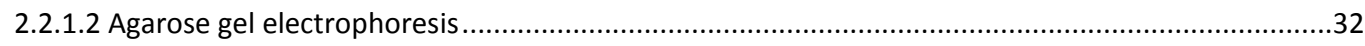

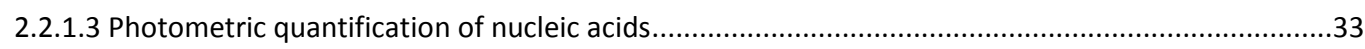

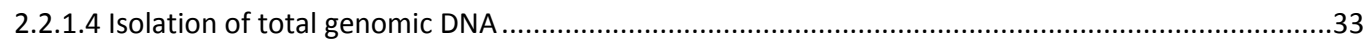

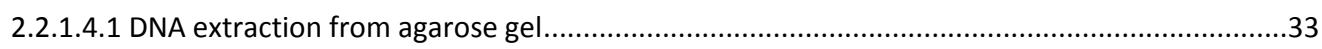

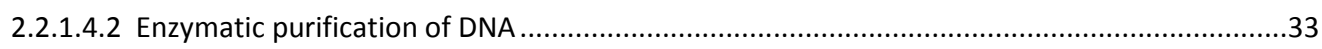

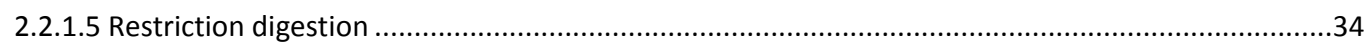

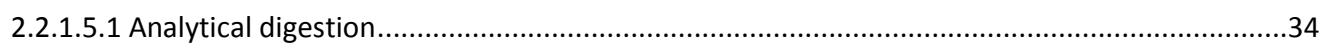

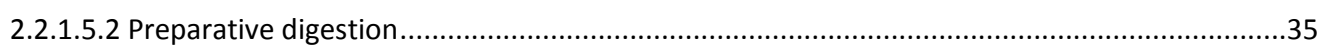

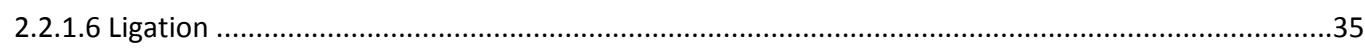

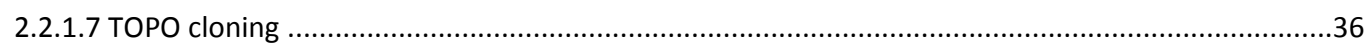

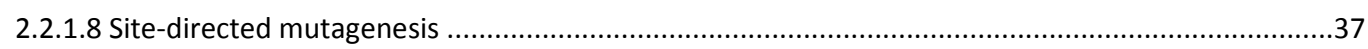

2.2.1.9 PCR for analyzing the chromosomal integration of pcDNA5 constructs .........................................39

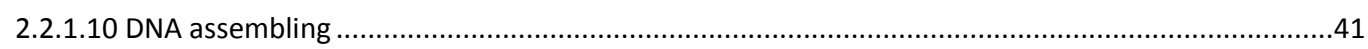

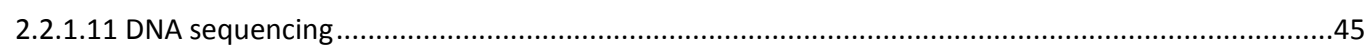

2.2.1.12 Genotyping using single base primer extension method (SNaPshot ${ }^{\circledR}$ ) .........................................47

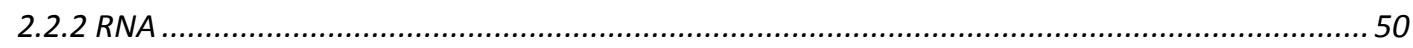

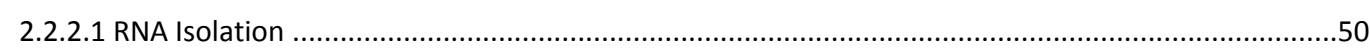

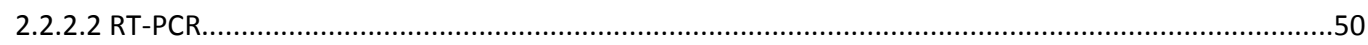

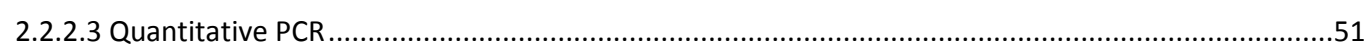

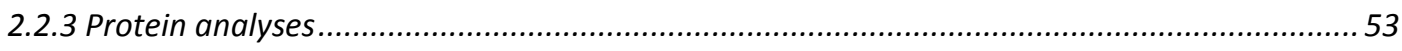

2.2.3.1 Quantification of total protein using bicinchoninic acid (BCA) ..................................................53

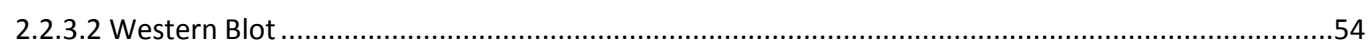

2.2.3.2.1 SDS-Polyacrylamid Gel Electrophoresis (SDS-PAGE) ..........................................................54

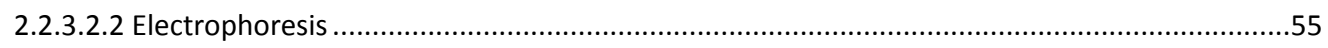

2.2.3.2.3 Protein blotting using a semidry method ......................................................................56

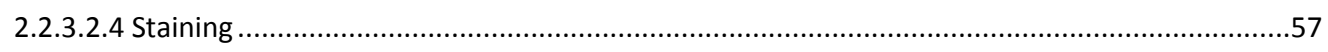

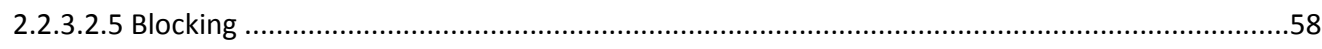

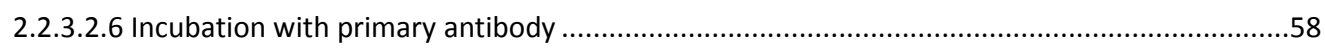

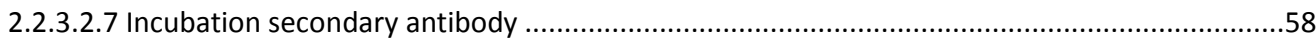

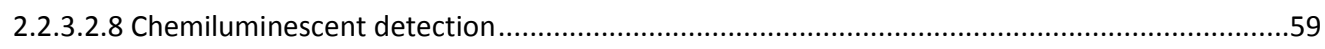

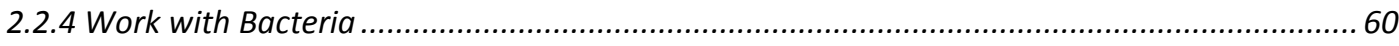

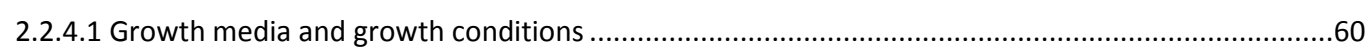

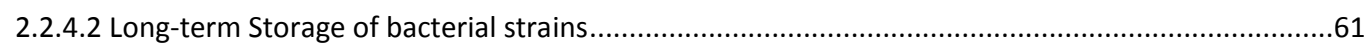

2.2.4.3 Transformation through electroporation ................................................................................61

2.2.4.4 Isolation of plasmid DNA by chloroform extraction (plasmid mini-prep) ......................................62

2.2.4.5 Isolation of plasmid DNA by solid extraction (plasmid midi prep) .................................................63

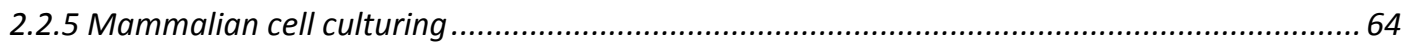

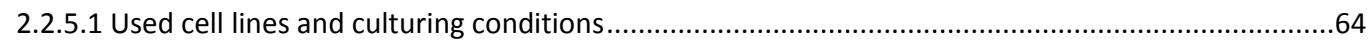

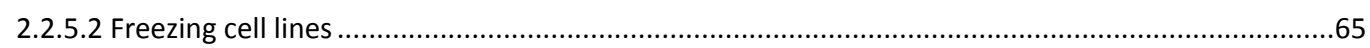




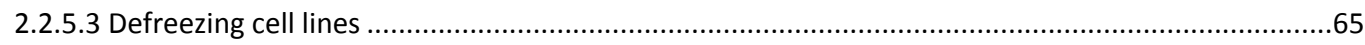

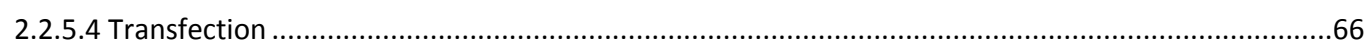

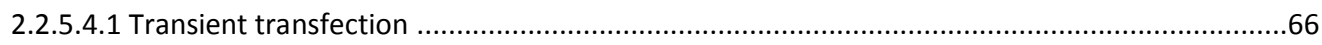

2.2.5.4.2 Stable transfection using Flp recombinase .......................................................................67

2.2.5.4.3 Determination of optimal screening antibiotic concentration ............................................69

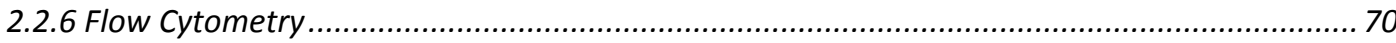

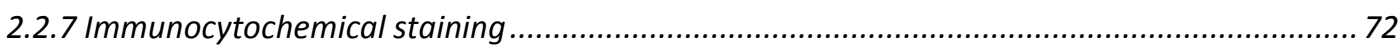

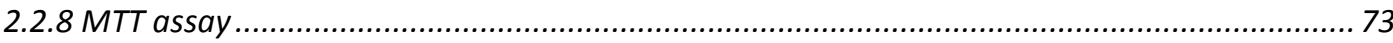

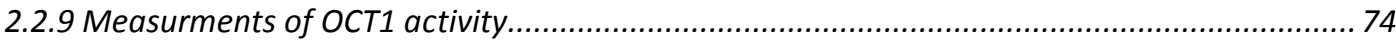

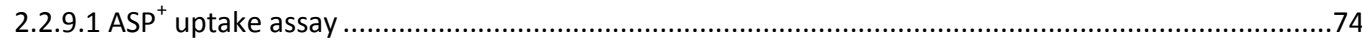

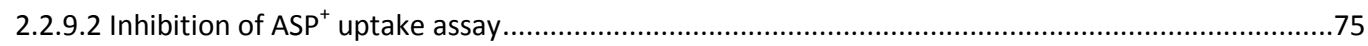

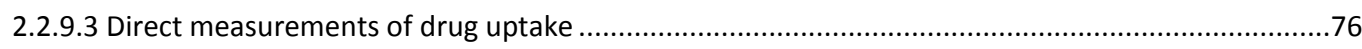

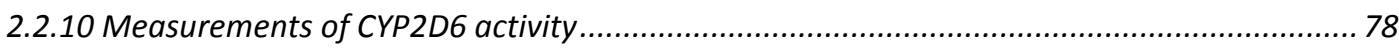

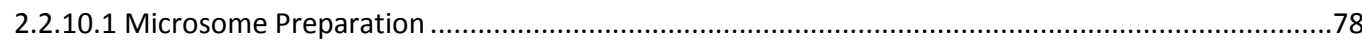

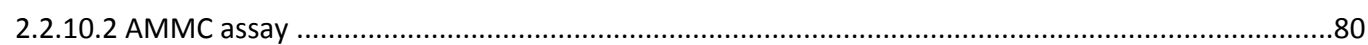

2.2.11 High-Performance Liquid Chromatography (HPLC) .................................................... 81

2.2.11.1 Quantification of intracellular tramadol and O-desmethyl-tramadol by HPLC ............................82

2.2.11.2 Quantification of intracellular debrisoquine and 4-hydroxy debrisoquine by HPLC ......................85

2.2.11.3 Quantification of intracellular tropisetron and ondansetron by HPLC ........................................86

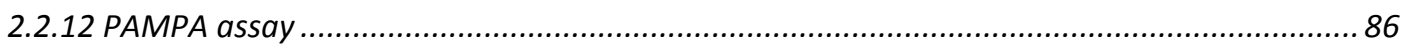

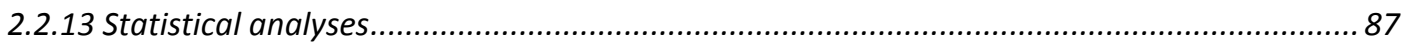

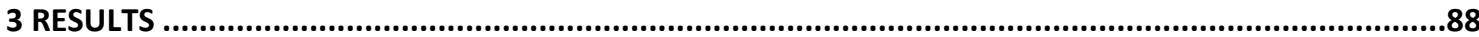

3.1 GENERATION OF OCT1 AND CYP2D6 EXPRESSION PLASMID CONSTRUCTS..................................................... 88

3.1.1 Generation of the pCDNA5.1::OCT1 plasmid...................................................................... 88

3.1.2 Generation of the pCDNA5.1::CYP2D6::IRES::POR construct ............................................ 90

3.2 GeNERATION AND CHARACTERIZATION OF THE TRANSGENIC CELLS MODELS ............................................. 96

3.2.1 Generation and characterization of OCT1 overexpressing cell lines .................................. 96

3.2.1.1 Generation of stably transfected HEK293 cell lines overexpressing OCT1 ......................................96

3.2.1.2 Confirming the chromosomal integration of the OCT1 con-structs in the genome of HEK293-TRex cells

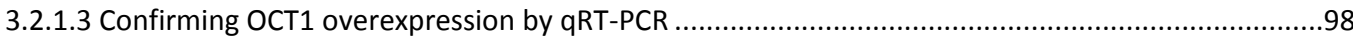

3.2.1.4 Confirming OCT1 overexpression on protein level .....................................................................99

3.2.1.5 Flow cytometry analysis for OCT1 overexpressing HEK cells .....................................................99

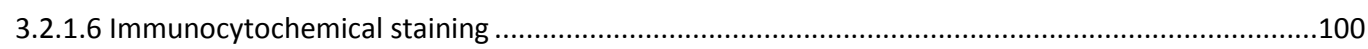

3.2.1.7 Confirming functional OCT1 overexpression by measuring OCT1 activity .................................102

3.2.2 Generation and characterization of cell lines co-overexpressing CYP2D6 and POR .............. 106

3.2.2.1 Generation of stabaly transfected HEK293 cell lines co-overexpressing CYP2D6 and POR ............106

3.2.2.2 Confirming the chromosomal integration of the pCDNA5puro::CYP2D6::IRES::POR constructs in the

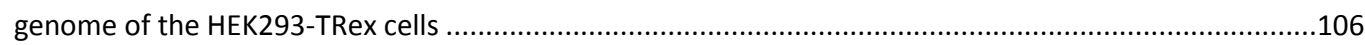

3.2.2.3 Confirming CYP2D6 and POR overexpression by qRT PCR …..................................................107

3.2.2.4 Confirming CYP2D6 overexpression by western blot....................................................................109 
3.2.2.5 Flow cytometry analysis for CYP2D6 overexpressing HEK cells .109

3.2.2.6 Immunocytochemical staining

3.2.2.7 Confirming the expression of functionally active CYP2D6

3.2.2.8 Time dependance of CYP2D6-mediated tramadol metabolism

3.2.3 Generation and characterization of the OCT1, CYP2D6 and POR co-overexpressing cell lines

3.2.3.1 Generation of stabaly double-transfected HEK293 cell lines co-overexpressing OCT1, CYP2D6 and POR

3.2.3.2 Confirming the chromosomal integration of the OCT1 con-structs in CYP2D6::IRES::POR overexpressing HEK cells. .115

3.2.3.3 Confirming OCT1, CYP2D6 and POR overexpression by qRT- PCR . .116

3.2.3.4 Confirming OCT1 and CYP2D6 co-overexpression by protein analyses .117

3.2.3.5 Flow cytometry analysis for OCT1 and CYP2D6 overexpressing HEK cells. .118

3.2.3.6 Immunocytochemical staining ..... .119

3.3 OCT1 AS A CELLULAR UPTAKE TRANSPORTER OF ANTIEMETIC DRUGS. 121

3.3.1 Inhibition of OCT1-mediated ASP+ uptake by tropisetron, ondansetron and palonosetron.. 121

3.3.2 $\mathrm{pH}$-dependance of the inhibitory effect of tropisetron and ondansetron. 122

3.3.3 Direct measurements of tropisetron and ondansetron cellular uptake by OCT1. 123

3.4 OCT1 AS A CELLULAR UPTAKE TRANSPORTER OF THE ANALGESIC DRUGS TRAMADOL AND O-DESMETHYLTRAMADOL

3.4.1 PAMPA assay for tramadol and O-desmethyltramadol. 125

3.4.2 Inhibition of OCT1-mediated $\mathrm{ASP}^{+}$uptake by tramadol and O-desmethyltramadol. 126

3.4.3 Tramadol and O-desmethyltramadol cellular uptake by OCT1 and effects of the OCT1 polymorphisms.

3.5. OCT1 AS A CELLULAR UPTAKE TRANSPORTER OF THE MODEL DRUG DEBRISOQUINE 129

3.5.1 PAMPA assay for debrisoquine 129

3.5.2 Inhibition of OCT1-mediated $\mathrm{MPP}^{+}$uptake by debrisoquine... 130

3.5.3 Direct measurements of debrisoquine cellular uptake by OCT1. 131

3.5.4 Effects of OCT1 genetic polymorphisms on debrisoquine uptake 134

3.5.5 Effects of drug-drug interactions on the OCT1-mediated debrisoquine uptake 136

3.5.6 Interaction between OCT1 and CYP2D6 during metabolism of debrisoquine. 137

3.5.7 Effects of loss of function polymorphisms in OCT1 on uptake and metabolism of debrisoquine 140

3.5.8 Effects of CYP2D6 inhibitors on debrisoquine metabolism in the triple transfected system 141

3.6 OCT1 AS A POSSIBLE UPTAKE TRANSPORTER OF THE CYTOTOXIC DRUGS IRINOTECAN AND DOXORUBICIN . 143

3.6.1 Inhibition of OCT1-mediated uptake by irinotecan and its active metabolite SN38. 143

3.6.2 $\mathrm{pH}$-dependance of the inhibitory effect of irinotecan and its metabolite SN38 ..... 144

3.6.3. Effects of OCT1 overexpression on irinotecan cytotoxicity

3.6.4. OCT1-mediated cellular uptake of doxorubicin 147

3.7 ANALYSING POTENTIAL DOMINANT NEGATIVE EFFECT OF THE OCT1 PROTEIN VARIANTS. 148 
3.7.1 Generation of pcDNA5.1::OCT1_GFP construct ........................................................... 148

3.7.2 Generation of HEK293 cell lines transiently expressing OCT1-GFP .................................. 151

3.7.3 Quantitative measurement of OCT1 activity ............................................................ 151

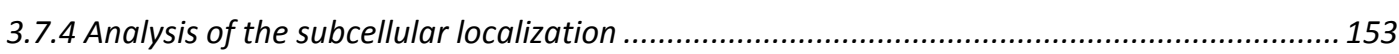

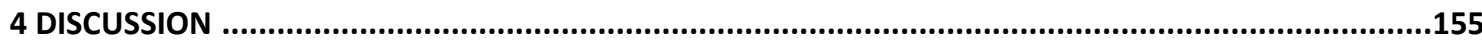

4.1 EFFECTS OF LOSS OF FUNCTION POLYMORPHISMS OF OCT1 TRANSPORTER ON THE UPTAKE AND KINETICS OF ASP ${ }^{+} 155$

4.2 EFFECTS OF LOSS OF FUNCTION POLYMORPHISMS OF OCT1 TRANSPORTER ON THE UPTAKE OF TROPISETRON AND ONDANSETRON

4.3 EFFECTS OF LOSS OF FUNCTION POLYMORPHISMS OF OCT1 TRANSPORTER ON THE UPTAKE OF TRAMADOL AND ODESMETHYLTRAMADOL 158

4.4 EFFECTS OF LOSS OF FUNCTION POLYMORPHISMS IN OCT1 TRANSPORTER ON THE UPTAKE OF DEBRISOQUINE....... 160 4.5 INTERACTIONS BETWEEN OCT1-MEDIATED TRANSPORTER AND CYP2D6-MEDIATED METABOLISM ON DEBRISOQUINE METABOLISM 162

4.6 EFFECTS OF LOSS OF FUNCTION POLYMORPHISMS OF OCT1 TRANSPORTER ON THE METASBOLISM OF DEBRISOQUINE 163

4.7 DRUG-DRUG INTERACTIONS ON THE CYP2D6-MADIATED DEBRISOQUINE METABOLISM................................. 164

4.8 EFFECTS OF OCT1 TRANSPORTER ON THE UPTAKE OF CYTOTOXIC DRUGS IRINOTECAN AND DOXORUBICIN.............. 166

4.9 EFFECTS OF DIFFERENT PH ON INTERACTION OF ORGANIC CATIONS WITH OCT1 ...................................... 167

4.10 ANALYSIS OF DOMINANT NEGATIVE EFFECT BETWEEN OCT1 VARIANTS................................................. 168

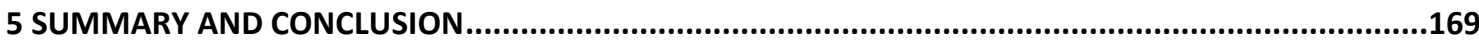

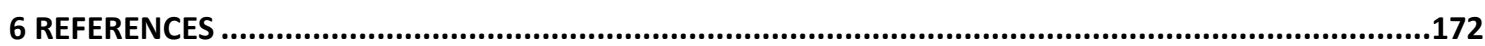




\section{Acknowledgments}

This research project would not have been possible without the support, patience and guidance of many people. It is to them that I owe my deepest gratitude.

I would like to gratefully and sincerely thank Prof. Dr. Brockmöller for giving me the opportunity to work in his group at the Department of Clinical Pharmacology University Göttingen, for his expert advice, understanding, patient guidance and encouragement. His wisdom and positive outlook in my research inspired me and gave me confidence.

I appreciate Prof. Dr. Burckhardt and Prof. Dr. von Ahsen, the members of my thesis committee, for the valuable discussions and co-supervision of this thesis.

I acknowledge Deutsche Forschungsgemeinschaft (DFG): Graduiertenkolleg GRK1034 for providing the funding which allowed me to undertake this research.

I would like to express my gratitude towards PD. Dr. Mladen Tzvetkov for his constant assistance and support over these years. His knowledge, experience and ideas motivated me during all my $\mathrm{PhD}$. Without his advice, help and active participation in every step of my work, this thesis may never have been completed. It was a great pleasure for me to work with him. I am also very grateful to him for corrections and proofing this thesis.

A special thanks to my wife Kateryna Filonenko, who kindly and patiently supported me throughout the writing of this thesis, for her assistance in preparing the pictures and editing my dissertation.

I am very grateful for the friendship of my colleagues at the Department of Clinical Pharmacology. I want to thank them for all their help, support and valuable hints. Especially, I would like to thank Caroline Jobst for kind cooperation and technical assistance.

My special acknowledgments go to my family in Iran, which has always supported me during my life, for their help and faith in me. 


\section{Abstract}

OCT1 is a polyspecific organic cation transporter belonging to the solute carrier gene family SLC22. Human OCT1 is mainly expressed on the sinusoidal membrane of hepatocytes and thus may play an important role in the hepatocellular uptake and metabolism of cationic drugs. Beside this OCT1 is highly polymorphic with $9 \%$ of Caucasians carrying functional amino acid substitutions in both their OCT1 alleles. These amino acid substitutions are known to decrease or abolish OCT1 activity. Therefore these variants may significantly affect pharmacokinetics and consequently efficacy and adverse effects of all those drugs, which are transported at typical therapeutic concentrations by OCT1. On the other hand, drugs when enter into the hepatocytes are metabolized by metabolizing enzymes such as the cytochrome P450 enzyme 2D6 (CYP2D6). CYP2D6 is one of the most important drug metabolizing enzymes in the liver and is also highly polymorphic. Since such intracellular metabolism changes the concentration gradient at the outer cell membrane and at intracellular compartments, a combined analysis of drug membrane transport and intracellular drug metabolism may give insights with general importance.

The aims of this study were to investigate whether OCT1 mediates the cellular uptake of clinically relevant drugs, what is the effect of the common genetic polymorphisms in OCT1on the uptake and how the interaction between the OCT1 and CYP2D6 may affect drug transport and metabolism.

To do this, stable transfection was used to generate HEK293 cells overexpressing OCT1alone, CYP2D6 with its helper enzyme POR, and a combination of OCT1 with CYP2D6 and POR. In addition to these 3 constructs reflecting transport, metabolism and transport+metabolism, I generated cells overexpressing variant OCT1s carrying the five common amino acid substitution polymorphisms known in Caucasians, Arg61Cys, Gly401Ser, and a single deletion of Met420, or combination of Met420 deletion with Cys88Arg or Gly465Arg. Drug uptake and metabolism were analyzed using high pressure liquid chromatography to quantify the intracellular concentration of the parental drugs and their metabolites.

Our results demonstrated that OCT1 mediates the cellular uptake of different groups of drugs. The antiemetic tropisetron and $O$-desmethyltramadol, the active metabolite of the opioid tramadol, were shown to be inhibitors and substrates of OCT1. The uptake of tropisetron and O-desmethyltramadol was abolished if any of the five common polymorphic OCT1 variants was expressed. On the other hand, the antiemetic 
ondansetron and the opioid tramadol itself were no substrates, but only inhibitors of OCT1.

A prototypic substrate of the enzyme CYP2D6 is debrisoquine. It was unknown how debrisoquine enters into cells. I demonstrated that it is an inhibitor and a substrate of OCT1 (IC50 of $6.2 \pm 0.8 \mu \mathrm{M}, \mathrm{K}_{\mathrm{M}}$ of $5.9 \pm 1.5 \mu \mathrm{M}$ and $\mathrm{V}_{\max }$ of $41.9 \pm 4.5 \mathrm{pmol} / \mathrm{min} / \mathrm{mg}$ of protein). The uptake of debrisoquine was significantly reduced in the presence of the variants OCT1s.

In the cells overexpressing CYP2D6 and POR, the co-expression of OCT1 led to a significant increase in the production of the metabolite, 4-OH debrisoquine, in a timedependent manner. The increase was not observed when the variant OCT1 was coexpressed. In addition, utilizing the OCT1 and CYP2D6-POR co-expressing cells we were able to measure drug-drug interactions separately by the uptake or by the metabolism of debrisoquine. Interestingly, paroxetine, known thus far as a CYP2D6 inhibitor, showed much higher potency in inhibiting OCT1 uptake than in inhibiting CYP2D6 metabolism. Thus, the experiments performed here might shed a new light on known and medically relevant interactions between drugs in humans.

It can be concluded that OCT1 may influence the pharmacokinetics of the drugs and may be substantially involved in drug-drug interactions. Therefore, as also supported by the human in vivo study data, OCT1 polymorphisms may affect the pharmacokinetics and efficacy of clinically relevant drugs like tropisetron and O-desmethyltramadol. This work show also that the cell models developed here are useful tool and may help in the future to better understand absorption, distribution and elimination of numerous other drugs and other endogenous and exogenous chemicals as well. 


\section{List of figures}

Fig.1. 1 Schematic structure of the three OCT genes in humans.

Fig.1. 2 Proposed secondary structure of the human organic cation transporter type 1 (hOCT1).............. 4

Fig.1. 3 Schematic diagram of drug metabolism in hepatocytes. ........................................................ 10

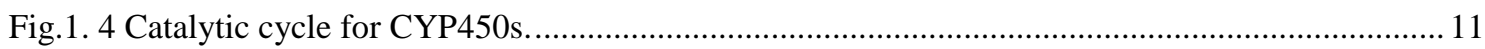

Fig.1. 5 Structures of the 5- $\mathrm{HT}_{3}$ antagonists ondansetrone, palonosetrone and tropisetrone. ................. 17

Fig.1. 6 Metabolism of tramadol to O-desmethyl-tramadol catalyzed by CYP2D6. ............................. 18

Fig.1. 7 Debrisoquine and its CYP2D6 catalyzed metabolite 4-hydroxydebrisoquine. .......................... 19

Fig.1. 8 The structures of irinotecan and its metabolite, SN38 ........................................................20

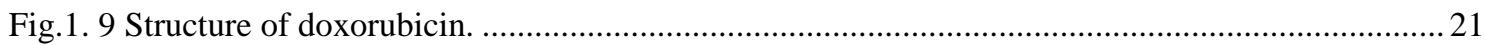

Fig.1. 10 Cellular localization of hepatic drug metabolizing enzymes, influx and efflux transporters ...... 22

Fig.2. 1 Scheme of fusion of CYP2D6 and POR genes using IRES fragment...................................42

Fig.2. 2 Assembly of a horizontal electroblotting apparatus. ......................................................... 57

Fig.2. 3 Major features of the stable transfection using the Flp-In system for targeted chromosomal integration.

Fig.3. 1 Scheme of cloning of OCT1 into the expression vector pcDNA5.1 ..................................... 89

Fig.3. 2 Scheme of assembling of POR with IRES fragment........................................................... 91

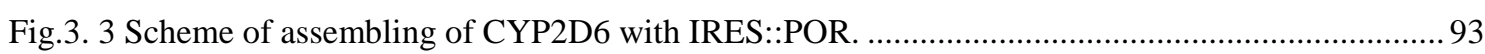

Fig.3. 4 Scheme for the generation of pcDNA5.1puro vector and recloning the CYP2D6::IRES::POR

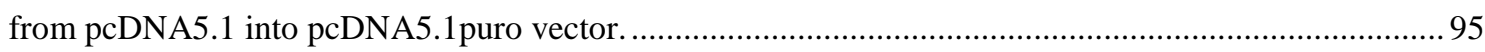

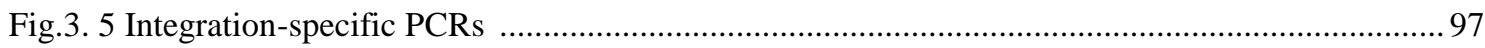

Fig.3. 6 Expression rate of OCT1 in the stabaly transfected HEK cells. ...........................................98

Fig.3. 7 Western blot for the OCT1 protein in the OCT1 overexpressing HEK cells ............................ 99

Fig.3. 8 Characterization of OCT1 expression protein in OCT1 overexpressing HEK cells and HEK cells

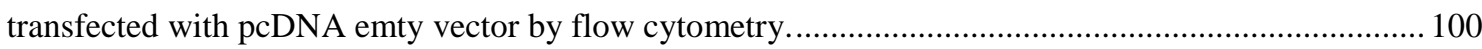

Fig.3. 9 Confocal image of the HEK cells overexpressing OCT1 ..................................................... 101

Fig.3. 10 OCT1 genetic variants are associated with different accumulation rates and responses to ASP $^{+}$

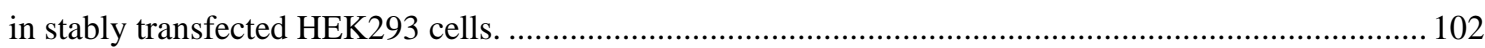

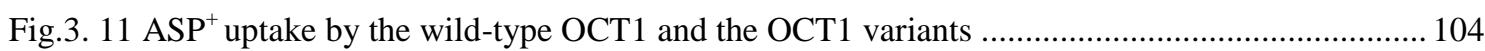

Fig.3. 12 Amplification of CYP2D6 and POR genes............................................................... 107

Fig.3. 13 qRT-PCR analyses of the CYP2D6 and POR co-overexpression in the

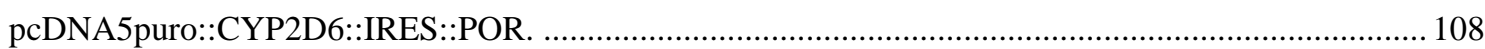

Fig.3. 14 Western blot detection of CYP2D6 protein in pcDNA5puro::CYP2D6::IRES::POR transfected HEK cells. 109

Fig.3. 15 Characterization of CYP2D6 expression protein in CYP2D6 overexpressing HEK cells and HEK cells transfected with pcDNA emty vector by flow cytometry. 110

Fig.3. 16 Confocal immunofluorescent analysis of HEK cells overexpressing CYP2D6 ...................... 111

Fig.3. 17 Measurement the activity of CYP2D6 enzyme using AMMC kit.. ................................... 112

Fig.3. 18 Measurement the activity of CYP2D6 enzyme using the model substrate debrisoquine..........113 
Fig.3. 19 Measuring time dependance activity of CYP2D6 enzyme using tramadol. 114

Fig.3. 20 Integration-specific PCR for the hygromycin resistance region

Fig.3. 21 qPCR analyses of the CYP2D6 and POR co-overexpression in the

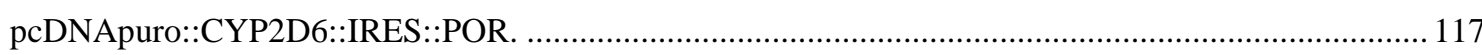

Fig.3. 22 Western blot analyses for OCT1 and CYP2D6

Fig.3. 23 Characterization of the expressed protein OCT1 in OCT1 and CYP2D6 overexpressing HEK cells and HEK cells transfected with pcDNA empty vector by flow cytometry.

Fig.3. 24 Confocal immunofluorescent analysis of HEK293TRex cells cooverexpressing OCT1 and CYP2D6. 120

Fig.3. 25 Inhibition of OCT1 uptake by tropisetron, ondansetron and palonosetron..

Fig.3. $26 \mathrm{pH}$ dependence of the OCT1 inhibition of tropisetron and ondansetron.

Fig.3. 27 Direct measurements for cellular uptake of tropisetron and ondansetron in OCT1 overexpressing HEK293-TRex cells.

Fig.3. 28 Carrier-independent membrane permeability of tramadol and $O$-desmethyltramadol. 126

Fig.3. 29 Inhibition of the cellular uptake of the OCT1 substrate $\mathrm{ASP}^{+}$by tramadol and $O$ desmethyltramadol.

Fig.3. 30 The cellular uptake of tramadol and O-desmethyltramadol in OCT1 overexpressing HEK293 cells.

Fig.3. 31Carrier-independent membrane permeability of debrisoquine measured by PAMPA. 130

Fig.3. 32 Debrisoquine inhibits the uptake of the OCT1 model substrate MPP ${ }^{+}$

Fig.3. 33 Time dependence of debrisoquine accumulation.

Fig.3. 34 Concentration dependence of the OCT1-mediated cellular uptake of debrisoquine.

Fig.3. 35 Effects of common loss-of-function polymorphism on the debrisoquine cellular uptake.

Fig.3. 36 Concentration dependence of OCT1-mediated debrisoquine uptake

Fig.3. 37 Inhibition of the OCT1-mediated uptake debrisoquine by OCT1 inhibitors and weakly basic drugs.

Fig.3. 38 Time dependence of debrisoquine uptake and 4- hydroxy debrisoquine production.... 139

Fig.3. 39 Interactive effects of polymorphisms in the OCT1 transporter with CYP2D6 metabolizing enzyme on debrisoquine uptake.

Fig.3. 40 Inhibitory effect of paroxetine on debrisoquine uptake and 4- hydroxy debrisoquine production.

Fig.3. 41 Inhibition of the OCT1 by irinotecan and SN38.

Fig.3. $42 \mathrm{pH}$-dependant effects of irinotecan and SN38 on the OCT1-mediated cellular uptake of $\mathrm{ASP}^{+}$..

Fig.3. 43 Effects of OCT1 on irinotecan cytotoxicity in HEK and CHO cells 146

Fig.3. 44 Doxorubicin uptake is not dependent on OCT1 transporter.

Fig.3. 45 Scheme of assembling of the OCT1_GFP fusion construct.

Fig.3. 46 Scheme of cloning of the OCT1-GFP fusion construct into the expression vector pcDNA5.1.150

Fig.3. $47 \mathrm{ASP}^{+}$kinetics in HEK cells overexpressing OCT1 wild type alone (homozygous) or in combination of wild type and a loss of function variants (heterozygous).

Fig.3. 48 Subcellular localization of OCT1 wild type and two genetic variants. 


\section{List of tables}

Table 1. 1 Tissue Distribution of Human OCT Isoforms 5

Table 1. 2 List of drugs known to be CYP2D6 substrates 12

Table 1. 3 Examples of Common Drug-Drug Interactions Involving the Cytochrome P450 Enzyme System 14

Table 2. 1 Site-directed mutagenesis primer list. 37

Table 2. 2 List of primer and corresponding sequences to test for chromosomal integration of pcDNA5.40

Table 2. 3 Primers and corresponding sequences for OCT1 wild type and its variants. 47

Table 2. 4 Primers and corresponding sequences for CYP2D6....................................................... 48

Table 2. 5 Primers and corresponding sequences for CYP2D6..........................................................5 52

Table 2. 6 Reagent required for preparation of Stacking gel and Separating gel ..................................55

Table 2. 7 Primary and secondary antibodies used in this study....................................................59

Table 2. 8 List of antibodies used for flow cytometry and immunocyto staining ................................. 72

Table 3. 1 The lists of primers used for amplification of IRES and POR. ....................................... 90

Table 3. 2 Primers used to amplify CYP2D6 contain appropriate restriction sites .................................92

Table 3. 3 Primers used to amplify purpmycine resistance region contain appropriate restriction sites .. 94 Table 3. 4 Effects of the common functional amino acid substitutions in OCT1 on the kinetics of ASP $^{+}$ uptake.

Table 3. 5 Primers used for amplification of the CYP2D6 and POR genes. 106

Table 3. 6 Effects of the common loss-of-function amino acid substitutions in OCT1 on the kinetic of debrisoquine. 136

Table 3. 7 The lists of primers used for amplification of OCT1 and GFP. ........................................ 148

Table 3. 8 Effects of the combined allels in OCT1 on the kinetics of $\mathrm{ASP}^{+}$uptake. 153

Table 4. 1 Comparison of physicochemical properties for tropisetron and ondansetron 


\section{Abbreviations}

\begin{tabular}{|c|c|}
\hline $5-\mathrm{HT}_{3}$ & Serotonin receptor 3 \\
\hline APS & Ammonium persulfate \\
\hline $\mathrm{ASP}^{+}$ & 4-(4-(dimethylamino)styryl)-N- methylpyridinium \\
\hline BSA & Bovine Serum Albumin \\
\hline $\mathrm{bp}$ & Base pair \\
\hline cDNA & copy DNA \\
\hline d- & Desoxy- \\
\hline $\mathrm{Da}$ & Dalton \\
\hline dd- & Didesoxy- \\
\hline $\mathrm{ddH}_{2} \mathrm{O}$ & bi-distilled Water \\
\hline DMEM & Dulbecco's Modifiziertes Eagle Medium \\
\hline DMFA & Dimethylformamid \\
\hline DMSO & Dimethylsulfoxide \\
\hline DNA & Desoxyribonucleic acid \\
\hline dNTP & Deoxynucleosidetriphosphate \\
\hline DTT & Dithiothreitol \\
\hline E. coli & Escherichia coli \\
\hline EDTA & Ethylene di-amine tetra-acetic acid \\
\hline et al. & et alii \\
\hline $\mathrm{F}$ & Farad \\
\hline FAM & 6-Carboxyfluorescein \\
\hline g & Gravity acceleration $\left(9.81 \mathrm{~m} / \mathrm{s}^{2}\right)$ \\
\hline $\mathrm{h}$ & hour \\
\hline HBSS & Hank's balanced salt solution Medium \\
\hline HPLC & High pressure (performance) liquid chromatography \\
\hline IRES & Internal Ribosomal Entry Site \\
\hline $\mathrm{kb}$ & Kilobase pair \\
\hline $\mathrm{kV}$ & Kilo volt \\
\hline LB & Luria-Bertani Medium \\
\hline M & Molarity \\
\hline $\min$ & Minutes \\
\hline $\mathrm{MPP}^{+}$ & 1-methyl-4-phenylpyridinium \\
\hline mRNA & messenger RNA \\
\hline
\end{tabular}


MTT

n. s.

$\mathrm{p}$

PAGE

PBS

PCR

$\mathrm{pH}$

RNA

RNase

RT

rpm

SDS

Taq

$\mathrm{TBA}^{+}$

$\mathrm{TEA}^{+}$

TBE-Buffer

TBP

TE-Buffer

TEMED

Tris

U

UV

$\mathrm{v} / \mathrm{v}$

$\mathrm{w} / \mathrm{v}$
3-(4,5-Dimethylthiazol-2-yl)-2,5-

diphenyltetrazolium bromide

not significant

Significant level

Polyacrylamide gel electrophoresis

Phosphate buffered saline

Polymerase chain reaction

$\mathrm{pH}$-value

Ribonucleic acid

Ribonuclease

Room temperature

Rotations per minute

Sodiumdodecylsulfate

Thermus aquaticus

Tetra-N-butylammonium

Tetraethylammonium

Tris-Borat-EDTA-buffer

TATA-Box-Bindeprotein

Tris-hydroxymethyl-aminomethan-EDTA-buffer

"N,N,N',N'-Tetramethylethylenediamine

Tris-hydroxymethyl-aminomethane

unit

Ultraviolet

Volume per Volume

Weight per Volume 


\section{Introduction}

\subsection{Importance of genetic polymorphisms in drug therapy}

Pharmacogenetics studies how inherited variants in specific genes may impact the reactions of human beings on drugs and other environmental factors and also how it can provide molecular diagnostic methods which improve drug therapy. Pharmacogenetics has changed the practices and requirements in preclinical and clinical drug research, so that nowadays, pharmacogenomic has become increasingly important in clinical trials. The field of pharmacogenetics not only focuses on drug metabolism (WEINSHILBOUM 2003), but also encompasses the full spectrum of drug disposition also known as pharmacokinetics, including drug transporters that influence drug absorption, distribution, and excretion (EvANS and MCLEOD 2003; EvANS and RELLING 1999; MEYER 2000).

Although many nongenetic factors such as age, organ function and drug interactions influence the effects of medications, there are numerous examples of cases in which interindividual differences in drug response (also known as pharmacodynamics) are due to variants in genes encoding drug-metabolizing enzymes, drug transporters or drug targets (BrockMOLLER and TzVETKOV 2008; EvAns and MCLEOD 2003; Evans and RELLING 1999). In 1000 genomes project, the location, allele frequency and local haplotype structure of approximately 15 million single-nucleotide polymorphisms (SNPs) distributed throughout the human genome, one million short insertions and deletions and 20,000 structural variants were described. Some of these SNPs may involve genes controlling drug metabolism, drug transport, disease susceptibility, or drug targets, and some are now being used to predict clinical response (EVANS and MCLEOD 2003).

Recently much attention has been focused on the pharmacogenetics of drug transporters. Genetic polymorphism in biotransformation and transmembrane transport represents a crucial factor in the pharmacokinetic variability of many drugs (Ho and KIM 2005; Ingelman-Sundberg 2004; Koepsell et al. 2007; LynCH and Price 2007; SEITHel et al. 2008; VORMFELDE et al. 2008). For instance, a wide range of drugs may be transported into the liver by the human organic cation transporter (hOCT1). Genetic variants in OCT1 have been shown to modulate the pharmacokinetics of metformin after oral administration and reduce the therapeutic response, presumably by decreasing 
the hepatic uptake (SHIKATA et al. 2007; SHU et al. 2007) and increasing the renal elimination of the drug (TZVETKOV et al. 2009).

On the other hand, individual variability in drug efficacy and toxicity is to a big extent determined by polymorphisms in drug metabolizing enzymes, in particular the cytochrome P450 enzymes (CYPs) (Johansson and Ingelman-Sundberg). CYPs play important role in the phase I of drug metabolism. In the past 30 years, convincing data have emerged about the impact of polymorphisms in cytochrome P450 enzymes on the pharmacokinetics and clinical effects of many drugs (BROCKMOLLER et al. 2000; INGELMAN-SUNDBERG 2004). This variability influences metabolism of 20\%-30\% of clinically used drugs (EICHELBAUM et al. 2006; INGELMAN-SUNDBERG 2005). Genetic polymorphism of several phase II enzymes, including some relevant to cancer chemotherapy, are also causing variability in the drug metabolism (EICHELBAUM et al. 2006).

The polymorphic nature of the CYP2D6 locus and the functional inequalities associated with its variants are responsible for the variable responses to number of drugs (INGELMAN-SUNDBERG 2005; LYNCH and PRICE 2007).Variant alleles usually encode a CYP450 enzyme which result in decreased or no enzyme activity (WILKINSON 2005). Individuals with two copies of no activity alleles lack CYP2D6 activity and are called "poor" metabolizers, people with one active and one inactive allele have reduced enzyme activity and are called inactive metabolizers and people with two active or one active and one decrease activity alleles have average CYP2D6 activity and are called extensive metabolizers. Finally, some persons inherit multiple copies of active alleles, which results in excess enzyme activity. This phenotype is termed an "ultrarapid" metabolizer (JOHANSSON et al. 1993; ZANGER et al. 2004). Also Mutations in cytochrome P450 genes or deficiencies of the enzymes are responsible for several human diseases (NELSON, 2003).

\subsection{Drug transporter: Organic Cation Transporters OCTs}

Transporters are proteins that span cellular membranes and selectively transfer the molecules through the membranes. The body is equipped with broad-specificity transporters that have an important role in regulating the absorption, distribution, and excretion of endogenous organic cations as well as cationic drugs and toxins (EVANS and MCLEOD 2003; KOEPSELL et al. 2007). 
The SLC22A family of solute carrier (SLC) transporters contains three isoforms of passive diffusion organic cation transporters also called electrogenic. Those are OCT1 (SLC22A1), OCT2 (SLC22A2), OCT3 (SLC22A3). Additionally there are two cation and carnitine transporters OCTN1 (SLC22A4) and OCTN2 (SLC22A5) (KOEPSELL et al. 2007). The three organic cation transporters (OCTs) share common genomic structures. The genes encoding the three OCTs are localized within a cluster on human chromosome 6q26 and each of these three genes has 11 coding exons and 10 introns (Fig.1.1). This suggests that the three isoforms evolved through gene duplication from a single ancestral OCT gene (URBAN and GIACOMINI, 2007).

Chr. 6

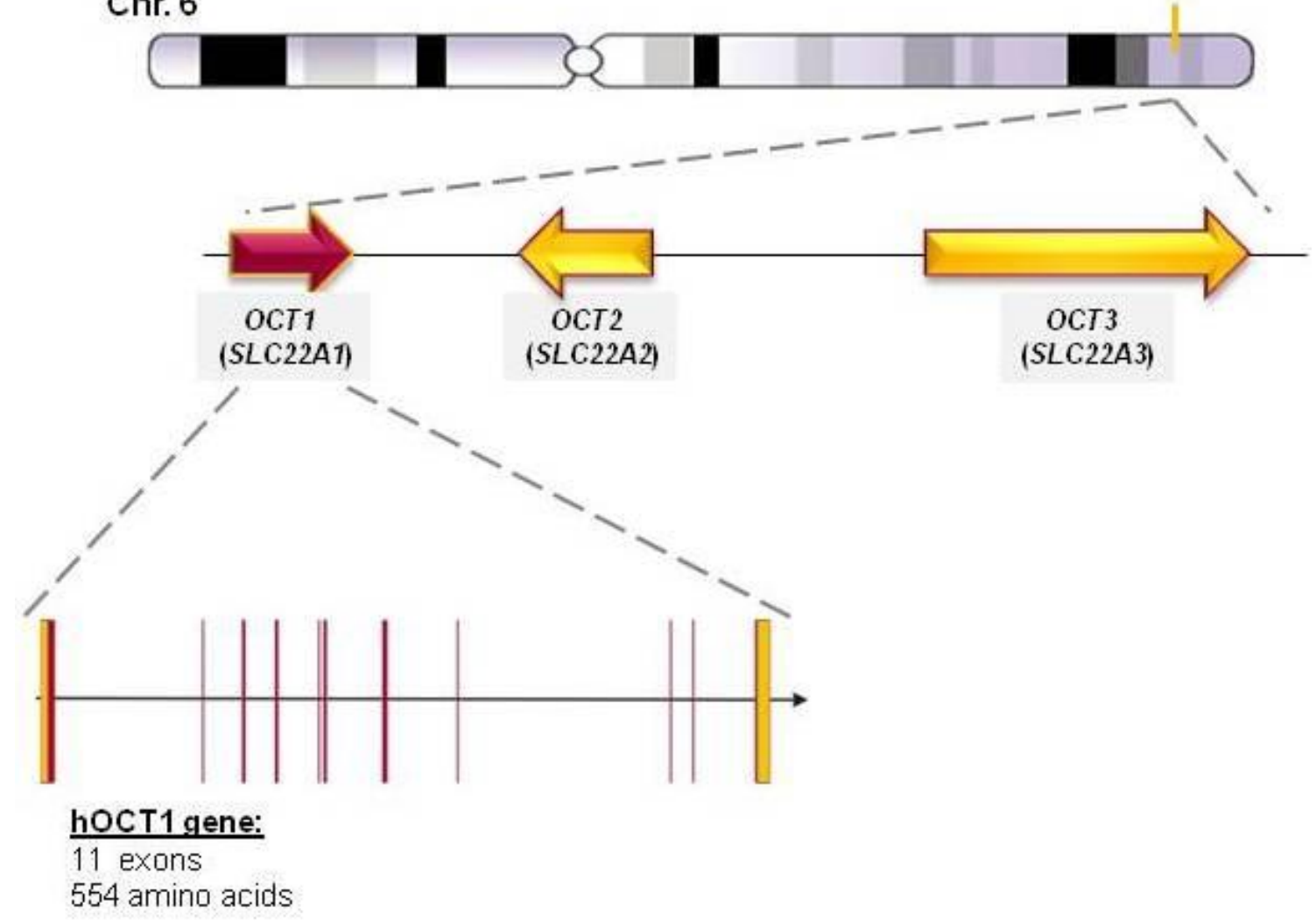

Fig.1. 1 Schematic structure of the three OCT genes in humans. The three genes are located on long arm of the chromosome 6 . All three genes share similar structure of 11 exons and 10 introns, as can be seen for the OCT1 gene.

Also OCTs proteins share a common secondary structure. The OCT proteins comprise 12 transmembrane domains (TMDs) with intracellular amino and carboxy termini, a large glycosylated extracellular loop between TMDs 1 and 2, as well as a large 
intracellular loop between TMDs 6 and 7 which includes predicted phosphorylation sites (Fig 1.2). The transmembrane domains (TMD4 and TMD10) have been shown to be important for substrate recognition by the OCTs (KOEPSELL et al. 2007). Sitedirected mutagenesis in rat OCT1 revealed the importance of transmembrane domain eleven in substrate translocation as substitution of aspartate at position 475 to glutamate largely reduced transport rates and increased the Michaelis Menten constant $(K \mathrm{~m})$ values for some substrates (GORBOULEV et al. 1999). Also mutations of the two residues in TMD4 (Trp218Tyr and Tyr222Leu) resulted in increased affinity for both tetraethylammonium (TEA) and 1-methyl-4- phenylpyridinium $\left(\mathrm{MPP}^{+}\right)$, whereas a third mutant (Thr226Ala) is only involved in the binding of $\mathrm{MPP}^{+}$but no change in affinity for TEA (POPP et al. 2005). This data suggests that OCT1, and presumably all of the OCTs, contain multiple overlapping but nonidentical recognition sites for the various structurally diverse substrates (KOEPSELL, 2011). Another study showed that the large extracellular loop located between TMDs 1 and 2 influences substrate affinity and this structure is required for oligomerization and membrane insertion of OCT1 (KELLER et al. 2011). Recent data indicated a substrate binding domain in the middle of TMD 11 which appears to be important for substrate translocation (EGENBERGER et al. 2012).

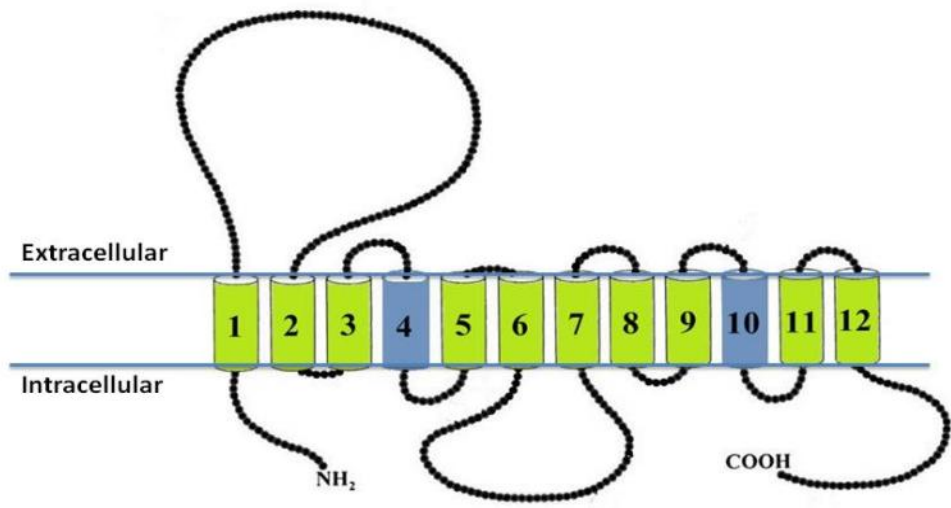

Fig.1. 2 Proposed secondary structure of the human organic cation transporter type 1 (hOCT1). The secondary structure of OCT1 is shown as an example for the structure of all OCTs. OCT1 contains 12 transmembrane domains (TMDs), a large extracellular loop between TMD1 and TMD2. TMD4 and TMD10 (highlighted here in blue) are suggested to contribute for substrate recognition by OCT1. 
The organic cation transporter 1 (OCT1; SLC22A1), is an integral membrane protein that transports cationic drugs and is highly expressed in the sinusoidal membrane of the human liver (ZHANG et al. 1997; Gorboulev et al. 1997; KOEPSELl et al. 2003; KOEPSELL et al. 2007; NIES et al. 2009).

Organic cations and weak bases that are positively charged at physiological $\mathrm{pH}$, can be transported into cells according to the electrochemical gradient. This transportation occurs by facilitated diffusion and is driven by the inside-negative membrane potential (URBAN and GIACOMINI, 2007).

\subsubsection{Tissue distribution and subcellular localization of the human OCT homologs}

Despite the similarities in structure and function in the three transporters OCT1, OCT2 and OCT3, there are important differences in the tissue distribution (Table 1.1). In human OCT1 is strongly expressed in the liver with lower levels of expression in other tissues (Gorboulev et al. 1997; ZHANG et al. 1997). OCT1 is localized on the sinusoidal membrane of the hepatocytes (KoEPSELL et al. 2007). Human OCT2 is specifically expressed in the kidney. Human OCT2 is localized to the basolateral membrane of epithelial cells in renal proximal tubules (KOEPSELL et al. 2007; TZVETKOV et al. 2009). In situ hybridization and preliminary immunohistochemical data revealed expression of hOCT2 in the luminal membrane of distal tubules suggesting that hOCT2 participates in cation reabsorption in the nephron segment (GORBOUlev et al. 1997). The tissue expression pattern of the OCT3 is very broad. This transporter is thought to be important for extraneuronal clearance of monoamine neurotransmitters as well as uptake of monoamines into the heart and across the placenta (URBAN and GIACOMINI, 2007).

Table 1. 1 Tissue Distribution of Human OCT Isoforms

\begin{tabular}{lccc}
\hline Human organs & OCT1 & OCT2 & OCT3 \\
\hline Liver & +++ & - & + \\
Kidney & + & +++ & + \\
Lung & + & - & + \\
Trachea & - & - & - \\
Heart & + & - & ++ \\
\hline
\end{tabular}




\begin{tabular}{lccc}
\hline Skeletal Muscle & ++ & - & ++ \\
Placenta & + & - & ++ \\
Pancreas & - & - & - \\
Brain & - & + & + \\
Spinal cord & - & - & + \\
Adrenal gland & + & - & - \\
Testis & - & - & - \\
Ovary & + & - & + \\
Fetal liver & + & - & - \\
Fetal lung & + & - & - \\
Fetal heart & + & - & - \\
Fetal brain & + & - & - \\
\hline
\end{tabular}

Data modified from Urban and Giacomini, 2007

An expression gradient from central vein to the peripheral parts of the hepatic lobuli was observed in rats (MEYER-WENTRUP et al. 1998), but the information whether such gradient exist in human is missing.

In other species, OCTs act in different organs, for example in mouse small intestine, OCT1 was located to the basolateral membrane of enterocytes (CHEN et al. 2001). Confocal microscopy revealed that in rat kidney both rOCT1 and rOCT2 were localized to the basolateral membranes of epithelial cells in proximal tubules (KARBACH et al. 2000; SUGAWARA-YOKOO et al. 2000). Using immunohistochemistry in the trachea and bronchi of human, rat and mouse OCT1, OCT2, and OCT3 were localized to the luminal membrane of ciliated epithelial cells (LIPS et al. 2005; KUMMER et al. 2006).

\subsubsection{Substrate and Inhibitor Specificities of OCTs}

Common compounds that are translocated by OCT transporters include low-molecularweight relatively hydrophilic organic cations such as model cations tetraethylammonium (TEA), the neurotoxin $\mathrm{MPP}^{+}$, and the endogenous compounds such as amine neurotransmitters like dopamine, epinephrine, norepinephrine, histamine, serotonin, choline, acethylcoline, $N$-methylnicotinamide (NMN) and agmatine. A detailed list summarizing known OCTs substrates and inhibitors was recently published by (NIES et al. 2011). Several clinically important drugs have been shown to interact with all of the OCTs, including quinidine, quinine (ZHANG et al. 1998), the antiviral 
agents, such as acyclovir and ganciclovir (TAKEDA et al. 2002), the antidiabetic drug metformin (Koepsell 2004; SHU et al. 2007; NIES et al. 2009; TZVETKOV et al. 2009) and the peptic ulcer drug famotidine (BOURDET et al. 2005). In general, OCTs may have a broad impact on drug disposition and drug action (AHLIN et al. 2008; BEDNARCZYK et al. 2003). Some of these drugs were used as typical OCT inhibitors. According to a comparison of the molecular structures of currently known OCT inhibitors, an inhibitor must have lipophilicity and hydrophobicity property with positively charge and low hydrogen bonding. Although most known substrates of the OCTs are cations, some OCT substrates are anionic or neutral compounds at physiological $\mathrm{pH}$. Thus, a net positive charge does not appear to be an absolute requirement for interaction with the OCTs (URBAN and Giacomini, 2007; KoEPSEll et al. 2007).

Although the affinities of transported substrate and non-transported inhibitors for individual transporters of OCT1, OCT2 and OCT3 broadly overlap, it is difficult to find isoform specific substrates or inhibitors. Still recent studies identify a number of OCT2 specific inhibitors (KIDO et al. 2011) and some examples of relatively isoform-specific substrates and inhibitors for other two isoforms were published (KOEPSELL et al. 2003).

\subsubsection{Functions of polyspecific OCTs in various organs}

OCT1 is by far the most abundant organic cation transporter in the human liver (Hilgendorf et al., 2007). In the liver, OCT1 and OCT3 are located in the sinusoidal (basolateral) membrane of the hepatocytes (MEYER-WENTRUP et al. 1998). This suggests that these transporters act as sinusoidal uptake transporters in liver, aiding in presentation of substrate drugs from blood into the hepatocyte for elimination by metabolism or biliary excretion. The tissue distribution and subcellular localization of these transporters suggest that their primary role is in the elimination of toxic xenobiotic and endogenous organic cations. In addition, for drugs that target the liver for their pharmacological activity, OCT1 may be a limiting step in drug access to hepatocytes and may therefore influence drug action.

\subsubsection{Implication of OCTs in tumor cells}

Organic cation transporters are involved in drug uptake in cancer cells (GUPTA et al. 2011). These transporters may be necessary to reach therapeutical cytostatic concentrations during treatment of tumors. Each cytostatic drug may be taken up by 
several influx transporters expressed in a specific tumor cell and may be released by efflux pumps (KOEPSELl et al. 2007). For example, cisplatin is transported by hOCT2 (CIARIMBOLI et al. 2005; ZHANG et al. 2006; YONEZAWA et al. 2006), or oxaliplatin is transported by hOCT2, hOCT3 and hOCT1 (ZHANG et al. 2006; YONEZAWA et al. 2006). Ballestero et al. showed that hOCTs can be detected in various tumors (BALLESTERO et al. 2006). Shnitsar et al showed that OCT3 is expressed in kidney carcinoma cells and may increase chemosensitivity to melphalan, irinotecan and vincristin (SHNITSAR et al. 2009). Other studies showed that OCT1 and OCT2 are major determinants of the anticancer activity of oxaliplatin and may contribute to its antitumor specificity (ZHANG et al. 2006). These examples indicate that hOCTs have a strong impact on the pharmaco- and toxicokinetics of many cationic cytostatic drugs and knowledge concerning the expression of drug transporters in tumor cells may help to develop cytostatic drugs that are targeted to specific tumors. Good candidates for targeting transporters are those that are highly expressed due to up regulation in tumors (KoEPSELl et al. 2007) Therefore we may in future be able to optimize cancer treatment in patients by knowing about specific cancer cell transporters and drugs that are substrates for these transporters, or using inhibitors that prevent uptake of the cytostatic drug into normal cells without any influence on uptake into tumor cells (CIARIMBOLI et al. 2010).

\subsubsection{Genetic variation in the SLC22A1 gene coding for OCT1}

Human OCT1 is highly genetically polymorphic. Many single-nucleotide polymorphisms (SNPs) with population dependent frequencies were identified by analyzing the SLC22A1, the gene that encodes for human OCT1. Some of these SNPs occur in coding region of the OCT1 gene and then result in single amino acid substitutions or the deletion of one amino acid. These SNPs may have different consequences in transporter activity, for example six mutations are known to reduce transporter activity (Arg61Cys, Cys88Arg, Gly220Val, Pro341Leu, Gly401Ser, Gly465Arg), whereas in one mutation (Ser14Phe) transport expression was increased (KERB et al. 2002; SHU et al. 2003). For polymorphisms Cys88Arg, Gly220Val, Gly401Ser, and Gly465Arg respective frequencies of $0.01 \%, 0.2 \%, 0.8 \%, 1.6 \%$, were obtained and transport of $\mathrm{MPP}^{+}$was reduced to $<10 \%$ compared to wild-type (KERB et al. 2002; SHU et al. 2003). However, for mutants Cys88Arg and Gly401Ser substrate specific effects were observed (KERB et al. 2002). Several polymorphisms altering the 
function have been described in the OCT1 gene. In a sample of 57 healthy Caucasians, 25 genetic variants were identified, eight of which change the protein sequence (KERB et al. 2002). Five of these (Arg61Cys, Cys88Arg, Phe160Leu, Gly401Ser, and Met420del) significantly reduce the transport efficiency. On the other hand, the Ser14Phe variant in the OCT1 gene showed a significant increase in activity (SHU et al. 2003). Some of these SNPs exhibit a changed substrate selectivity that could affect the disposition of OCT1 substrates and as a consequence may alter the duration and intensity of effects of drugs which are substrates for OCT1 (KERB et al. 2002). It was noted that all of the variants with reduced function occurred at evolutionarily conserved amino acid residues, and that variants with reduced function tended to be amino acid substitutions that result in a large chemical change (URBAN and GIACOMINI, 2007). Takeuchi et al, 2003 assessed three coding single nucleotide polymorphisms (cSNPs) in OCT1 that resulted in the amino acid changes Pro283Leu, Arg287Gly and Pro341Leu. They showed that the reduction in activity of these variants was not explained by reduction in protein expression, as immunofluorescence indicated that these SNPs did not affect the membrane localization of hOCT1 (TAKEUCHI et al. 2003). These results suggested that the amino acid residues Pro283 and Arg287 have a substantial role in substrate recognition of hOCT1.

Due to high frequency of this polymorphisms in the Caucasian population, nine percent of people are compound homozygous carriers of the five common coding polymorphisms resulting in reduced or absent function (Arg61Cys, Cys88Arg, Gly401Ser, Gly465Arg and deletion of Met420) and therefore have reduced ability to take up drugs such as metformin (SHU et al. 2007; TzVETKOV et al. 2009). These individuals have also impaired uptake into the liver of other hydrophobic cationic drugs.

\subsection{Drug metabolizing enzymes}

\subsubsection{Drug Metabolism}

Drugs are most often eliminated by biotransformation and excretion into the urine or bile. The liver is the major site for drug metabolism, but specific drugs may undergo biotransformation in other tissues, such as the intestines. The process of metabolism mostly transforms lipophilic drugs into more polar products that are more readily excreatable in the urine or have less re-absorption when excreted via the bile. Therefore, lipid-soluble agents must first be metabolized in the liver using two general sets of 
reactions, called Phase I and Phase II (Fig. 1.3). As it can be seen, typical Phase I reactions are oxidation, reduction and hydrolysis. This may increase, decrease, or leave unaltered the drugs pharmacologic activity. Phase II are conjugation reactions like sulfation, glucuronidation, methylation or acetylation which result in production of highly polar, most often therapeutically inactivate compounds.

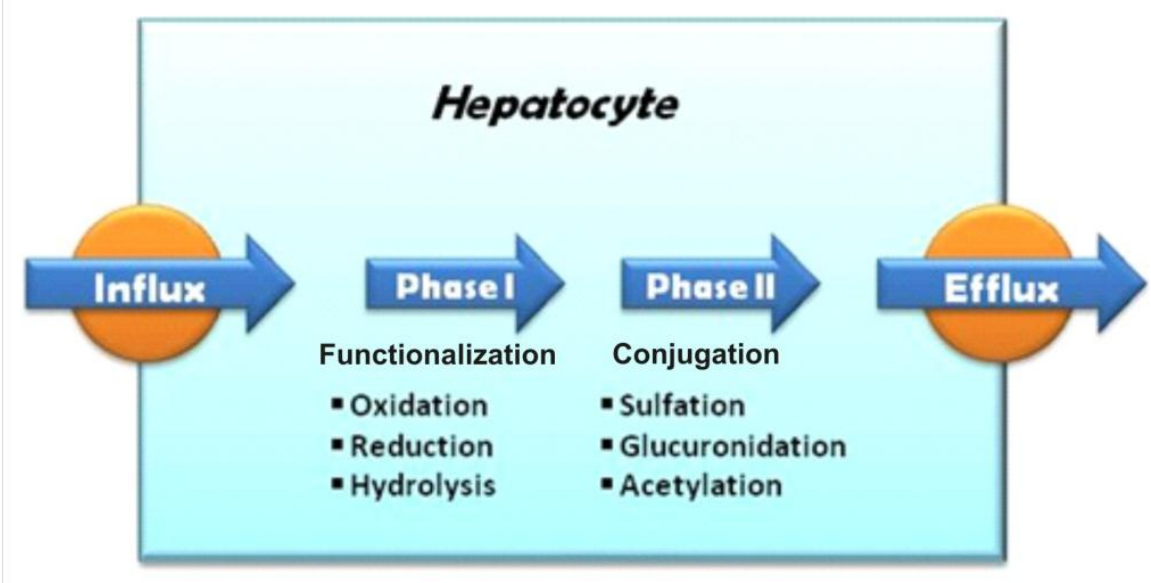

Fig.1. 3 Schematic diagram of drug metabolism in hepatocytes.

\subsubsection{Catalytic Mechanism}

There are more than 30 families of drug-metabolizing enzymes in humans (Evans and McLeod 2003). Among them, Cytochrome P450s (CYP450s) accounting for about $75 \%$ of the total number of different metabolic reactions (GUENGERICH, 2008). CYPs are a superfamily of monooxygenases that are predominantly expressed in the liver and are involved in phase I metabolism of many drugs. Different CYP isoforms catalyze the oxidative metabolism of drugs, other xenobiotics and different endogenous compounds. CYP450 enzymes are so named because they are bound to membranes within a cell (cyto) and contain a heme pigment (chrome, P) that absorbs light at a wavelength of 450 $\mathrm{nm}$ when exposed to carbon monoxide. There are more than 50 CYP450 enzymes, but the CYP1A2, CYP2C9, CYP2C19, CYP2D6, CYP3A4, and CYP3A5 enzymes metabolize 90 percent of drugs that undergo metabolism in the human body (LYNCH and PRICE 2007; WILKINSON 2005).

Drugs interact with the CYP450 system in several ways. Drugs may be metabolized by only one CYP450 enzyme (e.g., metoprolol by CYP2D6) or by multiple enzymes (e.g., warfarin by CYP1A2, CYP2D6, and CYP3A4) (Daly and King 2003). Drugs may also inhibit the activity of CYP450s or down-regulate or induce the expression of CYP450s 
and cause by that metabolic drug-drug interactions (Lynch and Price 2007). Inhibitors block the metabolic activity of one or more CYP450 enzymes like sertraline (Zoloft) which is considered a mild inhibitor of CYP2D6 (SPROULE et al. 1997), whereas inducers increase CYP450 enzyme activity by increasing transcription (e.g. rifampin which induces CYP2C9, (KANEBRATT et al. 2008) or by blocking degradation (e.g. ethanol prevents degradation of CYP2E1, (ROBERTS et al. 1995).

The catalytic cycle of CYP450 is shown in Figure 1.4. After the substrate is bound to the active site of the CYP450 an electron will be donated to the cytochrome's heme group by a NADPH-P450 reductase. This results in the reduction of $\mathrm{Fe}^{3+}$ to $\mathrm{Fe}^{2+}$. This reduction allows the breaking of the oxygen-oxygen bond in a molecule of oxygen that is attached to the heme. The complex formed by the binding of oxygen is very unstable and can result in the production of superoxide anions (GUENGERICH 2008). A second electron donated by NADPH-P450-reductase causes reduction of the iron-oxygen complex, and this is followed by the addition of a proton and the cleavage of the oxygen-oxygen $(\mathrm{O}-\mathrm{O})$ bond and releasing water. Finally, the resulting electron-deficient complex abstracts either hydrogen or an electron from the substrate, and the resulting intermediate collapses, producing the oxidized substrate and regenerates the iron centre (Fig. 1.4).

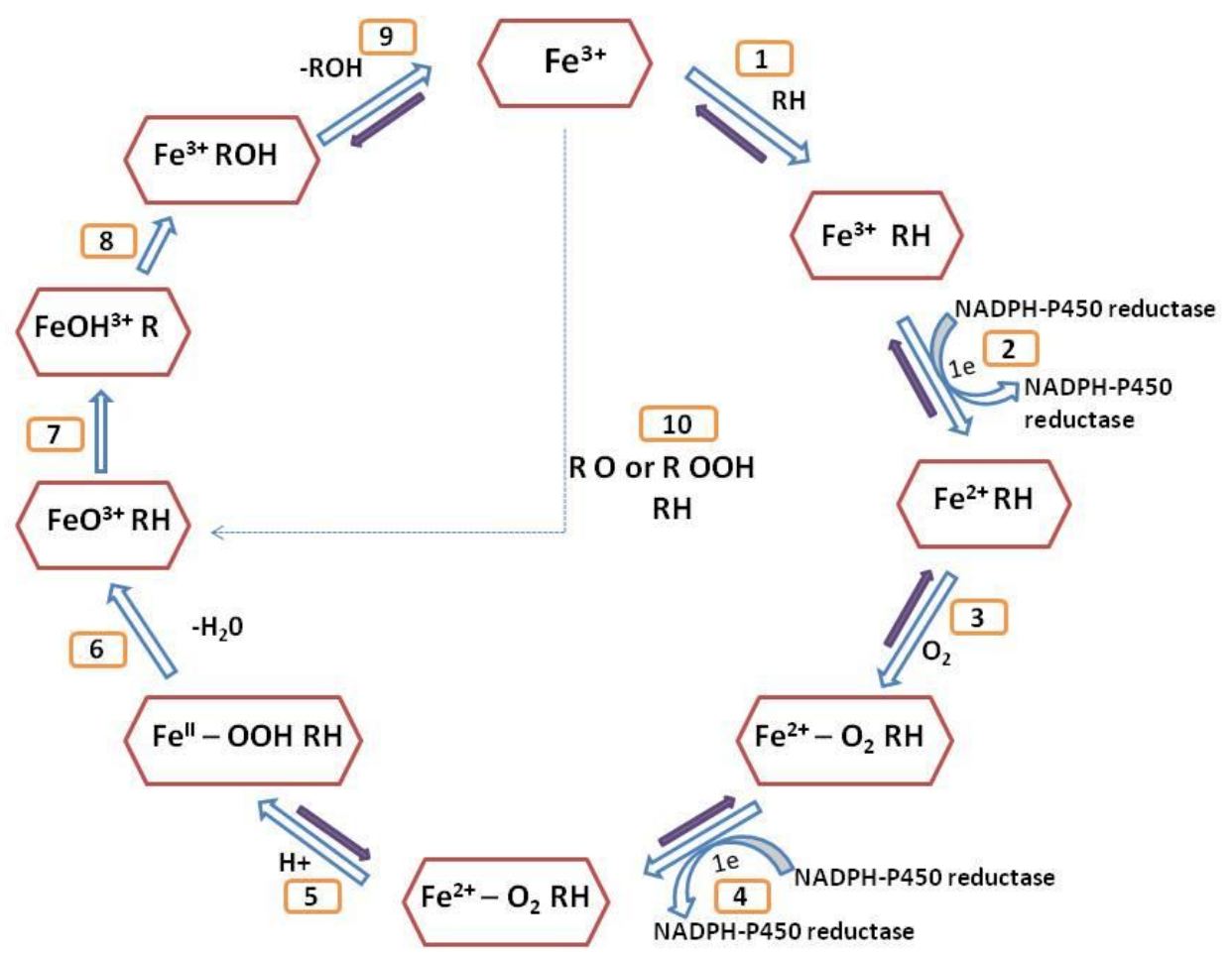

Fig.1. 4 Catalytic cycle for CYP450s. NADPH-P450 reductase mediates an electron donation to the cytochrome heme group (Step 2). This reduction allows for the breaking of the oxygen- 
oxygen bond in molecular oxygen (Steps 3-6). This allows for the hydroxylation of the compound to be metabolized (Step 8), which can then serve as a site for further hydroxylation (Step 10).

\subsubsection{Metabolizing enzyme CYP2D6}

A cytochrome P450 isoform CYP2D6 was originally cloned and characterized by Gonzales et al in 1988 (GonZALEZ et al. 1988). CYP2D6 is part of the extensive CYP2D family, which includes three members in humans, CYP2D6 and the pseudogenes CYP2D7P and CYP2D8P (Yasukochi and Satta, 2011). In human the three isoforms are located in tandem on chromosome 22 (KIMURA et al. 1989). However, CYP2D7P and CYP2D8P are so called pseudogenes and only CYP2D6 codes for an active protein. CYP2D6 is one of 57 cytochrome P450s, a class of metabolic enzymes found primarily in the human liver. Many of these enzymes, including CYP2D6, play an instrumental role in the breakdown and clearance of clinically prescribed drugs (Ingelman-Sundberg 2004). Indeed, together with CYP2C9 and CYP2C19, CYP2D6 is responsible for $40 \%$ of hepatic drug metabolism and is thought to be active in the enzymatic breakdown of $20-25 \%$ of all medicines now prescribed, a fraction that consists of approximately 100 identified drugs (INGELMAN-SUNDBERG 2005; LEDESMA and AgUNDEZ 2005; SODERBACK et al. 2005), some of which are listed in table 1.2.

Table 1. 2 List of drugs known to be CYP2D6 substrates (from Brockmöller and Tzvetkov, 2008)

\begin{tabular}{lll}
\hline Protein & Abbreviation & \multicolumn{1}{c}{ Substrates } \\
\hline Cytochrome P450 & CYP2D6 & Amitriptyline, clomipramine, debrisoquine, \\
& desipramine, doxepin, duloxetin, \\
& imipramine, nortriptyline, trimipramine, \\
& paroxetin, venlafaxin; haloperidol, \\
& perphenazine; chlorpromazine, perazine, \\
& promethazine, thioridazine, \\
& zuclopenthixol; aripiprazole, olanzapine; \\
& amphetamine, atomoxetin; carvedilol, \\
& metoprolol, nebivolol, propranolol, timolol; \\
& perhexiline; encainide, flecainide, \\
& mexilletine; ondansetron, tropisetron; \\
& codeine, tramadol; tamoxifen
\end{tabular}


The clinical impact of the CYP2D6 genotype depends on whether the drugs are bioactivated by CYP2D6 or inactivated. Most of the substrates of this enzyme are metabolized to inactive metabolites, whereas there are notable exceptions of drugs bioactivated by CYP2D6. For example, tropisetrone convertes to inactive form by CYP2D6, while codeine, tramadol, tamoxifen and encainide convert to the pharmacologically active forms by this enzyme (BROCKMOLLER and TZVETKOV 2008).

Phenotypic classification of CYP2D6 activity shows there is a wide range of enzyme activities ranging from a complete lack of enzyme activity to high activity. These phenotypes consist of: PMs, poor metabolizers, IMs, intermediate metabolizers, EMs, extensive metabolizers, and UMs, ultra metabolizers (MEYER 2004; ZANGER et al. 2004). For drugs that are inactivated by CYP2D6, PMs and, to a lesser extent, IMs are prone to exaggerated side effects from drugs metabolized by CYP2D6, whereas normal doses of the same drugs tend to be ineffective for UMs (INGELMAN-SUNDBERG 2005; MEYER 2004). For drugs that are bioactivated by CYP2D6 these phenotypes have reverse effect so that normal doses of drugs is ineffective for PMs and IMs, whereas the same dosage of drugs accompany with the side effect in EMs or UMs.

\subsection{Drug-Drug Interaction}

The mechanistic basis of many drug-drug interactions is well established. They can occur as a result of changes in pharmacodynamics and/or pharmacokinetics. The latter can occur through effects on absorption, distribution, metabolism or excretion. One of the most clinically important causes of drug-drug interactions is the inhibition or induction of the activity of cytochrome P450 (DAVIES et al. 2004; MichaleTS 1998; TUCKER et al. 2001). Cytochrome P450 enzymes can be inhibited or induced by drugs either by directly inhibiting the activity of the CYP or by down-regulating or inducing the biosynthesis of an enzyme. This is a major source of adverse drug interactions, since changes in CYP enzyme activity may influence on the metabolism and clearance of various drugs and resulting in clinically significant drug-drug interactions that can cause unanticipated adverse reactions or therapeutic failures. For example, if one drug inhibits the CYP-mediated metabolism of another drug, the second drug may accumulate within the body to toxic levels. Some other drugs, such as tramadol, are not therapeutic until they are metabolized by CYP450 to their active compounds. These medications, known as prodrugs, may cause an exaggerated therapeutic effect or adverse effect when a 
CYP450 inducer is added. Conversely, if a CYP450 inhibitor is combined with a prodrug, or a person is a CYP450 poor metabolizer, therapeutic failure is likely to result because of little or no production of the active drug (POULSEN et al. 1996).

Hence, these drug interactions may necessitate dose adjustments or choosing drugs that do not interact with the CYP450 system. Knowledge of the most important drugs metabolized by cytochrome P450 enzymes, as well as the most potent inhibiting and inducing drugs, can help to minimize the risk of adverse drug reactions and interactions (LYNCH and PRICE 2007). Table 1.3 lists some examples of common drug-drug interactions and their potential clinical effects.

Table 1. 3 Examples of drug-drug interactions involving the CYP450

\begin{tabular}{|c|c|c|c|c|}
\hline $\begin{array}{l}\operatorname{Drug}(\mathbf{s}) / \\
\text { product }\end{array}$ & $\begin{array}{l}\text { Enzyme } \\
\text { inhibitor } \\
\text { or inducer }\end{array}$ & Drug(s) & $\begin{array}{l}\text { Metabolizing } \\
\text { enzyme }\end{array}$ & $\begin{array}{l}\text { Possible clinical } \\
\text { effect }\end{array}$ \\
\hline $\begin{array}{l}\text { Amiodarone } \\
\text { (Cordarone) }\end{array}$ & $\begin{array}{l}\text { CYP2C9 and } \\
\text { CYP3A4 } \\
\text { inhibitor }\end{array}$ & $\begin{array}{l}\text { Warfarin } \\
\text { (Coumadin) }\end{array}$ & CYP2C9 & $\begin{array}{l}\text { Increased risk of } \\
\text { bleeding caused by } \\
\text { Increased warfarin level }\end{array}$ \\
\hline $\begin{array}{l}\text { Carbamazepine } \\
\text { (Tegretol), } \\
\text { phenobarbital, } \\
\text { phenytoin } \\
\text { (Dilantin) }\end{array}$ & $\begin{array}{l}\text { CYP3A4 } \\
\text { inducer }\end{array}$ & $\begin{array}{l}\text { Ethinyl } \\
\text { estradiol- } \\
\text { containing } \\
\text { contraceptives }\end{array}$ & CYP3A4 & $\begin{array}{l}\text { Unplanned pregnancy } \\
\text { caused by reduced } \\
\text { estradiol level }\end{array}$ \\
\hline $\begin{array}{l}\text { Clarithromycin } \\
\text { (Biaxin), } \\
\text { erythromycin, } \\
\text { telithromycin } \\
\text { (Ketek) }\end{array}$ & $\begin{array}{l}\text { CYP3A4 } \\
\text { inhibitor }\end{array}$ & $\begin{array}{l}\text { Simvastatin } \\
\text { (Zocor), } \\
\text { verapamil } \\
\text { (Calan) }\end{array}$ & CYP3A4 & $\begin{array}{l}\text { Myopathy or } \\
\text { rhabdomyolysis caused } \\
\text { by } \\
\text { increased simvastatin } \\
\text { level } 21 \\
\text { Hypotension and QT } \\
\text { interval } \\
\text { prolongation caused by } \\
\text { increased } \\
\text { verapamil level }\end{array}$ \\
\hline $\begin{array}{l}\text { Diltiazem } \\
\text { (Cardizem), } \\
\text { verapamil }\end{array}$ & $\begin{array}{l}\text { CYP3A4 } \\
\text { inhibitor }\end{array}$ & Prednisone & CYP3A4 & $\begin{array}{l}\text { Immunosuppression } \\
\text { caused by increased } \\
\text { prednisolone serum } \\
\text { levels }\end{array}$ \\
\hline $\begin{array}{l}\text { Fluoxetine } \\
\text { (Prozac), } \\
\text { paroxetine } \\
\text { (Paxil), }\end{array}$ & $\begin{array}{l}\text { CYP2D6 } \\
\text { inhibitor }\end{array}$ & $\begin{array}{l}\text { Risperidone } \\
\text { (Risperdal), } \\
\text { tramadol } \\
\text { (Ultram) }\end{array}$ & CYP2D6 & $\begin{array}{l}\text { Increased risk of } \\
\text { extrapyramidal } \\
\text { adverse effects caused } \\
\text { by increased } \\
\text { risperidone level24; } \\
\text { decrease in } \\
\text { analgesic effect caused } \\
\text { by low level of active } \\
\text { metabolite }\end{array}$ \\
\hline Grapefruit juice & CYP3A4 & Buspirone & CYP3A4 & Dizziness and serotonin \\
\hline
\end{tabular}


inhibitor (Buspar) syndrome caused by increased buspirone level

$\begin{array}{llll}\text { Metronidazole } & \text { CYP2C9 } & \text { Warfarin } & \text { CYP2C9 }\end{array}$
$\begin{array}{llll}\text { (Flagyl) } & \text { Warfarin } & \text { CYP2C9 bleeding caused by }\end{array}$ increased warfarin level Dry mouth, dizziness, and cardiac

Terbinafine CYP2D6 (Lamisil) inhibitor

Amitriptyline CYP2D6 toxicity caused by prolonged increase in amitriptyline and nortriptyline (Pamelor) levels

(from Lynch and Price, 2007)

All these reactions take place within the cell and thus a prerequisite for all these reactions is that the drug can enter the cell. With some very hydrophobic drugs this entering may be via simple diffusion, but many typical CYP2D6 substrates have only moderate hydrophobicity and therefore influx transporters like OCT1 may be relevant for the risk of drug-drug interactions.

\subsection{Drugs that may be OCT1 substrates}

In this chapter a detailed overview is given about drugs that based on their chemical properties and structure were analyzed as potential substrates of OCT1. The focus is on drugs that are weak organic bases and were not known before the start of this work to be OCT1 substrates.

\subsubsection{5-HT3 receptor antagonists}

Vomiting is a clinically relevant side effect of chemotherapy treatment that substantially reduces the quality of life of the patients and may lead to therapy discontinuation. Vomiting is triggered by serotonin (5-HT) which is released from the enterochromaffine cells of the small intestine. Under treatment with some chemotherapeutic agents, like cisplatin, an uncontrolled release of large amounts of serotonin occurs. The released serotonin activates sertotonin-type 3 (5-HT3) receptors that are located on the peripheral vagal nerve terminals in the intestine and that vagal stimulation results in triggering the vomiting reflex.

Significant progress in the treatment of chemotherapy-induced vomiting and nausea (CINV) has been achieved in the 1990s with the advent of selective 5-HT3 receptor 
antagonists (DE LEON 2006; HESKETH 2008). Nevertheless, approximately 15-30\% of the patients do not respond sufficiently to the current antiemetic therapy (AAPRO 2005; HESKETH 2008). One reason for the substantial differences in response may be genetic variability in the uptake and elimination of 5-HT3 receptor antagonists.

\section{Ondansetrone and tropisetrone}

The 5-HT3 receptor antagonists ondansetron and tropisetron (Fig.1.5) have become first line therapy for the treatment of chemotherapy induced as well as postoperative nausea and vomiting (HESKETH 2008). The biotransformation of tropisetron and ondansetron is mediated by multiple cytochrome P-450 enzymes, among them the polymorphic CYP2D6 (FISCHER et al. 1994; DIXON et al. 1995) resulting in a high interindividual variability in plasma concentrations and effectiveness of both drugs. Tropisetron is mainly, and ondansetron is partially, metabolized by cytochrome P450 2D6 (CYP2D6). Genetic polymorphisms in CYP2D6 are known to affect the pharmacokinetics and the efficacy of these two 5-HT3 antagonists. Ultra rapid metabolizer (UM) for CYP2D6 showed the highest, whereas poor metabolizer (PM) showed the lowest rates of vomiting and nausea, and significantly higher tropisetron blood concentrations (KAISER et al. 2002).

Therefore, genotyping for $C Y P 2 D 6$ before the start of the chemotherapy or the use of antiemetic drugs that are not metabolized by CYP2D6 may further reduce nausea and vomiting.

\section{Palonosetrone}

Palonosetron is the newest agent in the group of 5-HT antagonists. Polanosetron has a strong binding affinity to 5-HT3 receptors and thus selectively blocks serotonin from binding to these receptors peripherally and centrally. It has little or no affinity for other receptors. Palonosetron is indicated for the prevention of acute and delayed nausea and vomiting associated with initial and repeat courses of moderate to highly emetogenic cancer chemotherapy (DE LEON 2006). Due to its long half-life of about 40 hours and thus prolonged action, palonosetron is now the preferred antiemetic drug used in oncology. 
A)<smiles>Cc1nccn1CC1CCc2c(c3ccccc3n2C)C1=O</smiles>

Ondansetron
B)<smiles>O=C1c2cccc3c2[C@H](CCC3)CN1[C@H]1CN2CCC1CC2</smiles>

Palonosetrone

C)<smiles>CN1C2CCC1CC(CCOC(=O)c1c[nH]c3ccccc13)C2</smiles>

Tropisetron

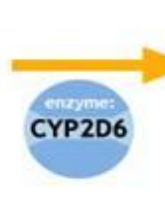

P2D6<smiles>CN1CC2CCC1C(OC(=O)c1c[nH]c3cc(O)ccc13)C2</smiles>

6-OH tropisetron

Fig.1. 5 Structures of the 5-HT 3 antagonists ondansetrone (A), palonosetrone (B) and tropisetrone (C). Tropisetrone is metabolized in hepatocytes by CYP2D6 to its metabolite 6hydroxy tropisetrone.

All these drug metabolism reactions take place within the cell and thus a prerequisite for all these reactions is that the drug can enter the cell. Since the 3-HT3 antagonists are only moderately hydrophobic influx transporters like OCT1 may be relevant for the pharmacokinetics and consequently for the efficacy.

\subsubsection{The analgesic drugs tramadol and O-desmethyl tramadol}

Tramadol is an analgesic and antitussive drug belonging to the class of synthetic opioids. Tramadol is a prodrug that is metabolized to its active form $\mathrm{O}$ desmethyltramadol. O-desmethyltramadol exerts its action through complex interactions between opiate, adrenergic, and serotonin receptors (POULSEN et al. 1996; STAMER et al. 2003) but it may be argued that activation of the $\mu$-opioid receptors is the main mechanism of analgesic action. Tramadol is administered as a racemic mixture of (+) and (-) tramadol, and both diastereomers are $O$-demethylated. In vitro receptor binding studies have indicated that opioidergic tramadol analgesia is mediated mostly by (+) Odesmethyltramadol (LAI et al. 1996). The (+) O-desmethyltramadol is more potent agonist of the $\mu$-opioid receptor than (-) O-desmethyltramadol or tramadol. However, 
both $(+)$ and (-) tramadol may contribute to analgesic effects by inhibiting serotonin and norepinephrine reuptake (DRIESSEN and REIMANN 1992; HALFPENNY et al. 1999). Tramadol is metabolized to $O$-desmethyltramadol by CYP2D6 (PAAR et al. 1992; PAAR et al. 1997; POULSEN et al. 1996) (Fig.1.6). Polymorphic cytochrome P450 (CYP) 2D6 activity has been shown to be a determinant of the pharmacokinetics and pharmacodynamics of tramadol (PEDERSEN et al. 2005). Therefore, CYP2D6 genotype can determine concentrations of O-desmethyltramadol enantiomers and thereby can influence efficacy of tramadol treatment (KIRCHHEINER et al. 2008; STAMER et al. 2007).

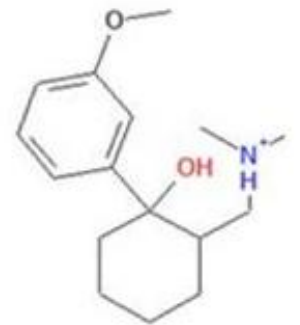

Tramadol

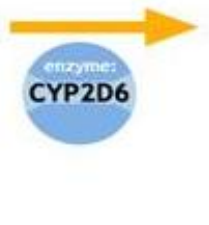

\section{O-desmethyl-tramadol}

Fig.1. 6 Metabolism of tramadol to O-desmethyl-tramadol catalyzed by CYP2D6.

All these drug metabolism reactions take place within the cell and thus a prerequisite for all these reactions is that the drug can enter the cell. Since tramadol and particularly desmethyltramadol are only moderately hydrophobic influx transporters like OCT1 may be relevant for the pharmacokinetics and consequently for the efficacy.

\subsubsection{The CYP2D6 model drug debrisoquine}

Debrisoquine, an antihypertensive drug metabolized to 4-hydroxydebrisoquine by CYP2D6, is commonly used as an in vivo probe of CYP2D6 activity and can be used to phenotype individuals as either extensive (EMs) or poor metabolizers (PMs). Debrisoquine is predominantly eliminated after metabolism via CYP2D6. The major metabolic pathway for debrisoquine is a hydroxylation at position 4, catalyzed by CYP2D6 (Fig.1.7). The results metabolite 4-hydroxydebrisoquine is then directly excreted into urine (CERQUEIRA et al. 2000; GONZALEZ et al. 1988).

In the 1970s and early 1980s, pioneer works by Robert Smith and colleagues described variations in debrisoquine metabolism as one of the first monogenetic autosomal 
recessive traits in pharmacology (MAHGOUB et al. 1977; Smith, 1986). Debrisoquine is weak base with a pKa value of 11.95 . More than $99.99 \%$ of this molecule is positively charged at the physiological $\mathrm{pH}$ of 7.4. Besides, debrisoquine is hydrophilic compound with $\log \mathrm{D}_{7.4}$ partition coefficient of -1.58 . Taken together, debrisoquine may probably only poorly penetrate cell membranes by passive diffusion and will likely require carrier-mediated membrane transport for its cellular uptake.<smiles>N=C(N)N1CCc2ccccc2C1</smiles>

Debrisoquine

pKa $11.9 \log D_{7.4}-1.58$

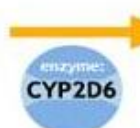<smiles>N=C(N)N1Cc2ccccc2C(O)C1</smiles>

4-hydroxydebrisoquine

Fig.1. 7 Debrisoquine and its CYP2D6 catalyzed metabolite 4-hydroxydebrisoquine.

\subsubsection{Cytostatic drugs}

\section{Irinotecan and its metabolite SN-38}

Irinotecan is used to treat several human cancers, including colon and lung cancer in adults and pediatric solid tumors such as rhabdomyosarcoma and neuroblastoma (EICHELBAuM et al. 2006). Irinotecan is a prodrug that is activated by hydrolysis to its active metabolite $\mathrm{SN}-38$ (Fig.1.8). SN-38 is a potent inhibitor of topoisomerase I. The inhibition of topoisomerase I prevents DNA from unwinding and eventually leads to inhibition of both DNA replication and transcription. The mechanisms of action of these topoisomerase inhibitors is different, namely they inhibit relegation of the DNA after initial single strand break (topoisomerase I inhibitors) or double strand break (topoisomerase II inhibitors). This inhibition of relegation means DNA strand breaks and these strand breaks then result in apoptosis.SN-38 is inactivated by glucuronidation by uridine diphosphate glucoronosyltransferase 1A1 (UGT1A1). The conjugated metabolite is relatively inactive and readily eliminated in bile and urine (ANDO et al. 2000). 


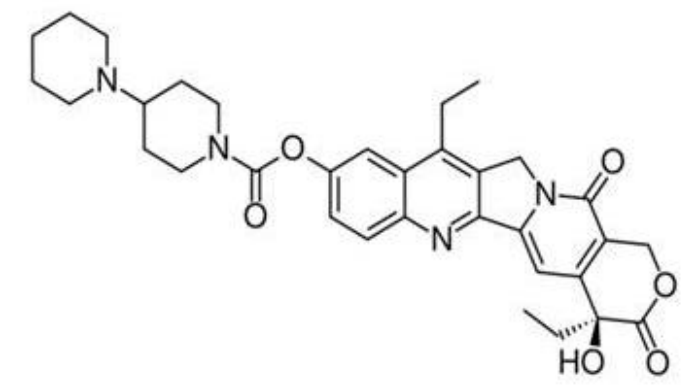

Irinotecan

pKa 8.48

$\log \mathrm{D}_{7.4} 2.6$

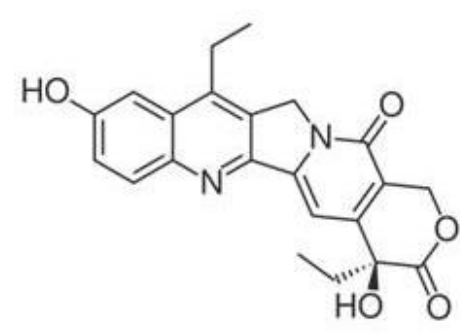

SN-38

pKa 2.83 (weak acid)

Fig.1. 8 The structures of irinotecan and its metabolite, SN38. Irinotecan is weak base with pKa 8.48 whereas SN38 is weak acid. But both have the same lipophilicity $\left(\log \mathrm{D}_{7.4}\right)$.

Inter-individual differences in irinotecan metabolism are caused by polymorphisms in the UGT1A1 enzyme. Homozygous carriers of two UTG1A1 allele 28 have lower expression of UGT1A1, have higher plasma concentrations of SN-38 and are at higher risk of neutropenia, the major adverse effect of irinotecan (INNOCENTI et al. 2004).

\section{Doxorubicin}

Doxorubicin is an anthracycline antibiotic used as cancer chemotherapeutic. Like all anthracyclines, doxorubicine works by intercalating DNA. Additional cytotoxic mechanisms of doxorubicine are inhibition of topisomerase II and increase in the the production of reactive oxygen species (RAVID et al. 1999). Doxorubicine is commonly used to treat breast cancer, non-Hogkin Lymphoma and other cancers. Doxorubicine is a weak organic base with pKa of 8.3 (Fig.1.9) and therefore may require carrier mediated uptake to enter cancer cells. 


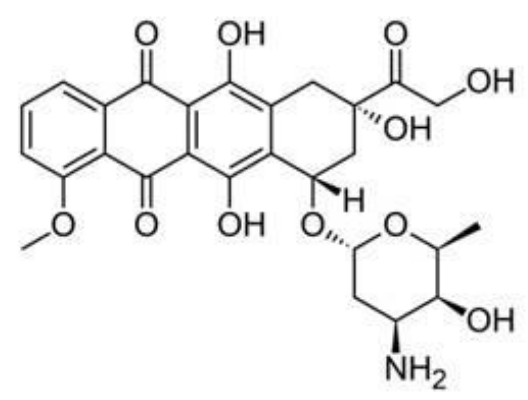

Doxorubicin

pKa 8.3

$\log \mathrm{D}_{7.4} 0.38$

Fig.1. 9 Structure of doxorubicin. Doxorubicin is weak base with pKa 8.3 and positively charged compound in physiological $\mathrm{pH}$. According to $\log \mathrm{D}$ value, this compound has lipophylic property.

\subsection{Interaction between drug transporters and drug metabolizing enzymes}

The liver is the major drug metabolizing organ in the human body. However, all metabolizing enzymes are localized intracellulary in the liver hepatocytes. Therefore to face liver metabolism drugs has to penetrate through the sinusoidal membrane from the systemic circulation into the hepatocytes. This may take place by passive diffusion or with the help of carrier mediated uptake transport. A number of drug uptake transporters are located on the sinusoidal membrane of the hepatocytes. These include the organic anion transporting polypeptides (OATPs), sodium-dependent taurocholatecotransporting polypeptide (NTCP), monocarboxylic acid transporter 2 (MCT2) and organic cation transporters (OCTs) (PANG et al., 2007; ZAMEK-GLISZCZYNSKI et al. 2006) (Fig.1.10). After a xenobiotic has been taken up into the hepatocytes, it may undergo biotransformation and this biotransformation typically changes the biological activity of the substance. After all the products of metabolism are excreted into bile via the efflux transporters like organic cation $-\mathrm{H}^{+}$exchanger MATE1, or MDR1 and MDR3 (multidrug resistance protein 1and 3), MRP2 (multidrug resistance-associated protein 2), BSEP (bile salt export pump), BCRP (breast cancer resistance protein) located on the canalicular membrane in hepatocytes or back into the blood by MRP3, MRP4 and MRP6 at the basolateral membrane. 


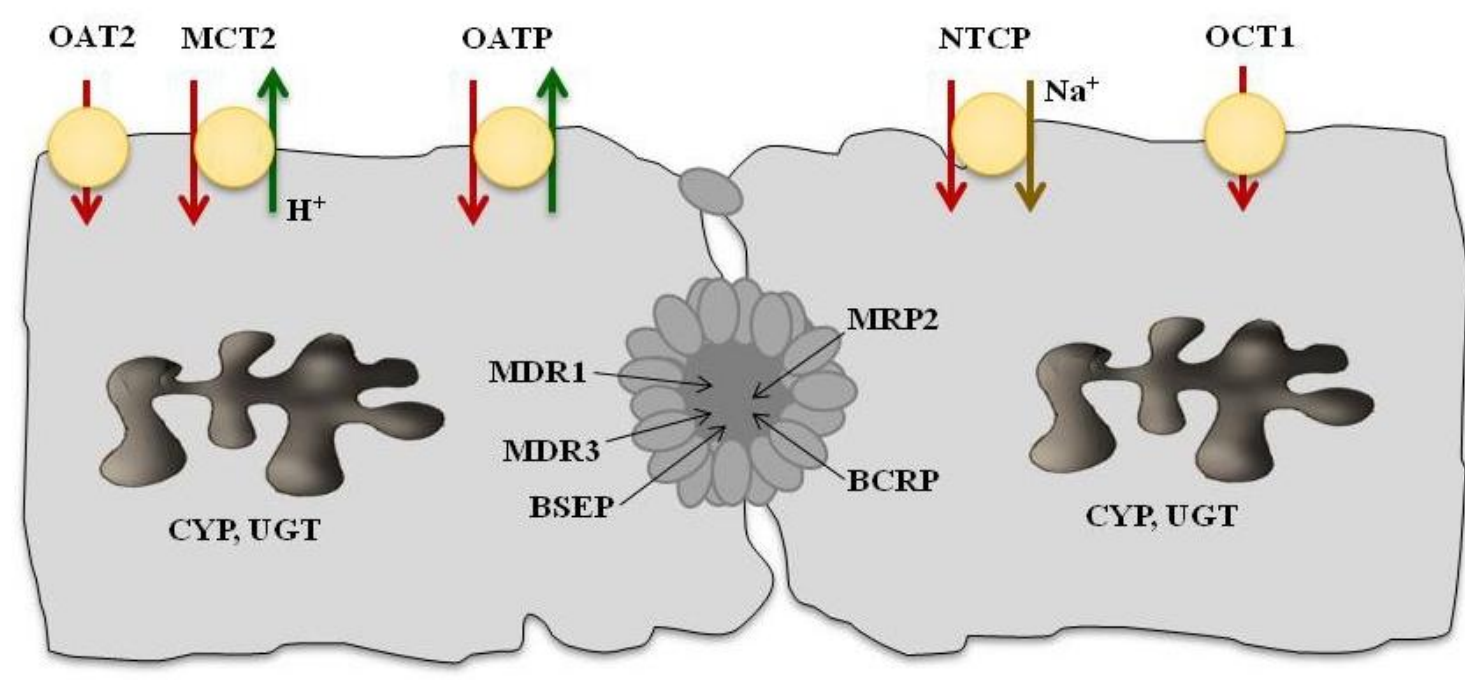

Fig.1. 10 Cellular localization of hepatic drug metabolizing enzymes, influx and efflux transporters. Influx transporters such as OATP, NTCP, OAT2, OCT1, and MCT2 at the sinusoidal membrane; and efflux transporters such as Pgp or MDR1, MDR3, MRP2, BSEP, and BCRP at the canalicular membrane are shown. The enzymes such as CYP, UGT, SULT and GST are present to mediate intracellular metabolism.

It is also recognized that rate-limit metabolism and excretion in the liver may correlate to hepatic uptake transporters (TIRONA and PANG 1999). Zonal heterogeneities of transporters and metabolic enzymes further modulate drug disposition in the liver (ABUZAHRA and PANG 2000). The rate-limiting effect of genetic polymorphisms in OCT1 on the uptake and metabolism of organic cationic drugs has thus for only infrequently been studied in relation to OCT1 and CYP2D6 genetic polymorphisms. But it may correspond to the well-studied effects of genetic polymorphisms in organic anion transporting polypeptide 1B1 (OATP1B1) on the metabolism of some organic anionic drugs (LinK et al. 2008; ROMAINE et al.; VoRMFELDE et al. 2008). Concerning OATP1B1, Vormfelde et al., 2008 showed there was a combination effect between the Val174Ala polymorphism and the Asp130Val174 haplotype with CYP2C9*3 on the extrarenal torsemide clearance. The OATP1B1 haplotypes explained $25.6 \%$ variation in renal torsemide excretion whereas the variation reached to $43.8 \%$ when CYP2C9, OAT1, and OAT4 polymorphisms have also been counted. This suggests that beside OATP1B1 polymorphisms, variation in other genes may also play a role to explain high interindividual variation in response to torsemide.

Until recently, the role of transporters during absorption and excretion of drugs received only minor attention. Even there is less information when we consider the combined 
effect of drug membrane transporters and drug metabolizing enzymes. On the other hand, it is also important to understand how genetic variants in different genes (those coding for drug transport and those coding for drug metabolism) are acting in a combined fashion.

\subsection{The aim of this work}

The aim of this work was to identify drugs depending on OCT1 for their hepatocellular uptake and investigate combined effect of OCT1 transporter and CYP2D6 metabolizing enzyme on drug metabolism.

Since OCT1 typically catalyses the influx transport of organic cations and CYP2D6 typically metabolizes such organic cations, epistatic effects between OCT1 and CYP2D6 may become an important focus of molecular and clinical pharmacological research. For this reason, we hypothesized that the organic cation transporter OCT1 is involved in the uptake of tropisetrone, ondansetrone, palonosetrone, debrisoquine, tramadol, O-desmethyltramadol, irrinotecan, its metabolite SN38 or doxorubicine into the liver, and that genetic polymorphisms in OCT1 may contribute to the high interindividual variability in uptake of these drugs. In this study we tested: 1) whether these drugs are substrates of OCT1, 2) whether drug-drug interactions or genetic polymorphisms in the OCT1 gene may affect cellular uptake of these drugs, 3) whether there is any combination effect between OCT1 and CYP2D6 metabolizing enzyme 


\section{Materials and Methods}

\subsection{Materials}

\subsubsection{Chemicals}

\begin{tabular}{l} 
Chemicals, Kits and Medium \\
\hline 1 kb Standard Ladder for Agarosegel \\
100 bp Standard Ladder for Agarosegel \\
2-Mercaptoethanol $\geq 99 \%$ \\
$40 \%$ (w/v) Acrylamide:Bisacrylamide/ Mix 37,5:1 \\
$4326322 \mathrm{E}$ (TBP,VIC-MGB) \\
40 micron cell strainer \\
Acetic acid 100\%, pro analysis \\
Acetonitril \\
Agar (for Bacteriology) \\
Agarose Ultra Pure
\end{tabular}

AMMC

Ammonium persulfate $\geq 98 \%$

Ammonium sulfate $\geq 99,5 \%$

Ampicillin 99\%

Bicinchoninic acid

BigDye ${ }^{\circledR}$ Sequencing Kit

Boric Acid 100\%

Bovine serum albumin (BSA)

Bromphenolblue Na-Salt (for Electrophoresis)

Chloroform $\geq 99,8 \%$

Collagen A

Coomassie Brilliant Blue R 250

Copper sulfate pentahydrate

Debrisoquine

Dimethyl sulfoxide (DMSO)

Disodium hydrogen phosphate $\geq 99,9 \%$

Dithiothreitol $\geq 99,5 \%$ (for Molecular biology)

DNeasy Blood \& Tissue Kit

dNTP Set

Doxorubicin hydrochloride

\section{Manufacturer}

Rapidozym, Berlin

Rapidozym, Berlin

Sigma-Aldrich, Deisenhofen

Biomol, Hamburg

Applied Biosystem, Darmstadt

BD Falcon (352340)

Merck, Darmstadt

Merck, Germany

AppliChem, Darmstadt

Invitrogen, Karlsruhe

Gentest

Sigma-Aldrich, Deisenhofen

Sigma-Aldrich, Deisenhofen

AppliChem, Darmstadt

Sigma-Aldrich, Deisenhofen

Applied Biosystems, Darmstadt

Merck, Darmstadt

Sigma-Aldrich, Deisenhofen

Roth, Karlsruhe

J.T. Baker, Phillipsburg, USA

Biochrom, Berlin

BioRad, München

Sigma-Aldrich, Deisenhofen

Sigma-Aldrich, Deisenhofen

AppliChem, Darmstadt

Merck, Darmstadt

AppliChem, Darmstadt

Qiagen, Hilden

ABgene, Hamburg

Sigma-Aldrich, Deisenhofen 
Dulbecco’s Modified Eagle Medium

EDTA $0,5 \mathrm{M}$ in water solution

EDTA pure

Ethanol 96\%

Ethanol denatured 99\% (Desinfection agent)

Ethidiumbromide $1 \%$ in $\mathrm{H} 2 \mathrm{O}$ (for electrophorese)

Exonuclease I E.coli $(20 \mathrm{u} / \mu \mathrm{l})$

Fluoromount-G

FuGene 6

GeneScanLIZ120 standard ladder for SNaPshot ${ }^{T M}$

Glycerol $85 \%$

HBSS medium

Goat anti mouse Alexa 488

Goat anti rabbit Alexa 546

Helipur $^{\circledR} \mathrm{H}$ plus $\mathrm{N}$ desinfection agent

Roti $^{\circledR}$-Histofix 4\%

HotStarTaq Master Mix Kit (250 units)

Hs00287016_A1 (POR)

Hs00427550_A1 (OCT1)

Hs02576158_g1 (CYP2D6)

Hydrogen chloride

Hygromycin B (50mg/ml)

Irinotecan hydrochloride

Isoamylalcohol $98 \%$

Isopropanol $\geq 99,9 \%$

Kanamycin $\geq 750 \mathrm{U} / \mathrm{mg}$

KOD HotStart DNA Polymerase

Ligate-IT $^{\mathrm{TM}}$ Rapid Ligation Kit

Lipofectamine $^{\mathrm{TM}} 2000$

LongRange PCR Kit (100)

Magnesium chloride $\geq 99 \%$

Magnesium sulfate $\geq 99,5 \%$

Methanol for analysis

Mini Quick Spin Oligo Columns

Neodisher® A 8, cleaning powder
Gibco/Invitrogen, Karlsruhe

Sigma-Aldrich, Deisenhofen

Merck, Darmstadt

Merck, Darmstadt

Chemie-Vertrieb Hannover

Merck, Darmstadt

Fermentas, St. Leon-Roth

SouthernBiotech, Birmingham, USA

Roche, Mannheim

Applied Biosystems, Darmstadt

Central Pharmacy, Clinic Hospital

Göttingen

Gibco/Invitrogen

Invitrogen

Invitrogen

Braun, Melsungen

Carl Roth, Gmbh, Karlsruhe

Qiagen, Hilden

Applied Biosystem, Darmstadt

Applied Biosystem, Darmstadt

Applied Biosystem, Darmstadt

Merck, Darmstadt, Germany

Invitrogen, Karlsruhe

Sigma-Aldrich, Deisenhofen

Schuchardt, Hohenbrunn

Merck, Darmstadt

AppliChem, Darmstadt

Novagen Merck, Darmstadt

usb, Staufen

Invitrogen, Karlsruhe

Qiagen, Hilden

Riedel-De Haën AG, Seelze

Merck, Darmstadt

Merck, Darmstadt

Roche, Mannheim

Chem. Fabrik Dr. Weigert, 


\begin{abstract}
Nonidet $® P 40$ Substitute (Nonylphenylethylenglyco
OCT1 rabbit polyclonal antibody (sc-133866)

O-desmethyl-tramadol

Ondansetron hydrochloride dihydrate

Palonosetron
\end{abstract}

Paroxetine hydrochloride hemihydrate

PBS

Pre-Coated PAMPA Plate System

PBS Powder (Dulbeccos 10-fold)

Penicillin/Streptomycin-Solution

Phenylmethansulfonyl fluoride (PMSF)

Polylysin-D-hydrobromide

Polymer POP6 und POP7 for sequencer

PureYield ${ }^{\text {TM }}$ Midiprep Kit

Puromycin

QIAquick Gel Extraction Kit

QIAquick PCR Purification Kit

qPCR $®$ Core Kit (RT-QP73-05)

qPCR $®$ Core Kit for SYBR® Green (RT-SN10-15)

Random hexanucleotide primers $d N 6$

RNAse A $\sim 70 \%$

RNeasy Mini Kit

RNeasy Plus Mini Kit

Roti-Aqua ${ }^{\circledR}$ phenol/chloroform/ isoamyl alcohol

$\mathrm{pH}=4,5-5$

Roti-Aqua ${ }^{\circledR}$ phenol/chloroform/ isoamyl alcohol $\mathrm{pH}=7-8$

Sephadex ${ }^{\mathrm{TM}} \mathrm{G}-50$ Superfine

Shrimp Alkaline Phosphatase $(1 \mathrm{u} / \mu \mathrm{l})$

Skim milk powder

SnapShot ${ }^{\mathrm{TM}}$ Multiplex Kit

Sodium acetate

Sodium chloride

Sodium dihydrogen phosphate monohydrate

Sodium dodecyl sulfate
Mühlenhagen

Sigma-Aldrich, Deisenhofen

Santa cruz Biotechnology, Heidelberg

Sigma-Aldrich, Deisenhofen

Sigma-Aldrich, Deisenhofen

Sigma-Aldrich, Deisenhofen

Sigma-Aldrich, Deisenhofen

Invitrogen, Karlsruhe

Gentest, BD Biosciences

AppliChem, Darmstadt

Invitrogen, Karlsruhe

Sigma-Aldrich, Deisenhofen

Sigma-Aldrich, Deisenhofen

Applied Biosystems, Darmstadt

Promega, Mannheim

Invitrogen, Karlsruhe

Qiagen, Hilden

Qiagen, Hilden

Eurogentec, Köln

Eurogentec, Köln

Roche, Mannheim

AppliChem, Darmstadt

Qiagen, Hilden

Qiagen, Hilden

Roth, Karlsruhe

Roth, Karlsruhe

Amersham Bioscience, Freiburg

usb, Staufen

Real, Göttingen

Applied Biosystems, Darmstadt

Merck, Darmstadt

Merck, Darmstadt

Merck, Darmstadt

BioRad, Hercules, USA 
Sodium hydrogen phosphate monohydrate

Sodium hydroxide pellets pure

Super Script II reverse transcriptase

Supersignal West Pico (Kit/100ml)

T4 DNA Ligase

Taq DNA polymerase

$\mathrm{TaqMan}^{\circledR}$ genexpression assays (Assay on Demand)

TEMED $\geq 99 \%$

Thiazolyl blue tetrazolium bromide

TOPO® XL PCR Cloning Kit

Tramadol

Tris $100 \%$

Triton X-100

Tropisetron

Trypan blue -solution $(0,4 \%)$

TrypLE ${ }^{\mathrm{TM}}$ Express

Tryptone

Tween 20 (Polyoxyethylen-Sorbit-Monolaurat)

Venor ${ }^{\circledR}$ GeM-Kit

X-ray film developer G150

$\mathrm{X}$-ray film fixer G354

Xylene cyanol FF (for molecular biology)

Zeocin
Merck, Darmstadt

Merck, Darmstadt

Invitrogen, Karlsruhe

Thermo Scientific

MBI Fermentas, St. Leon-Roth

Qiagen, Hilden

Applied Biosystem, Darmstadt

Sigma-Aldrich, Deisenhofen

Sigma, Steinheim, Germany

Invitrogen, Karlsruhe

Sigma-Aldrich, Deisenhofen

Roth, Karlsruhe

Roth, Karlsruhe

Sigma-Aldrich, Deisenhofen

Sigma-Aldrich, Deisenhofen

Gibco/Invitrogen, Karlsruhe

AppliChem, Darmstadt

BioRad, München

Minerva Biolabs, Berlin

AGFA, Leverkusen

AGFA, Leverkusen

AppliChem, Darmstadt

Invitrogen, Karlsruhe

\subsubsection{Used Materials}

\begin{tabular}{ll}
\hline Used Materials & Manufacturer \\
\hline 50 ml Centrifuge tube & Beckman, München \\
96 Millipore MAHV N45 Plate & Millipore, Bedford, USA \\
96 Millipore MANU 030 PCR-Plate & Millipore, Bedford, USA \\
96 White Plate for luminescence measurement & Greiner, Frickenhausen \\
96er PCR-Plate & ABgene, Epsom \\
Absolute QPCR Seal (Optical Folie for Taqman) & Thermo Scientific \\
Adhesive PCR Foil Seals & ABgene, Epsom \\
Amersham Hyperfilm ECL for Western Blot & GE Healthcare \\
$(24 \times 30 \mathrm{~cm})$ & \\
Culture flask $25 \mathrm{~cm}^{2}$ and $75 \mathrm{~cm}^{2}$ & Sarstedt, Nümbrecht
\end{tabular}


Cuvette (UVetten) 50-1000 $\mu 1$

Cuvette 10x4x45 mm

Dialyse filter VSWP01300

Electroporation cuvette $2 \mathrm{~mm}$

FBS

Filter paper Nr. 2668

Filter paper Nr. 2CHR

Flat cap strips, 12er

Flat cap strips, 8er

FrameStar 384

Glass Pasteur pipette $230 \mathrm{~mm}$

Minisart 2000 0,2 $\mu \mathrm{m}$

Minisart-plus 0,2 $\mu \mathrm{m}$

Nunclon ${ }^{\mathrm{TM}}$ Multidishes 6 und 12 Wells

Parafilm ${ }^{\circledR}$

Petri Dish

Petri Dish for Cell culture, Falcon 353003

Pipette Tip $(10 \mu \mathrm{l}, 100 \mu \mathrm{l}, 1000 \mu \mathrm{l})$

Plate loader for Sephadex

Plate Retainer for Sequencing

Quali-Filterpipett tip sterile

Reactions vessel 0,2 ml (RNase-free)

Reactions vessel 1,5 $\mathrm{ml}$ und $2 \mathrm{ml}$

Sterile Pipette ( $5 \mathrm{ml}, 10 \mathrm{ml}, 25 \mathrm{ml})$

Sterile Polypropylen-tube $15 \mathrm{ml}$

Sterile Polypropylen-tube $50 \mathrm{ml}$

Thermo-Fast 384er Plate (PCR-Plates for Taqman)

Thermo-Fast 96er Plate
Eppendorf, Hamburg

Sarstedt, Hamburg

Millipore, Bedford, USA

PeqLab, Erlangen

Gibco/Invitrogen

Schleicher und Schuell

Schleicher und Schuell

ABgene, Epsom

ABgene, Epsom

4titude, Wotton

WU, Mainz

Sartorius, Göttingen

Sartorius, Göttingen

Nunc, Wiesbaden

Brand, Wertheim

Sarstedt, Hamburg

Schütt, Göttingen

Sarstedt, Hamburg

Millipore, Schwalbach

Applied Biosystems, Darmstadt

Kisker, Steinfurt

Biozym, Hessisch Oldendorf

Sarstedt, Hamburg

Sarstedt, Hamburg

Greiner, Frickenhausen

Sarstedt, Hamburg

ABgene Epsom

ABgene, Epsom

\subsubsection{Equipment and software}

\section{Equipment and software}

3100 Data Collection Software

3130xl Genetic Analyser

Adobe Photoshop

Bacteria Incubator-Incudrive

Biofuge fresco

\section{Manufacturer}

Applied Biosystems , Darmstadt

Applied Biosystems, Darmstadt

Adobe Systems GmbH, München

Schütt, Göttingen

Heraeus, Hanau 
Biofuge pico

BioPhotometer

BioRobot $^{\circledR}$ EZ1

Centrifuge $5810 \mathrm{R}$

Centrifuge JA-20 Rotor

Clone Manager Suite

CO2-Incubator BBD 6220

ComPhor L Mini Gel-chamber

Concentrator 5301

Confocal laser scanning Microscope

CorelDRAW X3

DNA Sequencing Analysis

Electroporator Gene Pulser II

Fine weight mashine

Flow cytometer

Fluor-S ${ }^{\mathrm{TM}}$ MultiImager

Gel chamber Ruby SE600

HPLC Analysing System

Labofuge 400R

Magnetic stirrer

Mastercycler gradient

Membran-Vacuum pumpe

Microscope Axiovert 40 CFL

MS 2 Mini shaker-Vortexer

Nanodrop cuvette

Neubauer-Cell chamber

PTC-200 Peltier Thermal Gradient Cycler

QiaCube

Scintillation instrument LS1801

Shaker for Bacteria K2 260 basic

Stereomicroscope Stemi 1000

Sterile Bench-Clean Air type DFL/REC4 KL2A

TaqMan 7900HT

Thermomixer 5436

Transilluminator TI 2

Vertical-Autoclave KSG 40/60
Heraeus, Hanau

Eppendorf, Hamburg

Qiagen, Hilden

Eppendorf, Hamburg

Beckman, München

SECentral

Heraeus, Hanau

Biozym, Hessisch Oldendorf

Eppendorf; Hamburg

Carl Zeiss, Jena

Corel Corporation

Applied Biosystems

BioRad, Hercules USA

Sartorius, Göttingen

BD Bioscience

BioRad, Hercules, USA

Hoefer, San Francisco, USA

Merck Hitachi, Darmstadt, Germany

Heraeus, Hanau

IKAMAG

Eppendorf, Hamburg

Vacuubrand, Wertheim

Zeiss, Jena

IKA, Staufen

Implen

Schütt, Göttingen

MJ Research/BioRad, Hercules, USA

Qiagen, Hilden

Beckman, München

IKA, Staufen

Zeiss, Jena

Mahl, Trendelburg

Applied Biosystems, Darmstadt

Eppendorf, Hamburg

Biometra

KSG, Olching 
Vertical-Autoclave: FV

Water bath GFL 1083
Tecnorama, Fernwald

Schütt, Göttingen *

\subsubsection{Enzymes}

\begin{tabular}{ll}
\hline Restriction Enzyme & Manufacturer \\
\hline BamHI & Fermentas, St. Leon-Roth \\
$B g l \mathrm{II}$ & Fermentas, St. Leon-Roth \\
$D p n \mathrm{I}$ & New England Biolabs, Beverly, USA \\
EcoRI & Fermentas, St. Leon-Roth \\
EcoRV & Fermentas, St. Leon-Roth \\
HindIII & Fermentas, St. Leon-Roth \\
NotI & New England Biolabs, Beverly, USA \\
$P s t \mathrm{I}$ & Fermentas, St. Leon-Roth \\
$P v u I \mathrm{I}$ & Fermentas, St. Leon-Roth \\
SacI & Fermentas, St. Leon-Roth \\
SalI & Fermentas, St. Leon-Roth \\
$X h o \mathrm{I}$ & Fermentas, St. Leon-Roth \\
$X m a \mathrm{I}$ & New England Biolabs, Beverly, USA \\
\hline
\end{tabular}

2.1.5 Plasmid vectors used

\begin{tabular}{llll}
\hline Clone-Nr. & Vector & Resistance & Delivery \\
\hline$p c D N A 3$ & & Ampicillin & Invitrogen, Karlsruhe \\
pOG44 & & Ampicillin & Invitrogen, Karlsruhe \\
pcDNA5:FRT & Expression vector & Ampicillin & Invitrogen, Karlsruhe \\
pCRß-XL-TOPO & cloning vector & kanamycin & Invitrogen, Karlsruhe \\
pCR4-TOPO & cloning vector & kanamycin & ImaGenes, Berlin \\
pIRES & & Ampicillin & Invitrogen, Karlsruhe \\
pCMV-SPORT6 & & Ampicillin & Invitrogen, Karlsruhe \\
pIRES2-EGFP & & Neomycin & Addgene, Cambridge, \\
pSilencer 4.1-CMV & & Ampicillin & Invitrogen, Karlsruhe \\
\hline
\end{tabular}




\subsubsection{Cell lines}

\begin{tabular}{|c|c|c|c|}
\hline Cell line & Origin & Characteristics & Delivery \\
\hline & \multirow{6}{*}{ Human } & Embryonic kidney cell & \\
\hline & & line (contain Flp & \\
\hline HEK Flp-In ${ }^{\mathrm{TM}}$ & & Recombination & Invitrogen, \\
\hline \multirow[t]{3}{*}{ TREx 293} & & Target (FRT)- & Karlsruhe \\
\hline & & manipulate stable in & \\
\hline & & Genom integrate) & \\
\hline \multirow{2}{*}{ CHO Flp-In ${ }^{\mathrm{TM}}$} & Chinese Hamster & & Invitrogen, \\
\hline & Ovary & & Karlsruhe \\
\hline
\end{tabular}

\subsubsection{Strains of bacteria}

\begin{tabular}{ccll}
\hline Strain of Bacteria & & $\begin{array}{l}\text { Application } \\
\text { for Transfection }\end{array}$ & Delivery \\
\hline Top10 & Escherichia & Electro-competent & $\begin{array}{l}\text { Invitrogen, } \\
\text { Karlsruhe }\end{array}$ \\
(One shot TOP10 & coli & & \\
Electro-comp. E.coli) & & & \\
\hline
\end{tabular}

\subsection{Methods}

\subsubsection{DNA manipulations}

\subsubsection{Polymerase chain reaction $(\mathrm{PCR})$}

PCR is a process of DNA amplification under cell-free conditions. In PCR, doublestranded DNA (dsDNA) is heated to separate the two strands. Then the reaction is cooled to enable the primer annealing and heated again to a temperature of optimal function of the used thermostable DNA polymerase. The primers are chosen to flank the region of interest that should be selectively amplified. The three steps were repeated for a number of 18 to 35 cycles depending on the aim of the PCR amplification. A final step of elongation for 7 to $10 \mathrm{~min}$ at the optimal temperature for the thermostable DNA polymerase was performed. In this work KOD hot start DNA polymerase (Novagen, Darmstadt, Germany) and Long Range polymerase (Qiagen, Germany) were used. The reaction was carried out in thermal gradient cycler (BioRad, Hercules, USA) or thermal mastercycler machines (Eppendorf, Germany). 


\subsubsection{Agarose gel electrophoresis}

TBE-buffer (pH 8,3)

\begin{tabular}{lc}
\hline Substance & Final concentration \\
\hline Tris & $0,1 \mathrm{M}$ \\
Boric Acid & $0,1 \mathrm{M}$ \\
EDTA & $3,0 \mathrm{mM}$ \\
\hline
\end{tabular}

5x Loading buffer

\begin{tabular}{lc}
\hline Substance & Final concentration \\
\hline Glycerol & $30 \%(\mathrm{v} / \mathrm{v})$ \\
EDTA & $50 \mathrm{mM}$ \\
Bromphenol blue & $0,25 \%(\mathrm{v} / \mathrm{v})$ \\
Xylene cyanol & $0,25 \%(\mathrm{v} / \mathrm{v})$ \\
\hline
\end{tabular}

Agarose gel electrophoresis was used to separate DNA fragments according their size for both analytical and preparative purpose. To separate different sizes of DNA, agarose gel was used in different concentrations (ranging from 0.8-1\%). For this reason, corresponding amount of agarose was solved in TBE buffer and heated in microwave until agarose was completely dissolved. After the gel was cooled down to about $55^{\circ} \mathrm{C}$, $0.5 \mu \mathrm{g} / \mathrm{ml}$ Ethidiumbromid (Merck, Darmstadt) was added and distributed using magnet stirrer. Meanwhile gel casting tray was prepared and sealed ends of gel chamber using appropriate casting system and appropriate number of combs was placed in gel tray. Then, the gel was poured into gel tray and allowed it to cool for 15-30 min at room temperature. For loading the samples on the gel, loading buffer was added to a final concentration of $1 \mathrm{x}$ to each sample. For analytical electrophoresis $10 \mu \mathrm{l}$ DNA sample mixed with $2 \mu$ l loading buffer. For preparative purposes usually $50 \mu$ l DNA samples were mixed with $10 \mu$ l loading buffer and run in a wells obtained by sticking together two teeth the comb. The electrophoresis was conducted by $120 \mathrm{~V}$ using for $30 \mathrm{~min}$ using ComPhor L Mini Gel chamber (Biozym). A 100 bp. and 1 kb. Ladder (ABgene, Fermentas) were used as size standard. Fluor-S $S^{\text {TM }}$ Multilmager (BioRad, Hercules, USA) was used to visualize DNA bands, and signals were analyzed using Quantity One ${ }^{\circledR}$ S Version 4.3.1 (BioRad) Software. 


\subsubsection{Photometric quantification of nucleic acids}

The principle for quantification of nucleic acid samples is based on absorbance at 260nm. The concentration of DNA and RNA was measured by photometry on maximum absorption of $260 \mathrm{~nm}$. For this reason, $3 \mu 1$ of nucleic acid solution was placed on Implen-Nanodropcuvett (Implen) and measured in BioPhotometer (Eppendorf, Hamburg, Germany). The DNA and RNA concentrations were determined using the Beer-Lambert law as expressed:

$$
\mathbf{A}=\boldsymbol{\alpha c l},
$$

where $\mathrm{A}$ is the absorbance, the constant $\alpha$ is the absorption coefficient $(\mathrm{cm} 2 / \mu \mathrm{g}), \mathrm{c}$ is the solute concentration $(\mu \mathrm{g} / \mathrm{ml})$, and 1 is the length of the light path $(\mathrm{cm})$ (Gallagher, 1989). Additional measurements at $280 \mathrm{~nm}$ were performed and absorbance ratio 260/280 nm was calculated to evaluate the purity of the DNA. DNA samples with $260 / 280 \mathrm{~nm}$ ratio above 1.6 and RNA samples with ratio above 1.9 were regarded pure enough for further analyses.

\subsubsection{Isolation of total genomic DNA}

For rapid isolation of total DNA (genomic DNA) from fresh or frozen cells, DNeasy Blood \& Tissue Kit (Qiagen) was used according to the manufacturer's instructions. Automatic extraction was performed using QIACube robot (Qiagen) with $1 \times 10^{6}$ cells as starting material and genomic DNA was eluted in $50 \mu 1$ elution buffer.

\subsection{DNA extraction from agarose gel}

After a preparative agarose gel electrophoresis DNA fragments with the required size were cut out from the gel under UV-light using transilluminator TI2 (Biometra). The obtained gel fragment was applied to purify the DNA using QIAquick Gel Extraction Kit (Qiagen). The procedure was fully automatically on QiaCube robot (Qiagen) according to manufacturer's instructions. DNA was eluted in 50 $\mu 1$ elution buffer

\subsection{Enzymatic purification of DNA}

An enzyme digestion was used to purify PCR-product from excess primers and nucleotides. Shrimp alkalin phosphatase (SAP, Fermentas, Thermo Scientific) was used to remove excess nucleotides (dNTPs), while Exonuclease I from E.coli (Fermentas, 
Thermo Scientific) degradates the primers. The following reaction mixture was prepared:

\begin{tabular}{lc}
\hline Reagent & Volume \\
\hline rSAP $(1 \mathrm{U} / \mu \mathrm{l})$ & $5 \mu \mathrm{l}$ \\
ExoI $(10 \mathrm{U} / \mu \mathrm{l})$ & $0,2 \mu \mathrm{l}$ \\
$10 \mathrm{X} \mathrm{rSAP}$ buffer & $2 \mu \mathrm{l}$ \\
PCR product & $13 \mu \mathrm{l}$ \\
\hline Total volume & $20 \mu \mathrm{l}$
\end{tabular}

The reaction mix was incubated for $1 \mathrm{~h}$ at $37^{\circ} \mathrm{C}$ and then the enzymes were inactivated by incubation at $80^{\circ} \mathrm{C}$ for 15 min using thermal cycler (BioRad, Hercules, USA).

\subsubsection{Restriction digestion}

This enzymatic reaction using restriction endonucleases can be performed for cleaving DNA molecules at specific sites. This step was used both for analytical and preparative purposes during the DNA-recombination procedures.

\subsection{Analytical digestion}

Analytical digestion was performed using restriction enzymes to determine the fragment length pattern of a particular piece of DNA. The following reaction mixture was prepared:

\begin{tabular}{lc}
\hline Analytical reaction: & Volume \\
\hline 10 x Restriction buffer & $1 \mu \mathrm{l}$ \\
BSA (optional) & $0,1 \mu \mathrm{l}$ \\
DNA & $1 \mu \mathrm{l}(\sim 1 \mu \mathrm{g})$ \\
Enzyme & $1 \mu \mathrm{l}$ \\
$\mathrm{ddH}_{2} \mathrm{O}$ & $\mathrm{Up}$ to $10 \mu \mathrm{l}$ \\
\hline Total volume & $10 \mu \mathrm{l}$
\end{tabular}


This reaction mix was incubated for 1 hour at optimal temperature for the enzyme activity (in most of the cases $37^{\circ} \mathrm{C}$ ). The results of the restriction reaction were directly analyzed by agarose gel electrophoresis.

\subsection{Preparative digestion}

This restriction reaction was used to prepare the plasmid and genomic DNA for cloning. The following reaction mixture was prepared:

\begin{tabular}{lc}
\hline Preparative reaction: & Volume \\
\hline 10 x Restriction buffer & $5 \mu \mathrm{l}$ \\
BSA (optional) & $0,5 \mu \mathrm{l}$ \\
DNA & $\max .10 \mu \mathrm{g}$ \\
Enzyme & $5 \mu \mathrm{l}$ \\
$\mathrm{ddH}_{2} \mathrm{O}$ & Up to $50 \mu \mathrm{l}$ \\
\hline Total volume & $50 \mu \mathrm{l}$
\end{tabular}

In this case, the digestion was performed for 2 hours at the optimal temperature and then after adding $1 \mu 1$ additional enzyme, the incubation was continued for another 1 hour. When DNA is cleaved with two or more restriction enzymes, the digestions can be carried out simultaneously if both enzymes work in the same buffer using universal buffer (Tango; Fermentas, St. Leon-Roth), or it can be done consequently for each enzyme with a gel extraction reaction and using the special buffer for each enzyme.

\subsubsection{Ligation}

This process is used to introduce a foreign DNA fragment (insert) into the linearized plasmid vector. This reaction is usually catalyzed by a DNA ligase enzyme. This enzyme will ligate DNA fragments having 'blunt' end or overhanging complementary, 'sticky' end. The ligation mixtures were made using Ligate-ITTM Rapid Ligation Kit (USB, Staufen, Germany). For this purpose, an insert: vector ratio of 13:2 (v/v) was used. The following reaction mixture was prepared: 


\begin{tabular}{lc}
\hline Ligation reaction: & Volume \\
\hline 5x ligase buffer & $4 \mu \mathrm{l}$ \\
Plasmid vector & $2 \mu \mathrm{l}$ \\
Insert fragment & $13 \mu \mathrm{l}$ \\
Ligase & $1 \mu \mathrm{l}$ \\
\hline Total volume & $20 \mu \mathrm{l}$
\end{tabular}

The mixture was incubated for 5-10 min at RT. In order to estimate the number selfligate plasmid as negative control reaction was performed by using $\mathrm{ddH} 2 \mathrm{O}$ instead of insert fragment. In order to enhance efficiency of transformation, ligation mixture was concentrated using vacuum concentrator. For this reason, an open lid Eppendorf ${ }^{\circledR}$ microcentrifuge tube containing ligation mixture was placed in SpeedVac Plus ${ }^{\circledR}$ SC110A vacuum centrifuge (Schütt, Göttingen) and with highest temperature was centrifuged under vacuum (200 mbar, Membran-Vacuumpumpe, Vacuubrand, Wertheim) for $10 \mathrm{~min}$ to achieve about $60 \%$ of primary reaction volume. Afterwards remaining DNA attached on the eppi wall was detached by pipetting the residual liquid.

\subsubsection{TOPO cloning}

To ligate one DNA fragment into the TOPO vector, the TOPO® XL PCR Cloning Kit (Invitrogen) was used. This kit allows PCR inserts to ligate efficiently with a vector covalently bound to a Topoisomerase enzyme originated from Vaccinia virus. The linearized plasmid in this kit has been also supplied with single 3 '-thymidine (T) overhangs for TA Cloning.

The TOPO reaction requires the PCR product to have A-overhangs that are naturally produced by some thermostable polymerases like Taq-polymerase, but not by others like KOD- or Pfu-polymerases. For this reason, an additional incubation with Taqpolymerase was used to generate 3'-Adenosin-overhang on the flank of insert fragment when the PCR product was generated with $K O D$ or Pfu-polymerases. Taq-Polymerase has transferase activity that adds a single deoxyadenosine (A) to the $3^{\prime}$ ends of PCR products. The following reaction mixture was prepared: 


\begin{tabular}{lc}
\hline $\begin{array}{l}\text { Reaction for generation } \\
\text { of 3'-A-overhangs }\end{array}$ & Volume \\
\hline dATPs $(10 \mathrm{mM})$ & $1 \mu \mathrm{l}$ \\
$10 \mathrm{x}$ buffer & $5 \mu \mathrm{l}$ \\
Taq-Polymerase $(5 \mathrm{U} / \mu \mathrm{l})$ & $1 \mu \mathrm{l}$ \\
DNA-Fragment & $43 \mu \mathrm{l}$ \\
\hline Total volume & $50 \mu \mathrm{l}$
\end{tabular}

The reaction mixture was incubated for $15 \mathrm{~min}$ at $72^{\circ} \mathrm{C}$ in thermocycler. Then the ligation reaction was followed by adding $0.5 \mu \mathrm{l}$ TOPO-vector mix to $4.5 \mu 1$ of the reaction above:

\begin{tabular}{ll}
\hline Reaction mix & Volume \\
\hline DNA-Fragment solution & $4.5 \mu \mathrm{l}$ \\
TOPO XL® PCR Cloning Vector & $0.5 \mu \mathrm{l}$ \\
\hline
\end{tabular}

After 5 min incubation at room temperature, $1 \mu 1$ 6X TOPO Cloning Stop Solution (0.3 $\mathrm{M} \mathrm{NaCl}, 0.06 \mathrm{M} \mathrm{MgCl2}$ ) was added and ligation mix was placed on ice for $10 \mathrm{~min}$. After all the mixture was dialyzed and transformed in E.coli by electroporation as described in chapter 2.2.4.3.

\subsubsection{Site-directed mutagenesis}

The pcDNA3::hOCT1 plasmid was amplified by PCR using the KOD Hot Start DNA Polymerase Kit (Novagen Merck, Darmstadt) and site-directed mutagenesis primers (Table 3.1).

Table 2. 1 Site-directed mutagenesis primer list. The mutated bases are bolded and the genetic codons were underlined.

\begin{tabular}{ll}
\hline Amino acid variant & Primer sequence \\
\hline Arg61Cys & 5'-GGCTGAGCTGAGCCAGTGCTGTGGCTGGAGCCC-3' \\
& 5'-GGGCTCCAGCCACAGCACTGGCTCAGCTCAGCC-3' \\
Cys88Arg & 5'-GGCCTTCCTTGGCCAGCGCAGGCGCTATGAAGT-3' \\
& 5'-ACTTCATAGCGCCTGCGCTGGCCAAGGAAGGCC-3' \\
\hline
\end{tabular}




\begin{tabular}{ll}
\hline Gly401Ser & 5'-CACCATTGACCGCGTGAGCCGCATCTACCCCAT-3' \\
& 5'-ATGGGGTAGATGCGGCTCACGCGGTCAATGGTG-3' \\
Deletion of Met420 & 5'-GGGCAGCCTGCCTCGTCATTTTTATCTCACCTGA-3' \\
& 5'-TCAGGTGAGATAAAAATGACGAGGCAGGCTGCCC-3' \\
Gly465Arg & 5'-ATTCGTCAGGAACCTCAGAGTGATGGTGTGTTC-3' \\
& 5'-GAACACACCATCACT $\underline{\text { ThGAGGTTCCTGACGAAT-3' }}$ \\
\hline
\end{tabular}

In order to find the optimum annealing temperature for each primer, the gradient-PCR was performed according to the following conditions:

\begin{tabular}{lc}
\hline Standard-PCR-Reaction Mixture & Volume \\
\hline 10 x buffer & $2.5 \mu \mathrm{l}$ \\
dNTPs $(2 \mathrm{mM})$ & $2.5 \mu \mathrm{l}$ \\
$\mathrm{MgSO}_{4}(25 \mathrm{mM})$ & $1 \mu \mathrm{l}$ \\
$Q$-Solution & $5 \mu \mathrm{l}$ \\
Forward-Primer $(10 \mathrm{nM})$ & $0.65 \mu \mathrm{l}$ \\
Reverse-Primer $(10 \mathrm{nM})$ & $0.65 \mu \mathrm{l}$ \\
Template DNA $(50 \mathrm{ng} / \mu \mathrm{l})$ & $1 \mu \mathrm{l}$ \\
KOD HotStart Polymerase $(1.0 \mathrm{U} / \mu \mathrm{l})$ & $0.5 \mu \mathrm{l}$ \\
$\mathrm{ddH} \mathrm{H}_{2} 0$ & $11.2 \mu \mathrm{l}$ \\
\hline Total Volume & $25 \mu \mathrm{l}$
\end{tabular}

PCR-Condition

$\left.\begin{array}{lcc}\hline \text { Phase } & \text { Duration } & \text { Temperature } \\ \hline \text { Initial Denaturation } & 3 \mathrm{~min} & 95^{\circ} \mathrm{C} \\ \hline \text { Denaturation } & 30 \mathrm{sec} & 95^{\circ} \mathrm{C} \\ \text { Annealing } & 30 \mathrm{sec} & 50-70^{\circ} \mathrm{C} \\ \text { Elongation } & 3 \text { min } 30 \mathrm{sec} & 72^{\circ} \mathrm{C} \\ \hline \text { Cool down } & \text { for ever } & 8^{\circ} \mathrm{C}\end{array}\right\} 19$


For this purpose, DNA template was amplified in five different annealing temperatures $\left(50-70^{\circ} \mathrm{C}\right)$ in gradient-cycler and optimum annealing temperature was identified by analyze the PCR product on the agarose gel.

Following temperature cycling, the product is treated with $2 \mu$ l digestive enzyme Dpn I (NEBiolabs, Frankfurt am Main, Germany) for 1 hour at $37^{\circ} \mathrm{C}$ and again with $1 \mu \mathrm{l}$ of this enzyme for one hour more. The Dpn I endonuclease (target sequence: 5'-Gm6ATC$\left.3^{\prime}\right)$ which is specific for methylated and hemimethylated DNA is used to digest the parental DNA template and to select for mutation-containing synthesized DNA. Afterwards, the PCR products were dialyzed for $30 \mathrm{~min}$ and then transformed in E. coli TOP10 strain. The pcDNA3::OCT1 plasmids carrying the required mutations were then isolated and the correctness of OCT1 wild type and variants were validated by sequencing of the entire OCT1 reading frame.

\subsubsection{PCR for analyzing the chromosomal integration of pcDNA5 constructs}

Total DNA was extracted from the stably transfected cells using automatic DNA extraction with the DNeasy® blood and tissue kit and the QIACube robot (Qiagen, Hilden, Germany). Two independent PCR reactions were conducted to check integration of the OCT1 gene in to the genome using two pairs of primers complementary to the hygromycin resistance gene and the OCT1 gene. First, an integration-specific PCR was performed with the forward primer PSV40 located in the SV40 promoter of the pFRT/lacZeo plasmid (which is pre-integrated in the genome of the T-REx HEK293 cells and is the target of the integration) and the reverse primer Hyg (Table 3.2) located in the hygromycin B resistance gene of the pcDNA5.1 plasmid (which should be integrated within the Flp recombination target (FRT) sites of the pFRT/lacZeo plasmid) according to following procedure: 
Table 2. 2 List of primer and corresponding sequences to test for chromosomal integration of pcDNA5.1

\begin{tabular}{lc}
\hline Primer & \multicolumn{1}{c}{ Sequence } \\
\hline P $_{\mathrm{SV} 40-\mathrm{f}}$ & 5'-AGCTGTGGAATGTGTGTCAGTTAGG-3' \\
Hyg-r & 5'-ACGCCCTCCTACATCGAAGCTGAAA-3' \\
$\mathrm{P}_{\mathrm{CMV}}$ & 5'-CCATGGTGATGCGGTTTTGGCAGTA-3' \\
Lac & 5'-CCTTCCTGTAGCCAGCTTTCATCAA-3' \\
\hline
\end{tabular}

\begin{tabular}{lc}
\hline Integration-PCR-Reaction Mixture for Hyg & Volume \\
\hline 10 x buffer & $2.5 \mu \mathrm{l}$ \\
$\mathrm{dNTPs}(2 \mathrm{mM})$ & $2.5 \mu \mathrm{l}$ \\
$\mathrm{MgSO}_{4}(25 \mathrm{mM})$ & $1 \mu \mathrm{l}$ \\
$Q$-Solution & $5 \mu \mathrm{l}$ \\
Forward-Primer $\mathrm{P}_{\mathrm{SV} 40}(10 \mathrm{nM})$ & $0.65 \mu \mathrm{l}$ \\
Reverse-Primer Hyg $(10 \mathrm{nM})$ & $0.65 \mu \mathrm{l}$ \\
Templat DNA $(300 \mathrm{ng} / \mu \mathrm{l})$ & $1 \mu \mathrm{l}$ \\
KOD HotStart Polymerase $(1.0 \mathrm{U} / \mu \mathrm{l})$ & $0.5 \mu \mathrm{l}$ \\
ddH $_{2} 0$ & $11.2 \mu \mathrm{l}$ \\
\hline Total Volume & $25 \mu \mathrm{l}$
\end{tabular}

\section{PCR-Condition}

\begin{tabular}{lcc}
\hline \multicolumn{1}{c}{ Phase } & Duration & Temperature \\
\hline Initial Denaturation & $2 \mathrm{~min}$ & $95^{\circ} \mathrm{C}$ \\
\hline Denaturation & $30 \mathrm{sec}$ & $95^{\circ} \mathrm{C}$ \\
Annealing & $30 \mathrm{sec}$ & $68^{\circ} \mathrm{C}$ \\
Elongation & $1 \mathrm{~min} 30 \mathrm{sec}$ & $72^{\circ} \mathrm{C}$ \\
\hline Final elongation & $10 \mathrm{~min}$ & $72^{\circ} \mathrm{C}$ \\
\hline & for ever & $8^{\circ} \mathrm{C}$
\end{tabular}


Second, the OCT1 open reading frame was amplified using the primers $\mathrm{P}_{\mathrm{CMV}}$ and Lac and the KOD Hot Start DNA Polymerase Kit under the following conditions:

\begin{tabular}{lc}
\hline Integration-PCR-Reaction Mixture for OCT1 & Volume \\
\hline 10 x buffer & $2.5 \mu \mathrm{l}$ \\
$\mathrm{dNTPs}(2 \mathrm{mM})$ & $2.5 \mu \mathrm{l}$ \\
$\mathrm{MgSO}_{4}(25 \mathrm{mM})$ & $1 \mu \mathrm{l}$ \\
$Q$-Solution & $5 \mu \mathrm{l}$ \\
Forward-Primer $\mathrm{P}_{\mathrm{CMV}}(10 \mathrm{nM})$ & $0.65 \mu \mathrm{l}$ \\
Reverse-Primer Lac $(10 \mathrm{nM})$ & $0.65 \mu \mathrm{l}$ \\
Template DNA (300 ng/ $\mu \mathrm{l})$ & $1 \mu \mathrm{l}$ \\
KOD HotStart Polymerase $(1.0 \mathrm{U} / \mu \mathrm{l})$ & $0.5 \mu \mathrm{l}$ \\
ddH ${ }_{2} 0$ & $11.2 \mu \mathrm{l}$ \\
\hline Total volume & $25 \mu \mathrm{l}$
\end{tabular}

\section{PCR-Condition}

\begin{tabular}{lll}
\hline Phase & Duration & Temperature \\
\hline Initial Denaturation & $2 \mathrm{~min}$ & $95^{\circ} \mathrm{C}$ \\
\hline Denaturation & $30 \mathrm{sec}$ & $95^{\circ} \mathrm{C}$ \\
Annealing & $30 \mathrm{sec}$ & $68^{\circ} \mathrm{C}$ \\
Elongation & $2 \mathrm{~min}$ & $72^{\circ} \mathrm{C}$ \\
\hline Final elongation & $10 \mathrm{~min}$ & $72^{\circ} \mathrm{C}$ \\
\hline & for ever & $8^{\circ} \mathrm{C}$
\end{tabular}

\subsubsection{DNA assembling}

In order to assemble two or more different DNA regions together, assembly PCR was used according to procedure described by Stemmer et al., 1995. In this particular work I used assembly PCR technique to prepare a fused transcript of CYP2D6 and POR genes. An Internal Ribosomal Entry Site (IRES) was inserted between these two genes in order to increase translational efficiency of the second gene, in this case POR. Used IRES was 
a $650 \mathrm{bp}$ fragment originated from encephalomyocarditis virus (EMCV) which allows to recruit ribosome to start translation process in an independent manner to promoter (BOCHKOV and PALMENBERG 2006).

The assembly PCR protocol consists of three stages. In the first stage, two corresponding fragments are amplified separately using two pair primers which have homology in reverse primer of one fragment with forward primer of another fragment, in the second stage, both amplified products were mixed together and added to PCR master mix without any primers. Since single-stranded ends of complementary DNA fragments are filled-in during the gene assembly process, cycling with DNA polymerase results in the formation of increasingly larger DNA fragments until the full-length fragment is obtained. In the third stage, the full-length fragment was amplified using the forward primer of the first fragment along with the reverse primer of the second fragment (Fig.2.1).

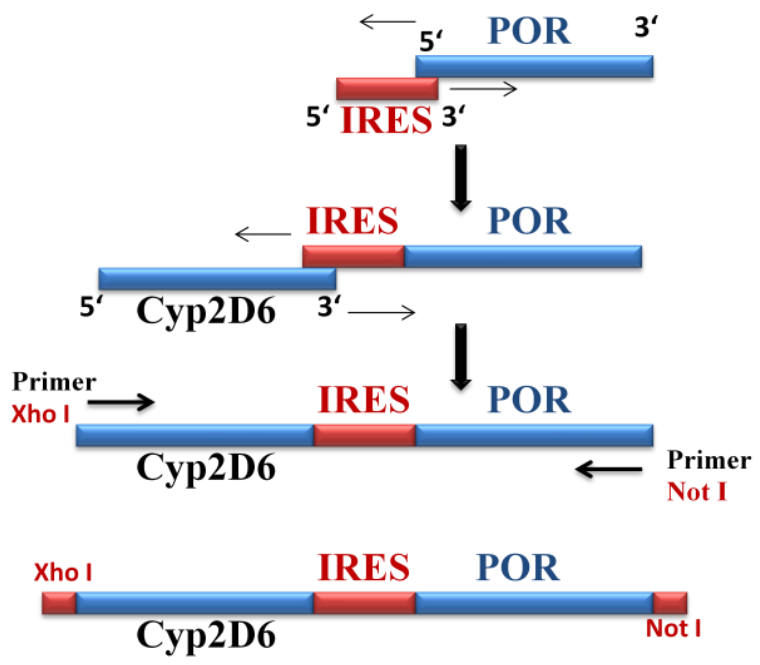

Fig.2. 1 Scheme of fusion of CYP2D6 and POR genes using IRES fragment. All these fragments were bond together by DNA assembling method.

For this purpose, each single fragment was amplified by PCR (first PCR) using specific primers designed for each one to have complementary part in reverse primer for first gene with forward primer of the second gene to cause two fragments bind together. The following reaction mixture and amplification conditions were used: 


\section{First-PCR}

\begin{tabular}{lc}
\hline Standart PCR-reaction mixture & Volume \\
\hline 10 x buffer & $2.5 \mu \mathrm{l}$ \\
dNTPs $(2 \mathrm{mM})$ & $2.5 \mu \mathrm{l}$ \\
$\mathrm{MgSO}_{4}(25 \mathrm{mM})$ & $1 \mu \mathrm{l}$ \\
$Q$-Solution & $5 \mu \mathrm{l}$ \\
Forward-Primer $(10 \mathrm{nM})$ & $0.65 \mu \mathrm{l}$ \\
Reverse-Primer $(10 \mathrm{nM})$ & $0.65 \mu \mathrm{l}$ \\
Template DNA $(300 \mathrm{ng} / \mu \mathrm{l})$ & $1 \mu \mathrm{l}$ \\
KOD HotStart Polymerase $(1.0 \mathrm{U} / \mu \mathrm{l})$ & $0.5 \mu \mathrm{l}$ \\
ddH ${ }_{2} 0$ & $11.2 \mu \mathrm{l}$ \\
\hline Total Volume & $25 \mu \mathrm{l}$
\end{tabular}

\section{PCR-Condition}

\begin{tabular}{lcc}
\hline Phase & Duration & Temperature \\
\hline Initial Denaturation & $2 \mathrm{~min}$ & $95^{\circ} \mathrm{C}$ \\
\hline Denaturation & $30 \mathrm{sec}$ & $95^{\circ} \mathrm{C}$ \\
Annealing & $30 \mathrm{sec}$ & $68^{\circ} \mathrm{C}$ \\
Elongation & $2 \mathrm{~min}$ & $72^{\circ} \mathrm{C}$ \\
\hline Final Elongation & $10 \mathrm{~min}$ & $72^{\circ} \mathrm{C}$ \\
\hline & for ever & $8^{\circ} \mathrm{C}$
\end{tabular}

Then the PCR products were run on $1 \%$ agarose gel, and the fragments were cut and eluted from the gel as described in chapter 2.2.1.5.1. Afterwards the eluted products which have complementary ends were mixed together to assemble a larger fragment containing both two genes and then amplified by PCR (second PCR).

The following reaction mixture and amplification conditions were used: 


\section{Second PCR}

\begin{tabular}{lc}
\hline Assembly-PCR-Reaction Mixture & Volume \\
\hline 10 x buffer & $5 \mu \mathrm{l}$ \\
$\mathrm{dNTPs}(2 \mathrm{mM})$ & $5 \mu \mathrm{l}$ \\
$\mathrm{MgSO}_{4}(25 \mathrm{mM})$ & $2 \mu \mathrm{l}$ \\
$Q$-Solution & $10 \mu \mathrm{l}$ \\
PCR-product gene 1 & $5 \mu \mathrm{l}$ \\
PCR-product gene 2 & $5 \mu \mathrm{l}$ \\
KOD HotStart Polymerase $(1.0 \mathrm{U} / \mu \mathrm{l})$ & $1 \mu \mathrm{l}$ \\
ddH ${ }_{2} 0$ & $17 \mu \mathrm{l}$ \\
\hline Total volume & $50 \mathrm{ml}$
\end{tabular}

\section{PCR-Condition}

\begin{tabular}{lcc}
\hline Phase & Duration & Temperature \\
\hline Initial Denaturation & $2 \mathrm{~min}$ & $95^{\circ} \mathrm{C}$ \\
\hline Denaturation & $30 \mathrm{sec}$ & $95^{\circ} \mathrm{C}$ \\
Annealing & $30 \mathrm{sec}$ & $60^{\circ} \mathrm{C}$ \\
Elongation & $2 \mathrm{~min}$ & $72^{\circ} \mathrm{C}$ \\
\hline Final Elongation & $7 \mathrm{~min}$ & $72^{\circ} \mathrm{C}$ \\
\hline & for ever & $8^{\circ} \mathrm{C}$
\end{tabular}

After running the second PCR, immediately proceed to the third PCR. For this purpose, $1 \mu \mathrm{l}$ from the second PCR reaction was added to PCR reaction mixture and amplified by PCR (third PCR).

The following reaction mixture and amplification conditions were used: 


\section{Third-PCR}

\begin{tabular}{lc}
\hline Standart PCR-reaction mixture & Volume \\
\hline 10 x buffer & $2.5 \mu \mathrm{l}$ \\
$\mathrm{dNTPs}(2 \mathrm{mM})$ & $2.5 \mu \mathrm{l}$ \\
$\mathrm{MgSO}_{4}(25 \mathrm{mM})$ & $1 \mu \mathrm{l}$ \\
$Q$-Solution & $5 \mu \mathrm{l}$ \\
Forward-Primer for first gene $(10 \mathrm{nM})$ & $0.65 \mu \mathrm{l}$ \\
Reverse-Primer for second gene $(10 \mathrm{nM})$ & $0.65 \mu \mathrm{l}$ \\
Assembled DNA $(300 \mathrm{ng} / \mu \mathrm{l})$ & $1 \mu \mathrm{l}$ \\
KOD HotStart Polymerase $(1.0 \mathrm{U} / \mu \mathrm{l})$ & $0.5 \mu \mathrm{l}$ \\
ddH ${ }_{2} 0$ & $11.2 \mu \mathrm{l}$ \\
\hline Total Volume & $25 \mathrm{ml}$
\end{tabular}

\section{PCR-Condition}

$\left.\begin{array}{lcc}\hline \text { Phase } & \text { Duration } & \text { Temperature } \\ \hline \text { Initial Denaturation } & 2 \mathrm{~min} & 95^{\circ} \mathrm{C} \\ \hline \text { Denaturation } & 30 \mathrm{sec} & 95^{\circ} \mathrm{C} \\ \text { Annealing } & 30 \mathrm{sec} & 60^{\circ} \mathrm{C} \\ \text { Elongation } & 3 \mathrm{~min} & 72^{\circ} \mathrm{C}\end{array}\right\} 35$

The obtained products were purified through agarose gel, cloned and the correct assembly was verified by sequencing.

\subsubsection{DNA sequencing}

A capillary end-terminal sequencing was performed using BigDye ${ }^{\circledR}$ terminator v1.1 Sequencing Kits (Applied Biosystems, Darmstadt). The end-terminal sequencing method, which was originally described by Frederick Senger and coworkers (Sanger and Coulson 1975) is based on pre-mature termination of DNA synthesis by using a mixture of desoxy (dNTPs) and di-deosoxiy nucleotide triphosphates (ddNTPs). 
Different bases in the ddNTP are marked with different fluorescence dye. These nucleotides are integrated randomly in the growing DNA-strand and terminate chain extension based on missing 3'-OH-Group. This will result in product with different size that terminates at different positions in the sequence. In the capillary sequencer, the different size is separated through a capillar-gel electrophoresis and a laser-based detection was performed at the end of the capillary. The different fluorescence dye will give different emission expected corresponding to different bases in the DNA sequencing.

The sequencing reaction was performed using the following reaction mixture under the following condition:

\begin{tabular}{lc}
\hline Sequencing reaction mix & Volume \\
\hline DMSO & $0,25 \mu l$ \\
Primer $(10 \mu \mathrm{M})$ & $0,5 \mu \mathrm{l}$ \\
BigDye ${ }^{2}$ & $1 \mu \mathrm{l}$ \\
$\mathrm{ddH}_{2} \mathrm{O}$ & $2,25 \mu \mathrm{l}$ \\
$\mathrm{DNA}(\sim 300 \mu \mathrm{g} / \mathrm{ml})$ & $1 \mu \mathrm{l}$ \\
\hline Total volume & $5 \mu \mathrm{l}$
\end{tabular}

\section{Reaction conditions}

\begin{tabular}{lcc}
\hline Phase & Duration & Temperature \\
\hline Initial Denaturation & $2 \mathrm{~min}$ & $94^{\circ} \mathrm{C}$ \\
\hline Denaturation & $15 \mathrm{sec}$ & $96^{\circ} \mathrm{C}$ \\
Annealing & $15 \mathrm{sec}$ & $56,5^{\circ} \mathrm{C}$ \\
Elongation & $4 \mathrm{~min}$ & $60^{\circ} \mathrm{C}$ \\
\hline Final Elongation & $7 \mathrm{~min}$ & $72^{\circ} \mathrm{C}$ \\
\hline & for ever & $8^{\circ} \mathrm{C}$
\end{tabular}

The different sequencing primers used in this work are listed in table 2.3. 
Table 2. 3 Primers and corresponding sequences for OCT1 wild type and its variants.

\begin{tabular}{ll}
\multicolumn{1}{c}{ Primer } & \multicolumn{1}{c}{ Primer sequence } \\
\hline OCT1-ORF (f) & 5'-CATGAGCAAGCTTAGCCATCATGCCCACCGTGGA-3' \\
OCT1-Cys88Arg (f) & 5'-GGCCTTCCTTGGCCAGCGCAGGCGCTATGAAGT_3' \\
OCT1-Cys88Arg (r) & 5'-ACTTCATAGCGCCTGCGCTGGCCAAGGAAGGCC-3' \\
OCT1-Gly401Ser (f) & 5'-CACCATTGACCGCGTGAGCCGCATCTACCCCAT-3', \\
OCT1-Gly465Arg (r) & 5'-GAACACACCATCACTCTGAGGTTCCTGACGAAT-3' \\
\hline
\end{tabular}

The sequencing reactions were purified prior to injection into the sequencer in order to remove both the unincorporated dideoxynucleotides as well as salts from the reaction buffers. For this reason, first $35 \mathrm{mg}$ Sephadex G50 superfine (Amersham, Freiburg) was poured on plate loader (Millipore, Schwalbach) to fill all holes, and then this plate was turned upside down on 96-well filter plate (MAHV-N45, Millipore). Afterwards, $300 \mu 1$ $\mathrm{ddH}_{2} \mathrm{O}$ was added to each well and allowed them to swell for 3 hours at RT. Then the filter plate was spined in centrifuge $(650 \mathrm{~g}, 5 \mathrm{~min}, \mathrm{RT})$ to remove the surplus water. The

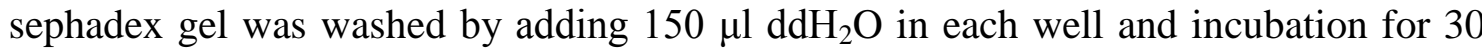
min at RT. Again the surplus water was removed by centrifugation (Centrifuge $5810 \mathrm{R}$, Eppendorf, $650 \mathrm{~g}, 5 \mathrm{~min}, \mathrm{RT}$ ) and then $35 \mu \mathrm{l} \mathrm{ddH}_{2} \mathrm{O}$ was added to $5 \mu \mathrm{l}$ sequencing reaction and pipetted on Sephadex-containing filter plate and centrifuged (650 g, $5 \mathrm{~min}$, RT). Finally filtered Sequencing product was collected in one clean 96-Well-Plate. This Plate was used directly for sequencing in 3130xl Genetic Analyser (Applied Biosystems).

The sequencing data was analyzed using Sequencing Analysis Version 5.2 (Applied Biosystems) and afterwards with Staden Package Version 4.0 (SourceForge.net) or Clone Manager (SECentral).

\subsubsection{Genotyping using single base primer extension method (SNaPshot $\left.{ }^{\circledR}\right)$}

The single base primer extension ( $\mathrm{SNaPshot}{ }^{T M}$ ) is a method for genotyping Single Nucleotide Polymorphism (SNPs) or small deletions and insertions. The principle of this method is based on the dideoxy single-base extension of an unlabeled oligonucleotide primer. Each primer binds with his 3'-end located directly upstream of the polymorphic position in the DNA. The DNA synthesis is performed in the presence of fluorescently labeled ddNTPs but in the absence of dNTPs. Therefore, the 
polymerase extends the primer by only one nucleotide, adding a single ddNTP to its 3 ' end on the SNP position. This ddNTP does not carry OH- group in 3' end which cause to stop DNA extension. In multiloci analysis using Multiplex Kit (ABI PRISM ${ }^{\circledR}$ SNaPshot ${ }^{\mathrm{TM}}$ ), mixture of primers with different lengths are used to analyze a wide range of SNPs in DNA template. To analyze the final products successfully and robustly, a fluorescent marked internal standard (Gene Scan ${ }^{T M} 120$ LIZ $^{T M}$ Size Standard, Applied Biosystems) was added to each sample.

In this study, the single-base primer extension reaction was performed using the SNaPshot ${ }^{\circledR}$ kit (Applied Biosystems). Therefore, $2 \mu 1$ purified PCR-product or plasmid was mixed with $3 \mu$ l of following master mix:

\begin{tabular}{lc}
\hline Reagents & Volume \\
\hline 2x SNaPshot reaction mix & $2.5 \mu \mathrm{l}$ \\
10x pooled primer mix & $0,5 \mu \mathrm{l}$ \\
\hline Total volume & $3 \mu \mathrm{l}$
\end{tabular}

The pooled primer mix contains polymorphism specific primers as given in the table 2.4 and then the reaction was done under following condition:

Table 2. 4 Primers and corresponding sequences for CYP2D6.

\begin{tabular}{|c|c|c|c|}
\hline Name & Sequence & $\begin{array}{c}\text { Length } \\
\text { [bp] }\end{array}$ & $\begin{array}{c}\text { Con- } \\
\text { centration in } \\
\text { Primer-Mix }\end{array}$ \\
\hline $2850 \mathrm{C}>\mathrm{T}$ & $5^{\prime}-(\mathrm{A})_{7} \mathrm{CAGGTCAGCCACCACTATGC-3^{ \prime }}$ & 27 & $250 \mathrm{nM}$ \\
\hline $1846 \mathrm{G}>\mathrm{A}$ & $5^{\prime}-(\mathrm{A})_{16} \mathrm{TACCCGCATCTCCCACCCCCA} \mathrm{-3'}$ & 37 & $250 \mathrm{nM}$ \\
\hline $1707 \mathrm{~T}>\mathrm{del}$ & $5^{\prime}-(\mathrm{A})_{21}$ GGCAAGAAGTCGCTGGAGCAG -3' & 42 & $500 \mathrm{nM}$ \\
\hline $\begin{array}{l}2613-15 \\
\text { AGA>del }\end{array}$ & $5^{\prime}-(\mathrm{A})_{26} \mathrm{GCCTTCCTGGCAGAGATGGAG-3'}$ & 47 & $500 \mathrm{nM}$ \\
\hline $100 \mathrm{C}>\mathrm{T}$ & $5^{\prime}-(\mathrm{A})_{31} \mathrm{CAACGCTGGGCTGCACGCTAC-3'}$ & 52 & $1,5 \mu \mathrm{M}$ \\
\hline $4180 \mathrm{G}>\mathrm{C}$ & $5^{\prime}-(\mathrm{A})_{37} \mathrm{CAAAGCTCATAGGGGGATGGG-3'}$ & 58 & $1,5 \mu \mathrm{M}$ \\
\hline $1023 \mathrm{C}>\mathrm{T}$ & $5^{\prime}-(\mathrm{A})_{42} \mathrm{CCGCCCGCCTGTGCCCATCA-3^{ \prime }}$ & 62 & $1,5 \mu \mathrm{M}$ \\
\hline $2988 \mathrm{G}>\mathrm{A}$ & $5^{\prime}-(\mathrm{A})_{45} \mathrm{AACAGTGCAGGGGCCGAGGGAG-3'}$ & 67 & $1 \mu \mathrm{M}$ \\
\hline $31 \mathrm{G}>\mathrm{A}$ & $5^{\prime}-(\mathrm{A})_{43} \mathrm{CCAGGAGCAGGAAGATGGCCACTATCA-3'}$ & 70 & $2,5 \mu \mathrm{M}$ \\
\hline $\begin{array}{l}2549 \\
\text { A>del_var3 }\end{array}$ & $5^{\prime}-(\mathrm{A}){ }_{54} \mathrm{GGGCTGGGTCCCAGGTCATCC-3'}$ & 75 & $5 \mu \mathrm{M}$ \\
\hline
\end{tabular}


SNaPshot reaction conditions

$\left.\begin{array}{lcc}\hline \text { Phase } & \text { Duration } & \text { Temperature } \\ \hline \text { Initial Denaturation } & 1 \mathrm{~min} & 96^{\circ} \mathrm{C} \\ \hline \text { Denaturation } & 30 \mathrm{sec} & 96^{\circ} \mathrm{C} \\ \text { Primer annealing } & 5 \mathrm{sec} & 50^{\circ} \mathrm{C} \\ \text { Elongation } & 30 \mathrm{sec} & 60^{\circ} \mathrm{C} \\ \hline \text { Cool down } & \text { for ever } & 8^{\circ} \mathrm{C}\end{array}\right\} 25$

To prevent the unincorporated fluorescent ddNTPs from comigrating with the fragments of interest, the SNaPshot reaction was purified to remove non-integrated ddNTPs from reaction. To do this, $0.5 \mu \mathrm{l}$ fast alkaline phosphatase (Fermentas, St. Leon-Rot, Germany) with the same volume of FastAP-buffer were added to reaction and incubated for $1 \mathrm{~h}$ at $37^{\circ} \mathrm{C}$. Afterwards, alkaline phosphatase was inactivated by incubation at $75^{\circ} \mathrm{C}$ for $15 \mathrm{~min}$. Finally, $1 \mu \mathrm{l}$ of the $\mathrm{SNaPshot}$ reaction was added to $10 \mu \mathrm{L}$ of the following mixture:

\begin{tabular}{ll}
\hline Sequencing mix & Volume \\
\hline Formamid $\left(\mathrm{Hi}-\mathrm{Di}{ }^{\mathrm{TM}}\right.$ Formamid, Applied Biosystems) & $10 \mu \mathrm{l}$ \\
Gene Scan $^{\mathrm{TM}} 120 \mathrm{LIZ}^{\mathrm{TM}}$ Size & $0,5 \mu \mathrm{l}$ \\
\hline
\end{tabular}

The reaction was denatured for $5 \mathrm{Min}$ at $95^{\circ} \mathrm{C}$, and then immediately placed on ice. The products were analyzed in 3130xl Genetic Analyser using Gene mapper v3.7 software ${ }^{\circledR}$ (Applied Biosystems). 


\subsubsection{RNA}

\subsubsection{RNA Isolation}

\begin{tabular}{lc}
\hline PBS-buffer, $\mathbf{p H ~ 7 , 4}$ & Volume \\
\hline $\mathrm{NaCl}$ & $140,0 \mathrm{mM}$ \\
$\mathrm{KCl}$ & $2,5 \mathrm{mM}$ \\
$\mathrm{Na} 2 \mathrm{HPO} 4$ & $8,1 \mathrm{mM}$ \\
$\mathrm{KH} 2 \mathrm{PO} 4$ & $1,5 \mathrm{mM}$ \\
\hline ddH2O & Up to 1 lit
\end{tabular}

Before RNA extraction to avoid contamination and reduce RNase in the bench, antiRNase spray (RNaseZap; Sigma-Aldrich) was used for cleaning the working surfaces and pipettes. Also during the experiments RNase free plastic ware was used. Total RNA was extracted as follows:

$1 \times 10^{6}$ cells were harvested by centrifugation ( $\left.3500 \mathrm{rpm}, 3 \mathrm{~min}, \mathrm{RT}\right)$, the medium was

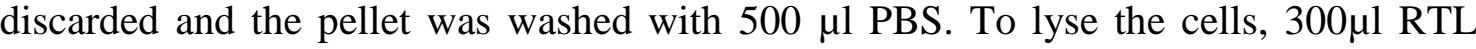

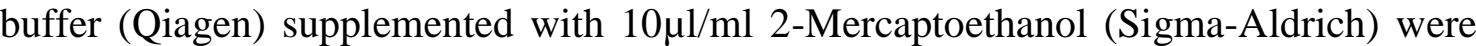
added to each sample. The RNA was extrcated using RNeasy Mini Kit or RNeasy Plus Mini Kit (Qiagen) in combination with QiaCube (Qiagen) robot according manufacturer's instruction. RNA concentration was measured by absorbance at $260 \mathrm{~nm}$ using biophotometer as described in chapter 2.2.1.3.

\subsubsection{RT-PCR}

In order to evaluate expression rate of the genes of interest, total RNA was reversed transcribed to complementary DNA (cDNA) using SuperScript ${ }^{\mathrm{TM}}$ II reverse transcriptase (Invitrogen) as follows:

One microlittre of random hexanucleotide primers (dN6, Roche, Mannheim) was added to $1 \mu \mathrm{g}$ mRNA, the samples were incubated at $70^{\circ} \mathrm{C}$ for $10 \mathrm{~min}$ and left to cool down at room temperature for $10 \mathrm{~min}$. Afterwards, 11,25 $\mu \mathrm{l}$ of the following RT-mastermix were added to each RNA-primer reaction mix. 


\begin{tabular}{lc}
\hline RT-Mastermix (per Reaction) & Volume \\
\hline 5 x Superscript RT buffer & $6 \mu \mathrm{l}$ \\
DTT $(0,1 \mathrm{M})$ & $3,5 \mu \mathrm{l}$ \\
dNTPs $(10 \mathrm{mM})$ & $1 \mu \mathrm{l}$ \\
RNase Inhib P/N $(40 \mathrm{un} / \mu \mathrm{l})$ & $0,5 \mu \mathrm{l}$ \\
Super Script ${ }^{\mathrm{TM}} \mathrm{II}(200 \mathrm{U} / \mu \mathrm{l})$ & $0,25 \mu \mathrm{l}$ \\
\hline Total volume & $11,25 \mathrm{ml}$
\end{tabular}

The cDNA was synthesized by incubation at $42^{\circ} \mathrm{C}$ for $60 \mathrm{~min}$. Each sample was filled up with $70 \mu \mathrm{ddH} 2 \mathrm{O}$ to reach to the final cDNA-concentration of estimated $10 \mathrm{ng} / \mu \mathrm{l}$.

\subsubsection{Quantitative PCR}

Quantitative PCR (qPCR or also called real-time PCR) is based on monitoring the amount of PCR-product throughout the PCR amplification process rather than at the end, thereby allowing PCR reactions to be monitored in real time. Quantitative PCR reactions are characterized by the time point during cycling when amplification of a target is first detected rather than measuring the amount of target after a fixed number of reaction cycles. Therefore, the higher the starting copy number of the target, the sooner a significant increase in the fluorescent signal is detected (HIGUCHI et al. 1993) .

In this work the expression of the genes of interest was determined in relation to the expression of an endogenous normalization gene and the ratio was related to the expression of both genes in a control sample, the so called relative expression or $\Delta \Delta \mathrm{C}_{\mathrm{T}}$ method. In order to measure the expression rate of the gene of interest, below equation was used.

$$
\text { Relative expression }=2^{-[(\mathrm{Ct}-\mathrm{Ct} \mathrm{NGen})-(\mathrm{Ct} \text { controll }-\mathrm{Ct} \mathrm{NGen} \mathrm{controll})]}=2^{-[\Delta \Delta \mathrm{Ct}]}
$$

According to the equation, the threshold cycle $\left(\mathrm{C}_{\mathrm{T}}\right)$ value is the cycle number at which the fluorescence emission exceeds the fixed threshold level. The $\mathrm{C}_{\mathrm{T}}$ values are inversely proportional to the expression level of the target gene. The expression level for the gene of interest was normalized to the expression level of an endogenous normalization gene 
with known constant expression (so called housekeeping gene). Housekeeping genes are genes which are commonly expressed in most cell types and are present at consistent levels which can be used to normalize target cDNA across experiments and cell types. In this work TATA-Box Binding Protein (TBP) was used as such endogenous control. The expression of $O C T 1, C Y P 2 D 6$ and POR genes was quantified by real-time RT-PCR using ready-to-use TaqMan ${ }^{\circledR}$ based gene expression assays (Table 2.5) and eurogentec Master Mix (Köln, Germany).

Table 2. 5 Primers and corresponding sequences for CYP2D6.

\begin{tabular}{ll}
\hline TaqMan assay & \multicolumn{1}{c}{ Manufacturer } \\
\hline Hs00427550_A1 & Applied Biosystems, Darmstadt, Germany \\
Hs02576158_g1 & Applied Biosystems, Darmstadt, Germany \\
Hs00287016_A1 & Applied Biosystems, Darmstadt, Germany \\
\hline
\end{tabular}

The following reaction mix was prepared:

\begin{tabular}{lc}
\hline Mastermix for qPCR & Volume \\
\hline 2 x Mastermix (Eurogentec) & $9 \mu \mathrm{l}$ \\
20 x AssayMix & $0,9 \mu \mathrm{l}$ \\
cDNA $(10 \mathrm{ng} / \mu \mathrm{l})$ & $3 \mu \mathrm{l}$ \\
$\mathrm{ddH}_{2} \mathrm{O}$ & $5,1 \mu \mathrm{l}$ \\
\hline Total volume & $18 \mu \mathrm{l}$
\end{tabular}

Where the 2xMastermix (Eurogentec) was prepared as follows:

\begin{tabular}{lc}
\hline 2 x Mastermix (Eurogentec) & Volume \\
\hline $10 \times$ Buffer & $1,8 \mu \mathrm{l}$ \\
$\mathrm{MgCl}_{2}(50 \mathrm{mM})$ & $1,26 \mu \mathrm{l}$ \\
$\mathrm{dNTPs}(5 \mathrm{mM})$ & $0,72 \mu \mathrm{l}$ \\
Hot Goldstar Polymerase $(5 \mathrm{U} / \mu \mathrm{l})$ & $0,09 \mu \mathrm{l}$ \\
$\mathrm{ddH}_{2} \mathrm{O}$ & $11,13 \mu \mathrm{l}$ \\
\hline Total volume & $15 \mu \mathrm{l}$
\end{tabular}


The qPCR reaction was run in a Sequence Detection System 7900HT (Applied Biosystems) under the following conditions:

\section{PCR-condition:}

$\left.\begin{array}{lcc}\hline \text { Phase } & \text { Duration } & \text { Temperature } \\ \hline \text { Taq Polymerase activation } & 2 \mathrm{~min} & 95^{\circ} \mathrm{C} \\ \hline \text { Denaturation } & 15 \mathrm{sec} & 95^{\circ} \mathrm{C} \\ \text { Primer annealing } & 30 \mathrm{sec} & 60^{\circ} \mathrm{C} \\ \text { Elongation } & 1 \mathrm{~min} & 72^{\circ} \mathrm{C}\end{array}\right\} 40$

The gene expression was normalized on the expression of TATA-box binding protein (TBP, Applied Biosystem TaqMan assay \# 4326322E). Relative expression of OCT1, CYP2D6 and POR was calculated using the $2^{-\Delta \Delta} \mathrm{Ct}$ method according to the above equation.

\subsubsection{Protein analyses}

\subsubsection{Quantification of total protein using bicinchoninic acid (BCA)}

\begin{tabular}{ll}
\hline RIPA buffer $(\mathbf{5 0} \mathbf{~ m l})$ & Volume \\
\hline Tris-HCl & $50 \mathrm{mM}$ \\
$\mathrm{NaCl}$ & $150 \mathrm{mM}$ \\
$\mathrm{EDTA}$ & $1 \mathrm{mM}$ \\
$\mathrm{NP}-40$ & $1 \%(\mathrm{v} / \mathrm{v})$ \\
Na-deoxycholate & $0.25 \%(\mathrm{w} / \mathrm{v})$ \\
PMSF (optional) & $1 \mathrm{mM}$ \\
\hline
\end{tabular}

\begin{tabular}{ll}
\hline BSA Stock solutions $(\mathbf{1 m g} / \mathbf{m l})$ & Volume \\
\hline BSA & $50 \mathrm{mg}$ \\
1x RIPA buffer & $50 \mathrm{ml}$
\end{tabular}




\begin{tabular}{lc}
\hline $\begin{array}{l}\text { Cupric sulfate pentahydrate solution } \\
\left(\mathbf{C u S O}_{4} \times 5 \mathbf{H}_{2} \mathbf{O}\right)\end{array}$ & Volume \\
\hline Cupric sulfate $4 \%$ & $2 \mathrm{mg}$ \\
$\mathrm{ddH}_{2} \mathrm{O}$ & $50 \mathrm{ml}$ \\
\hline
\end{tabular}

The BCA assay, originally described by Smith et al. in 1985 (Smith et al., 1985), measures the formation of $\mathrm{Cu}^{1+}$ from $\mathrm{Cu}^{2+}$ by the Biuret complex in alkalic conditions. The detection is based on complexing the $\mathrm{Cu}^{1+}$ ion with BCA that give a colour complex with absorption maximum at $562 \mathrm{~nm}$. By this assay the total protein concentration is exhibited by a color change of the sample solution from green to purple in proportion to protein concentration, which can then be measured using colorimetric techniques. The BCA assay was performed as follows:

$10 \mu$ of diluted protein samples (dilution 1:3 in RIPA buffer) were pipette in a single well of a transparent 96-well plate (Sarstedt). The samples were analyzed in duplicate. Then BCA-cupric sulfate solution was added. To prepare this solution, 50 portion of BCA solution with one portion of cupric sulfate $4 \%$ solution were mixed (green colour), and $200 \mu 1$ of this solution was added to each well. After that the plate was incubated at $37^{\circ} \mathrm{C}$ for $30 \mathrm{~min}$ and then protein absorption was measured at $570 \mathrm{~nm}$ wave length in Tecan Ultra Microplate device (Tecan, Crailsheim) and finally the protein concentration was calculated from the standard curve. The standard curve was prepared using bovine serum albumin (BSA). The range of BSA concentrations for the standard curve was selected $(0,1,5,10,15,20,25$ and $30 \mathrm{mg} / \mathrm{ml})$. For this reason, the amounts of $0,1,5$, $10,15,20,25$ and $30 \mu \mathrm{l}$ of BSA stock solution $(1 \mathrm{mg} / \mathrm{ml})$ were pipette in duplicate. The BSA was treated with put into the same 96-well plate, treated and measured in the same way as the samples of interest.

\subsubsection{Western Blot}

\subsection{SDS-Polyacrylamid Gel Electrophoresis (SDS-PAGE)}

By using SDS-PAGE, denatured negative charged proteins can be separated according to their molecular weight. First the proteins were denatured by heating them at $95^{\circ} \mathrm{C}$ for 5 min and in the presence of $\beta$-Mercaptoethanol or DTT to break down disulfide bonds 
in the structure of protein. Second the denatured proteins are run on a polyacrylamide gel. In this step, first the samples run through a low concentration gel (stacking gel) and then were separated on higher concentration polyacrylamide gel (separation gel). First the separating gel was prepared. To prepare the separating gel, the compounds were mixed together in concentrations given in table 2.6. The mixture was degassed for 10 min using water jet pump for $10 \mathrm{~min}$ and ammonium peroxydisulfate (APS) and N,N,N',N'-Tetramethylethylendiamine (TEMED) were added to start gel polymerization. A gel chamber Mighty Small SE Dual Gel Caster (Hoeffer, Holliston, MA) was filled until the level reached approximately $1.5 \mathrm{~cm}$ before the top end. The rest part was filled up with water to make smooth and even the top side edge of the gel. Then the gel was left for $30 \mathrm{~min}$ at RT to polymerize. Meanwhile the stacking gel was prepared. The water was removed from top and degassed stacking gel was added on the top of the separation gel and incubated for $30 \mathrm{~min}$ at RT to polymerize. Then the gel was fixed in the electrophoresis chamber Mighty Small II (Hoeffer, Holliston, MA) and the chamber was filled with $1 \mathrm{x}$ Running buffer.

Table 2. 6 Reagent required for preparation of Stacking gel and Separating gel

\begin{tabular}{lll}
\hline Reagent & $\mathbf{4 \%}$ Stacking gel & $\mathbf{1 2 \%}$ Separating gel \\
\hline $\mathrm{ddH}_{2} \mathrm{O}$ & $1625 \mu \mathrm{l}$ & $2180 \mu \mathrm{l}$ \\
$1,5 \mathrm{M}$ Tris- $\mathrm{HCl}(\mathrm{pH} \mathrm{8,8)}$ & - & $1250 \mu \mathrm{l}$ \\
$0,5 \mathrm{M}$ Tris- $\mathrm{HCl}(\mathrm{pH} \mathrm{6,8)}$ & $625 \mu \mathrm{l}$ & - \\
$10 \%(\mathrm{w} / \mathrm{v}) \mathrm{SDS}$ & $25 \mu \mathrm{l}$ & $50 \mu \mathrm{l}$ \\
$40 \%(\mathrm{w} / \mathrm{v})$ Acrylamid/Mix 37:5:1 & $250 \mu \mathrm{l}$ & $1500 \mu \mathrm{l}$ \\
$10 \%$ APS & $12.5 \mu \mathrm{l}$ & $25 \mu \mathrm{l}$ \\
TEMED & $2.5 \mu \mathrm{l}$ & $2.5 \mu \mathrm{l}$ \\
\hline
\end{tabular}

\subsection{Electrophoresis}

\begin{tabular}{lc}
\hline 1x Running buffer & Volume \\
\hline Tris- $\mathrm{HCl}(\mathrm{pH} 8.4)$ & $3.03 \mathrm{~g}$ \\
Glycin & $14.41 \mathrm{~g}$ \\
$\mathrm{SDS}$ & $1.00 \mathrm{~g}$ \\
$\mathrm{ddH}_{2} \mathrm{O}$ & Add $1 \mathrm{~L}$ \\
\hline
\end{tabular}




\begin{tabular}{ll}
\hline 4x Loading buffer & Volume \\
\hline $0,5 \mathrm{M}$ Tris- $\mathrm{HCl}(\mathrm{pH} 6,8)$ & $6,6 \mathrm{ml}$ \\
Glycerin & $7,5 \mathrm{ml}$ \\
$10 \%(\mathrm{w} / \mathrm{v}) \mathrm{SDS}$ & $12,0 \mathrm{ml}$ \\
$2 \%(\mathrm{w} / \mathrm{v})$ Brome phenole blue & $0,5 \mathrm{ml}$ \\
$\mathrm{ddH}_{2} \mathrm{O}$ & $\mathrm{ad} 25 \mathrm{ml}$ \\
\hline Stored at $-20^{\circ} \mathrm{C}$ in $100 \mu$ l Aliquots &
\end{tabular}

The gel was pre-run at $12 \mathrm{~mA}$ for about $30 \mathrm{~min}$. Meanwhile $15 \mu \mathrm{l}$ of the protein samples were denatured at $95^{\circ} \mathrm{C}$ for $5 \mathrm{~min}$ in the presence of $5 \mu \mathrm{l}$ of $4 \mathrm{x}$ loading buffer (Thermomixer 5436, Eppendorf) and then were placed on ice. Then $5 \mu$ molecular weight marker (SeeBlue®Plus2 Prestained Standard, Invitrogen) and $100 \mu \mathrm{g}$ of each sample were loaded onto the gel. The samples were run on the collection gel at $12 \mathrm{~mA}$ (per gel) for about 10-20 min till reached to the border of separation gel and then raised the current up to $25 \mathrm{~mA}$ (per gel) on the separation gel until loading buffer run out of the gel. During the electrophoresis, the gel chamber was cooled down using tap water stream. After electrophoresis was completed, the gel was removed from the assembly and processed for blotting.

\subsection{Protein blotting using a semidry method}

\begin{tabular}{lc}
\hline Transfer buffer (pH 9) & Volume \\
\hline Tris- $\mathrm{HCl}$ & $48 \mathrm{mM}$ \\
Glycin & $39 \mathrm{mM}$ \\
SDS & $0.0374 \%(\mathrm{w} / \mathrm{v})$ \\
Methanol & $15 \%$ \\
$\mathrm{ddH}_{2} \mathrm{O}$ & Add to $1 \mathrm{~L}$ \\
\hline
\end{tabular}

Protein blotting involves the transfer of proteins to an immobilizing membrane. In this study a semidry transfer method originally described by Kyhse-Andersen, 1984 was used. Electrophoretic transfer of resolved proteins from a polyacrylamide gel to a polyvinylidene difluoride (PVDF) membrane was used. The PAGE-separated proteins were transferred on the PVDF membrane. Therefore, first of all, the PVDF membrane 
(Imobilon-P Transfer Membrane No. IPVH00010 Pore diameter $0.45 \mu \mathrm{m}$, Millipore) was activated by incubation with methanol for $30 \mathrm{sec}$. The activated membrane was washed with $\mathrm{ddH}_{2} \mathrm{O}$ and equilibrated in transfer buffer for $10 \mathrm{~min}$. Meanwhile 6 thick (Whatman ${ }^{\circledR}$, No. 2668) and 2 thin (Whatman ${ }$, No. 2CHR) filter papers $(5.2 \times 8.3 \mathrm{~cm}$ ) were soaked in transfer buffer for $10 \mathrm{~min}$. The gel sandwich consisting of filter paper, SDS-PAGE gel, PVDF membrane and filter paper was prepared and arranged on the electroblotting apparatus (Biometra) (Fig.2.2). The air bubbles were eliminated between layers using glass rolling tube. Protein transfer was done at $45 \mathrm{~mA}$ (per gel) for 1.5 hour at room temperature (90 $\mathrm{mA}$ if two gels were blotted simultaneously).

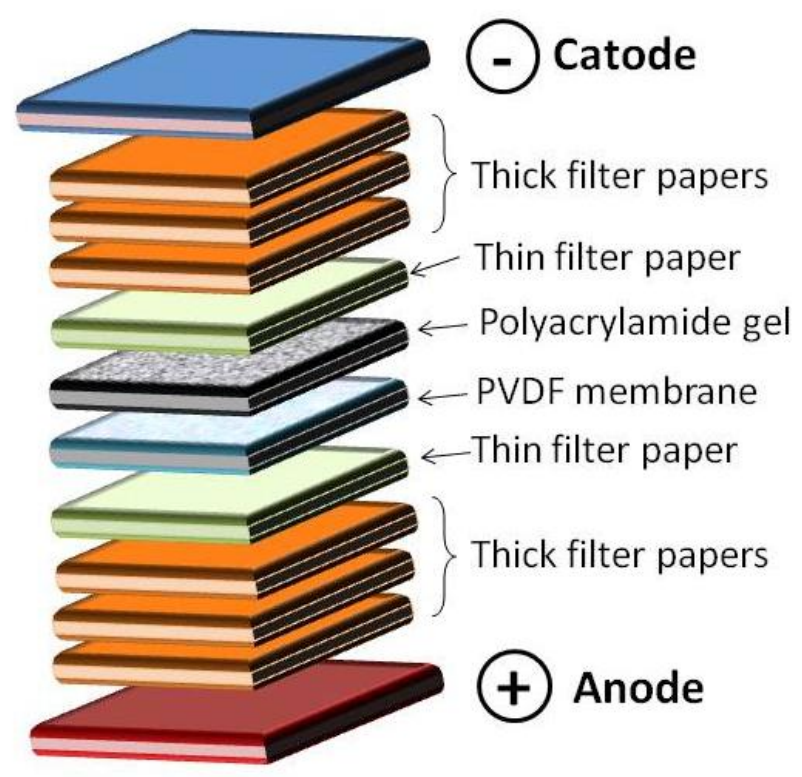

Fig.2. 2 Assembly of a horizontal electroblotting apparatus.

\subsection{Staining}

\begin{tabular}{lc}
\hline Coomasse blue staining solution & Volume \\
\hline Coomassie® Brilliant Blue R250 & $1 \%(\mathrm{w} / \mathrm{v})$ \\
Methanol & $5 \%(\mathrm{v} / \mathrm{v})$ \\
Acetic acid & $7 \%$ \\
\hline
\end{tabular}


In order to examine the efficiency and uniformity of the transfer, the polyacrylamid gel was stained after the transfer. The polycrylamide gel was incubated with Coomassie Blue staining solution for $5 \mathrm{~min}$ at room temperature and then destained by washing for overnight with water.

\subsection{Blocking}

\begin{tabular}{lc}
\hline Buffer C (pH 7.5) & Volume \\
\hline Tris- $\mathrm{HCl}$ & $25 \mathrm{mM}$ \\
$\mathrm{NaCl}$ & $150 \mathrm{mM}$ \\
Tween 20 & $0.01 \%$ \\
$\mathrm{ddH}_{2} \mathrm{O}$ & Add $1 \mathrm{~L}$ \\
\hline
\end{tabular}

After blotting, the membrane was washed with $\mathrm{ddH} 2 \mathrm{O}$ and incubated for one hour in 20 $\mathrm{ml}$ buffer $\mathrm{C}$ supplemented with $5 \%$ milk powder $(1 \mathrm{~g})$ to block the protein bands on the membrane.

\subsection{Incubation with primary antibody}

The primary antibody was diluted (between 1:500 to 1:1500) in $5 \mathrm{ml}$ buffer $\mathrm{C}$ supplemented with $5 \%$ milk powder $(250 \mathrm{mg})$. The primary and secondary antibodies used in this work are given in table 2.5. Then the membrane was placed in a plastic foil sealed the edges with the sealing apparatus. Afterwards the plastic foil was filled with the antibody-containing buffer $\mathrm{C}$ and fixed on the overhead shaker and incubated overnight at $4^{\circ} \mathrm{C}$.

\subsection{Incubation secondary antibody}

After incubation with primary antibody, the membrane was washed 3 times for $5 \mathrm{~min}$ with the buffer A. Then a horse radisch peroxidase conjugated IgG was added as a secondary antibody. The secondary antibody was diluted 1:10000 in $10 \mathrm{ml}$ buffer A 
supplemented with $0.5 \%(\mathrm{w} / \mathrm{w})$ milk powder. The membrane was put in a $50 \mathrm{ml}$ falcon tube containing the secondary antibody solution and incubated for one hour on the roll shaker. Then the membrane was washed 3 times for 5 min with the buffer A.

\begin{tabular}{lc}
\hline Buffer A (pH 7.5) & Volume \\
\hline Tris- $\mathrm{HCl}$ & $25 \mathrm{mM}$ \\
$\mathrm{NaCl}$ & $150 \mathrm{mM}$ \\
$\mathrm{ddH}_{2} \mathrm{O}$ & Add 1 L \\
\hline
\end{tabular}

Table 2. 7 Primary and secondary antibodies used in this study.

\begin{tabular}{lll}
$\begin{array}{l}\text { Antibody } \\
\text { Primary Antibody }\end{array}$ & Dilution & Manufacturer \\
OCT1 & $1: 500$ & Novus Biologicals (\#NBP1-51684) \\
CYP2D6 & $1: 1500$ & BD Gentest (\#458246) \\
GAPDH & $1: 2500$ & Serotec (\#AHP996) \\
Secondary Antibody & & \\
Anti Mouse IgG-HRP & $1: 10000$ & Biomol (\#111-035-003) \\
Peroxidase (for OCT1, & & \\
CYP2D6 and GAPDG) & & \\
\hline
\end{tabular}

\subsection{Chemiluminescent detection}

Chemiluminescence detection was used to specifically detect the antibody-targeted proteins of interest. Chemiluminescence detection uses light produced by the peroxidase catalyzed reaction of luminol with hydrogen peroxide. The peroxidase enzyme is conjugated on the secondary antibody. The chemiluminiscence detection was performed as follows: the membrane was incubated for 5 minutes with $1 \mathrm{ml}$ Luminol/Enhancer and $1 \mathrm{ml}$ Peroxide Solution (SuperSignal® West Pico Trial Kit, Perbio Science, Bonn). Then the membrane was dried on paper towel and put in transparent plastic foil and fixed in the developer cassette. Treated membranes were 
exposed to the ECL film (HyperfilmTM MP, Amersham) for 1-5 minutes in the autoradiographic cassette (FUJIX Cassette 2040) in darkness to detect the light emitted by the reaction. Then the film was developed using developer solution (Entwickler G150 AGFA) and the colour was fixed in fixer solution (Fixierer G354 AGFA). The presence of the protein of interest was determined by the appearance of a band at the appropriate molecular weight when compared to the molecular size standard. Alternatively, after treating the membrane with peroxide/luminol enhancer solutions, the membrane was placed in VersaDoc equipment (BioRad, Hercules USA) to visualize the signal using Quantity One software.

\subsubsection{Work with Bacteria}

\subsubsection{Growth media and growth conditions}

\begin{tabular}{lc}
\hline LB-media & Volume \\
\hline Trypton & $10 \mathrm{~g}$ \\
Yeast extract & $5 \mathrm{~g}$ \\
$\mathrm{NaCl}$ & $5 \mathrm{~g}$ \\
$\mathrm{ddH} 2 \mathrm{O}$ & Up to $1000 \mathrm{ml}$ \\
\hline
\end{tabular}

Luria-Bertani (LB) complex medium was used for propagation of the E.coli strains top 10 (Invitrogen). The LB medium was autoclaved at $120^{\circ} \mathrm{C}$ for $20 \mathrm{~min}$. To prepare solid LB medium, $14 \mathrm{~g} / 1$ Agar (AppliChem, Darmstadt) was added to 1 L liquid LB medium before autoclaving. The medium was left to cool down to $60^{\circ} \mathrm{C}$ or below and antibiotic were added to reach to the final concentration of $100 \mu \mathrm{g} / \mathrm{ml}$ for Ampicillin, or $20 \mu \mathrm{g} / \mathrm{ml}$ for Kanamycin. The solid media was poured into $92 \mathrm{~mm}$ disposable plastic plates. The antibiotics were dissolved in $\mathrm{ddH}_{2} \mathrm{O}$, and after passing through sterile filter (Minisart $0.2 \mu \mathrm{m}$, Sartorius, Göttingen), aliquot and stored at $-20^{\circ} \mathrm{C}$ until used. The prepared liquid and solid LB media were stored at $4{ }^{\circ} \mathrm{C}$.

Bacterial strains were cultured both in liquid and solid media. Liquid cultures with appropriate antibiotic were either $100 \mathrm{ml}$ in $500 \mathrm{ml}$ glass bottles (used for Midi Prep 
plasmid extraction, see chapter 2.2.4.5) or $5 \mathrm{ml}$ in $15 \mathrm{ml}$ falcon tubes (for Mini Prep plasmid extraction, see chapter 2.2.4.4).

\subsubsection{Long-term Storage of bacterial strains}

The bacterial clones were stored for long time in $25 \%$ glycerol at $-80^{\circ} \mathrm{C}$. For this reason $600 \mu \mathrm{l}$ of fresh over night culture of the bacteria was mixed with an equal volume of sterile $50 \%$ glycerol solution in one $1.5 \mathrm{ml}$ eppi and immediately store at $-80^{\circ} \mathrm{C}$.

\subsubsection{Transformation through electroporation}

Bacterial transformation is the process to introduce a foreign plasmid into bacteria and to use that bacteria to amplify the plasmid in order to make large quantities of it.

Two major methods of bacterial transformation are known, the chemical (or heat) transformation and electroporation. For chemical transformation, cells are treated with divalent cations such as $\mathrm{CaCl}_{2}$. Cells treated in such a way called competent cells. To chemically transform cells, competent cells are mixed with the DNA on ice, followed by a brief heat shock. Then, cells are incubated with rich medium. For electroporation, cells are washed extensively with water to eliminate all salts. To electroporate DNA into cells, washed cells are mixed with the DNA to be transformed and then pipette into a plastic cuvette containing electrodes. A short electric pulse, about 2400 volts $/ \mathrm{cm}$, is applied to the cells causing smalls holes in the membrane through which the DNA enters.

In this work electroporation was used to transform bacteria with genetically recombinant plasmids as follows. First the amount of salt in electroporation mixture was reduced as much as possible by dialyzing the plasmid solution before electoporation. To do this, a $0.025 \mu \mathrm{m}$ dialyze filter from type VSWP01300 (Millipore, Schwalbach) was put on petri dish filled with $\mathrm{ddH}_{2} \mathrm{O}$ from brighter side upward of water surface. The plasmid solution (usually 15 to $20 \mu \mathrm{l}$ ) was carefully pipette in the middle of the filter preventing direct contact with the $\mathrm{ddH}_{2} \mathrm{O}$ below. After $30 \mathrm{~min}$, dialyzed plasmid solution was carefully transferred from filter to a new $1.5 \mathrm{ml}$ eppi.

A $50 \mu 1$ Aliquot of one shot TOP10 electrocompetent E.coli (Invitrogen, Karlsruhe) was

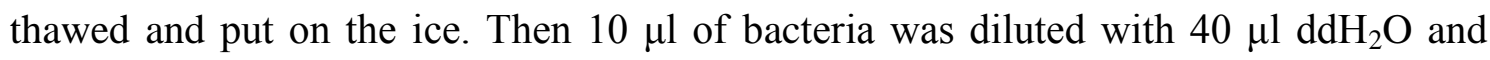
transferred in a pre-cooled $2 \mathrm{~mm}$ electroporation cuvette (PeqLab, Erlangen). After that 
1-3 $\mu$ l of Plasmid solution was added in the bacterial mix in the cuvette. The electroporation was carried out in Gene Pulser II (BioRad, Hercules USA) under following condition: power of $2.5 \mathrm{kV}$, capacitance of $25 \mu \mathrm{F}$ and resistance of $200 \Omega$. The high excitation puls should be between 4.5 and 5 milisec. Right after the electroporation $800 \mu \mathrm{l}$ LB-Medium pre-warmed at $37^{\circ} \mathrm{C}$ was added and then bacterial mix was incubated for 1 hour at $37^{\circ} \mathrm{C}$ to allow the expression of the antibiotic resistance genes encoded in the plasmid. After all $50-200 \mu \mathrm{l}$ of the transformed bacteria were spread on LB-agar plates supplemented with corresponding antibiotic.

\subsubsection{Isolation of plasmid DNA by chloroform extraction (plasmid mini-prep)}

\begin{tabular}{lc}
\hline Resuspension buffer B1 & Volume \\
\hline Tris- $\mathrm{HCl}(\mathrm{pH}$ 8.0) & $150 \mathrm{mM}$ \\
EDTA & $10 \mathrm{mM}$ \\
RNase A & $100 \mu \mathrm{g} / \mathrm{ml}$ \\
\hline add this after autoclave above mixture and store at $4^{\circ} \mathrm{C}$ \\
\\
\hline Lysis buffer B2 & Volume \\
\hline NaOH & $200 \mathrm{mM}$ \\
SDS & $1 \%(\mathrm{w} / \mathrm{v})$ \\
\hline store at room temperature & \\
\hline Neutralization buffer B3 & Volume \\
\hline Potassium acetate (pH 5.5) & $3 \mathrm{M}$ \\
\hline store at room temperature
\end{tabular}

After transformation, sub-population of the clones appeared on the agar plate were picked up using sterile pipette tips, resuspended in $5 \mathrm{ml} \mathrm{LB}$-medium supplemented with the corresponding antibiotics and incubated at $37^{\circ} \mathrm{C}$ for overnight. After that the growing cells were pelleted by centrifugation (4000 rpm, $10 \mathrm{~min}$, RT; Centrifuge 5810 $\mathrm{R}$; Eppendorf). The supernatant was discarded and the pellet was resuspended in $250 \mu 1$ 
resuspension buffer (B1) and transferred in a $1.5 \mathrm{ml}$ Eppendorf reaction tube. The cells were lysed, $250 \mu \mathrm{l}$ Lysis buffer (B2) was added and shaked strongly. The reaction was neutralized by adding $350 \mu 1$ neutralization buffer (B3) and mixed through invertion. In this step denatured proteins and genomic DNA will be appeared as white flakes. To remove the debris and purify the plasmid following steps were performed. Samples were centrifuged at $13000 \mathrm{rpm}$ for $10 \mathrm{~min}$ at RT (Biofuge pico, Heraeus, Hanau). The supernatant was transferred in a new $1.5 \mathrm{ml}$ eppendorf reaction tube and $500 \mu 1$ mixture of chloroform/isoamylalchohol $(24: 1 \mathrm{v} / \mathrm{v})$ was added and vortexed under the fume hood. The samples were centrifuged again at $13000 \mathrm{rpm}$ (Biofuge pico) for $5 \mathrm{~min}$ at RT (Biofuge pico) and the upper phase was transferred to the new $1.5 \mathrm{ml}$ Eppendorf reaction tube. The plasmid DNA was pelleted by adding $650 \mu \mathrm{l}$ iso-propanol (precooled at $-20^{\circ} \mathrm{C}$ ). The samples were centrifugated at $13000 \mathrm{rpm}$ for $15 \mathrm{~min}$ at $4^{\circ} \mathrm{C}$ (Biofuge fresco, Heraeus, Hanau). The supernatant was discarded and the pellet was washed once with $1000 \mu \mathrm{l}$ of $70 \%$ ethanol (pre-cooled at $-20^{\circ} \mathrm{C}$ ). After the centrifugation $\left(13000 \mathrm{rpm}, 10 \mathrm{~min}, 4^{\circ} \mathrm{C}\right)$ the supernatant was removed, the pellet was dried at $37^{\circ} \mathrm{C}$ until it became transparent. The pellet containing the plasmid DNA was resuspended in $50 \mu \mathrm{l}$ TE-buffer and quantified and qualified photometricaly (as described in chapter 2.2.1.3)

\subsubsection{Isolation of plasmid DNA by solid extraction (plasmid midi prep)}

In order to isolate large quantities of high-quality plasmid DNA for transfection of eukaryotic cells a midiprep plasmid extraction was made using PureYieldTM Plasmid Midiprep System (Promega, Mannheim) according to manufacturer's instruction. Briefly, the bacteria were pre-cultured for 5 hours at $37^{\circ} \mathrm{C}$ in $5 \mathrm{ml} \mathrm{LB}$ medium supplemented with corresponding antibiotic. Afterwards $10 \mu \mathrm{l}$ of the pre-culture was transferred to a 500ml glass flask containing $100 \mathrm{ml} \mathrm{LB}$ medium with the corresponding antibiotic (dilution 1:10000). This "main" culture was incubated overnight at $37^{\circ} \mathrm{C}$. On the next day, the culture was transferred into two $50 \mathrm{ml}$ falcon tube, the cells were pelleted using centrifugation (5000 g, $10 \mathrm{~min}$, RT, Centrifuge $5810 \mathrm{R}$, Eppendorf) and the supernatant was discarded. The cell pellet was resuspended in $3 \mathrm{ml}$ cell resuspension solution and transferred to $50 \mathrm{ml}$ Beckman centrifuge tube (Beckman, München). Then $3 \mathrm{ml}$ cell lysis solution was added and mixed by gently inverting the tube 3-5 times. 
Following 3 min incubation, $5 \mathrm{ml}$ neutralization solution was added, mixed the tube 510 times by gently inverting and incubated for $2-3 \mathrm{~min}$ at room temperature. The cellular debris was pelleted by centrifugation $(15000 \mathrm{~g}, 10 \mathrm{~min}, \mathrm{RT}, \mathrm{J} 2-21 \mathrm{M} / \mathrm{E}$ Centrifuge, JA-20 Rotor, Beckman).

Meanwhile the PureYield ${ }^{\mathrm{TM}}$ clearing column (blue) was assembled on the top of a PureYield ${ }^{\mathrm{TM}}$ binding column (white), and the assembled columns were stacked into the vacuum manifold was placed. Then the supernatant after the centrifugation was decanted into the PureYield ${ }^{\mathrm{TM}}$ clearing column. By applying vacuum the lysate was passed through the clearing membrane in the PureYield ${ }^{\mathrm{TM}}$ clearing column, and the DNA was bound to the binding membrane in the PureYield ${ }^{\mathrm{TM}}$ binding column. Afterwards $5 \mathrm{ml}$ of Endotoxin Removal Wash solution was added to the column, and the vacuum was allowed to pull the solution through the column. Then $20 \mathrm{ml}$ of Column Wash Solution was added to the column, and again the vacuum was used to draw the solution through. The membrane was dried by applying the vacuum for 1 min without adding any solution on the column. The PureYield ${ }^{\mathrm{TM}}$ binding column was removed from the vacuum manifold and placed into a new $50 \mathrm{ml}$ disposable plastic tube. The plasmid DNA was eluted by adding 400-600 $\mu$ l of nuclease-free water (pre-warmed to $\left.70^{\circ} \mathrm{C}\right)$ to the DNA binding column and centrifugation $(1800 \mathrm{~g}, 5 \mathrm{~min}, \mathrm{RT})$. Finally the eluted plasmids were transferred into a $1.5 \mathrm{ml}$ eppi and quantified photometricaly and analyzed using agarose gel electrophoresis (as described in chapters 2.2.1.3 and 2.2.1.2, respectively).

\subsubsection{Mammalian cell culturing}

\subsubsection{Used cell lines and culturing conditions}

Flp- $\operatorname{In}^{\mathrm{TM}} \mathrm{T}-\mathrm{REx}^{\mathrm{TM}} 293$ cell line is a derivate of the human embryonic kidney cell line HEK 293, that contains Flp Recombination Target (FRT) integrated into genome. The presence of FRT enables stable transfection using the Flp-In ${ }^{\mathrm{TM}}$ system (Invitrogen). Chinese Hamster Ovary (CHO) cell line (Invitrogen) was also used in this study. This cell line is the most widely used mammalian cells for transfection, expression, and large-scale recombinant protein production. 
Flp-In ${ }^{\mathrm{TM}} \mathrm{TREx}^{\mathrm{TM}} 293$ cells were cultured in DMEM medium supplemented by $10 \%$ FBS and $1 \%$ Penicillin/Streptomycin and $0,1 \%$ Zeocin. The cells were cultured at $37^{\circ} \mathrm{C}$ under 5\% CO2 and $95 \%$ humidity.

Upon reaching approximately $80 \%$ confluency, the cells were subcultured at a ratio of 1:5. Thereto, the old culture medium was removed. Cells were detached from the flasks by adding $5 \mathrm{ml}$ fresh medium and pipetting up and down. Then $1 \mathrm{ml}$ of the cells were transferred into a new $75 \mathrm{~cm}^{2}$ culture flask and placed in the $5 \% \mathrm{CO} 2$ incubator. Media was changed every 3-4 days.

If the cells were prepared for a transport experiment a tripsination was performed to assure homogenous distribution of single cells for the experiments. Therefore, the cells were treated with $5 \mathrm{ml}$ of trypsin (TrypLETM Express, Gibco/Invitrogen) for approximately $4 \mathrm{~min}$ at $37^{\circ} \mathrm{C}$. The trypsin was neutralized by addition of an equal volume of serum-containing growth media. The cells were collected in $15 \mathrm{ml}$ falcon tubes and centrifuged at $300 \mathrm{x}$ g for $3 \mathrm{~min}$. The trypsin and media were removed and the cell pellet was resuspended in fresh media and used to determine the cell count for plating.

\subsubsection{Freezing cell lines}

Cells were periodically frozen to maintain a stock of the cell line for future use.

For this reason, the cells were grown in $75 \mathrm{~cm}^{2}$ culture flask. After reaching $80 \%$ confluency, the cells were transferred to $50 \mathrm{ml}$ falcon tube and pelleted by centrifugation (300 g, $3 \mathrm{~min}$ at room temperature; Heraeus Laborfuge 400R). The supernatant was removed and the cell pellet was resuspended in $6.8 \mathrm{ml}$ of ice-cold freezing medium (90\% FBS with 10\% DMSO). Aliquots of $1.6 \mathrm{ml}$ resuspended cells were transferred into $2 \mathrm{ml}$ cryovials (Nunc, Thermo Scientific, Denmark) and placed on ice pack (ice $+\mathrm{NaCl}+$ water) for 1 hour. Then the cells transferred to $-80^{\circ} \mathrm{C}$ approximately for one week and afterwards stored in liquid nitrogen $\left(-170^{\circ} \mathrm{C}\right)$.

\subsubsection{Defreezing cell lines}

DMEM medium (with $10 \% \mathrm{FBS}$ and $1 \% \mathrm{P} / \mathrm{S}$ ) was prewarmed at $37^{\circ} \mathrm{C}$. An aliquot of cells was removed from the liquid nitrogen $\left(-170^{\circ} \mathrm{C}\right)$ tank and rapidly thawed by holding in a hand or using the $37^{\circ} \mathrm{C}$ water bath. The cells were rapidly transferred to $15 \mathrm{ml}$ 
falcon tube containing $10 \mathrm{ml}$ of pre-warmed DMEM medium (with $10 \%$ FBS and $1 \%$ P/S). The cells were pelleted by centrifugation (300 g, $3 \mathrm{~min}, \mathrm{RT}$; Heraeus Laborfuge 400R). Then supernatant was discarded. The cells were resuspended in $5 \mathrm{ml}$ DMEM medium (with $10 \%$ FBS and $1 \% \mathrm{P} / \mathrm{S}$ ), transferred to $25 \mathrm{~cm}^{2}$ culture flask and cultured under standard condition. These cells can be used for experiment after 2-3 times passage to assure they reach to stable vital condition.

\subsubsection{Transfection}

Transfection is the process of introducing exogenous nucleic acids into eukaryotic cells. There are various methods of introducing foreign DNA into a eukaryotic cell like electroporation, lipofection and other chemical-based transfection such as calcium phosphate. The technique used for transfection in this study was lipofection. In this technique the DNA to be transfected is coated by a lipid, which either interacts directly with the plasma membrane of the cell or is taken into the cell by nonreceptor-mediated endocytosis (Sambrook and Russell, 2007).

\subsection{Transient transfection}

The following procedure was used for transiently expression of the gene of interest in HEK293_TRex cells: $500 \mu \mathrm{l}$ of poly-D-lysine (poly-D-lysine hydrobromide Sigma, 100mg dissolved in $50 \mathrm{ml} \mathrm{H} 2 \mathrm{O}$ ) was added to each well of a 12-well plate and incubated for $15 \mathrm{~min}$ at $37^{\circ} \mathrm{C}$. The poly-D-lysine was recollected (the same poly-Dlysine solution may be reused up to 20 times) and the plates were let dried for $10 \mathrm{~min}$ with open lids in sterile bench. In each well $6 \times 10^{5}$ cells were plated and incubated for overnight. A master-mix with $100 \mu$ l of DMEM pure medium and $12 \mu 1$ FuGene 6 transfection reagent (Roche, Mannheim) was prepared in $1.5 \mathrm{ml}$ Eppendorf reaction tube and incubated for $5 \mathrm{~min}$ at room temperature. Four $\mu \mathrm{g}$ plasmid DNA was added and incubated for additional $15 \mathrm{~min}$ at RT. In the meantime, the cells grown in the 12well plate were washed with $1 \mathrm{ml}$ of DMEM medium supplemented with $10 \%$ FCS serum. After that $1 \mathrm{ml}$ of the same medium was added to each well and DNA/FuGene6 mix was added. After 4-6 hours of incubation, the medium was changed with DMEM medium supplemented by $10 \%$ FBS serum and $1 \%$ Penicillin/Streptomycin antibiotics. The transfected cells were used 24 to 48 hours later for further experiments. 


\subsection{Stable transfection using Flp recombinase}

Unlike transient transfection, in which introduced DNA persists in cells for few days only, stable transfection results in chromosomal integration of the transfected DNA. And the stably transfected cells pass the introduced DNA to their progeny. This enables long-therm analyses of the transfected cells. In this work, HEK Flp-In ${ }^{T M}$ TREx 293 cell line was used which is stably transfected with the plasmid pFRT/lacZeo. This plasmid contains Flp-Recombination Target (FRT), which is a target site for Flp recombinase and Zeocin resistance region for selection of the recombinant cells. In order to stably transfect the gene of interest in this cell line, an expression vector (pcDNA5.1) containing the gene of interest (GOI) was used. The pcDNA5.1 vector contains a FRT site linked to the hygromycin resistance gene and the gene of interest may be cloned under the control of the human cytomegalovirus (CMV) promoter (Fig. 2.3). The FRT site is necessary for Flp recombinase-mediated integration. Hygromycine is used for selection of a cell line stably integrated the pcDNA5.1 vector in their genomes. Another plasmid, the pOG44, is cotransfected with the pcDNA5 vector. The pOG44 plasmid enables the transient expression of the Flp recombinase under the control of the human CMV promoter. 


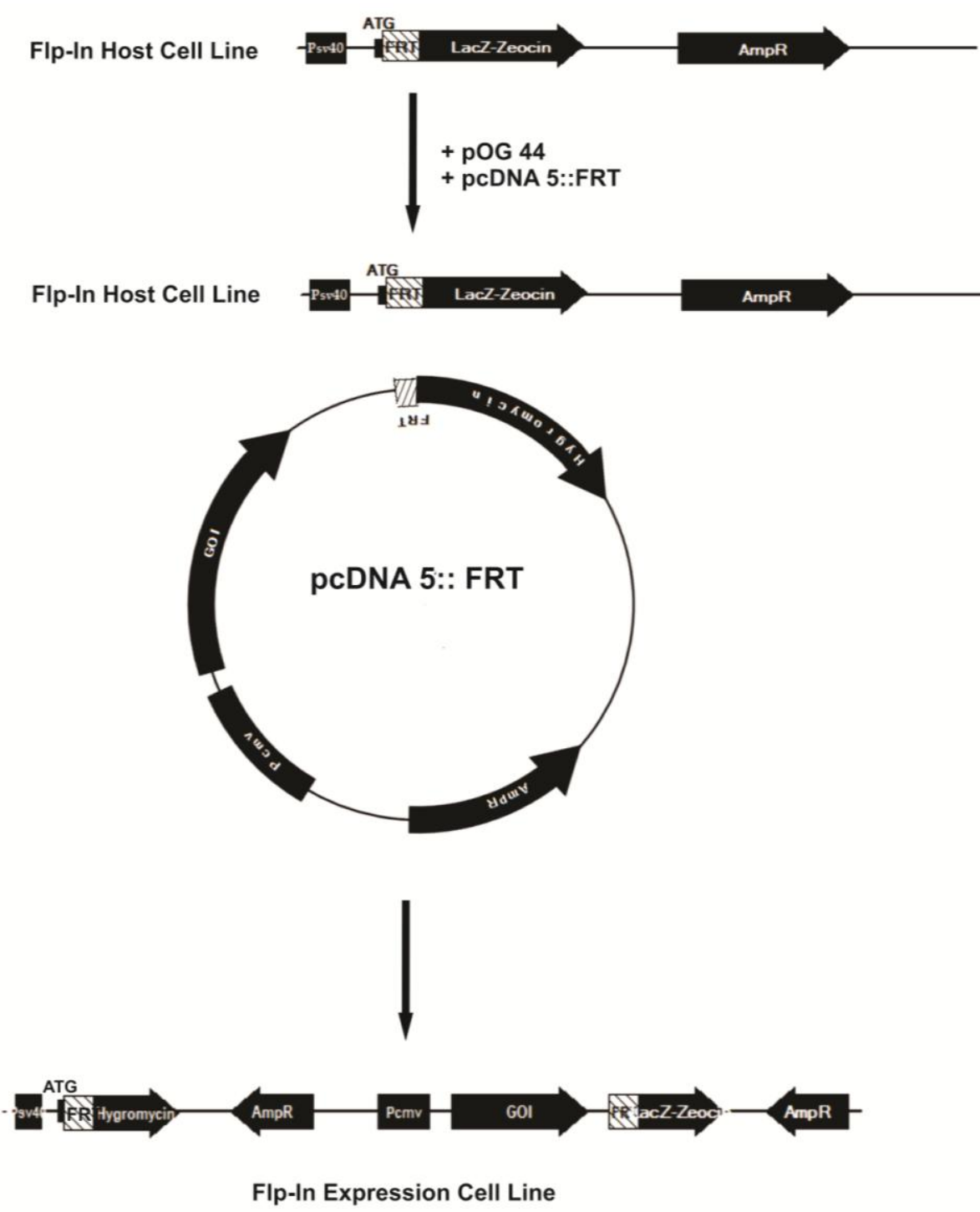

Fig.2. 3 Major features of the stable transfection using the Flp-In system for targeted chromosomal integration.

Following procedure was used for stable transfection using Flp-in system in this work: a 6-well plate was coated with poly-D-lysine for $15 \mathrm{~min}$ and was let to dry with open lid under the sterile bench for $15 \mathrm{~min} .9 \times 10^{5}$ to $1 \times 10^{6}$ cells were plated in each well of the 6-well plate and incubated overnight to reach to $80 \%$ confluence.

For the co-transfection, a master mix containing 100 $\mu$ l of DMEM medium without additives and $12 \mu \mathrm{l}$ FuGene 6 transfection reagent (Roche, Mannheim) per transfection well was prepared. The mix was incubated for $5 \mathrm{~min}$ at room temperature. The master mix was distributed to Eppendorf reaction tubes $(112 \mu \mathrm{l}$ per well) and $4 \mu \mathrm{g}$ DNA was added to each mixture and incubated for $15 \mathrm{~min}$ at room temperature. The DNA 
represents a mixture of the pOG44 plasmid and pcDNA5.1 plasmid carrying the gene of interest in a ratio of 9:1. All plasmids were isolated from bacteria using the midi prep extraction method (chapter 2.2.4.5). Meantime the cells plated in 6-well plate were washed with $2 \mathrm{ml}$ of DMEM medium supplemented with 10\% FCS serum and $1.9 \mathrm{ml}$ of the same medium was added to each well. Following the 15 min of incubation the DNA-FuGene 6 mix was added to each well and incubated for maximum 72 hours.

48 hours after the cotransfection, the cells were transferred to the $92 \mathrm{~mm}$ Petri dishes (Falcon, Schütt, Goettingen) and cultured overnight in $9 \mathrm{ml}$ of DMEM medium supplemented with 10\% FBS serum and 1\% Penicillin/Streptomycin antibiotics. On the day after, the medium was removed and DMEM medium containing 10\% FBS serum and $1 \%$ Penicillin/Streptomycin and the screening antibiotic (either hygromycine or puromycin) was added and incubated until single colonies appeared. Each colony was picked up and transferred into a single well of a 12-well plate and then to 6-well plate with same medium used for selection. Finally the cells were passaged to a $25 \mathrm{~cm}^{2}$ culture flask and then to the $75 \mathrm{~cm}^{2}$ culture flask. Stable transfection was confirmed by the means of DNA, RNA, protein and activity analyses.

\subsection{Determination of optimal screening antibiotic concentration}

An essential role in successfully generation of stably transfected cell lines is determination of the minimum concentration of antibiotics which is required to kill untransfected host cell line. For this purpose, preliminary experiment was performed using HEK TRex cells exposed for 1-2 weeks to DMEM culture medium containing $10 \%$ FBS serum, 1\% Penicillin/Streptomycin and varying concentrations of hygromycin B (Invitrogen, Karlsruhe). Concentrations of 0, 10, 100, 200, 300, 400 and $600 \mu \mathrm{g} / \mathrm{ml}$ were used. The concentration of $300 \mu \mathrm{g} / \mathrm{ml}$ hygromycin was chosen as a minimum concentration and was used to screen for successfully transfected cell lines.

Additionally, the appropriate concentration of puromycin (Invitrogen, Karlsruhe) necessary to screen CYP2D6_IRES_POR transfected cells from untransfected cells was determined. To do this, the HEK-TRex cells were cultured for 5-10 days in DMEM culture medium containing 10\% FBS serum, 1\% Penicillin/Streptomycin and varying concentrations of puromycin $(0,5,10,20,50,100$ and $200 \mathrm{ng} / \mathrm{ml})$. The concentration of $5 \mathrm{ng} / \mathrm{ml}$ puromycin was chosen as a minimal concentration and was used to screen for successfully transfected cell lines. 
The cells overexpressing CYP2D6 under puromycine selection required different hygromycine concentration to select for Flp-In-mediated stable transfection. To determine the optimal hygromycine concentration in this case, CYP2D6_IRES_POR overexpressing HEK cells were cultured for 1-2 weeks in DMEM medium containing $10 \%$ FBS serum, $1 \%$ Penicillin/Streptomycin and varying concentrations of hygromycin B. Concentrations of $0,10,20,50,100,200$ and $400 \mu \mathrm{g} / \mathrm{ml}$ were used. The concentration of $10 \mu \mathrm{g} / \mathrm{ml}$ of hygromycin was selected as a minimum concentration for screening double transfected cells.

\subsubsection{Flow Cytometry}

\begin{tabular}{ll}
\hline Blocking buffer: $(\mathbf{p H}$ 7,2- 7,4) & Volume \\
\hline PBS & $45 \mathrm{ml}$ \\
FBS & $5 \%(\mathrm{v} / \mathrm{v})$ \\
\hline
\end{tabular}

\begin{tabular}{ll}
\hline Permeabilization buffer & Volume \\
\hline PBS & $45 \mathrm{ml}$ \\
FBS & $5 \%(\mathrm{v} / \mathrm{v})$ \\
Triton X-100 & $0.5 \%(\mathrm{v} / \mathrm{v})$ \\
\hline
\end{tabular}

Flow cytometry is a technique that simultaneously measures multiple physical characteristics of single particles, usually cells, as they flow in a fluid stream through a beam of light. The properties measured include a particle's relative size, relative granularity or internal complexity, and relative fluorescence intensity (e.g. resulting for antigen-specific labeling). These characteristics are determined using an optical-toelectronic coupling system that records how the cell or particle scatters incident laser light and emits fluorescence. A single cell analyzes for four parameters (FSC, SSC, FITC, and PE fluorescence). Forward-scattered light (FSC) is proportional to cellsurface area or size, whereas side-scattered light (SSC) is proportional to cell granularity or internal complexity. Two other parameters reflect fluorescence 
characteristics of the cells using fluorochromes like fluorescein isothiocyanate (FITC) and phycoerythrin (PE). One of the fluorochromes used in flow cytometry is FITC. In the absorption spectrum of FITC, the 488-nm line is close to the FITC absorption maximum. Excitation with this wavelength will result in a high FITC emission. Using secondary antibody conjugated to this fluorochrome we can identify protein of interest in a mixed sample. Because the amount of fluorescent signal detected is proportional to the number of fluorochrome molecules on the particle.

In this work following flow cytometry protocol was used. First the $10 \times 10^{6}$ cells were trypsinized with $4 \mathrm{ml}$ TrypLE ${ }^{\mathrm{TM}}$ Express (Gibco/Invitrogen) for $4 \mathrm{~min}$ in incubator. The trypsin was inactivated by adding $4 \mathrm{ml}$ DMEM medium and the cells were passed through the 40 micron cell strainer (Falcon) and collected in $50 \mathrm{ml}$ falcon tube. The cells were pelleted by centrifugation (1400 rpm, $3 \mathrm{~min}$, Room Temperature), washed once with PBS buffer, resuspended in $200 \mu \mathrm{l}$ blocking buffer and transferred into $2 \mathrm{ml}$ Eppendorf reaction tubes $\left(2.5 \times 10^{5}\right.$ cells/tube $)$. Next the cells were fixed with $500 \mu \mathrm{l}$ Histofix 4\% (Carl Roth, Gmbh, Karlsruhe) for $5 \mathrm{~min}$ at RT and pelleted by centrifugation (300 g, $4 \mathrm{~min}, 4^{\circ} \mathrm{C}$ ). The supernatant was discarded; the pellet was washed with $1 \mathrm{ml}$ PBS buffer and again centrifuged $\left(300 \mathrm{~g}, 4 \mathrm{~min}, 4^{\circ} \mathrm{C}\right)$. After removing the supernatant, $1 \mathrm{ml}$ permeabilization buffer was added to each sample and incubated for $10 \mathrm{~min}$ on ice and then centrifugation $\left(300 \mathrm{~g}, 4 \mathrm{~min}, 4^{\circ} \mathrm{C}\right)$. The supernatant was discarded, the cells were resuspended in $100 \mu$ primary antibody in blocking buffer (1:400 dilution) and the samples were incubated on ice for $30 \mathrm{~min}$. The cells were washed twice in $1 \mathrm{ml}$ blocking buffer and centrifuged $\left(300 \mathrm{~g}, 4 \mathrm{~min}, 4^{\circ} \mathrm{C}\right)$. A hundred $\mu \mathrm{l}$ secondary antibody labeled with fluorochrome (1:1000 dilution in blocking buffer) was added to each sample and incubated on ice for $30 \mathrm{~min}$. Used primary and secondary antibodies are listed in table 2.6. After the incubation, $1 \mathrm{ml}$ blocking buffer was added and the cells were pelleted by centrifugation $\left(300 \mathrm{~g}, 4 \mathrm{~min}, 4^{\circ} \mathrm{C}\right)$. The supernatant was removed and the pellet was washed again with $500 \mu 1$ blocking buffer, resuspended in $450 \mu \mathrm{l}$ PBS and transferred in $10 \mathrm{ml}$ FACS tubes (Falcon). The measurements were performed using flow cytometer BD LSR II (BD Bioscience) and the data was analyzed using BD FACSDiva software. 
Table 2. 8 List of antibodies used for flow cytometry and immunocyto staining

$\begin{array}{lll}\text { Antibody } & \text { Dilution } & \text { Manufacturer } \\ \text { Primary Antibody } & & \\ \text { OCT1 } & 1: 400 & \text { Novus Biologicals (\#NBP1-51684) } \\ \text { CYP2D6 } & 1: 1000 & \text { BD Gentest (\#458246) }\end{array}$

Secondary Antibody

Goat anti mouse $\quad 1: 400 \quad$ Invitrogen (\# A-11001)

Alexa 488

Goat anti rabbit $\quad 1: 400 \quad$ Invitrogen (\# A11010)

Alexa 546

\subsubsection{Immunocytochemical staining}

\begin{tabular}{lc}
\hline Blocking buffer: $(\mathbf{p H}$ 7,2- 7,4) & Volume \\
\hline PBS & $45 \mathrm{ml}$ \\
FBS & $5 \%(\mathrm{v} / \mathrm{v})$ \\
Triton X-100 & $0.5 \%(\mathrm{v} / \mathrm{v})$ \\
BSA & $1 \%(\mathrm{v} / \mathrm{v})$ \\
\hline
\end{tabular}

In order to investigate the expression and localization of OCT1 transporter and CYP2D6 metabolizing enzyme in HEK cells overexpressing OCT1 alone, CYP2D6::IRES::POR or combination of OCT1::CYP2D6::IRES::POR, specific primary antibodies for OCT1 and CYP2D6 proteins were used and visualized by fluorescence and confocal microscopies using secondary antibody conjugated with fluorochrome. The described above transgenic cells were trypsinized using TrypLETM Express medium (Gibco/Invitrogen) for $4 \mathrm{~min}$ in a 5\% $\mathrm{CO} 2$ incubator. The cells were harvested and passed through a 40 micron cell strainer (BD falcon) and collected in 50 $\mathrm{ml}$ falcon tube. Then the cells were centrifuged (1400 rpm, $3 \mathrm{~min})$, the supernatant was removed and the cells were washed one time with PBS buffer. Next the cells were plated on the sterile cover-slip in 12 well-plate that previously coated with poly-Dlysine. After reaching the cells to $80 \%$ or full confluency, the culture medium was removed, $500 \mu 1$ Histofix 4\% (Carl Roth, Gmbh, Karlsruhe) was added to each eppis as a fixative agent and incubated for $20 \mathrm{~min}$ at RT. Then the wells were washed with $1 \mathrm{ml}$ 
PBS buffer and $1 \mathrm{ml}$ blocking buffer was added to each well and incubated for 90-120 min at RT. After that $500 \mu$ l blocking buffer containing the primary antibody (in a dilution 1:400) was added to each well and the samples were incubated for $60 \mathrm{~min}$ at RT or overnight at $4^{\circ} \mathrm{C}$ for extremely packed cells. Afterwards $1 \mathrm{ml}$ blocking buffer was added to each well and incubated for $3 \mathrm{~min}$ and subsequently washed once with $1 \mathrm{ml}$ blocking buffer and then $500 \mu \mathrm{l} /$ well secondary antibody labeled with fluorochrome (1:400 dilution in blocking buffer) was added and incubated at RT for 60 min. After incubation time, $1 \mathrm{ml}$ blocking buffer was added to each well and incubated for $3 \mathrm{~min}$ and this step repeated again and finally the wells were washed with 500 $\mu 1$ PBS buffer. The primary antibodies used here are the same listed in table 2.8 chapter 2.2.6. To prepare the slide for fluorescence or confocal microscopy, one drop of Fluoromount-G (Southern Biotech) was added to slide and the cover-slip invertly transferred on slide. For this purpose the slide must be covered with this buffer cover with no air bubbles and after drying the slides, they were used for imaging by confocal laser scanning microscopy (Carl Zeiss, Jena).

\subsubsection{MTT assay}

\begin{tabular}{lc}
\hline Stock solution for MTT $(\mathbf{5} \mathbf{m g} / \mathbf{m l})$ & Volume \\
\hline Thiazolyl Blue Tetrazolium Bromid & $100 \mathrm{mg}$ \\
PBS & $20 \mathrm{ml}$ \\
\hline (and then filtrated and aliqouted and stored in $\left.1-2 \mathrm{ml} \mathrm{at}-20^{\circ} \mathrm{C}\right)$ &
\end{tabular}

\begin{tabular}{lc}
\hline Lysis buffer & Volume \\
\hline Sodiumdodecylsulfate (SDS) & $20 \mathrm{~g}$ \\
$\mathrm{HCl} 1 \mathrm{M}$ & $2 \mathrm{ml}$ \\
$\mathrm{ddH}_{2} \mathrm{O}$ & $98 \mathrm{ml}$ \\
\hline
\end{tabular}

This colorimetric assay is used for measuring the activity of enzymes that reduce the yellow MTT (3-(4,5-Dimethylthiazol-2-yl)-2,5-diphenyltetrazolium bromide) to formazan, giving a purple colour. It is used to determine cell cytotoxicity on application of different substances, which would disrupt metabolic functions. Since the reduction of 
MTT to formazan takes places only by active reductase enzymes, the test is a measure of active and viable (living) cells.

The 6-well plates were pre-coated with poly-D-lysine for 15 min and $8 \times 10^{5}$ cells per well were grown in $1 \mathrm{~mL}$ DMEM medium supplemented with $10 \%$ fetal bovine serum (FBS, Gibco/Invitrogen) and 1\% penicillin/streptomycin antibiotics. After 24 hours 50$70 \%$ confluency was reached.

The experiment was started by adding $1 \mathrm{~mL}$ of F12 medium (Gibco, Invitrogen) with/without desired concentration of the test substrate $(100 \mu \mathrm{M}$ irinotecan $)$ to each well and the cells were incubated for $15 \mathrm{~min}$ at $37^{\circ} \mathrm{C}$. Following this incubation, cells were washed and incubated in $1 \mathrm{~mL}$ of the F12 medium overnight. On the next morning, the medium was removed and cell viability was determined by adding $1 \mathrm{ml}$ MTT (750 $\mu \mathrm{g} / \mathrm{ml}$ ) to each well and incubated for 2 hours at $37^{\circ} \mathrm{C}$. The cells were lysed by $1 \mathrm{~mL}$ of lysis buffer and the plates were covered by foil and placed on shaker incubator for overnight. After that purple formazan crystals were diluted in acidified isopropanol (96\% isopropanol $+4 \% 1 \mathrm{~N} \mathrm{HCl}$ ) and the absorbance was measured at $570 \mathrm{~nm}$.

\subsubsection{Measurments of OCT1 activity}

\subsubsection{1 $\mathrm{ASP}^{+}$uptake assay}

The method described here is used to quantify the activity of organic cation transporter OCT1 using the model substrate $\mathrm{ASP}^{+}$(4-(4-(dimethylamino) styryl)-Nmethylpyridinium. $\mathrm{ASP}^{+}$is a fluorescent organic cationic mitochondrial dye that possesses strong fluorescence after uptake into the cells (excitation $475 \mathrm{~nm}$ and emission $605 \mathrm{~nm}$ ), but has negligible fluorescence in the extracellular medium.

The stock solution of $\mathrm{ASP}^{+}$(50mM, Invitrogen) in Dimethylformamid (DMFA) was prepared and stored it in the fridge. The cells were cultured in DMEM medium supplemented with $10 \%$ FBS, penicillin $(100 \mathrm{U} / \mathrm{ml})$, streptomycin $(100 \mu \mathrm{g} / \mathrm{ml})$ and Hygromycine B $(100 \mu \mathrm{g} / \mathrm{ml})$. The $\mathrm{ASP}^{+}$uptake experiments were performed using Hank's buffered salt solution medium (HBSS, Invitrogen). HBSS was supplemented with varying concentrations of $\mathrm{ASP}^{+}: 0,1,5,10,20,50,100,200$ and $400 \mu \mathrm{M}$.

The $\mathrm{ASP}^{+}$uptake assay was performed as follows: 800000 cells per well were plated in a 12 well plate pre-coated with $1 \mathrm{ml}$ poly-D-lysine and incubated for $48 \mathrm{~h}$ to reach full confluence. On the day of measurement, the cells were washed two times with $1 \mathrm{ml}$ prewarmed HBSS medium. Uptake measurements were performed at room temperature. 
The uptake measurement was started by adding $0.5 \mathrm{ml}$ pre-warmed HBSS medium containing $\mathrm{ASP}^{+}$. The uptake was stopped after $3 \mathrm{~min}$ by adding $2 \mathrm{ml}$ ice-cold HBSS . The medium was discarded and the cells were lysed in $0.5 \mathrm{ml}$ RIPA buffer (see section 2.2.3.1). Duplicates $200 \mu 1$ each of the cell lysates were transferred into a black 96-wells plate with a transparent bottom (Nunce, Wiesbaden) for fluorescence measurement. The amount of intracellular $\mathrm{ASP}^{+}$was determined using plate photometer (TECANUltra, TECAN, Crailsheim, Germany) with excitation and emission wavelengths of 485 and $612 \mathrm{~nm}$ respectively. The rest of the cell lysates were transferred to another Eppendorf reaction tubes to measure the protein concentration for each sample for further data normalization (See section 2.2.3.1).

Alternatively, the $\mathrm{ASP}^{+}$uptake was evaluated using fluorescence microscopy. For this purpose, the uptake experiment was carried out as described above. The uptake was stopped after 3 min by adding $2 \mathrm{ml}$ ice-cold HBSS, the medium was discarded and $1 \mathrm{ml}$ ice-cold HBSS was added. The $\mathrm{ASP}^{+}$uptake was visualized using fluorescence microscopy (Carl Zeiss, Jena).

In experiments performed to measure the functional activity of OCT1 at different $\mathrm{pH}$ an HBSS medium with different $\mathrm{pH}(5.4,6,6.4,7,7.4,8,8.4$ and 9) containing $1 \mu \mathrm{M}$ $\mathrm{ASP}^{+}$was used. The $\mathrm{pH}$ adjustment was performed using $\mathrm{NaH}_{2} \mathrm{PO}_{4}(1 \mathrm{M})$ and $\mathrm{Na}_{2} \mathrm{HPO}_{4}$ $(1 \mathrm{M})$.

\subsubsection{Inhibition of $\mathrm{ASP}^{+}$uptake assay}

For this assay, the cells were plated in 12 well plates according to the method described in the previous section. After reaching full confluence, the cells were washed twice with $1 \mathrm{ml}$ pre-warmed HBSS medium and then $0.5 \mathrm{ml}$ warm $\left(37^{\circ} \mathrm{C}\right)$ HBSS medium containing $1 \mu \mathrm{M} \mathrm{ASP}^{+}$and varying concentrations $(0,1,10,50,100,500,1000$ and $5000 \mu \mathrm{M})$ of the respective inhibitory substance was added. The uptake was stopped after 3 min by adding $2 \mathrm{ml}$ ice-cold HBSS to each well. The medium was discarded, the cells were lysed and intracellular $\mathrm{ASP}^{+}$and total protein were quantified as described in the previous chapter.

Graphical representations and regression analyses were performed using Sigma Plot1 version 11.0 (Systat Software Inc., Chicago, IL, USA). The half-maximal inhibitory concentration (IC50) was calculated by regression analyses of the equation: 


$$
\mathbf{Y}(\mathrm{C})=\mathrm{Y}_{\min }+\left(\mathrm{Y}_{\max }-\mathrm{Y}_{\min }\right) / 1+\left(\mathrm{C} / \mathrm{IC}_{\mathbf{5 0}}\right)^{-\mathrm{H}}
$$

where $\mathrm{C}$ is the drug concentration, $\mathrm{Y}(\mathrm{C})$ is the $\mathrm{ASP}^{+}$or $\mathrm{MPP}^{+}$uptake as inhibitor at a drug concentration of $\mathrm{C}, \mathrm{Y}_{\min }$ and $\mathrm{Y}_{\max }$ are the maximal and minimal $\mathrm{ASP}^{+}$or $\mathrm{MPP}^{+}$ uptakes, respectively, and $\mathrm{H}$ is the Hill slope.

\subsubsection{Direct measurements of drug uptake}

\begin{tabular}{lc}
\hline Lysis buffer & Volume \\
\hline Acetonitril & $80 \mathrm{ml}$ \\
Sodium acetate buffer (pH 5.0) (0.05 mol/l) & $20 \mathrm{ml}$ \\
\hline
\end{tabular}

\begin{tabular}{lc}
\hline Runing buffer & Volume \\
\hline Acetonitril & $20 \mathrm{ml}$ \\
Sodium acetate buffer (pH 5.0) & $80 \mathrm{ml}$ \\
$(0.05 \mathrm{~mol} / \mathrm{l})$ & \\
\hline
\end{tabular}

The measurement of the direct uptake of substances by cells was performed as described elsewhere (SAADATMAND et al.; TZVETKOV et al.). Briefly, the $100 \mathrm{~mm}$ plates (BD Falcon, Heidelberg, Germany) were coated with $2 \mathrm{ml}$ poly-D-lysine (P0296, Sigma-Aldrich) and incubate for 15-30 min in the $\mathrm{CO}_{2}$ incubator. The poly-D-lysine was recollected and the plates were kept open lid under the sterile bench to dry. Then $4 \times 10^{6}$ cells were plated and incubated for 48 hours at $37^{\circ} \mathrm{C}$ to reach full confluence. On the day of the measurements, the cells were washed with $10 \mathrm{ml}$ pre-warmed HBSS (pH 7.4). The experiment was started by adding $5 \mathrm{ml}$ pre-warmed HBSS medium ( $\mathrm{pH} 7.4$ ) supplemented with the analyzed drug at concentration of $1 \mu \mathrm{M}$. The cells were incubated for $1 \mathrm{~min}$ and the reaction was stopped with $20 \mathrm{ml}$ ice cold HBSS (pH 7.4). The cells were rapidly washed twice with the ice cold HBSS, resuspended in $2 \mathrm{ml}$ ice cold HBSS ( $\mathrm{pH} 7.4$ ) and transferred in $2 \mathrm{ml}$ Eppendorf reaction tube and immediately placed on ice. An aliquot of $500 \mu 1$ of the cell suspension was transferred to another tube and was used to measure the protein concentration needed for normalization. That remaining cells 
were pelleted by centrifugation $\left(3000 \mathrm{rpm}, 10 \mathrm{~min}, 4^{\circ} \mathrm{C}\right)$ and supernatant was discarded. The cells were lysed by adding $1 \mathrm{ml}$ lysis buffer and $10 \mu 1$ of $10 \mu \mathrm{g} / \mathrm{ml}$ internal standard was added. All drugs used and the corresponding internal standards are listed in table 2.7. The sample was centrifugated $\left(13000 \mathrm{rpm}, 10 \mathrm{~min}, 4^{\circ} \mathrm{C}\right)$ to remove the cell debris. The supernatant was transferred to the glass tube, evaporated by incubating at $37^{\circ} \mathrm{C}$ under a nitrogen stream for $60 \mathrm{~min}$. The residue was reconstituted in $200 \mu 1$ running buffer and mixed by vortexing. Then $100 \mu \mathrm{l}$ of the solution was transferred to HPLC tube immediately prior to analysis and thereof $50 \mu \mathrm{l}$ aliquots were injected on the column. The protocols for drug quantification by HPLC are described in chapter 2.2.11.

Table 2.9. Drugs measured by HPLC in this study

\begin{tabular}{ll}
\hline Drug & Internal standard \\
\hline Tropisetron & Ondansetron \\
Ondansetron & Tropisetron \\
Tramadol & O-desmethyl-tramadol \\
O-desmethyltramadol & Tramadol \\
Debrisoquine & Venlafaxin \\
\hline
\end{tabular}

For measuring the concentration dependence of the drug uptake, the cells were incubated for 1 min with $5 \mathrm{ml}$ pre-warmed HBSS medium $(\mathrm{pH}$ 7.4) containing increasing concentrations of substances. The concentrations varied from 1 to $40 \mu \mathrm{M}$ for debrisoquine and from 0 to $200 \mu \mathrm{M}$ for $\mathrm{ASP}^{+}$. The $\mathrm{K}_{\mathrm{M}}$ and $\mathrm{V}_{\max }$ values were estimated by regression analyses based on the Michaelis-Menten equation using Sigma Plot software version 11.0 (Systat Software Inc., Chicago, IL, USA).

For measuring the time-dependence of drug uptake, the cells were incubated with $5 \mathrm{ml}$ pre-warmed HBSS medium ( $\mathrm{pH}$ 7.4) supplemented with $1 \mu \mathrm{M}$ of the analyzed drug for $30 \mathrm{sec}, 1 \mathrm{~min}, 5 \mathrm{~min}, 15 \mathrm{~min}$ or $30 \mathrm{~min}$.

Drug-drug interaction at the OCT1 transporter were measured as follows: the cells were exposed to $5 \mathrm{ml}$ pre-warmed HBSS medium ( $\mathrm{pH}$ 7.4) supplemented with $1 \mu \mathrm{M}$ of the analyzed drug in combination with increasing concentrations of inhibitors (from 100 to $200 \mu \mathrm{M}$ ) and incubated for $1 \mathrm{~min}$ and the experiment was followed as described previously in this chapter. 
To measure the activity of CYP2D6 enzyme using microsome, 500 $\mu \mathrm{g}$ of extracted microsome was treated with increasing concentration of debrisoquine $(1,10$ and 100 $\mu \mathrm{M})$. For this reason, a 96 well plate with black walls and clear bottom was used. Then $100 \mu 1$ of the enzyme/substrate mix (mixture of CYP2D6-containing microsome and varied concentration of debrisoquine) was added to each well and incubated for $5 \mathrm{~min}$ at $37^{\circ} \mathrm{C}$. The reaction was started by adding $100 \mu \mathrm{l}$ of the cofactor mix (a mixture delivering and assuring the regeneration of NADPH, see section 2.2.5.2) and incubated for $60 \mathrm{~min}$ at $37^{\circ} \mathrm{C}$. After this incubation time, the reaction was stopped by adding $75 \mu \mathrm{l}$ stop solution (see section 2.2.5.2) and the amount of 4-OH debrisoquine was measured using HPLC.

For measurement of drug-drug interaction at the OCT1 transporter and CYP2D6 enzyme, the cells were exposed to $5 \mathrm{ml}$ pre-warmed HBSS medium (pH 7.4) supplemented with $10 \mu \mathrm{M}$ of the debrisoquine in combination with increasing concentrations of paroxetine as a inhibitor for OCT1transporter or CYP2D6 enzyme (0, $0.1,0.2,0.5,1,5,10$ and $50 \mu \mathrm{M})$ and incubated for $3 \mathrm{~min}$ and the experiment was followed as described previously in this chapter.

\subsubsection{Measurements of CYP2D6 activity}

\subsubsection{Microsome Preparation}

\begin{tabular}{lc}
\hline Homogenization buffer (TES) & Volume \\
\hline Tris- $\mathrm{HCl}(\mathrm{pH} 7.4)$ & $20 \mathrm{mM}$ \\
Na-EDTA & $5 \mathrm{mM}$ \\
Sucrose & $254 \mathrm{mM}$ \\
Pefablock SC (Roche) & $0.2 \mathrm{mM}$ \\
\hline
\end{tabular}

\begin{tabular}{ll}
\hline $\begin{array}{l}\text { Microsome Buffer } \\
\text { (TES without inhibitor and EDTA) }\end{array}$ & Volume \\
\hline Tris-HCl (pH 7.4) & $20 \mathrm{mM}$ \\
Sucrose & $254 \mathrm{mM}$ \\
\hline
\end{tabular}


Human liver microsomes (HLM) are used widely to characterize the role of cytochrome P450s (P450) and other enzymes in drug metabolism. Typically, liver samples are homogenized and centrifuged at a lower force to form a crude pellet of cell debris, nuclei, peroxisomes, lysosomes, and mitochondria (premicrosomal pellet). The resulting supernatant is then centrifuged at a higher force to precipitate the microsomes. The microsomal pellet is resuspended in a final suspension buffer and is then ready for use in incubation studies (Nelson et al., 2001). In this study we modified the techniques which usually used to extract the microsome from the tissue in order to isolate microsome from mammalian cell lines like the CYP2D6 and POR overexpressing HEK cells.

$20 \times 10^{6}$ cells were cultured for 3 days in $75 \mathrm{~cm}^{2}$ culture flask. The medium of the culture flask was discarded; the cells were resuspended in $5 \mathrm{ml}$ of homogenization buffer and transfered to a Teflon-glass homogenizer $(15 \mathrm{ml}$ volume, Sartorius, Goettingen, Germany). The collected cells were homogenized with 5-10 strokes at 1000 rpm using Potter S homogenizer (Sartorius, Goettingen, Germany). Strokes were even and steady which lasted approximately $15 \mathrm{sec}$ for passage. The glass tube was submersed in a small bucket of ice and water during the homogenization. This cell lysis was confirmed analyzing a mixture of $20 \mu 1$ trypan blue and $20 \mu \mathrm{l}$ of homogenized cells. The majority of the cells (90\%) should be lysed and tryptan blue positive.

Then the samples were transferred to centrifugation tubes $(50 \mathrm{ml}$ falcon tubes $)$ and centrifugated (3000 g, $30 \mathrm{~min}$ at room temperature; Eppendorf 5810R). The supernatant was transferred into the $13 \mathrm{ml}$ screw cap tubes and centrifuged at higher force $(17000 \mathrm{~g}$, $30 \mathrm{~min}$ at room temperature; JA20, $12000 \mathrm{rpm}$, in Beckman J2-21 M/E). Afterwards, the supernatant was transferred in centrifugation tube (Ti 50.2) and balanced by weighing and ultra-centrifugated $(100000 \mathrm{~g}, 60 \mathrm{~min}$ at room temperature; Ti 50.2, $29000 \mathrm{rpm}, \mathrm{r}_{\max }$ 107,9mm in Beckman L8-70 M-Ultracentrifuge). After that supernatant (representing cytosolic proteins) was transferred in a falcon tube and aliqouted in $2 \mathrm{ml}$ Eppendorf reaction tube and stored at $-80^{\circ} \mathrm{C}$ and. The pellet (containing the microsomes) was resuspended in $3 \mathrm{ml}$ microsome buffer, aliqouted in $70 \mu \mathrm{l}$ fractions and stored at $-20^{\circ} \mathrm{C}$ for measuring the protein concentration and functional assay. 


\subsubsection{AMMC assay}

\begin{tabular}{ll}
\hline AMMC (10mM) & Volume \\
\hline AMMC & $25 \mathrm{mg}$ \\
Acetonitrile & $5.8 \mathrm{ml}$ \\
\hline
\end{tabular}

aliquoted to $250 \mu \mathrm{l}$ in $1.5 \mathrm{ml}$ tubes and stored at $-20^{\circ} \mathrm{C}$.

\begin{tabular}{lc}
\hline Phosphate buffer (pH7.4) & Volume \\
\hline $\mathrm{NaH}_{2} \mathrm{PO}_{4}$ & $100 \mathrm{mM}$ \\
$\mathrm{Na}_{2} \mathrm{HPO}_{4}$ & $100 \mathrm{mM}$ \\
\hline
\end{tabular}

\begin{tabular}{ll}
\hline Stop solution & Volume \\
\hline Acetonitrile & $40 \mathrm{ml}$ \\
$0.5 \mathrm{M}$ Tris (base) & $10 \mathrm{ml}$ \\
\hline
\end{tabular}

\begin{tabular}{ll}
\hline 20x (1/20) cofactors solution & Volume \\
\hline Glucose 6-Phosphate (Sigma \#G7879) & $282 \mathrm{mg}$ \\
$\mathrm{MgCl}_{2}($ Sigma \#M8266) & $47.6 \mathrm{mg}$ \\
$\mathrm{NADP}^{+}$(Sigma \#N5755) & $3.72 \mathrm{mg}$ \\
$\mathrm{ddH}_{2} \mathrm{O}$ & $\mathrm{Up}$ to $5 \mathrm{ml}$ \\
\hline The solution was aliquoted at $200 \mu$ l and stored at $-20^{\circ} \mathrm{C}$. &
\end{tabular}

\begin{tabular}{ll}
\hline 100x G6PDH solution & Volume \\
\hline $\begin{array}{l}\text { Glucose 6-phosphate dehydrogenase } \\
\text { (G6PDH, Sigma \#g6378) }\end{array}$ & $30 \mathrm{U}$ \\
$5 \mathrm{mM}$ Na-Citrate & Up to $1 \mathrm{ml}$ \\
\hline
\end{tabular}

The solution was aliquoted at $100 \mu \mathrm{l}$ and stored at $-20^{\circ} \mathrm{C}$.

\begin{tabular}{ll}
\hline $\mathbf{2}$ ml 2X Cofactor Mix & Volume \\
\hline “1/20" the cofactor solution & $200 \mu \mathrm{l}$ \\
G6PDH solution & $40 \mu \mathrm{l}$ \\
Phosphate buffer $(\mathrm{pH} 7.4)$ & Up to $2 \mathrm{~mL}$ \\
\hline
\end{tabular}

This mix was incubated at $37^{\circ} \mathrm{C}$ in a water bath.

\begin{tabular}{ll}
\hline $\mathbf{2} \mathbf{~ m l} 2 X$ Enzyme/Substrate Mix & Volume \\
\hline Microsome protein & $0.8 \mathrm{mg}$ \\
$1 / 100$ diluted AMMC stock solution & $10 \mu \mathrm{l}$ \\
$0.1 \mathrm{M}$ Phosphate buffer $(\mathrm{pH} 7.4)$ & $\mathrm{Up}$ to $2 \mathrm{ml}$ \\
\hline (pre-warmed to $37^{\circ} \mathrm{C}$ in a water bath) &
\end{tabular}

(pre-warmed to $37^{\circ} \mathrm{C}$ in a water bath) 
The activity of CYP2D6 enzyme in produced microsomes was measured using an AMMC probe (3-[2-(N,N-diethyl-N-methylammonium)- ethyl]-7- ethoxy-4methylcoumarin; Gentest, BD Biosciences). If active CYP2D6 is present, the nonflurescent AMMC probe will be transformed into its fluorescent metabolite AMHC (3-[2-N,N-diethyl-Nmethylammonium) ethyl]-7-hydroxy-4-methylcoumarin). The produced AMMC fluorescence was measured photometricaly and used to quantify the CYP2D6 activity.

In this procedure, a 96 well plate with black walls and clear bottom was used. Then 100 $\mu 1$ of the enzyme/substrate mix (mixture of CYP2D6-containing microsome and AMMC substrate) was added to each well and incubated for 5 min at $37^{\circ} \mathrm{C}$.

The reaction was started by adding $100 \mu 1$ of the cofactor mix (a mixture delivering and assuring the regeneration of NADPH) and incubated for $30 \mathrm{~min}$ at $37^{\circ} \mathrm{C}$. After this incubation time, the reaction was stopped by adding $75 \mu 1$ stop solution. The amount of fluorescent $\mathrm{AMHC}$ as a subsequent metabolite was measured at excitation $340 \mathrm{~nm}$ and emission $465 \mathrm{~nm}$ wavelengths using 96 wells plate readers (TECAN-ULTRA, Männedorf, Switzerland).

\subsubsection{High-Performance Liquid Chromatography (HPLC)}

High-Performance Liquid Chromatography (HPLC) is a chromatographic technique used to separate single components of a complex mixture with the purpose of identifying, quantifying and purifying the individual components of the mixture. HPLC uses high pressure to force eluent through a chromatographic column density packed with micron-size particles. The high number of small size particle used leads to more precise separations. The principle of HPLC is that the solvent competes with the solute for the available adsorption sites on the stationary phase. Elution with a single solvent or a constant solvent mixture is called isocratic elution. If one solvent does not discriminate adequately between the components of a mixture or if the solvent does not provide sufficiently rapid elution of all components, the gradient elution can be used. In this case with increasing acetonitrile fraction in a water-acetonitrile mixture, solutes which were initially strongly retained by stationary phase (silica column) are eluted. 


\subsubsection{Quantification of intracellular tramadol and O-desmethyl- tramadol by HPLC}

\section{Stock solutions for Tramadol and O-Desmethyl-Tramadol:}

\section{1) Tramadol (C16H25NO2, MW $263.4 \mathrm{~g} / \mathrm{mol}$ )}

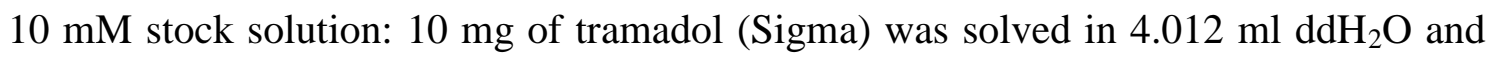
thereof $1 \mathrm{ml}$ aliquots were prepared and stored at $-20^{\circ} \mathrm{C}$.

$1 \mathrm{mg} / \mathrm{ml}(3.7 \mathrm{mM}): 379 \mu \mathrm{l}$ of $10 \mathrm{mM}$ tramadol was mixed with $621 \mu \mathrm{ldd} \mathrm{H}_{2} \mathrm{O}$ and stored at $4^{\circ} \mathrm{C}$.

$4 \mathrm{ng} / \mu \mathrm{l}: 1 \mathrm{mg} / \mathrm{ml}$ solution was diluted (1:10) with $\mathrm{ddH}_{2} \mathrm{O}$ to get $100 \mathrm{ng} / \mu \mathrm{l}$. Then $40 \mu \mathrm{l}$ of

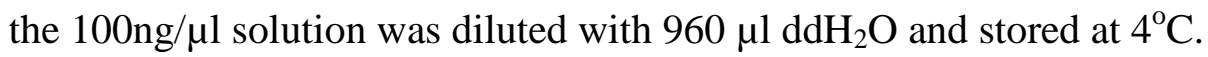

$0.4 \mathrm{ng} / \mu \mathrm{l}: 4 \mathrm{ng} / \mu \mathrm{l}$ solution was diluted (1:10) with $\mathrm{ddH}_{2} \mathrm{O}$ to prepare $1 \mathrm{ml}$ solution

$0.04 \mathrm{ng} / \mu \mathrm{l}: 0.4 \mathrm{ng} / \mu \mathrm{l}$ solution was diluted (1:10) with $\mathrm{ddH}_{2} \mathrm{O}$ to prepare $1 \mathrm{ml}$ solution

$1 \mathrm{ng} / \mu \mathrm{l}: 1 \mathrm{mg} / \mathrm{ml}$ solution was diluted (1:10) with $\mathrm{ddH}_{2} \mathrm{O}$ to get $100 \mathrm{ng} / \mu \mathrm{l}$. Then $10 \mu \mathrm{l}$ of

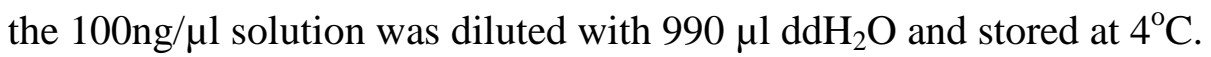

Standard test 100ng Tramadol with 25ng O-desmethyl-tramadol as internal standard: $100 \mu \mathrm{l}$ of $4 \mathrm{ng} / \mu \mathrm{l}$ tramadol stock solution was mixed with $100 \mu \mathrm{l}$ of $1 \mathrm{ng} / \mu \mathrm{l}$ O-desmethyltramadol stock solution (see below) and $50 \mu 1$ from this solution was injected by HPLC apparatus.

Standard test 10ng Tramadol with 25ng O-desmethyl-tramadol as internal standard: $100 \mu \mathrm{l}$ of $0.4 \mathrm{ng} / \mu \mathrm{l}$ tramadol stock solution was mixed with $100 \mu \mathrm{l}$ of $1 \mathrm{ng} / \mu \mathrm{l} \mathrm{O}$ desmethyl-tramadol stock solution (see below) and 50 $\mathrm{\mu l}$ from this solution was injected by HPLC apparatus.

Standard test 1 ng Tramadol with $25 \mathrm{ng}$ O-desmethyl-tramadol as internal standard: $100 \mu \mathrm{l}$ of $0.04 \mathrm{ng} / \mu \mathrm{l}$ tramadol stock solution was mixed with $100 \mu \mathrm{l}$ of $1 \mathrm{ng} / \mu \mathrm{l}$ O- 
desmethyl-tramadol stock solution (see below) and 50 $\mu$ l from this solution was injected by HPLC apparatus.

\section{2) O-Desmethyl-Tramadol (C15H23NO2, MW $249.349 \mathrm{~g} / \mathrm{mol})$}

$5 \mathrm{mM}$ stock solution: $5 \mathrm{mg}$ of O-desmethyl-tramadol (Sigma) was solved in $4.012 \mathrm{ml}$ $\mathrm{ddH}_{2} \mathrm{O} .1 \mathrm{ml}$ aliquots were prepared and stored at $-20^{\circ} \mathrm{C}$.

$1 \mathrm{mg} / \mathrm{ml}(4 \mathrm{mM}): 802 \mu \mathrm{l}$ of $5 \mathrm{mM}$ O-desmethyl-tramadol was mixed with $198 \mu 1 \mathrm{ddH}_{2} \mathrm{O}$ and stored at $4^{\circ} \mathrm{C}$.

$4 \mathrm{ng} / \mu \mathrm{l}: 1 \mathrm{mg} / \mathrm{ml}$ solution was diluted (1:10) with $\mathrm{ddH}_{2} \mathrm{O}$ to get $100 \mathrm{ng} / \mu \mathrm{l}$. Then $40 \mu \mathrm{l}$ of

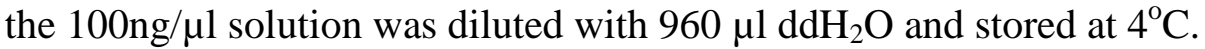

$0.4 \mathrm{ng} / \mu \mathrm{l}: 4 \mathrm{ng} / \mu \mathrm{l}$ solution was diluted (1:10) with $\mathrm{ddH}_{2} \mathrm{O}$ to prepare $1 \mathrm{ml}$ solution and then was stored at $4^{\circ} \mathrm{C}$.

$0.04 \mathrm{ng} / \mu \mathrm{l}: 0.4 \mathrm{ng} / \mu \mathrm{l}$ solution was diluted $(1: 10)$ with $\mathrm{ddH}_{2} \mathrm{O}$ to prepare $1 \mathrm{ml}$ solution and stored at $4^{\circ} \mathrm{C}$.

$1 \mathrm{ng} / \mu \mathrm{l}: 1 \mathrm{mg} / \mathrm{ml}$ solution was diluted (1:10) with $\mathrm{ddH}_{2} \mathrm{O}$ to get $100 \mathrm{ng} / \mu \mathrm{l}$. Then $10 \mu \mathrm{l}$ of

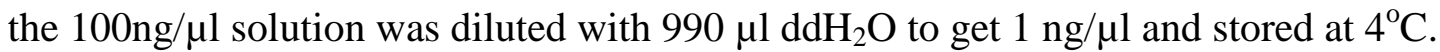

Standard test 100ng O-desmethyl-tramadol with 25ng tramadol as internal standard: $100 \mu \mathrm{l}$ of $4 \mathrm{ng} / \mu \mathrm{l}$ O-desmethyl-tramadol stock solution was mixed with $100 \mu \mathrm{l}$ of $1 \mathrm{ng} / \mu \mathrm{l}$ tramadol stock solution and $50 \mu 1$ from this solution was injected by HPLC apparatus.

Standard test 10ng O-desmethyl-tramadol with $25 \mathrm{ng}$ tramadol as internal standard: $100 \mu 1$ of $0.4 \mathrm{ng} / \mu 1$ O-desmethyl-tramadol stock solution was mixed with $100 \mu 1$ of $1 \mathrm{ng} / \mu 1$ tramadol stock solution and 50 $\mu 1$ from this solution was injected by HPLC apparatus.

Standard test 1 ng O-desmethyl-tramadol with $25 \mathrm{ng}$ tramadol as internal standard: 
$100 \mu \mathrm{l}$ of $0.04 \mathrm{ng} / \mu \mathrm{l}$ O-desmethyl-tramadol stock solution was mixed with $100 \mu \mathrm{l}$ of $1 \mathrm{ng} / \mu \mathrm{l}$ tramadol stock solution and $50 \mu \mathrm{l}$ from this solution was injected by HPLC apparatus.

\begin{tabular}{ll}
\hline Reagents & Manufacturer \\
\hline Methanol & Merck, Germany \\
Acetonitrile & Merck, Germany \\
\hline & \\
\hline Buffer A (pH 5.7) & Volume \\
\hline $\mathrm{NaH}_{2} \mathrm{PO}_{4} * \mathrm{H}_{2} \mathrm{O}(50 \mathrm{mM})$ & $6.9 \mathrm{~g}$ \\
$\mathrm{Na}_{2} \mathrm{HPO}_{4} * 2 \mathrm{H}_{2} \mathrm{O} \quad(2.5 \mathrm{mM})$ & $0.45 \mathrm{~g}$ \\
$\mathrm{H}_{2} \mathrm{O}$ & $1 \mathrm{~L}$ \\
\hline
\end{tabular}

\begin{tabular}{ll}
\hline Buffer B & Volume \\
\hline Acetonitrile & $50 \%(\mathrm{v} / \mathrm{v})$ \\
Buffer A & $50 \%(\mathrm{v} / \mathrm{v})$ \\
\hline Buffer A and B were degassed with vacuum water jet pomp before running
\end{tabular}

The concentrations of tramadol and O-desmethyl-tramadol were analyzed by HPLC using a LaChrom system (Merck Hitachi, Darmstadt, Germany) consisting of an interface (D-7000,Merck Hitachi), a pump (L-7100, Merck Hitachi), an automatic sampler (L-7200, Merck Hitachi), a Fluorescence detector (L-7485, Merck Hitachi) and a degasser (L-7614,Merck Hitachi). Separation was carried out on a LiChrospher 100 RP$18 \mathrm{e}(5 \mu \mathrm{m}, 4 \times 150 \mathrm{~mm})$ column with a LiChrospher100CN guard column $(5 \mu \mathrm{m}$, both from Merck). The peaks were detected by fluorescence monitoring with excitation and emission wavelengths of $230 \mathrm{~nm}$ and $296 \mathrm{~nm}$, respectively. Gradient elution was performed with an initial mobile phase of $77 \%(\mathrm{v})$ buffer A and 23\% (v) buffer B and then the concentration of acetonitrile was increased to reach to 5\% (v) buffer A and 95\% (v) buffer B during 13 min and after that declined to the initial concentration (77\% (v) buffer A and $23 \%$ (v) buffer B) at a flow-rate of $1.5 \mathrm{ml} / \mathrm{min}$ at room temperature. The peaks of tramadol and O-desmethyl-tramadol were detected with retention times of $3.8 \mathrm{~min}$ and $10.8 \mathrm{~min}$, respectively, and were quantified using peak area with external 
standardization. The amount of intracellular tramadol and O-desmethyl-tramadol indicated as area under curve (AUC) was normalized to the total amount of protein measured by BCA assay (section 2.2.3.1).

\subsubsection{Quantification of intracellular debrisoquine and 4-hydroxy debrisoquine by HPLC}

The concentrations of debrisoquine were analysed by HPLC using a LaChrom system (Merck Hitachi, Darmstadt, Germany) consisting of an interface (D-7000,Merck Hitachi), a pump (L-7485, Merck Hitachi), an automatic sampler (L-7200, Merck Hitachi), a fluorescence detector (L-7400, Merck Hitachi) and a degasser (L-7614,Merck Hitachi). Separation was carried out on a LiChrospher $100 \mathrm{CN}(5 \mu \mathrm{m}, 4 \times 150 \mathrm{~mm})$ column with a LiChrospher $4-4,100 \mathrm{CN}$ guard column (5 $\mu \mathrm{m}$, both from Merck). The peaks were detected by fluorescence monitoring with excitation and emission wavelengths of 210 $\mathrm{nm}$ and $290 \mathrm{~nm}$, respectively according to the previous report (Cerqueira et al., 2000). Isocratic elution was performed with a mobile phase of 5\% (v) acetonitrile and $95 \%(\mathrm{v})$ $0.05 \mathrm{~mol} / \mathrm{l}$ sodium acetate buffer $(\mathrm{pH} 5.0)$ at a flow-rate of $0.7 \mathrm{ml} / \mathrm{min}$ at room temperature. Venlafaxine was used as internal standard, and the peaks of debrisoquine and venlafaxine were detected with retention times of $9 \mathrm{~min}$ and $16 \mathrm{~min}$, respectively, and were quantified using peak area with external standardization. The amount of intracellular debrisoquine indicated as AUC was normalized to the total amount of protein measured by BCA assay (See section 2.2.3.1).

Individual stock solutions of debrisoquine and venlafaxine as internal standard (IS) were prepared at concentrations of $100 \mu \mathrm{g} \mathrm{ml}^{-1}$ in water. The procedure for preparation of standard solutions was similar to those described for Tramadol and O-desmethyl tramadol (see section 2.2.11.1). To do this, aliquots of the stock solutions of debrisoquine were diluted with mobile phase to prepare a series of standard solutions containing 4 , 0.4 and $0.04 \mu \mathrm{g} \mathrm{ml}^{-1}$ of the drug. The initial stock solution of the internal standard (venlafaxine) was diluted with mobile phase to yield a $1 \mu \mathrm{g} \mathrm{ml}^{-1}$ and then aliquots of the standard solutions and internal solution were mixed together in same volume and then $50 \mu 1$ of these final solution was injected in column. 


\subsubsection{Quantification of intracellular tropisetron and ondansetron by HPLC}

Tropisetron and ondansetron quantifications were performed using a modification of a previously described HPLC method (BAUER et al. 2002). Briefly, tropisetron and ondansetron were quantified using a LaChrom HPLC system (Merck Hitachi, Darmstadt, Germany) consisting of an interface (D-7000, Merck Hitachi), a pump (L-7100, Merck Hitachi), an automatic sampler (L-7200, Merck Hitachi), an ultraviolet detector (L-7400, Merck Hitachi) and a degasser (L-7614, Merck Hitachi). The compounds were separated at room temperature on a LiChrospher 100 reverse phase-18e $(5 \mathrm{~mm}$, 4_150mm) column with a LiChrospher 100CN guard column ( $5 \mathrm{~mm}$, both from Merck) and quantified by ultraviolet detection at $284 \mathrm{~nm}$ for tropisetron and $305 \mathrm{~nm}$ for ondansetron. The mobile phase consisted of $20 \%$ acetonitrile and $80 \% 0.05 \mathrm{M}$ sodium acetate buffer ( $\mathrm{pH}$ 5.0) and was delivered at a flow rate of $1.5 \mathrm{ml} \mathrm{min}{ }^{-1}$. Tropisetron and ondansetron were detected as peaks with retention time of 5.7 and $4.3 \mathrm{~min}$, respectively, and quantified using peak area with external standardization. The amount of intracellular tropisetron and ondansetron indicated as AUC was normalized to the total amount of protein measured by BCA assay (See section 2.2.3.1).

The procedure for preparation of standard solutions was like those described for tramadol and O-desmethyl tramadol (see section 2.2.11.1).

\subsubsection{PAMPA assay}

Parallel Artificial Membrane Permeability Assay (PAMPA) is a useful screening tool for carrier-independent membrane permeability and has become a very useful tool for predicting in vivo drug permeability and is well-suited as a ranking tool for the assessment of compounds with passive transport mechanisms. In this work PAMPAs were performed using precoated PAMPA 96-well plates in accordance with the manufacturer's instructions (BD Biosciences, Heidelberg, Germany). Prior to use, the pre-coated PAMPA plate system should be warmed to room temperature for at least 30 minutes. While the plate system is warming, the compound solutions were prepared by diluting stock solutions into a buffer (PBS). Then $300 \mu \mathrm{l}$ of phosphate-buffered saline (PBS, pH 7.4) containing increasing concentrations of the drug $(0,1,10,50$ and 100 $\mu \mathrm{M}$ ) were pipetted into the donor wells and $200 \mu \mathrm{l}$ of PBS ( $\mathrm{pH} 7.4$ ) into the acceptor wells. The acceptor plate was then coupled with the donor plate and the resulting plate 
assembly was incubated at room temperature without agitation for 5 hours. During the incubation, compounds in the donor solution permeate through the artificial membrane into the acceptor solution. At the end of the incubation, the plates were separated and $150 \mu \mathrm{L}$ solution from each well were used to measure the final concentrations of compounds in both donor wells and acceptor wells by means of HPLC (see section 2.2.11). Membrane permeability $\left(\mathrm{P}_{\mathrm{e}}\right)$ was calculated using the following equation:

$$
\mathrm{P}_{\mathrm{e}}=-\ln [1-C \mathrm{~A} \times(V \mathrm{D}+V \mathrm{~A}) /(C \mathrm{D} \times V \mathrm{D}+C \mathrm{~A} \times V \mathrm{~A})] /[A \times(1 / V \mathrm{D}+1 / V \mathrm{~A}) \times t],
$$

Where $\mathrm{CD}$ and $\mathrm{CA}$ are the end concentrations in the donor and the acceptor wells, respectively. VD and VA are the volumes of the liquids in the donor and the acceptor wells, respectively. A is the membrane surface area, and $\mathrm{t}$ is the incubation time. VD, $\mathrm{VA}, \mathrm{A}$, and t were constant in all experiments, with values of $0.3 \mathrm{ml}, 0.2 \mathrm{ml}, 0.3 \mathrm{~cm}^{2}$, and $18,000 \mathrm{~s}$, respectively.

\subsubsection{Statistical analyses}

Statistical analyses were performed using PASW Statistics, version 18.0 (SPSS, Chicago, IL). $P$ values $<0.05$ were considered statistically significant.

Statistical analyses were performed using SPSS1 Statistics version 19 (SPSS Inc., IBM, Chicago, USA). Analyses of variance (ANOVA) were applied for multi-group comparisons. If two groups among the multiple groups were compared this was done using ANOVA followed by post hoc analyses applying Tukey's Honestly Significant Difference (HSD) test. P-values $<0.05$ were regarded as significant. 


\section{Results}

\subsection{Generation of OCT1 and CYP2D6 expression plasmid constructs}

\subsubsection{Generation of the pcDNA5.1::OCT1 plasmid}

In order to generate pcDNA5.1::OCT1 plasmid, an OCT1 expression plasmid pcDNA3::OCT1 (kindly supplied by Herman Koepsell and Valentin Gorboulev, University of Wuerzburg, Germany) was used. For this purpose, the wild-type OCT1 was re-cloned into the expression vector pcDNA5.1 plasmid according to following procedure. Both pcDNA3::OCT1 and pcDNA 5.1 plasmids were cut with HindIII and $E c o R V$ restriction enzymes (Fermentas, St. Leon-Roth). After running on the $1 \%$ agarose gel electrophoresis and purified from the gel, the OCT1 fragment was ligated into the linearized pcDNA 5.1 plasmid using Ligate-IT ${ }^{T M}$ Rapid Ligation Kit (USB, Staufen) and then ligation mixture was used to transform in E.coli strain top ten. The resulting construct pcDNA5.1:OCT1 carries the OCT1wild-type (Fig.3.1).

In this study also five variant cDNA clones of OCT1 that represent the five loss-offunction amino acid substitutions in OCT1 were constructed by site-directed mutagenesis (see section 2.2.1.8). The five substitutions are most common genetic polymorphisms in Caucasians. The substitutions were introduced either as a single amino acid substitutions, i.e. Arg61Cys (rs12208357), Gly401Ser (rs34130495), and a single deletion of Met420 (rs72552763), or combination of two substitutions as they were observed in the Caucasians, i.e. Met420 deletion with Cys88Arg (rs55918055) and Met420 deletion with Gly465Arg (rs34130495). 

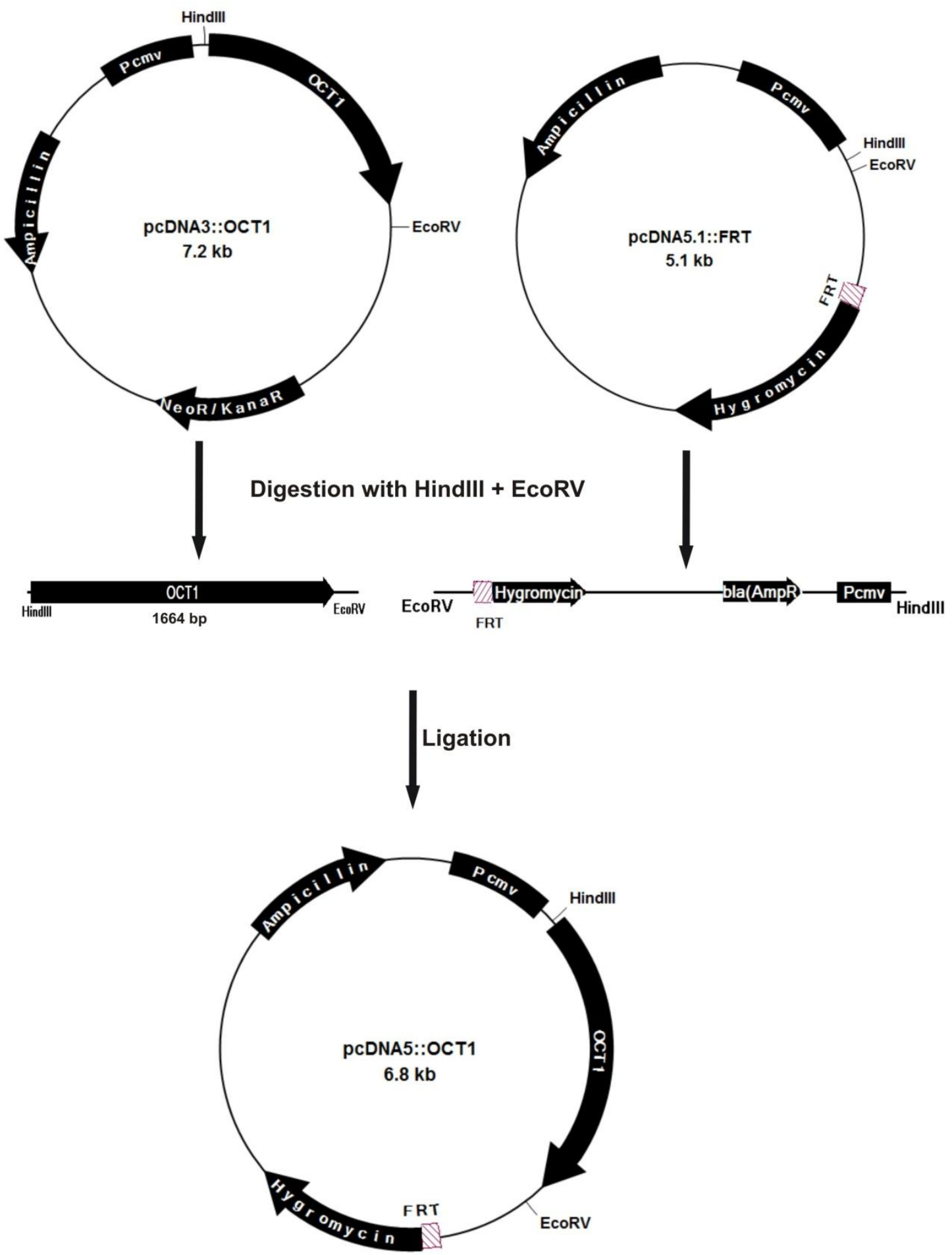

Fig.3. 1 Scheme of cloning of OCT1 into the expression vector pcDNA5.1. The pcDNA3 containing OCT1 fragment was cut out with HindIII and EcoRV and the OCT1-containing fragment was cloned in the pcDNA5.1 plasmid opened with the same restriction enzymes. 


\subsubsection{Generation of the pcDNA5.1::CYP2D6::IRES::POR construct}

Cytochrome P450 reductase (POR) is a helper enzyme essential for CYP activity. Therefor to generate cells actively expressing CYP2D6 both CYP2D6 and POR genes should be overexpressed. In this work we used a bicistronic CYP2D6-POR construct to overexpress simultaneously both genes.

To assure both cytochrome P450 isoform CYP2D6 and cytochrome P450 reductase (POR) sufficient protein expression, an internal ribosome entry site (IRES) fragment originated from encephalomyocarditis virus (EMCV) was introduced upstream of POR gene according to DNA assembling procedure described in chapter 2.2.1.10. The IRES::POR fragment was generated using pIRES (Invitrogen, Karlsruhe) and the pCMV-SPORT6 (Invitrogen, Karlsruhe) that contain the complete open reading frame of the human POR. Then POR gene and IRES fragment were amplified by PCR using primers which designed to have homologous for both POR and IRES (Table.3.1). More precisely the reverse primer of the IRES fragment shared a $30 \mathrm{bp}$ homology fragment with the forward primer of the POR gene (underlined in table 3.1). This caused POR to tag in the downstream of IRES fragment (Fig.3.2).

Table 3. 1 The lists of primers used for amplification of IRES and POR. (appropriate restriction sites are shown in italic)

\begin{tabular}{|c|c|}
\hline Amino acid variant & Primer sequence \\
\hline IRES_NotI_f & 5'-GAATTCT $\boldsymbol{G} \boldsymbol{C} \boldsymbol{G} \boldsymbol{C} \boldsymbol{C} \boldsymbol{C} \boldsymbol{C G A C G G T A C C G C G G G C C C G G G A T C - 3 '}$ \\
\hline IRES_r & 5'-TCCCATGTTGATCATATTATCATCGTCTTTTTCAAAGG-3' \\
\hline POR_f & 5'-AAACACGATGATAATATGATCAACATGGGAGACTCCCACGT-3' \\
\hline POR_XhoI_r & 5'-GGGGCAGGCTCGAGGCCCCTAGCTCCACACGTCCAG-3' \\
\hline
\end{tabular}



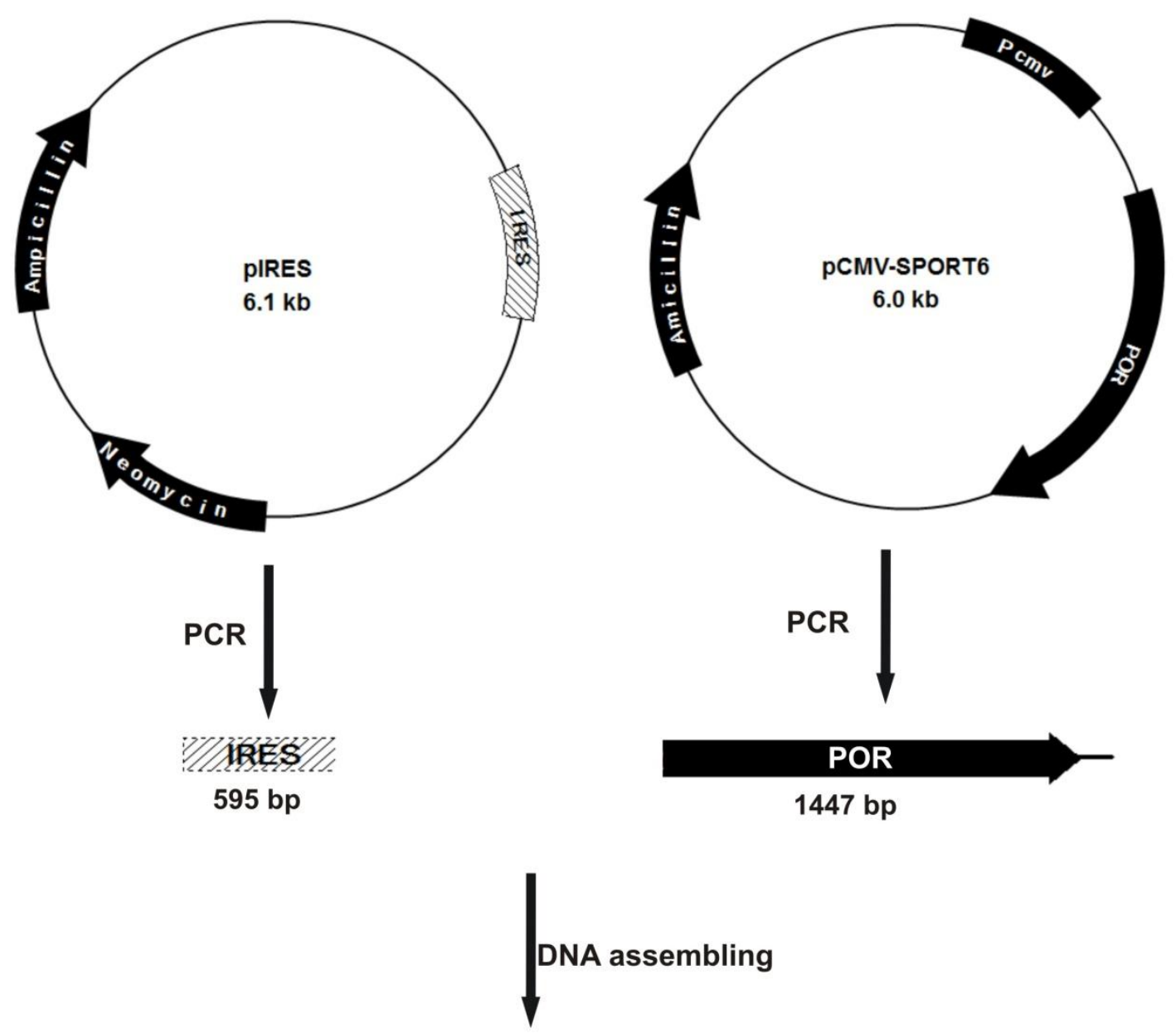

\section{Primer with Notll}

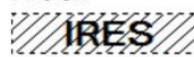

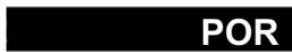

Primer with Xhol

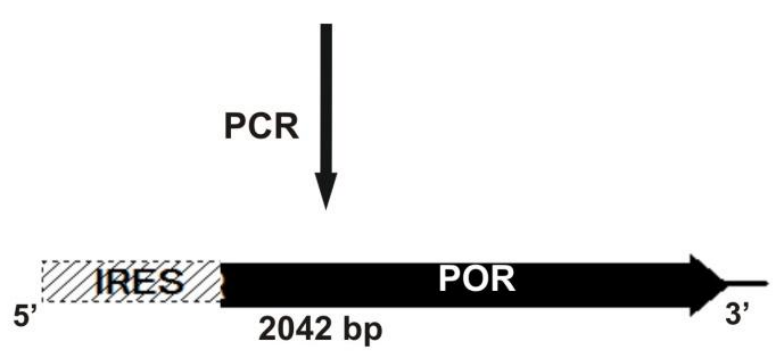

Fig.3. 2 Scheme of assembling of POR with IRES fragment. POR complementary DNA was tagged to the downstream of IRES fragment according to DNA assembling method. For this reason, pIRES plasmid containing IRES and pCMV-SPORT6 plasmid containing POR were used as templates in amplification by PCR. Then two amplified products fused to each other and then the whole fragment was amplified by PCR using a pair of primers involved restriction sites for NotI and XhoI. 
Then the assembled product IRES::POR was amplified with a pair of primer, IRES_NotI_f and POR_XhoI_r, designed to carry appropriate restriction sites (NotI and XhoI) in each flank (Fermentas, St. Leon-Roth). Afterwards this product was cut with the two restriction enzymes $N o t I$ and $X h o I$ and inserted to the pcDNA5.1 plasmid which was linearized with the same restriction enzymes.

The plasmid pcDNA5.1::CYP2D6::IRES::POR was obtained from Nadia Ayyad. This construct was made by tagging CYP2D6 gene in the upstream of IRES::POR fragment. The CYP2D6 fragment was amplified from the pCR-XL-TOPO plasmid with the forward primer CYP2D6_NheI_f and the reverse primer CYP2D6_NotI_r (Table 3.2) and cut with NheI and NotI and cloned into the pcDNA5.1::IRES::POR plasmid which was linearized with the same enzymes (Fig.3.3).

Table 3. 2 Primers used to amplify CYP2D6 contain appropriate restriction sites (shown in italic)

\begin{tabular}{lc}
\hline Primer & Sequence \\
\hline CYP2D6_NheI_f & 5'-TAGTGGCTAGCAGGTATGGGGCTAGCAAGCACTGGT-3' \\
CYP2D6_NotI_r & 5'-TGGGGACGCGGCCGCATTCTAGCGGGGCACAGCACAA-3' \\
\hline
\end{tabular}




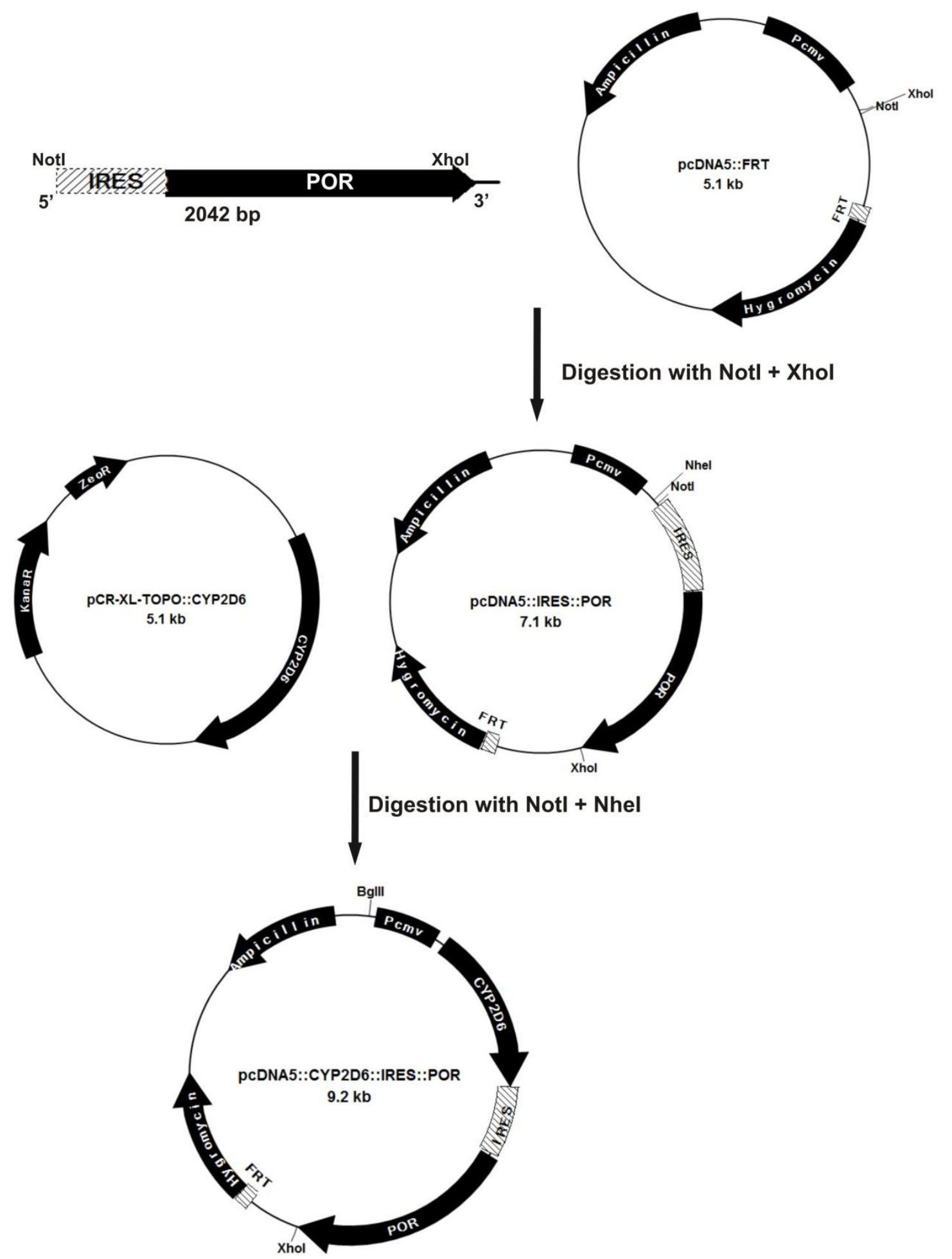

Fig.3. 3 Scheme of assembling of CYP2D6 with IRES::POR. CYP2D6 complementary DNA was tagged to the upstream of IRES::POR fragment in the pcDNA5.1 plasmid. For this reason, CYP2D6 was amplified and inserted in the upstream of IRES::POR using NheI and NotI.

The plasmid pcDNA 5.1 puro was obtained after replacement of the hygromycin resistance gene and the FRT locus by puromycine resistant one. The puromycine resistance cassette was obtained from pSilencer plasmid (Invitrogen, Karlsruhe) by PCR 
amplification using the primers listed in table 3.3. The PCR product was cut with the artificially introduced NaeI sites and cloned into the pcDNA5.1 plasmid open with the same restriction sites.

Table 3. 3 Primers used to amplify purpmycine resistance region contain appropriate restriction sites (shown in italic)

\begin{tabular}{lc}
\hline Primer & Sequence \\
\hline Puro_casete_f & 5'-GAAAGTCGCCGGCTCCCCAGCAGGCAGAAGTATGC-3' \\
Puro_casete_r & 5'-ATAAAAGCCGGCGTATCACGAGATTGCAGTGAAAA-3' \\
\hline
\end{tabular}

The CYP2D6::IRES::POR cassette is then recloned from the pcDNA5.1 into the pcDNA5.1puro plasmid using the BglII and XhoI restriction sites (Fig.3.4). 

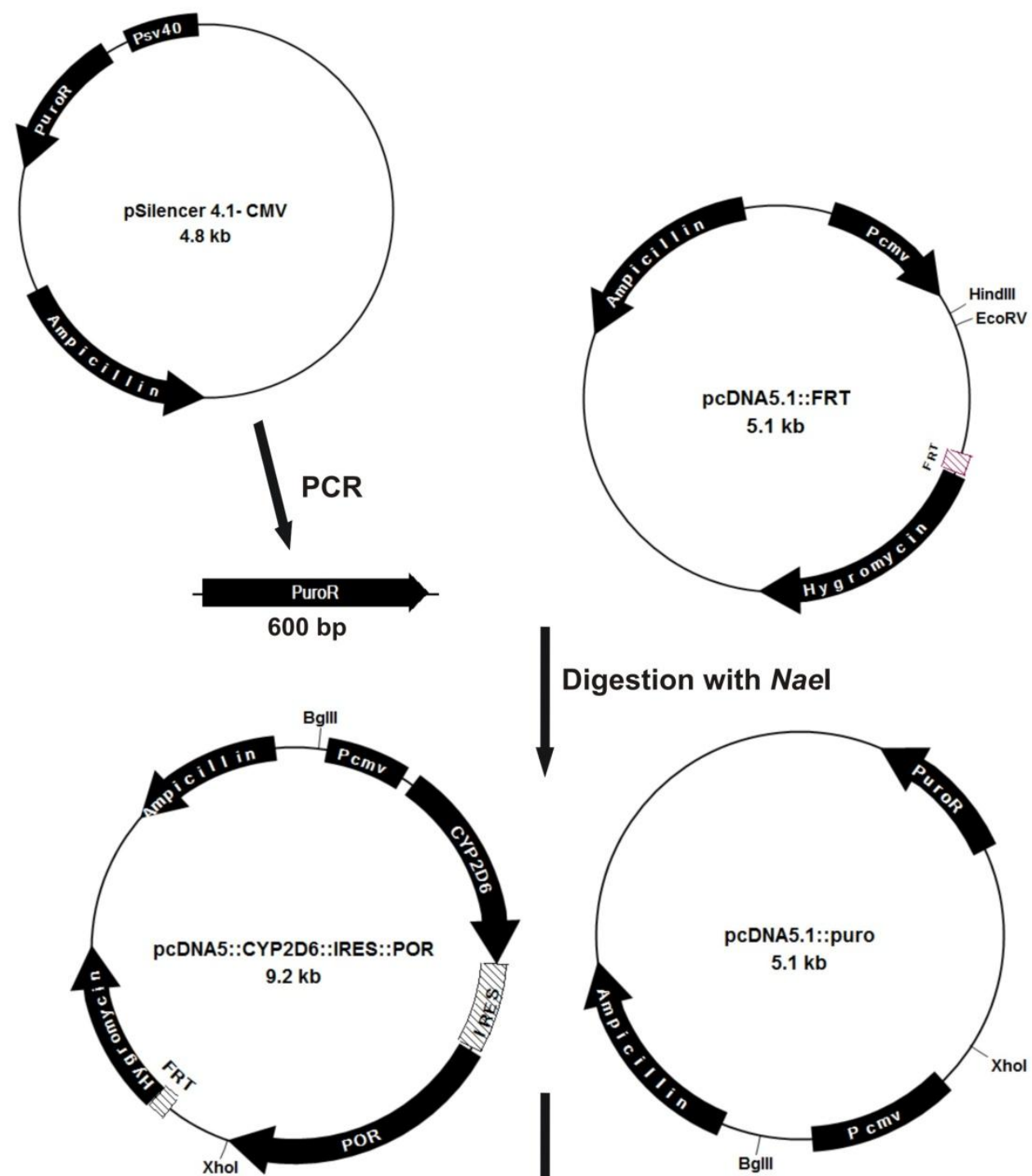

Digestion with Nael

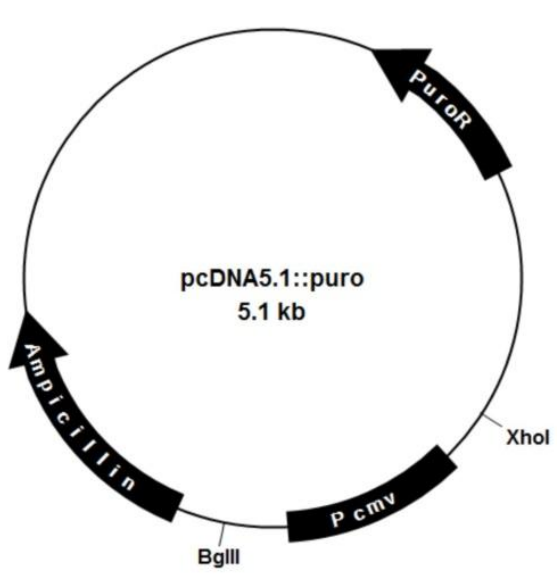

Digestion with Bg/lI + Xhol

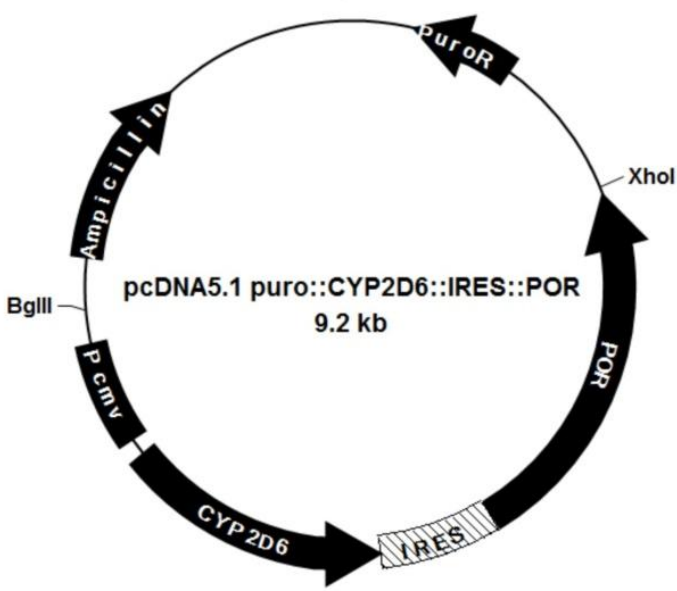

Fig.3. 4 Scheme for the generation of pcDNA5.1puro vector and recloning the CYP2D6::IRES::POR from pcDNA5.1 into pcDNA5.1puro vector. The pcDNA5.1 plasmid containing whole fragment of CYP2D6::IRES::POR was digested with XhoI and BglII. The manipulated pcDNA5.1::puro also opened with the same restriction enzyme and then whole 
fragment of CYP2D6::IRES::POR ligated to make the final construct pcDNA5puro::CYP2D6::IRES::POR.

\subsection{Generation and characterization of the transgenic cells models}

\subsubsection{Generation and characterization of OCT1 overexpressing cell lines}

\subsubsection{Generation of stably transfected HEK293 cell lines overexpressing OCT1}

To generate cells overexpressing OCT1 and its polymorphic naturally occurring variants, pcDNA5.1::OCT1 wild- type and variant constructs were stably transfected to HEK293 T-Rex cells using the Flp-In system. (section 2.2.5.4.2), and screened using DMEM medium containing 10\% FBS serum, 1\% Penicillin/Streptomycin and 300 $\mu \mathrm{g} / \mathrm{ml}$ concentrations of hygromycin B. After 10-14 days single colonies of cells resistant to hygromycine B were selected and transferred and grown in 12-well and later in 6-well plates in DMEM medium supplemented with reduced concentration of hygromycine $\mathrm{B}$ to $100 \mathrm{mg} / \mathrm{ml}$. Then successful genomic integration of the pcDNA5.1::OCT1 constructs was confirmed by integration-specific PCR (see section 2.2.1.9)

Correct plasmid integration was confirmed by PCR and resequencing. Overexpression of the wild type and variant OCT1 genes was confirmed on RNA, protein and activity levels as will be illustrated in the following chapters in more detail.

\subsubsection{Confirming the chromosomal integration of the OCT1 con- structs in the genome of HEK293-TRex cells}

Successful genomic integration was confirmed by integration-specific PCR. For this reason, two PCR reactions were performed. The first PCR amplified the region contains the downstream part of $\mathrm{P}_{\mathrm{sv} 40}$ promotor and the upstream part of the Hygromycin resistance region. A PCR signal of 614 bp length was observed confirming the correct integration of the pcDNA5 constructs (Fig.3.5). 
A second PCR was performed to confirm the correct sequence of the chromosomally integrated gene of interest (in this case OCT1). The second PCR amplified the region between the downstream part of $\mathrm{P}_{\mathrm{CMV}}$ promoter and the upstream part of lacZ-Zeocin resistance region which contains OCT1 complementary DNA and the length of this amplified fragment is $2532 \mathrm{bp}$.

And then the correctness of the obtained OCT1 wild type and variants was validated by sequencing using the primers mentioned in section 2.2.1.11.

A)

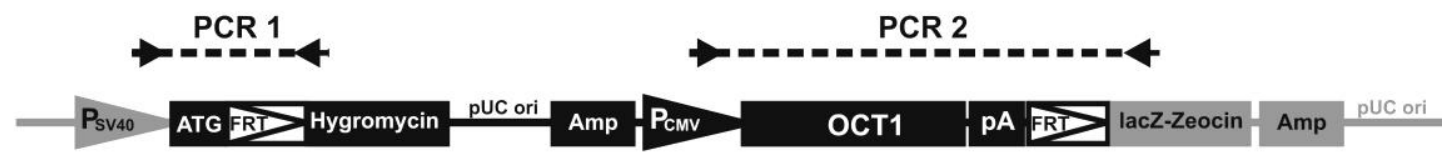

B) $\quad$ PCR 1

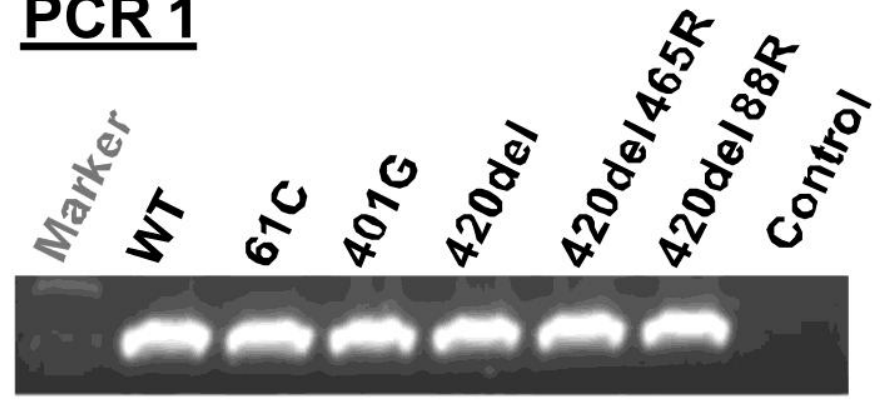

C) $\quad$ PCR 2

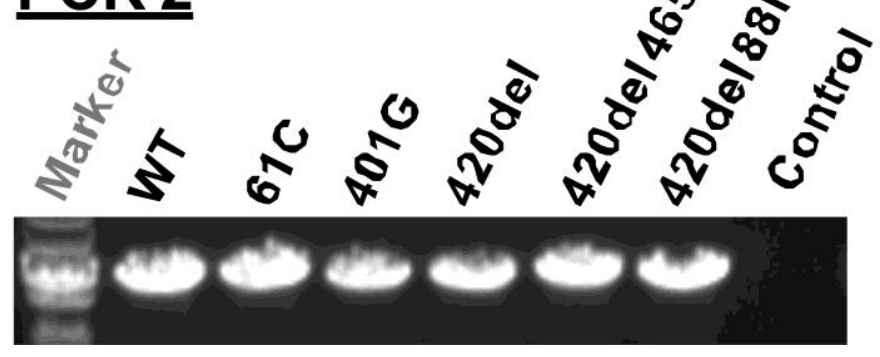

Fig.3. 5 Integration-specific PCRs confirming the correct integration of the plasmid constructs in the genome of OCT1 overexpressing HEK cells. A) Two regions of the genome of HEK cells which amplified by PCR1 and PCR2. B) a 614 bp fragment was amplified for 
hygromycin resistance region in OCT1 overexpressing HEK cells of wild type and SNPs in compare to control HEK TRex cells that did not have this integrated fragment in the genome. C) A $2532 \mathrm{bp}$ fragment was amplified for the region contains gene of interest in OCT1 overexpressing HEK cells of wild type and SNPs in compare to control HEK TRex untransfected cells. This PCR product was used for full length sequencing of OCT1 complementary DNA in wild type and SNPs samples.

\subsubsection{Confirming OCT1 overexpression by qRT-PCR}

OCT1 overexpression was first confirmed using quantitative reverse transcription PCR (qRT-PCR). The results obtained by real-time reverse transcriptase-PCR indicate the clones stably transfected with the wild-type or the loss-of-function OCT1 variants showed 15-fold higher OCT1 mRNA expression compared with the control clone carrying genomic integration of the pcDNA5.1 vector alone. No significant differences were detected in the OCT1 mRNA expression between the wild-type and the loss-offunction variants (Fig.3.6).

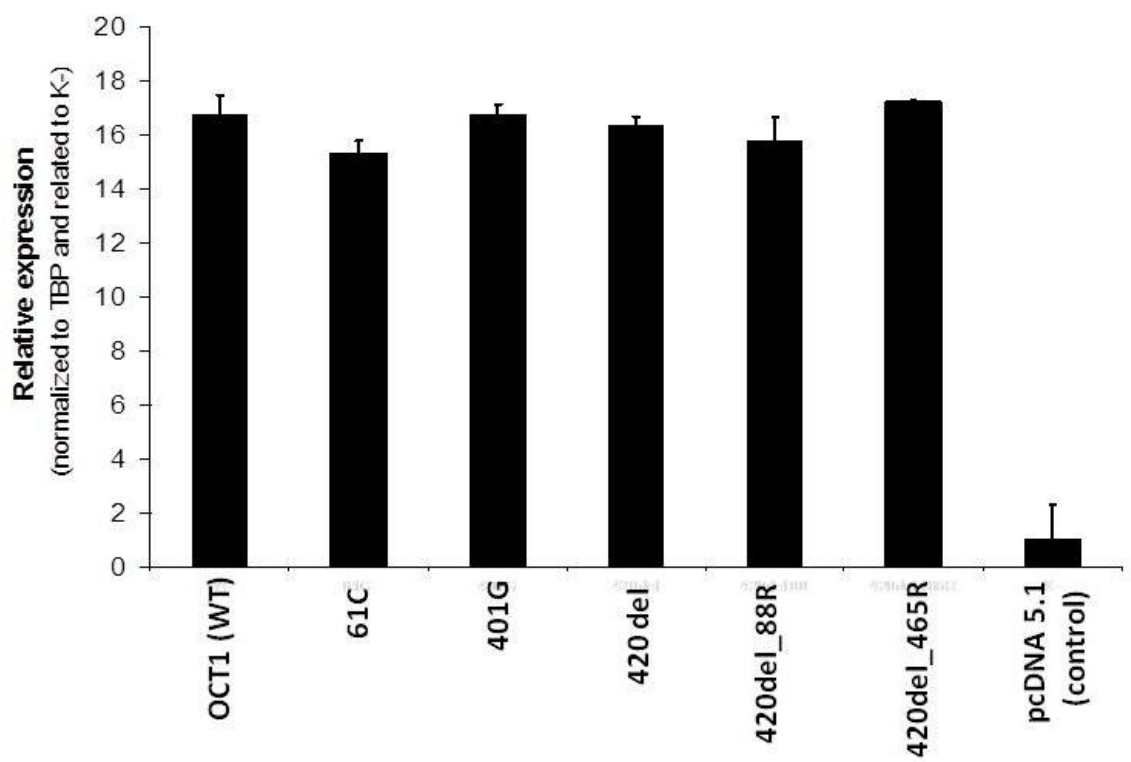

Fig.3. 6 Expression rate of OCT1 in the stably transfected HEK cells. The graphic shows mRNA levels of HEK cells overexpressing OCT1 wild type and five common variants in relation to the HEK cell containing pcDNA5 empty vector as control. The mRNA levels were normalized to the housekeeping gene TPB. Mean values and standard errors from three repetitions are shown. 


\subsubsection{Confirming OCT1 overexpression on protein level}

Following the confirmation of OCT1 mRNA overexpression, the OCT1 protein levels were analyzed. OCT1 protein overexpression was confirmed by means of western blot, FACS and immunocyto staining. Western blot analysis confirmed expression of OCT1 protein in the wild type and variants of the transfected cells. Using a monoclonal SLC22A1 antibody (2c5) (Novus Biologicals, Cambridge, UK), two protein signals with 75 and $60 \mathrm{kDa}$ weight were detected for all the samples containing wild type or polymorphisms of OCT1, but not in the control cells (Fig.3.7).

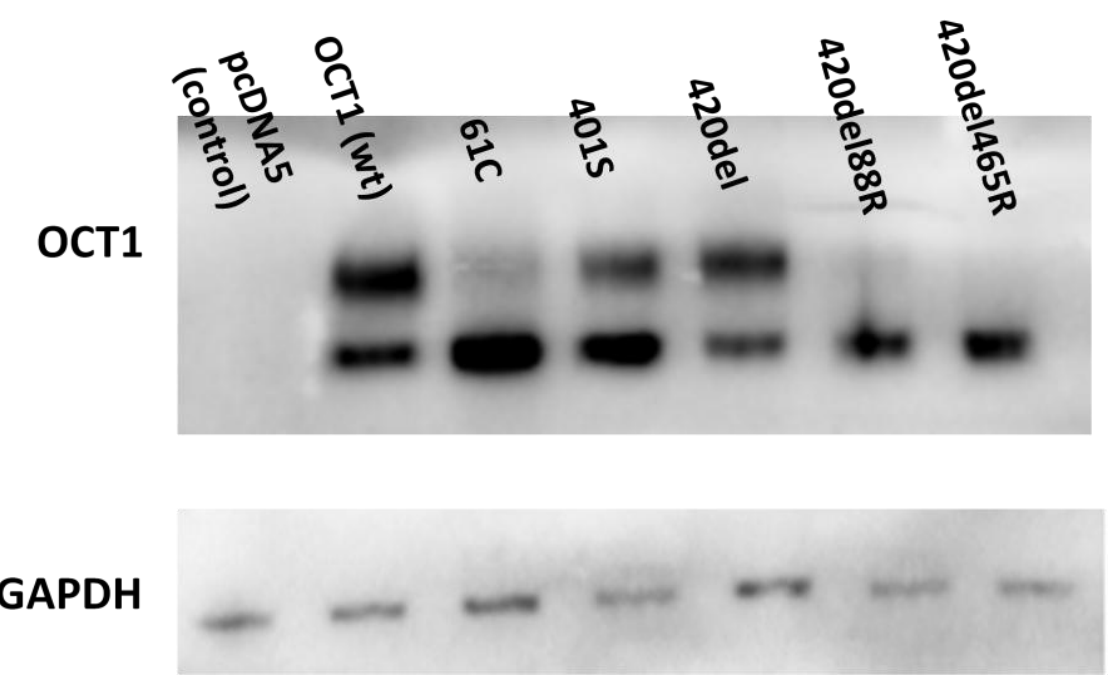

Fig.3. 7 Western blot for the OCT1 protein in the OCT1 overexpressing HEK cells. The OCT1 protein with 75 and $60 \mathrm{kDa}$ weights were detected for clones containing OCT1 wild type and variants. The housekeeping protein GAPDH was used to normalize the signal intensity of the samples. A mouse anti-(human) primary antibody SLC22A1 (2c5, Novus Biologicals, Cambridge, UK) was used for specific detection of the OCT1 protein and a GAPDH mouse monoclonal antibody (ZG003, Invitrogen) was used to detect GAPDH. The images were visualized by VersaDoc imaging system.

\subsubsection{Flow cytometry analysis for OCT1 overexpressing HEK cells}

Flow cytometry is a convenient tool for quantifying the OCT1 transporter in the cells. For this purpose, the OCT1 overexpressing HEK cells as well as the control cells transfected with pcDNA5 empty vector were fixed and permeabilized as described previously (section 2.2.6). The The $2.5 \times 10^{5}$ cells were stained by indirect 
immunofluorescence using primary antibody SLC22A1 (2c5, Novus Biologicals, Cambridge, UK) and flourochrome conjugated secondary antibody (Goat anti mouse Alexa 488, Invitrogen) and were analyzed by flow cytometry on a FACScan instrument BD LSR II (BD Bioscience) and the data were analyzed using BD FACSDiva software. Electronic gating of FSC (forward scatter) versus SSC (side scatter) was used to eliminate cellular fragments and debris from the population of cells to be analyzed for the presence of OCT1. The histogram showed that $97.9 \%$ of the HEK cells overexpressing OCT1 stained positively above the control HEK cells transfected with pcDNA5 vector (Fig. 3.8).

A)

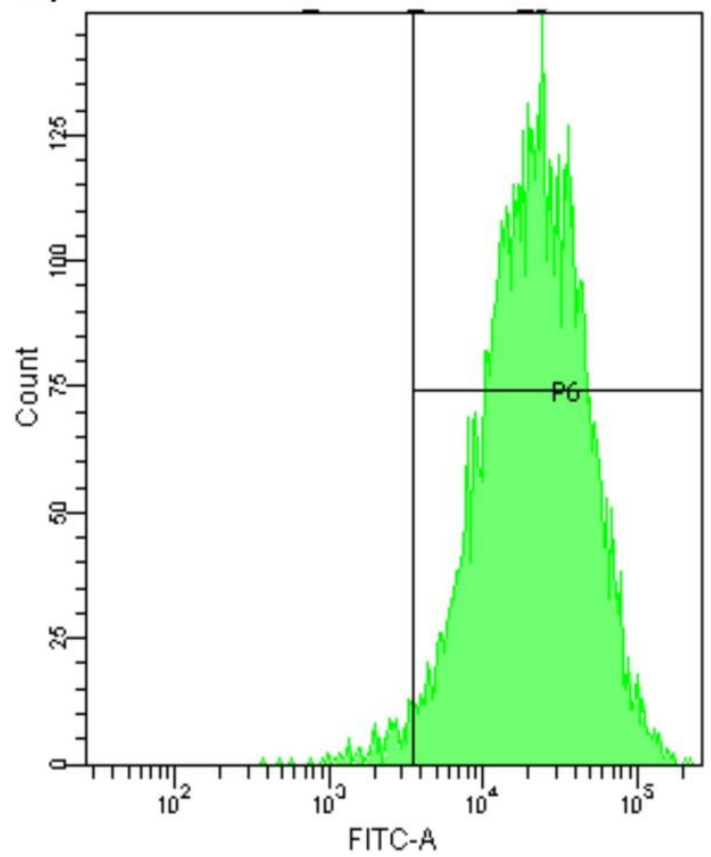

B)

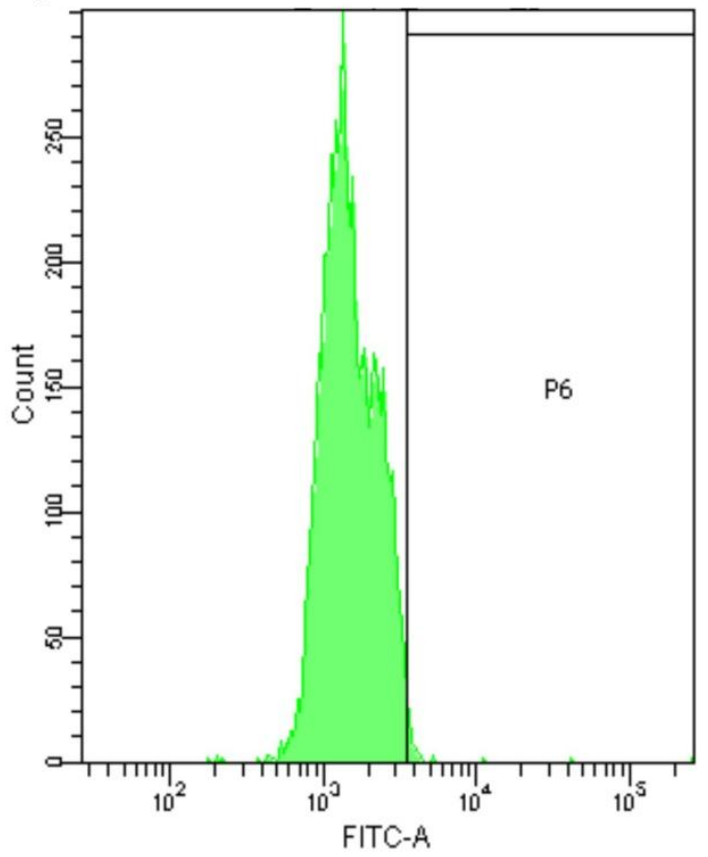

Fig.3. 8 Characterization of OCT1 expression protein in OCT1 overexpressing HEK cells (A) and HEK cells transfected with pcDNA empty vector (B) by flow cytometry. A) The results show maximum amount of the OCT1 overexpressing cells can bind to antibody conjugated to FITC and emit the fluorescence after threshold line (P6 region). B) The control HEK cells show no emitted fluorescence after threshold line which means no antibody bind to these cells.

\subsubsection{Immunocytochemical staining}

The OCT1 overexpressing HEK cells as well as the control cells transfected with pcDNA5 empty vector were fixed and permeabilized as described before (section 2.2.7). 
After reaching the cells to $80 \%$ confluency, the cells were stained by indirect immunofluorescence using primary antibody SLC22A1 (2c5, Novus Biologicals, Cambridge, UK) and flourochrome conjugated secondary antibody (Goat anti mouse Alexa 488, Invitrogen) and then visualized by confocal microscopy (Carl Zeiss, Jena). The results showed that the OCT1 protein localized in the cytoplasmic membrane of the HEK cells overexpressing OCT1 (Fig. 3.9).

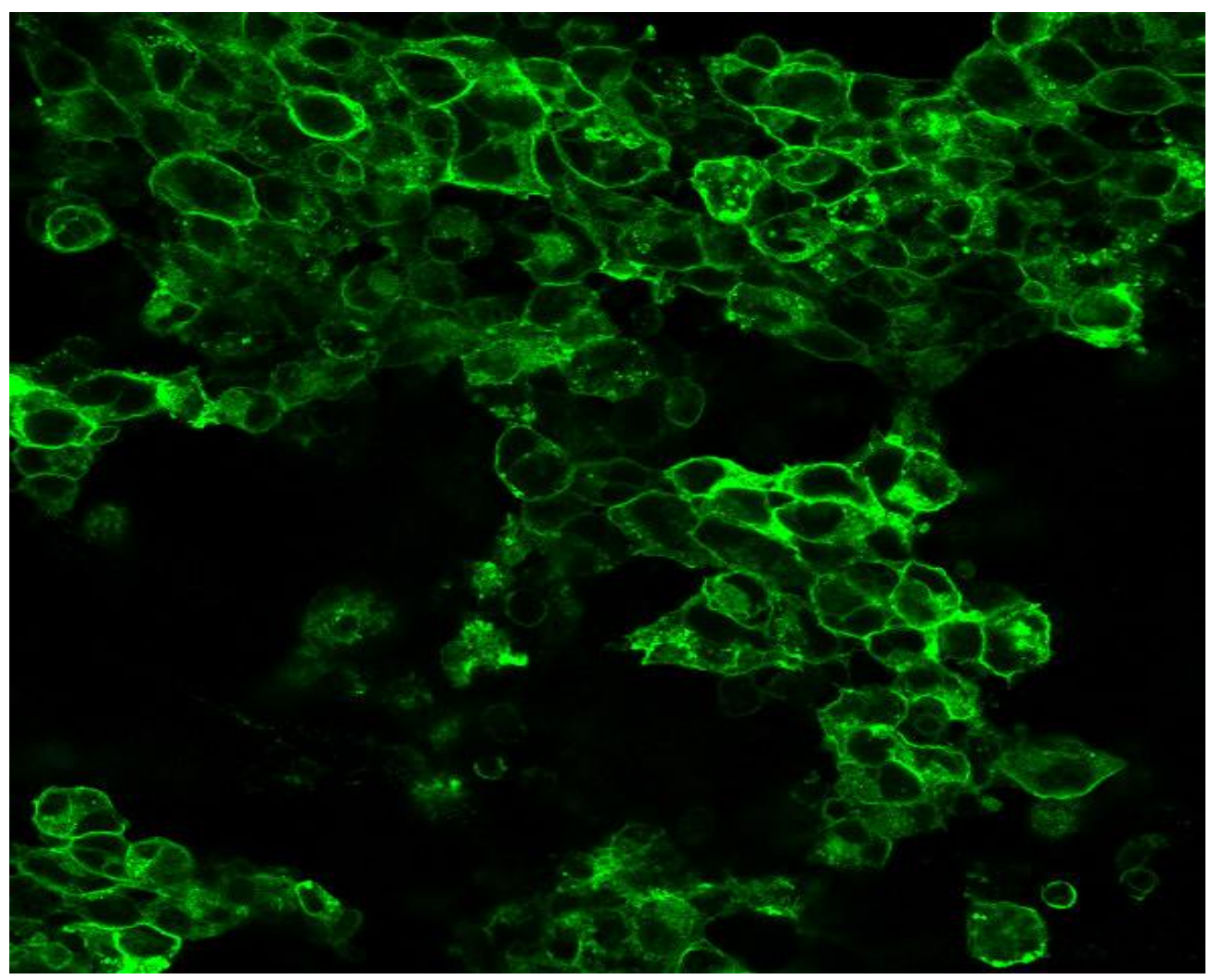

Fig.3. 9 Confocal image of the HEK cells overexpressing OCT1. The cells were treated with mouse anti-(human) primary antibody SLC22A1 (2c5, Novus Biologicals, Cambridge, UK) for OCT1 and visualized using goat anti-mouse conjugated to fluorochrome Alexa 488 secondary antibody (Invitrogen). The green particles depict localization of OCT1 protein mostly in the cytoplasmic membrane. 


\subsubsection{Confirming functional OCT1 overexpression by measuring OCT1 activity}

$\mathrm{ASP}^{+}$was used as a model substrate for hOCT1 to confirm functionally active expression of the OCT1 transporter. The overexpression of functional OCT1 was confirmed using both fluorescence microscopy and photometric concentration analysis. Using $\mathrm{ASP}^{+}$it was shown that wild type OCT1 can mediate the cellular uptake of $\mathrm{ASP}^{+}$. Furthermore as expected, despite similar OCT1 mRNA and protein levels, all loss of function polymorphisms exhibit reduced activity for $\mathrm{ASP}^{+}$uptake in comparison to wild type (Fig.3.10).

A)

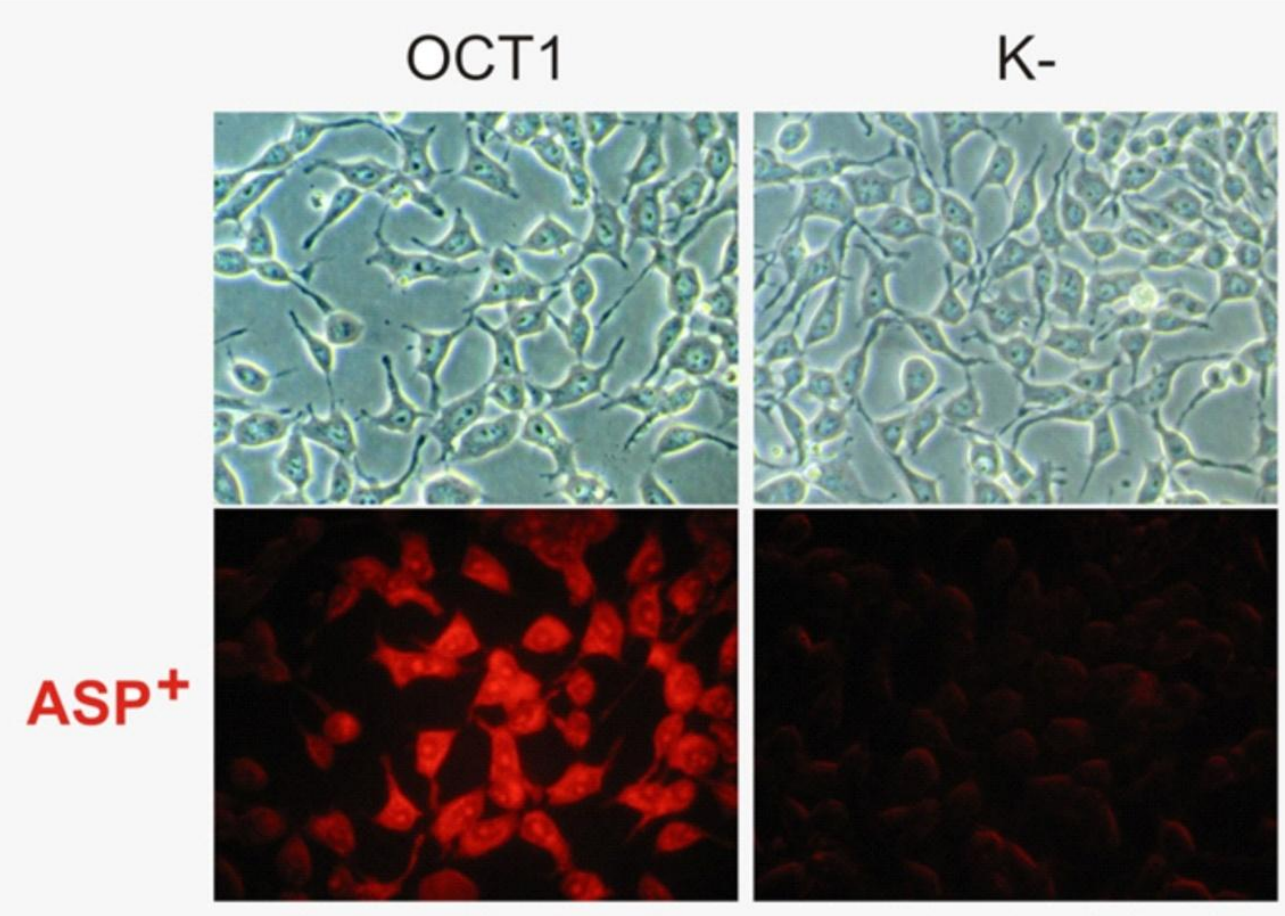

B)

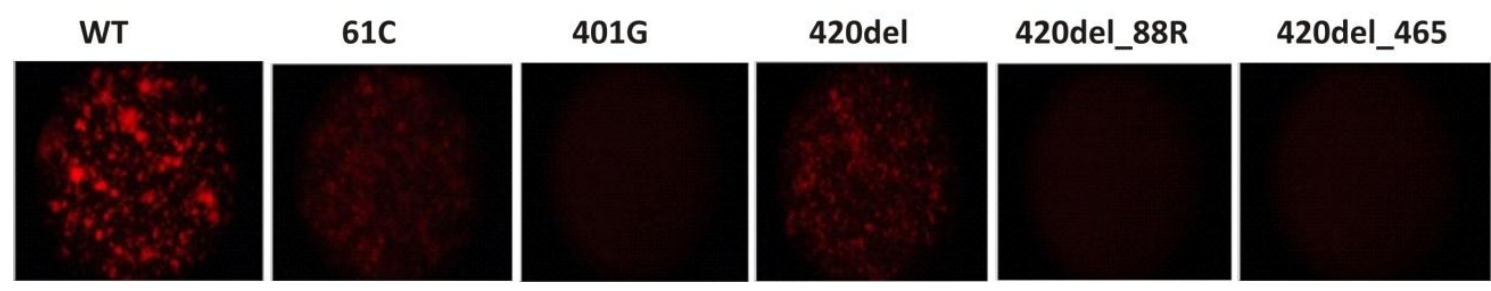

Fig.3. 10 OCT1 genetic variants are associated with different accumulation rates and responses to $\mathrm{ASP}^{+}$in stably transfected HEK293 cells. A) Phase contrast micrograph of HEK293 cells overexpressing wild type OCT1 and the empty vector (top) and the corresponding 
fluorescent micrograph B) Fluorescent micrographs competing the $\mathrm{ASP}^{+}$uptake between the HEK cells overexpressing wild type (WT) and five common variant of OCT1 visualized by fluorescence microscopy. The pictures show that the five OCT1 variants exhibited reduced $\mathrm{ASP}^{+}$uptake as compared with OCT1(WT). All images were obtained with 40 objective lens.

Next the ability of the wild type OCT1 overexperssing cell lines to transport $\mathrm{ASP}^{+}$was quantified and compared to the cells overexpressing the variant OCT1s.

In this assay, the OCT1 overexpressing HEK cells were incubated for 3 min with $0.5 \mathrm{ml}$ pre-warmed HBSS medium (pH 7.4) containing increasing concentrations of $\mathrm{ASP}^{+}(0$, 1, 5, 10, 20, 50, 100 and $200 \mu \mathrm{M})$. With increasing concentration of extracellular $\mathrm{ASP}^{+}$, the $\mathrm{ASP}^{+}$uptake in OCT1 wild type overexpressing cells was considerably higher than in the OCT1 variants overexpressing cells and control cells with empty vector (Fig.3.11). 
A)

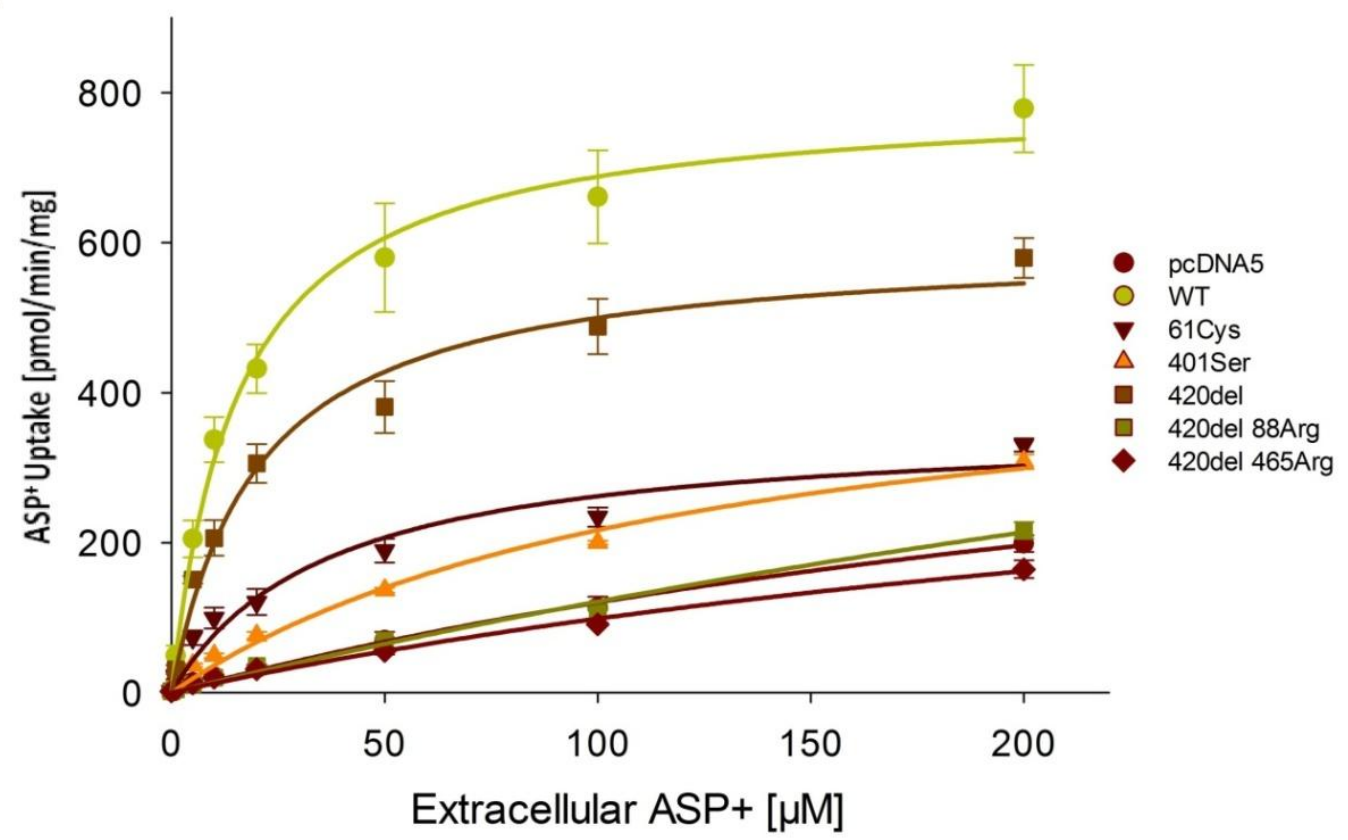

B)

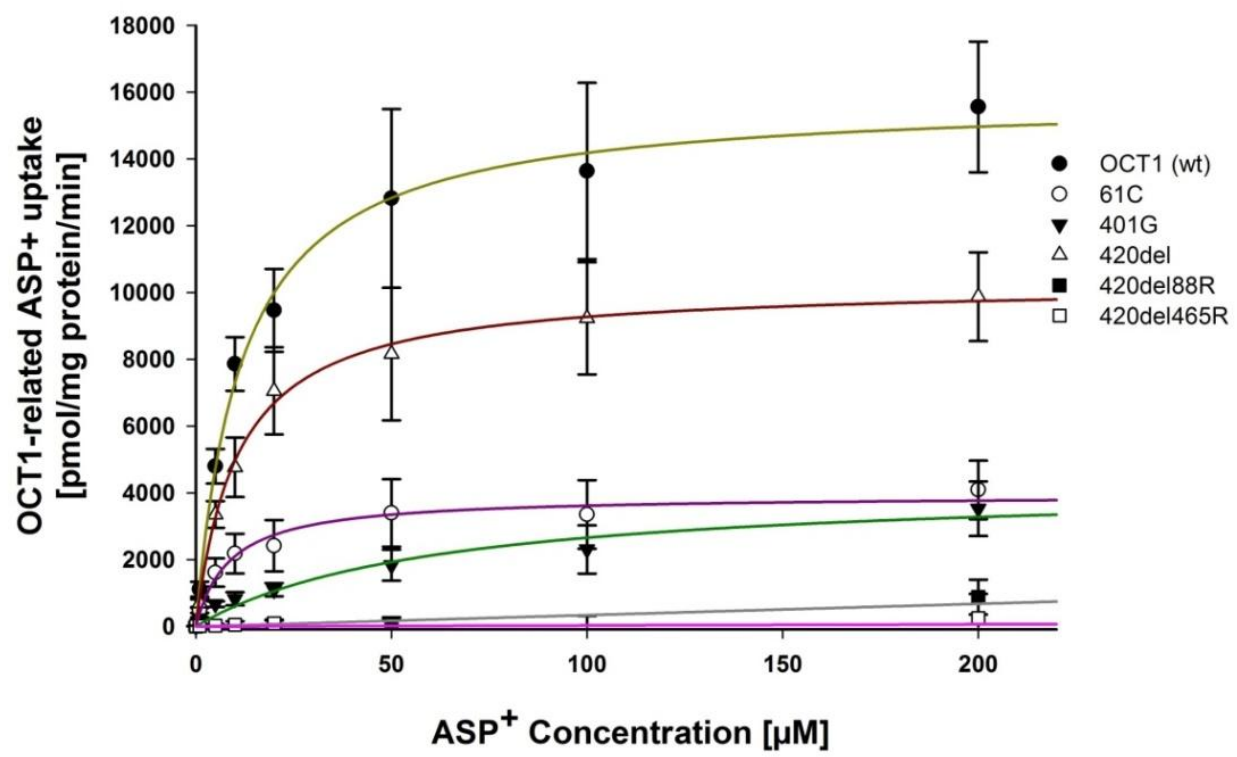

Fig.3. $11 \mathrm{ASP}^{+}$uptake by the wild-type OCT1 and the OCT1 variants carrying the common loss-of-function polymorphisms of OCT1. A)The cellular uptake of $\mathrm{ASP}^{+}$was measured using TECAN Ultra plate photometer and the results were normalized to the total protein amount of the cells. B) The OCT1 mediated uptake of $\mathrm{ASP}^{+}$calculated by subtracting the uptake in the control cells from the uptake in the OCT1- overexpressing cells using the dataset shown in (A). The graph shows mean values and standards errors from three independent experiments.

Using regression to a Michaelis-Menten equation, the $\mathrm{V}_{\max }$ and $\mathrm{K}_{\mathrm{m}}$ of the $\mathrm{ASP}^{+}$by the wild-type and variant OCT1 were determined and the intrinsic clearance of $\mathrm{ASP}^{+}$was 
calculated (Table.3.4). OCT1 wild type exhibited maximum clearance rate compared to SNPs variants, whereas between the OCT1 variants studied here, the 420del variant had the highest clearance rate from the variant-carrying OCT1s (71.1\% of the wild type). The decrease in the intrinsic clearances was based on the decrease in the $\mathrm{V}_{\max }$. The $\mathrm{ASP}^{+}$uptake of the OCT1 variants 420del-88R and 420del-465R did not differ from the uptake in the control cells. The observed significant decrease or the lack of uptake in the variant expression cells is in concordance with previously published data about the effect of loss-of-function variants (SHU et al. 2003).

Table 3. 4 Effects of the common functional amino acid substitutions in OCT1 on the kinetics of $\mathrm{ASP}^{+}$uptake.

\begin{tabular}{|c|c|c|c|c|c|c|}
\hline \multirow[b]{2}{*}{ SNP } & \multicolumn{2}{|c|}{$\mathbf{V}_{\text {max }}$} & \multicolumn{2}{|c|}{$\mathbf{K}_{\mathrm{m}}[\boldsymbol{\mu M}]$} & \multirow{2}{*}{$\begin{array}{c}\mathbf{C} \mathbf{L}_{\text {int }} \\
\left(\mathbf{V}_{\max } / \mathbf{K}_{\mathbf{m}}\right)\end{array}$} & \multirow{2}{*}{$\begin{array}{c}\mathbf{C L}_{\text {int }} \\
\left(\begin{array}{ll}\% & w t\end{array}\right)\end{array}$} \\
\hline & Mean & SEM & Mean & SEM & & \\
\hline$W T$ & 15845.8 & 2877.1 & 11.42 & 1.79 & 1387.34 & 100.0 \\
\hline $61 C$ & $3951.42 *$ & 1013.15 & 9.25 & 1.13 & $427.11^{*}$ & 30.7 \\
\hline $401 S$ & $3698.2^{*}$ & 1784.76 & $47.88 *$ & 6.5 & $77.22 *$ & 5.5 \\
\hline 420del & 10312 & 1787.89 & 11.22 & 1.9 & 918.77 & 66.2 \\
\hline 420del88R & na & na & na & na & na & na \\
\hline 420 del465R & na & na & na & na & na & na \\
\hline
\end{tabular}

na., not applicable. ${ }^{*} \mathrm{P}<0.01$ compared to the WT reference in a Tukey's HSD post hoc analysis following one-way ANOVA $\left(\mathrm{P}<10^{-4}\right)$.

Based on the analyses of the DNA, RNA, protein and activity, it could be concluded that the constructed OCT1 overexpressing cell lines represent a functional model for analyzing OCT1 activity and the effects of OCT1 polymorphisms. 


\subsubsection{Generation and characterization of cell lines co-overexpressing CYP2D6 and POR}

\subsubsection{Generation of stably transfected HEK293 cell lines co- overexpressing CYP2D6 and POR}

The pcDNA5puro::CYP2D6::IRES::POR construct was chromosomally integrated in HEK293-TRex cells by random integration. For this purpose, this construct was extracted from the bacteria by midi prep method and transfected to the HEK293-TRex cells using FuGene 6 transfection reagent (Roche, Mannheim) and after adding screening medium containing $5 \mathrm{ng} / \mu 1$ puromycine, positive clones were selected.

The chromosomal integration of the construct was confirmed by PCR and resequencing. Overexpression of the CYP2D6 and POR genes was confirmed on RNA, protein and activity levels.

\subsubsection{Confirming the chromosomal integration of the} pcDNA5puro::CYP2D6::IRES::POR constructs in the genome of the

\section{HEK293-TRex cells}

The integration of the CYP2D6::IRES::POR into the genome of the HEK293-TRex cells was confirmed by two PCR reactions. The PCR reactions were designed to amplify separately the CYP2D6 and the POR gene using the primers listed in table 3.5 using cells genomic DNA as template.

Table 3. 5 Primers used for amplification of the CYP2D6 and POR genes.

\begin{tabular}{ll}
\hline Primer & \multicolumn{1}{c}{ Primer sequence } \\
\hline CYP2D6(f) & 5'-ACACGATGATAATATGGGGCTAGAAGCACTGGTGCCCCTG-3' \\
CYP2D6 $(\boldsymbol{r})$ & 5'-TGGGGACGCGGCCGCATTCTAGCGGGGCACAGCACAA-3' \\
POR_f & 5'-AAACACGATGATAATATGATCAACATGGGAGACTCCCACGT-3' \\
POR_XhoI_r & 5'-GGGGCAGGCTCGAGGCCCCTAGCTCCACACGTCCAG-3' \\
\hline
\end{tabular}

PCR signals of $1450 \mathrm{bp}$ and $2075 \mathrm{bp}$ were obtained for the CYP2D6 and POR genes respectively (Fig.3.12 A and B). The signals were presented in the pcDNA5puro::CYP2D6::IRES::POR transfected cells and were lacking in the control cells transfected with the empty pcDNA5puro plasmid. The signals were obtained from 
cells resistant to puromycine in their 10 passage after transfection suggesting chromosomal integration of the plasmid. The correctness of the integrated construct was validated by SNaPshot (see section 2.2.1.12).

A)

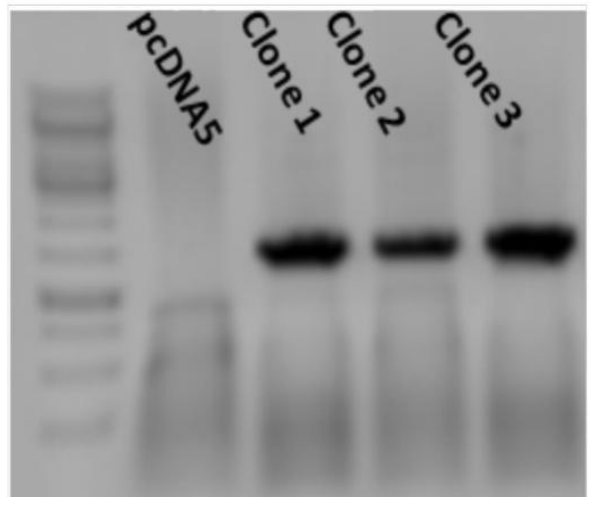

B)

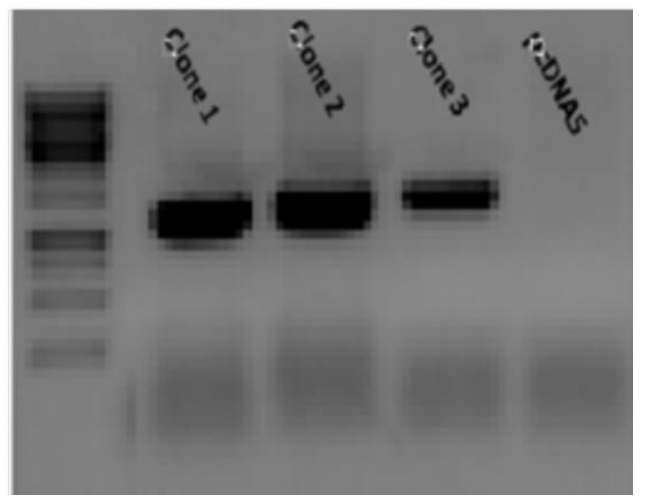

Fig.3. 12 Amplification of CYP2D6 (A) and POR (B) genes from the genome of HEK293TRex cells stably transfected with bicistronic CYP2D6::IRES::POR construct. Total DNA from three clones of CYP2D6 and POR co-overexpressing HEK cells were isolated and PCR was done to amplify the CYP2D6 and POR cDNA fragments. HEK cell transfected with empty vector (pcDNA5 puro) was used as a control.

\subsubsection{Confirming CYP2D6 and POR overexpression by qRT PCR}

The mRNA levels of CYP2D6 and POR genes were quantified by quantitative RT-PCR. For this purpose, total RNA which extracted from the pcDNA5puro::CYP2D6::IRES::POR transfected HEK cells were reverse transcribed and used as templates for real-time quantitative PCR, and then normalized to TATAbox binding protein (TBP) as a housekeeping gene. The CYP2D6 mRNA was 30587 -fold stronger expressed in the stably transfected as in the control cells. The POR mRNA was 60-fold stronger expressed in the stably transfected as in the control cells (Fig.3.13). 
A)

CYP2D6

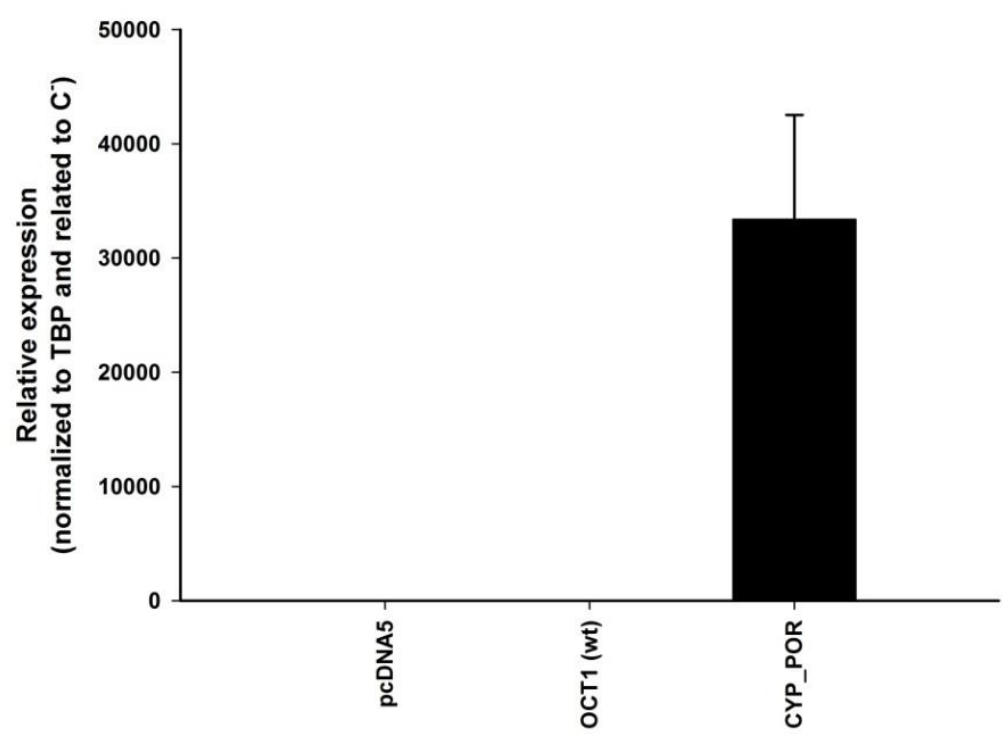

B)

POR

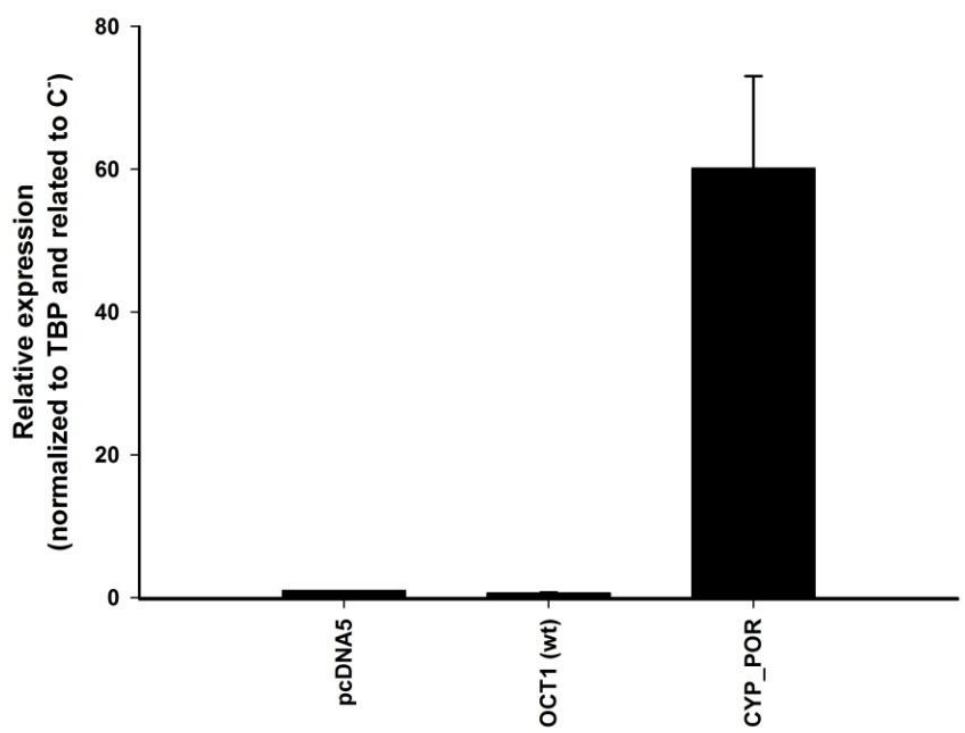

Fig.3. 13 qRT-PCR analyses of the CYP2D6 and POR co-overexpression in the pcDNA5puro::CYP2D6::IRES::POR. The graph shows mRNA levels of CYP2D6 (A) and POR (B) in HEK cells overexpressing CYP2D6_IRES_POR in compare with HEK cells overexpressing OCT1 (wt) wild type or HEK cells transfected with empty vector (pcDNA 5) as controls. The mRNA expression of the genes of interest was normalized to the expression of the house-keeping gene TBP. The graph shows mean values and standard errors from three independent experiments. 


\subsubsection{Confirming CYP2D6 overexpression by western blot}

Expression of CYP2D6 protein in HEK cell transfected with pcDNA5puro::CYP2D6::IRES::POR was determined by western blot. Three clones of the stably transfected cells were selected and total protein of these samples were extracted for western blot analysis. Using the CYP2D6-specific monoclonal antibody MAB-2D6 (BD Gentest ${ }^{\mathrm{TM}}$ ) a signal of $50 \mathrm{kDa}$ in all three transfected clones was shown, whereas this signal was missing in the control-transfected cells (Fig.3.14).

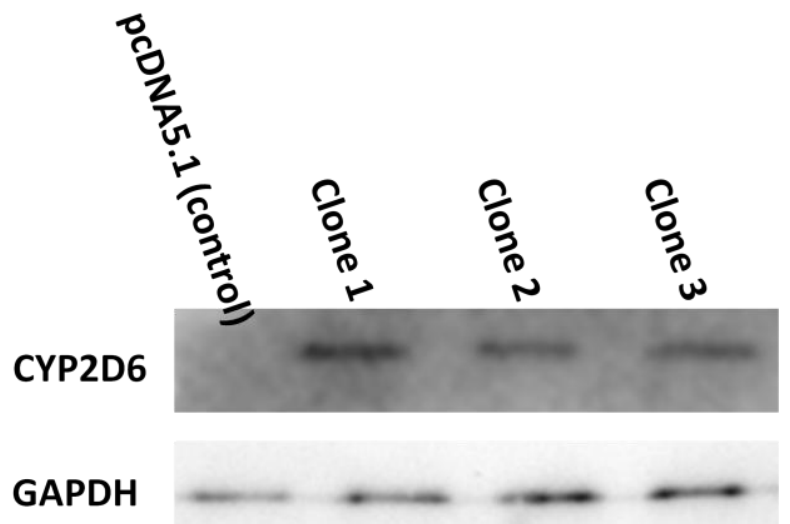

Fig.3. 14 Western blot detection of CYP2D6 protein in pcDNA5puro::CYP2D6::IRES::POR transfected HEK cells. A monoclonal anti-CYP2D6 primary antibody MAB-2D6 was used for specific detection of the $50 \mathrm{kDa}$ CYP2D6 protein. A goat anti-mouse-HRP secondary antibody with chemiluminescence detection was used. The housekeeping protein GAPDH was used to control for equal loading of the gel. The images were visualized by VersaDoc imaging system.

\subsubsection{Flow cytometry analysis for CYP2D6 overexpressing HEK cells}

In this experiment the CYP2D6 overexpressing HEK cells as well as the control cells transfected with pcDNA5 empty vector were fixed and permeabilized as described previously (section 2.2.6). The $2.5 \times 10^{5}$ cells were then stained by indirect immunofluorescence using monoclonal anti-CYP2D6 antibody (MAB-2D6, BD Gentest) and flourochrome conjugated anti-mouse antibody (Goat anti mouse Alexa 488, Invitrogen) and were analyzed by flow cytometry on a FACScan instrument BD LSR II (BD Bioscience) and the data were analyzed using BD FACSDiva software. Electronic gating of FSC (forward scatter) versus SSC (side scatter) was used to eliminate cellular fragments and debris from the population of cells to be analyzed for the presence of CYP2D6.The histogram showed that $90.6 \%$ of the HEK cells 
overexpressing CYP2D6 stained positively above the control HEK cells transfected with pcDNA5 vector (Fig. 3.15).

A)

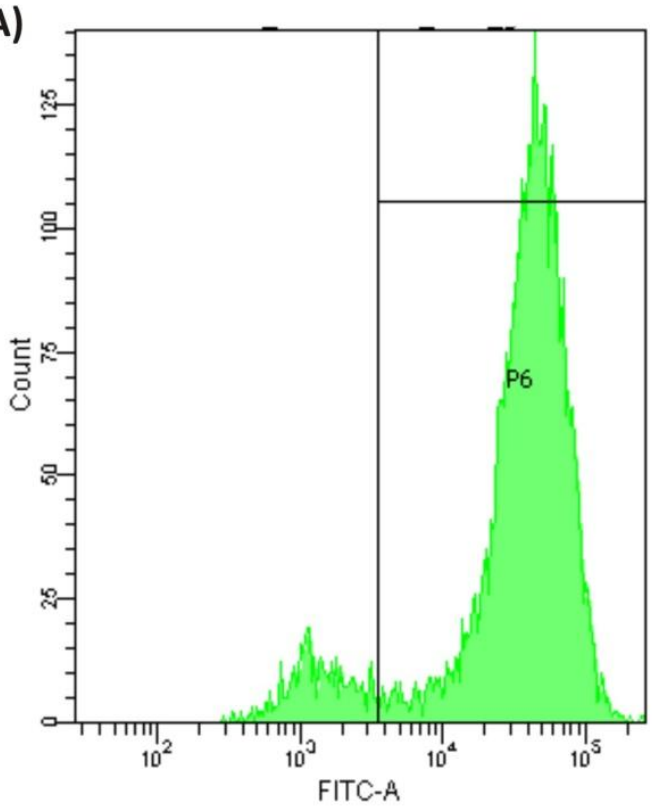

B)

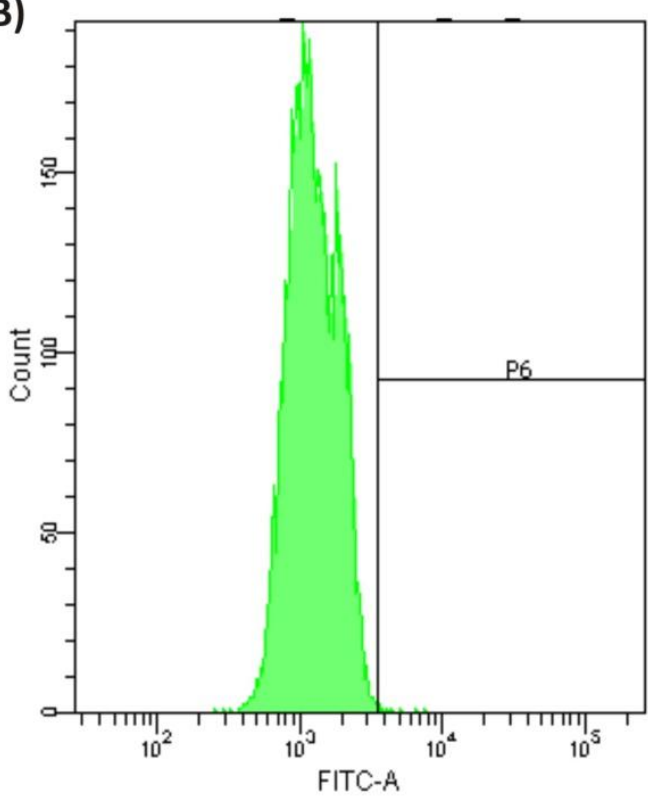

Fig.3. 15 Characterization of CYP2D6 expression protein in CYP2D6 overexpressing HEK cells (A) and HEK cells transfected with pcDNA empty vector (B) by flow cytometry. A) The results show that the maximum amount of the CYP2D6 overexpressing HEK cells bind to antibody conjugated to FITC and emit the fluorescence after threshold line (P6 region). B) The control HEK cells show no emitted fluorescence after threshold line which means no antibody bind to these cells.

\subsubsection{Immunocytochemical staining}

The CYP2D6 overexpressing HEK cells as well as the control cells transfected with pcDNA5 empty vector were fixed and permeabilized as described before (section 2.2.7). After reaching the cells to $80 \%$ confluency, the cells were treated by monoclonal antiCYP2D6 antibody (MAB-2D6, BD Gentest) and stained by flourochrome conjugated anti-mouse antibody (Goat anti mouse Alexa 488, Invitrogen) and then visualized by confocal microscopy (Carl Zeiss, Jena). The results showed that the CYP2D6 protein localized mostly in the cytosol of the HEK cells overexpressing CYP2D6 (Fig. 3.16). 


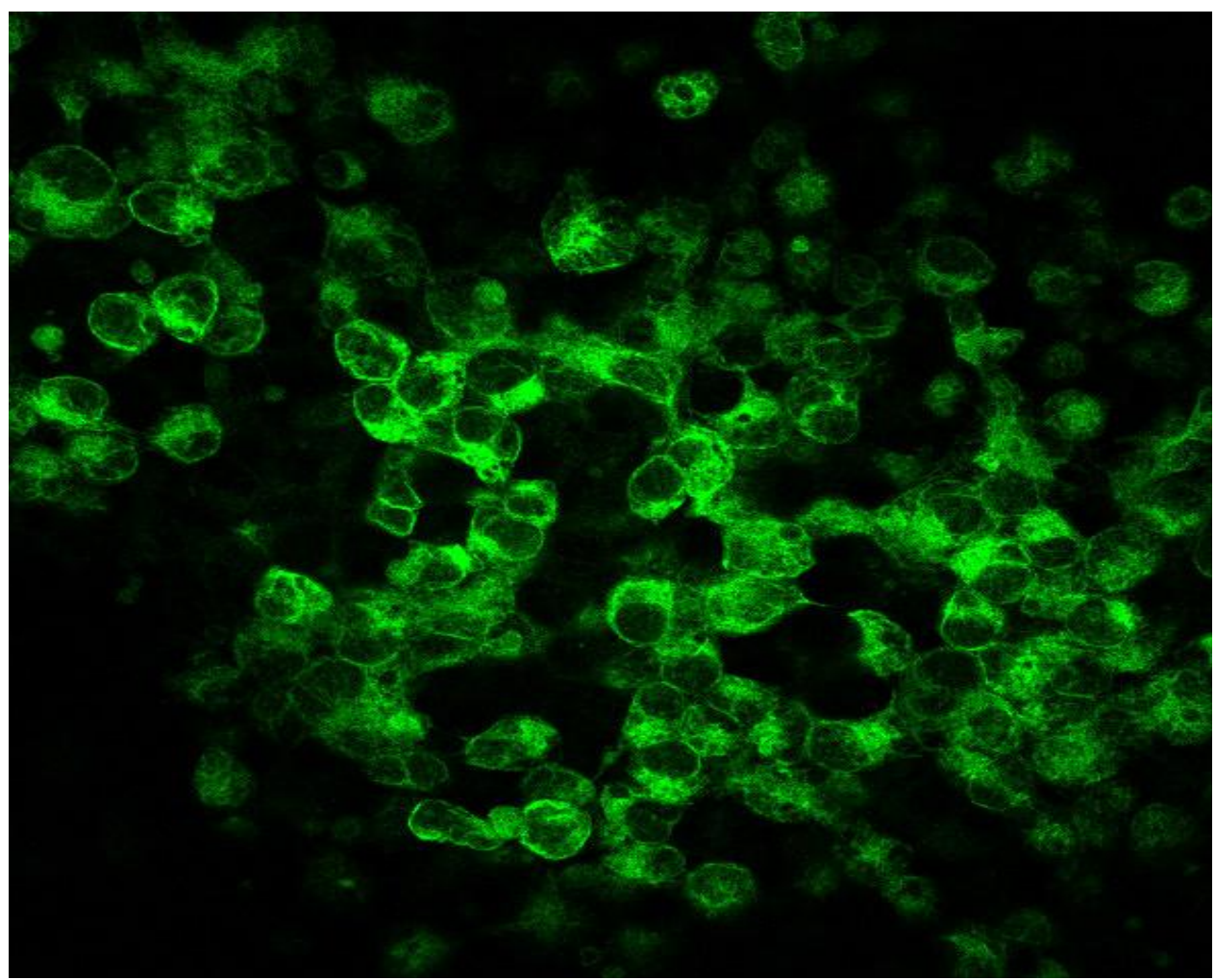

Fig.3. 16 Confocal immunofluorescent analysis of HEK cells overexpressing CYP2D6. The cells were treated using monoclonal anti-CYP2D6 primary antibody (MAB-2D6, BD Gentest) and visualized using Alexa Fluor 488-conjugated goat anti-mouse $\operatorname{lgG}$ (Invitrogen). The green particles depict localization of CYP2D6 protein mostly in the cytosol of the cells.

\subsubsection{Confirming the expression of functionally active CYP2D6}

To confirm functional CYP2D6 expression, microsomes were extracted from three clones of HEK293-TRex cells stable transfected with pcDNA5puro::CYP2D6::IRES::POR. The CYP2D6 enzyme activity was assessed using the AMMC kit. As it can be seen, the maximum amount of AHMC, the product of CYP2D6 catalyzed oxidation of AMMC, was detected for microsome of kit (used as a positive control), however no significant activity was detected for extracted microsome from the stably transfected cells (Fig.3.17) indicating that the amount of enzyme expressed may only be very low or enzyme was lost during preparation of the microsomes. 


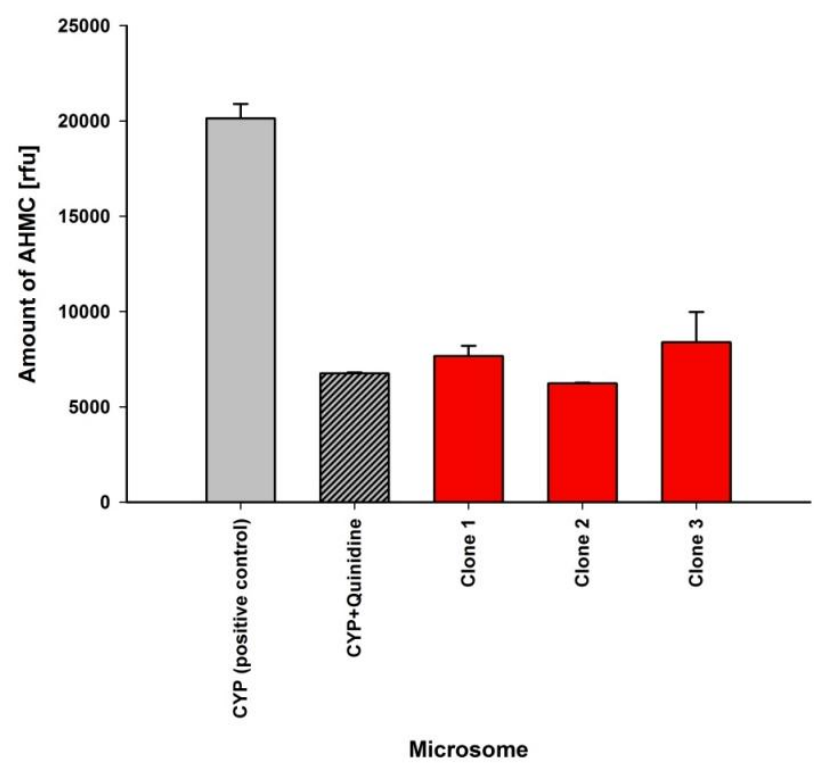

Fig.3. 17 Measurement the activity of CYP2D6 enzyme using AMMC kit. Microsomes extracted from HEK293 cells transfected with pcDNA5puro::CYP2D6::IRES::POR were treated with AMMC substance and incubated for $30 \mathrm{~min}$ as described in section 2.2.10.2 The amount of AHMC, the fluorescent metabolite of AMMC, was measured by TECAN Ultra plate photometer at excitation $340 \mathrm{~nm}$ and emission $465 \mathrm{~nm}$ wavelengths. The data was normalized to the total protein amounts in the microsomes. Quinidine was used as inhibitor of CYP2D6 enzyme. The graph shows mean values and standard errors from two independent experiments. Rfu is an abbreviation for relative fluorescence units.

Therefore, we continued characterization of the single and double transfected clones using debrisoquine instead of AMMC as a model substrate for CYP2D6 enzyme. In this case we detected 4-OH debrisoquine as the main product of CYP2D6 catalyzed oxidation by HPLC. For this reason, microsomes extracted from HEK cells transfected with pcDNA5puro::CYP2D6::IRES::POR exposed to three different concentrations of debrisoquine (1, 10 and $100 \mu \mathrm{M})$ for 1 hour using the same cofactors, buffers and stop solution from the AMMC kit, and then the amount of 4-OH debrisoquine was measured by HPLC. HEK293-TRex cells overexpressing OCT1were used as a negative control. In this experiment the samples were divided to two parts treated with and without $100 \mu \mathrm{M}$ paroxetine as a well known inhibitor of the CYP2D6 enzyme (Fig. 3.18). The amount of 4-OH debrisoquine produced by microsomes from the two clones of CYP2D6::IRES::POR (No. 1 and 2) was significantly higher than those obtained from the control cells. Furthermore paroxetine inhibited the production of 4-OH debrisoquine 
in all samples except for the HEK cells overexpressing OCT1 (wt) which no change was seen.

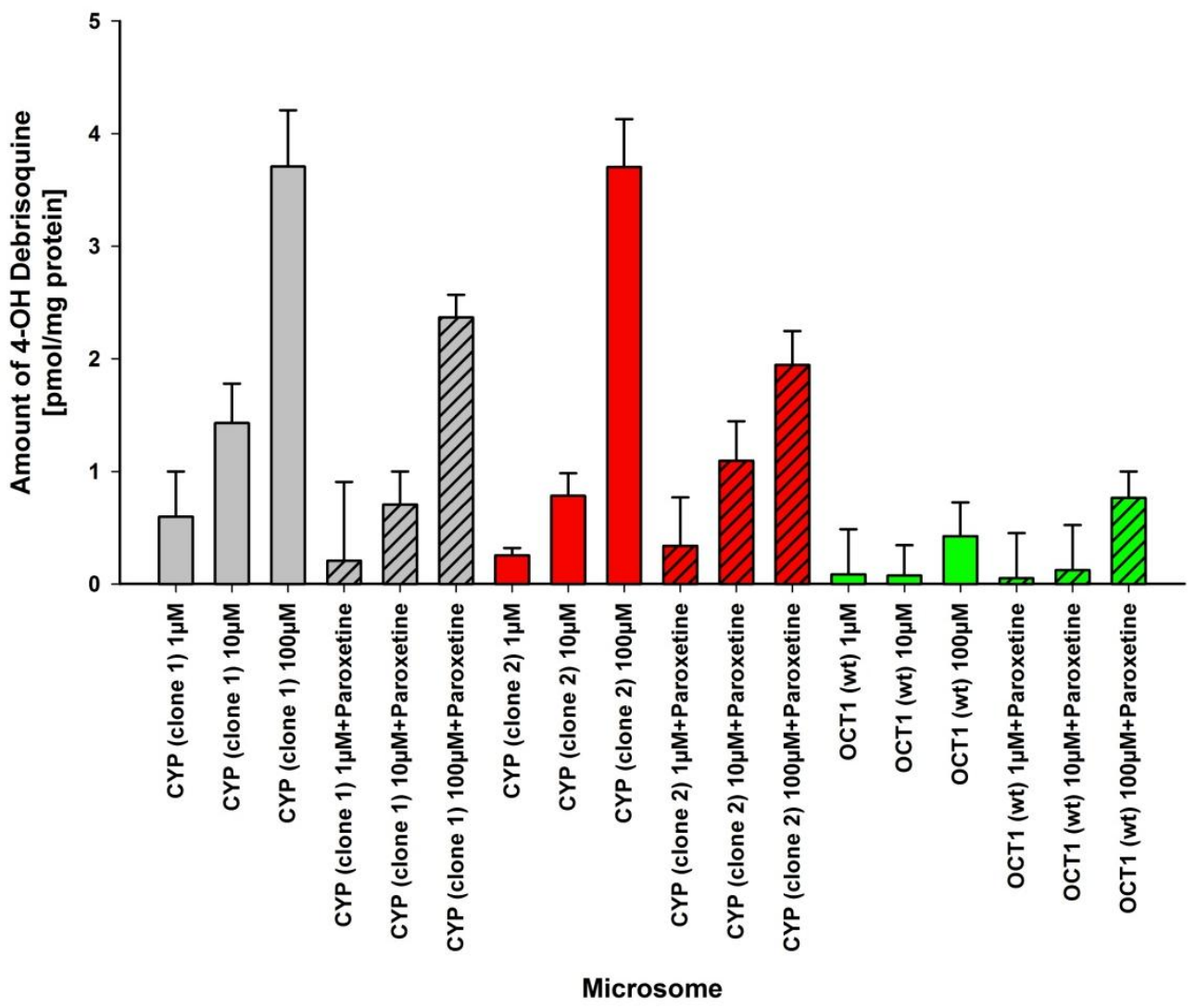

Fig.3. 18 Measurement the activity of CYP2D6 enzyme using the model substrate debrisoquine. Microsomes extracted from HEK293-TRex cells transfected with pcDNA5puro::CYP2D6::IRES::POR were incubated for 1 hour with different concentration of debrisoquine $(1,10$ and $100 \mu \mathrm{M})$ in the absence (simple bars) or present of $100 \mu \mathrm{M}$ paroxetine as an inhibitor for CYP2D6 enzyme (hatched bars). As a control, microsomes extracted from HEK293-TRex cells transfected with OCT1 wild type were used. The amount of 4OHdebrisoquine produced by CYP2D6 was measured by means of high-performance liquid chromatography and normalized to the total protein amounts in the microsomes. The graph shows mean values and standard errors from three independent experiments.

\subsubsection{Time dependence of CYP2D6-mediated tramadol metabolism}

This experiment was performed to measure the activity of CYP2D6 enzyme in the HEK293-TRex cells stably transfected with pcDNA5puro:: CYP2D6::IRES::POR. For this purpose, we modified the AMMC assay using tramadol as a substrate for CYP2D6 enzyme and detecting O-desmethyltramadol as a produced metabolite by HPLC. 
Microsomes obtained from the transfected cells were exposed to $1 \mu \mathrm{M}$ tramadol for different incubation times $(0,15,30,60$ and $90 \mathrm{~min})$ using the cofactor mix, buffers and stop solution used for AMMC assay (see section 2.2.10.2). After the reaction was stopped, the amount of the CYP2D6 product O-desmethyltramadol was measured by HPLC. The observed time-dependent increase in the O-desmethyltramadol production confirmed the presence of active CYP2D6 in the cells (Fig.3.19).

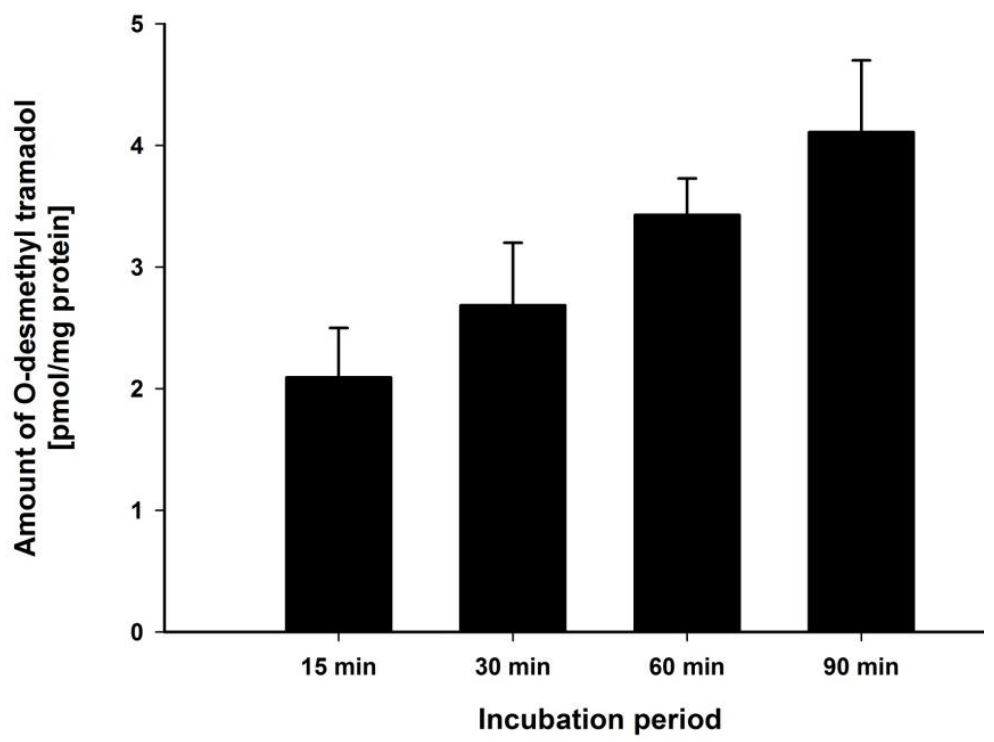

Fig.3. 19 Measuring time dependence activity of CYP2D6 enzyme using tramadol. Microsome produced from HEK293-TRex cells stably transfected with pcDNA5puro::CYP2D6::RES::POR were incubated with the same concentration of tramadol $(1 \mu \mathrm{M})$ for different incubation times $(0,15,30,60$ and $90 \mathrm{~min})$. The O-desmethyltramadol produced by microsomes was measured by means of high-performance liquid chromatography and normalized to the total protein amounts in the microsomes. The graph shows mean values and standard errors from two independent experiments. 


\subsubsection{Generation and characterization of the OCT1, CYP2D6 and POR co-overexpressing cell lines}

\subsubsection{Generation of stably double-transfected HEK293 cell lines co- overexpressing OCT1, CYP2D6 and POR}

After generation of CYP2D6::POR co-overexpressing HEK cells, the constructs including pcDNA5::OCT1 wild type and OCT1 variant 420del88R were used to transfect these cells using Flp-In system (see section 2.2.5.4.2). The positive clones were selected using DMEM medium containing 10\% FBS serum, 1\% penicillin/streptomycin and $10 \mu \mathrm{g} / \mathrm{ml}$ hygromycin B. After 10-14 days the single colonies of double-transfected cells (OCT1 and CYP2D6::IRES::POR) resistant to hygromycin B were selected and transferred and grown in 12-well and later in 6-well plates and culture flask.

Correct plasmid integration was confirmed by PCR. Overexpression of the OCT1 gene was confirmed on RNA and protein levels.

\subsubsection{Confirming the chromosomal integration of the OCT1 con- structs in CYP2D6::IRES::POR overexpressing HEK cells}

Successful genomic integration of these constructs was confirmed by integrationspecific PCR as described in section 2.2.1.9 (Fig. 3.20).

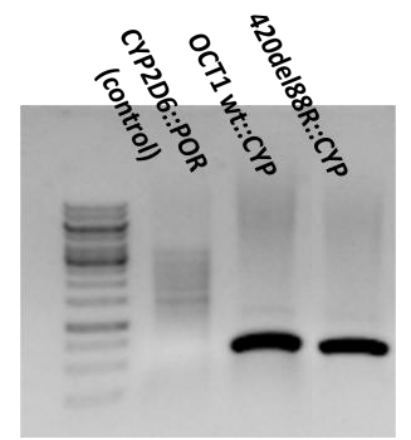

Fig.3. 20 Integration-specific PCR for the hygromycin resistance region to check integration of the OCT1 plasmid constructs in the genome. A 614 bp fragment was amplified for hygromycin resistance region in OCT1::CYP2D6::IRES::POR overexpressing HEK cells for OCT1 wild type and 420del88R variant in compare to HEK cells overexpressing CYP2D6:.IRES:.POR as control. 


\subsubsection{Confirming OCT1, CYP2D6 and POR overexpression by qRT-}

\section{PCR}

The expression of the mRNA transcripts of OCT1, CYP2D6 and POR genes were clearly much higher in OCT1, CYP2D6 and POR double-transfected cells compared with control cells transfected with empty vector (Fig.3.21). The results showed that mRNA levels of OCT1, CYP2D6 and POR significantly increased in the cells which doubletransfected with pcDNA5::OCT1 and pcDNA5puro::CYP2D6::IRES::POR constructs in compared to HEK cells transfected with pcDNA5 empty vector as control.

A)

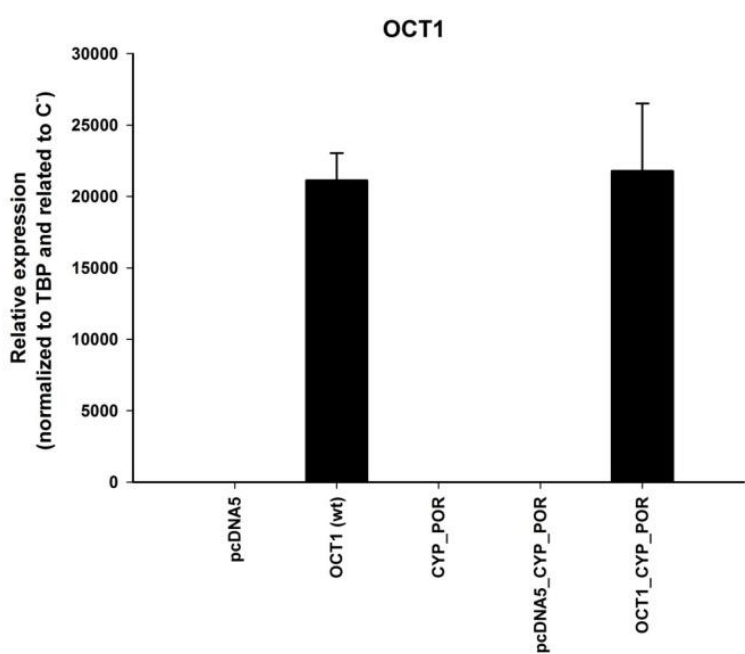

B)

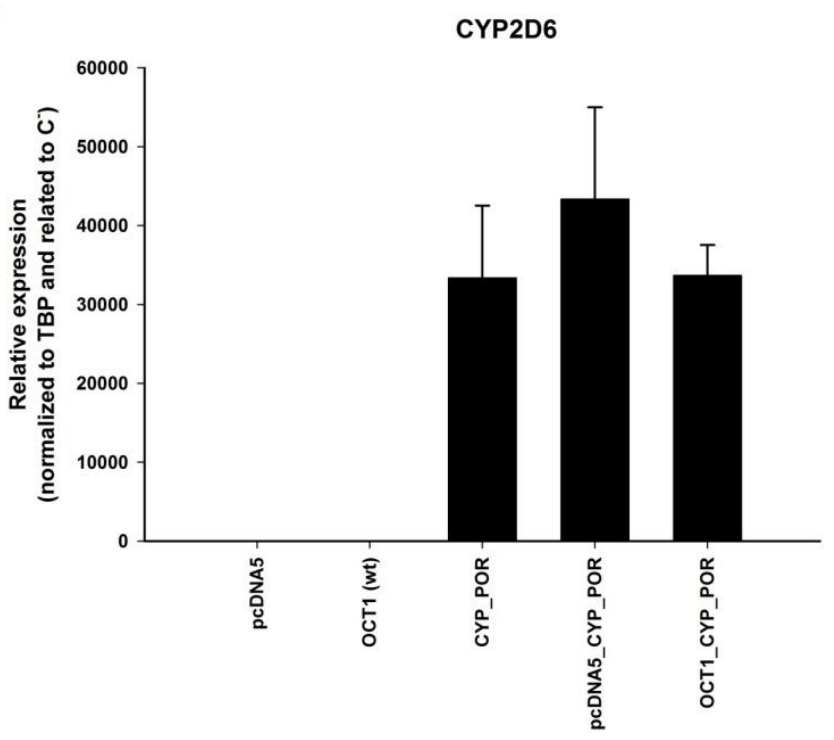


C)

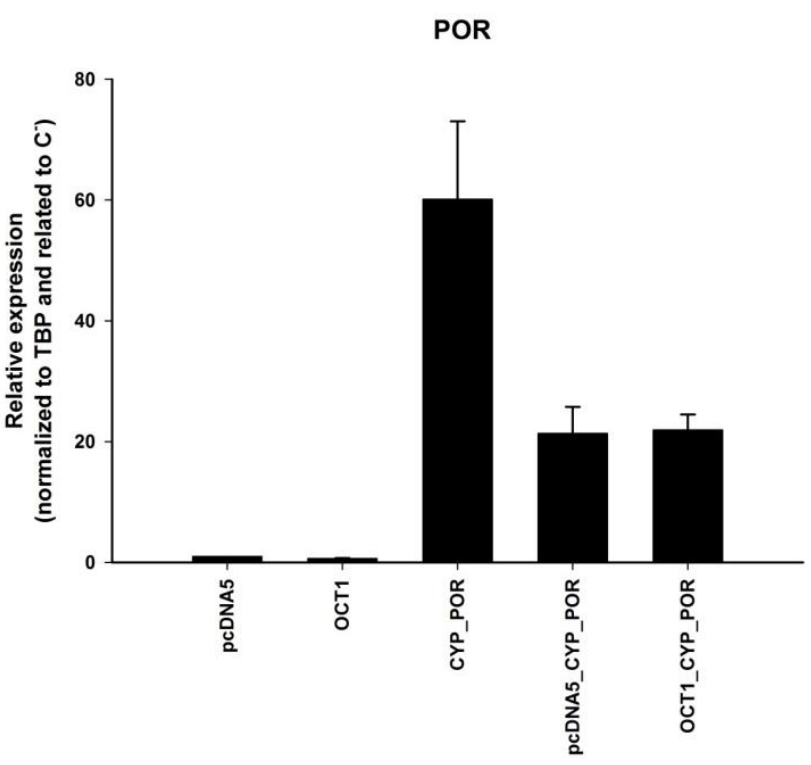

Fig.3. 21 qPCR analyses of the CYP2D6 and POR co-overexpression in the pcDNApuro::CYP2D6::IRES::POR. The graphs show normalized mRNA levels of OCT1, CYP2D6 and POR in HEK cells overexpressing OCT1::CYP2D6::IRES::POR in compare with HEK cells overexpressing CYP2D6::IRES::POR or OCT1 wild type or HEK cells containing empty vector as control. A) The expression rate for OCT1 mRNA in OCT1::CYP2D6::IRES::POR transfected cells compared to those cells overexpressed OCT1 alone showed no differences, whereas the huge differences was seen compared to the cells transfected with CYP2D6::IRES::POR or empty vector. B) The expression rate of CYP2D6 mRNA in OCT1_CYP2D6_IRES_POR transfected cells compared to CYP2D6::IRES::POR transfected cells and cells transfected with OCT1wild type (wt) or HEK cells transfected with empty vector as control. C) The expression rate of POR mRNA in OCT1::CYP2D6::IRES::POR transfected cells compared to CYP2D6::IRES::POR transfected cells and cells transfected with OCT1 (wt) or empty vector. The graphs show mean values and standard errors from three repetitions.

\subsubsection{Confirming OCT1 and CYP2D6 co-overexpression by protein analyses}

Expression of OCT1 and CYP2D6 proteins in the double-transfected HEK293-TRex cell was determined by western blot analysis. The results showed an obtained signal with 75 and $61 \mathrm{kDa}$ for OCT1 and a signal with $50 \mathrm{kDa}$ for CYP2D6 on SDS-PAGE gel (Fig.3.22). 


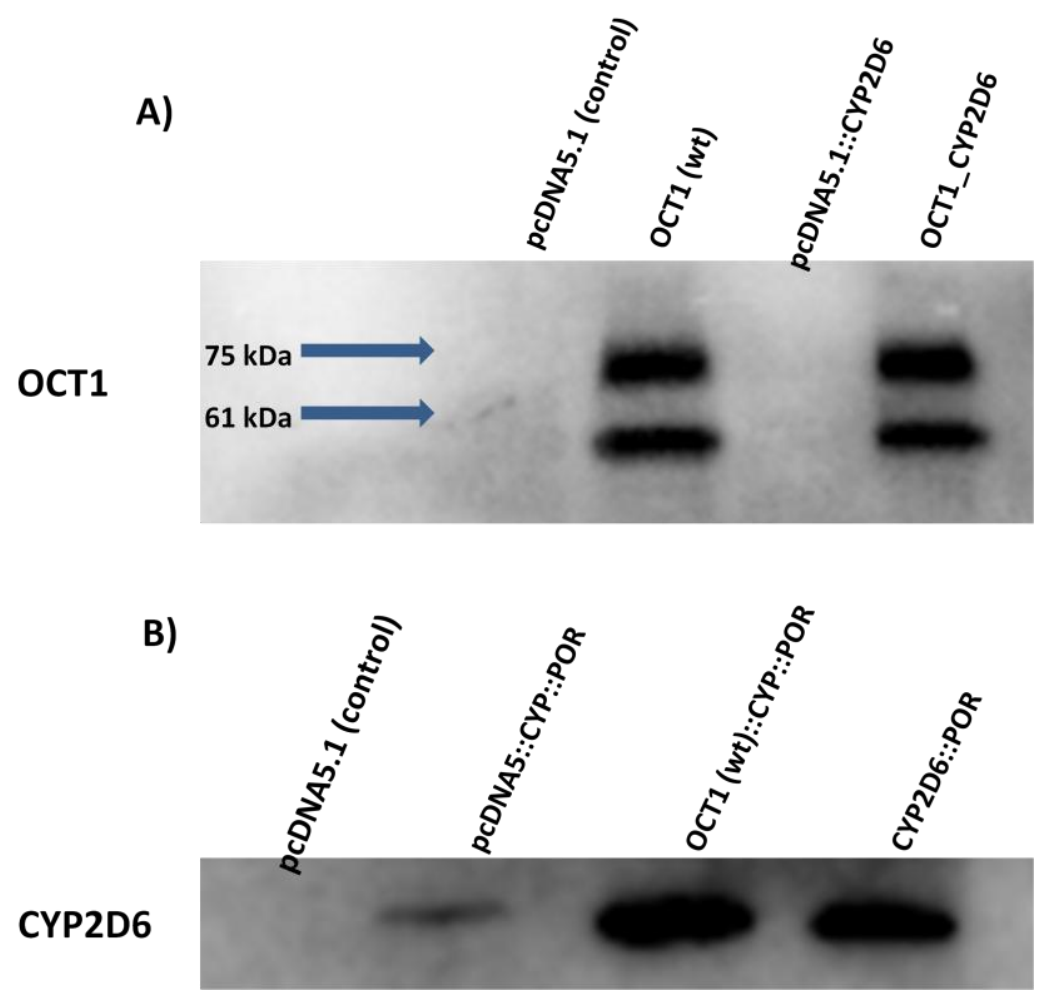

Fig.3. 22 Western blot analyses for OCT1 and CYP2D6 in pcDNA5::OCT1 and pcDNA5puro::CYP2D6::IRES::POR double transfected HEK293-TRex cells. A) A monoclonal anti-(human) OCT1 primary antibody was used for specific detection of the 75 and $61 \mathrm{kDa}$ proteins corresponding to OCT1. A goat anti-mouse-HRP secondary antibody with chemiluminescence detection was used. B) A monoclonal anti-(human) CYP2D6 primary antibody was used for specific detection of the $50 \mathrm{kDa}$ CYP2D6 protein. A goat anti-mouse-HRP secondary antibody with chemiluminescence detection was used. The images were visualized by VersaDoc imaging system.

\subsubsection{Flow cytometry analysis for OCT1 and CYP2D6 overexpressing HEK cells}

In this experiment the OCT1::CYP2D6::POR overexpressing HEK cells as well as the control cells transfected with pcDNA5 empty vector were fixed and permeabilized as described previously (section 2.2.6). The $2.5 \times 10^{5}$ cells were then stained by indirect immunofluorescence using primary antibody SLC22A1 (2c5, Novus Biologicals, Cambridge, UK) and fluorochrome conjugated anti-mouse antibody (Goat anti mouse Alexa 488, Invitrogen) and were analyzed by flow cytometry on a FACScan instrument BD LSR II (BD Bioscience) and the data were analyzed using BD FACSDiva software. 
Electronic gating of FSC (forward scatter) versus SSC (side scatter) was used to eliminate cellular fragments and debris from the population of cells to be analyzed for the presence of OCT1.The histogram showed that $96.4 \%$ of the HEK cells overexpressing OCT1 and CYP2D6 stained positively above the control HEK cells transfected with pcDNA5 vector (Fig. 3.23).
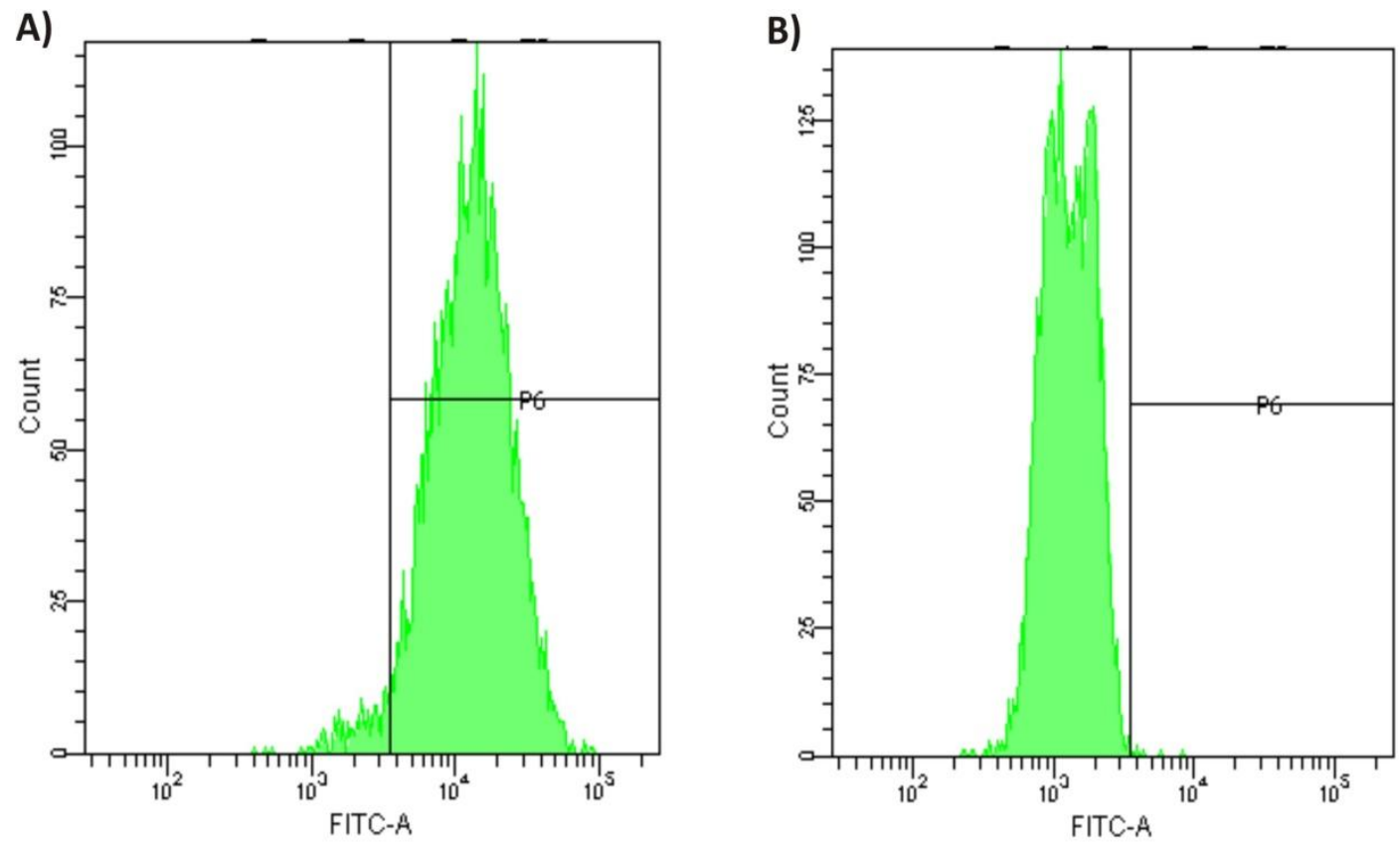

Fig.3. 23 Characterization of the expressed protein OCT1 in OCT1 and CYP2D6 overexpressing HEK cells (A) and HEK cells transfected with pcDNA empty vector (B) by flow cytometry. A) The results show maximum amount of the OCT1 and CYP2D6 overexpressing HEK cells can bind to antibody conjugated to FITC and emit the fluorescence after threshold line (P6 region). B) The control HEK cells show no emitted fluorescence above the threshold line which means no antibody bind to these cells.

\subsubsection{Immunocytochemical staining}

The OCT1 and CYP2D6 overexpressing HEK cells as well as the control cells transfected with pcDNA5 empty vector were fixed and permeabilized as described before (section 2.2.7). After reaching the cells to $80 \%$ confluency, the cells were treated with primary antibody SLC22A1 (2c5, Novus Biologicals, Cambridge, UK) for OCT1 protein or monoclonal anti-CYP2D6 antibody (MAB-2D6, BD Gentest) for CYP2D6 protein and stained with flourochrome conjugated anti-mouse antibody (Goat anti 
mouse Alexa 488, Invitrogen) and then visualized by confocal microscopy (Carl Zeiss, Jena). The results showed that the OCT1 protein localized on the membrane, whereas the CYP2D6 protein localized mostly in the cytosol (Fig. 3.24 A and B).

\section{A)}

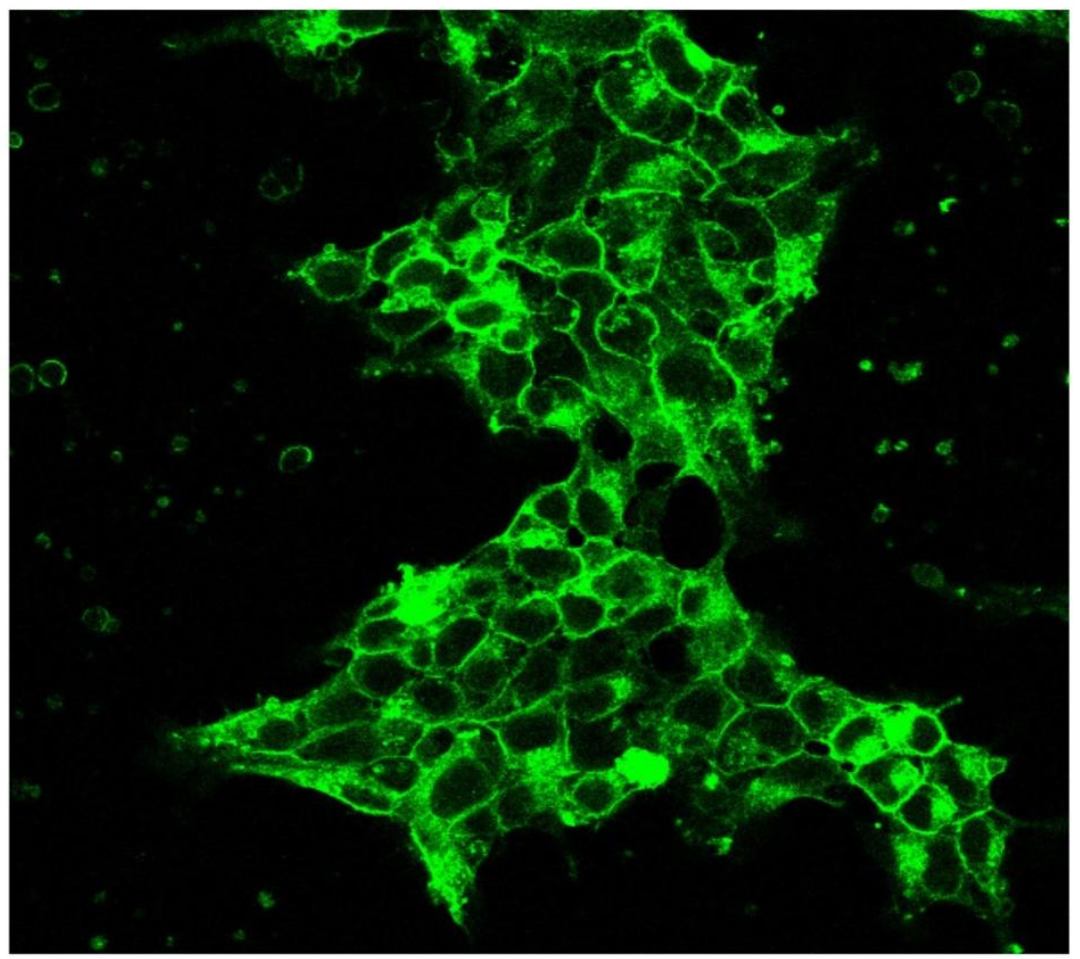

B)

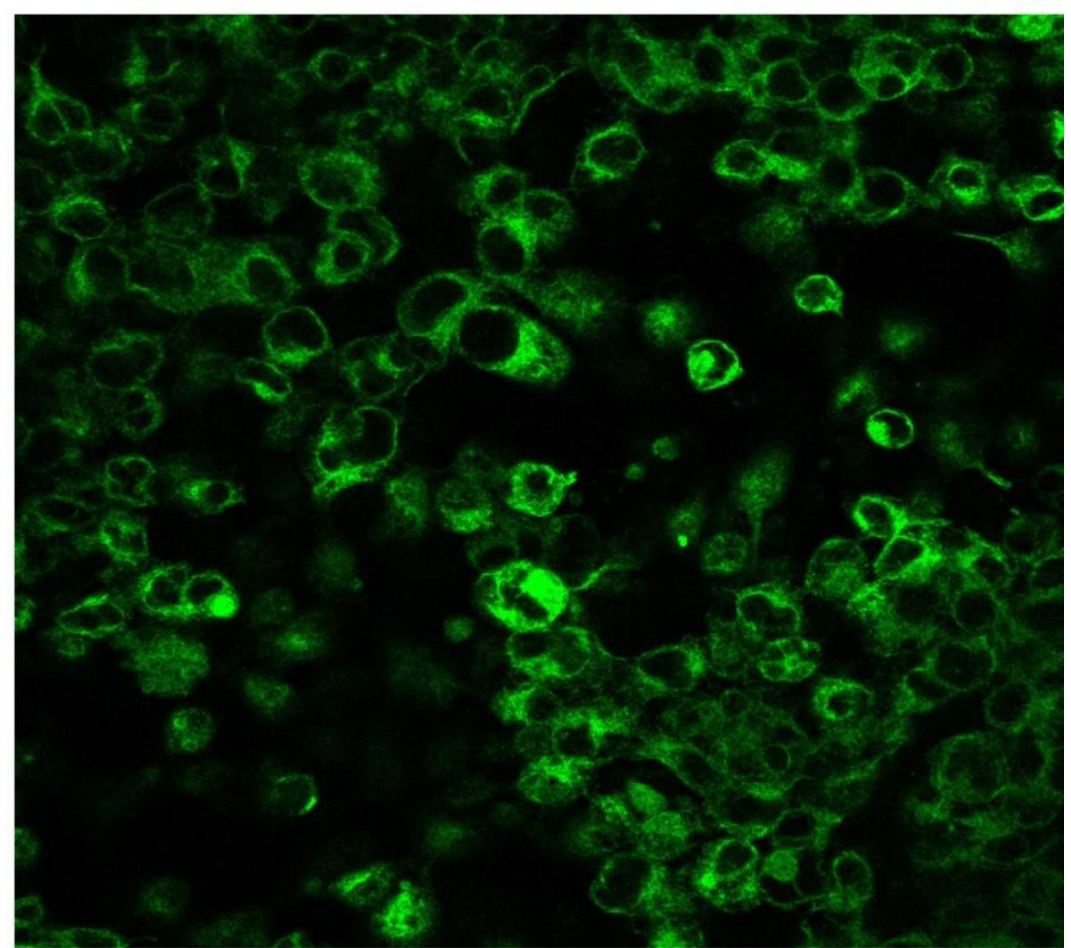

Fig.3. 24 Confocal immunofluorescent analysis of HEK293TRex cells cooverexpressing OCT1 and CYP2D6. The cells were treated with mouse anti-(human) primary antibody SLC22A1 
(2c5, Novus Biologicals, Cambridge, UK) for detecting OCT1 (A) or with the monoclonal antiCYP2D6 primary antibody (MAB-2D6, BD Gentest) for detecting CYP2D6 (B) and visualized using Alexa Fluor 488-conjugated goat anti-mouse lgG (Invitrogen). The green particles depict localization of OCT1 protein on the membrane (A) and CYP2D6 protein mostly in the cytoplasm of the cells (B).

Based on the analyses of the DNA, RNA, protein and activity, it could be concluded that the constructed OCT1, CYP2D6 and POR co-overexpressing cell lines represent a functional model for analyzing OCT1-CYP2D6 interactions in drug metabolism and the effects of OCT1 polymorphisms on it.

\subsection{OCT1 as a cellular uptake transporter of antiemetic drugs}

\subsubsection{Inhibition of OCT1-mediated ASP+ uptake by tropisetron, ondansetron and palonosetron}

We analyzed whether OCT1 mediates the cellular uptake of the antiemetic drugs tropisetron, ondansetron or palonosetron. First, we analyzed if these three drugs may inhibit the uptake of $\mathrm{ASP}^{+}$, which is a model substrate of OCT1. For this reason, HEK293-TRex cells overexpressing the wild type OCT1 were incubated with $1 \mu \mathrm{M}$ $\mathrm{ASP}^{+}$for $3 \mathrm{~min}$ in the presence of increasing concentrations of either tropisetron, ondansetron or palonosetron. The inhibition caused by the three antiemetic drugs was compared with the inhibition caused by the weak OCT1 inhibitor tetraethylammonium $\left(\mathrm{TEA}^{+}\right)$and the strong OCT1 inhibitor quinine. All these three antiemetic compounds examined in this experiment effectively inhibited the $\mathrm{ASP}^{+}$uptake (Fig.3.25). Tropisetron decreased the $\mathrm{ASP}^{+}$uptake with an $\mathrm{IC}_{50}$ value of $8.5 \pm 1.4 \mu \mathrm{M}$, whereas the corresponding $\mathrm{IC}_{50}$ values for ondansetron and palonosetrone were $63 \pm 15.6 \mu \mathrm{M}$ and $22.9 \pm 11.6 \mu \mathrm{M}$, respectively. The inhibition constants were comparable (ondansetron) or even tenfold (tropisetron) and fourfold (palonosetron) lower than the inhibition constant of quinine, a well-known OCT1 substrate. These results correspond to previously reported data (AHLIN et al. 2008; KOEPSELl et al. 2007), but still did not clarify whether these drugs are substrates that are actively transported by OCT1, or act only as inhibitors of OCT1. 


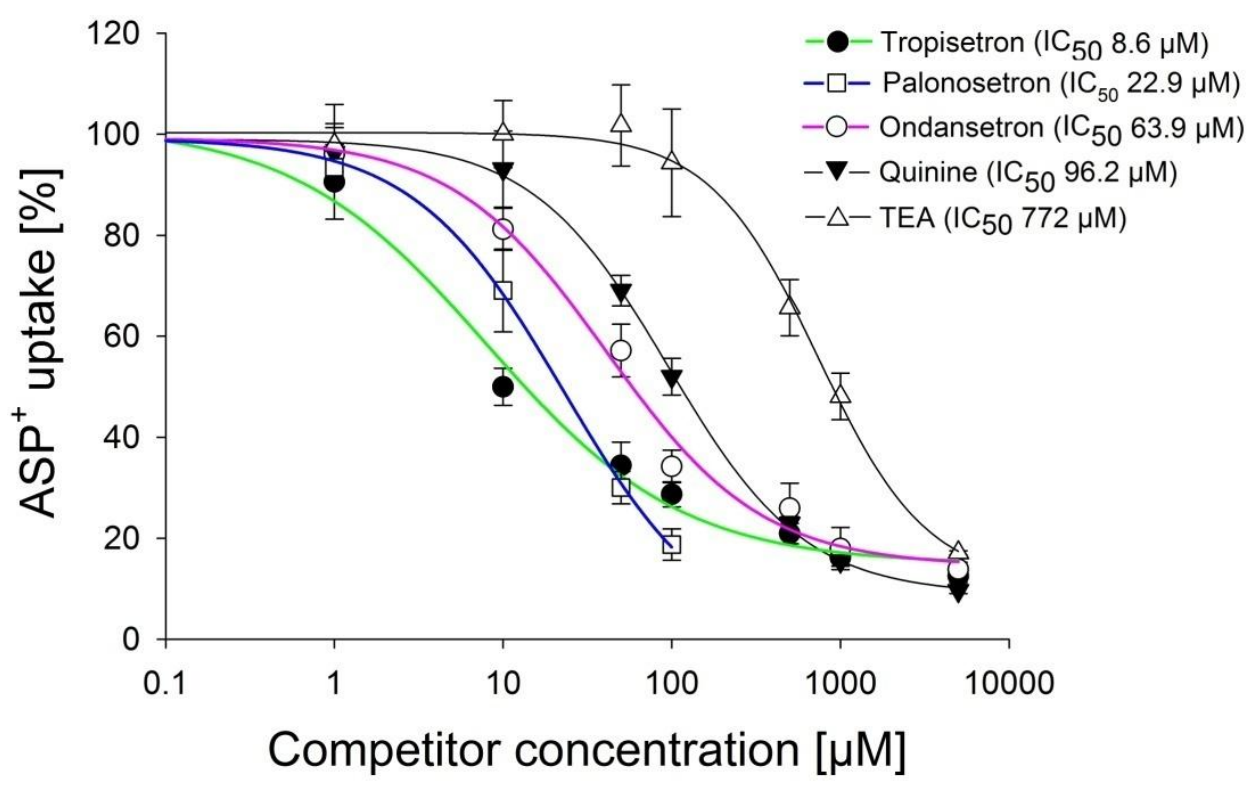

Fig.3. 25 Inhibition of OCT1 uptake by tropisetron, ondansetron and palonosetron. The inhibition of $1 \mu \mathrm{M} \mathrm{ASP}{ }^{+}$uptake in OCT1 overexpressing cell lines was compared between the three antiemetic drugs and quinine and TEA as two model substrates of OCT1 on the OCT1mediated $\mathrm{ASP}^{+}$uptake. All three antiemetic drugs, tropisetron, ondansetron and palonosetron were stronger inhibitors of the $\mathrm{ASP}^{+}$uptake than the model substrates quinine and TEA. The graph shows mean values and standard errors of three independent experiments.

\subsection{2 $\mathrm{pH}$-dependance of the inhibitory effect of tropisetron and ondansetron}

Tropisetron and ondansetron are weak organic bases. Thay are protonated and positively charged depending on the $\mathrm{pH}$ of the media. The change in the $\mathrm{pH}$ will automatically lead to change in the fraction of the drug that is protonated and thus positively charged. This experiment was performed in order to investigate whether any changes in ectracellular $\mathrm{pH}$ affect the affinity of tropisetron and ondansetron to react with OCT1 measured as change in their ability to inhibit $\mathrm{ASP}^{+}$uptake. For this purpose, the uptake of $\mathrm{ASP}^{+}$in HEK293-TRex cells that overexpress OCT1 was measured in the presence and in the absence of $100 \mu \mathrm{M}$ tropisetron or ondansetron at four different $\mathrm{pH}$ values (5.4, 6.4, 7.4 and 9). As expected, the highest $\mathrm{ASP}^{+}$uptake was observed at physiological $\mathrm{pH}$, as measured cells treated with $\mathrm{ASP}^{+}$only (Fig.3.26). The inhibitory assay using tropisetron and ondansetron showed tropisetron significantly inhibited the $\mathrm{ASP}^{+}$uptake in all four different $\mathrm{pH}$. On contrary the inhibitory effect of ondansetron declined by 
increasing of the $\mathrm{pH}$ medium with $100 \mu \mathrm{M}$ ondansetron showing almost no inhibition at $\mathrm{pH}$ of 9.

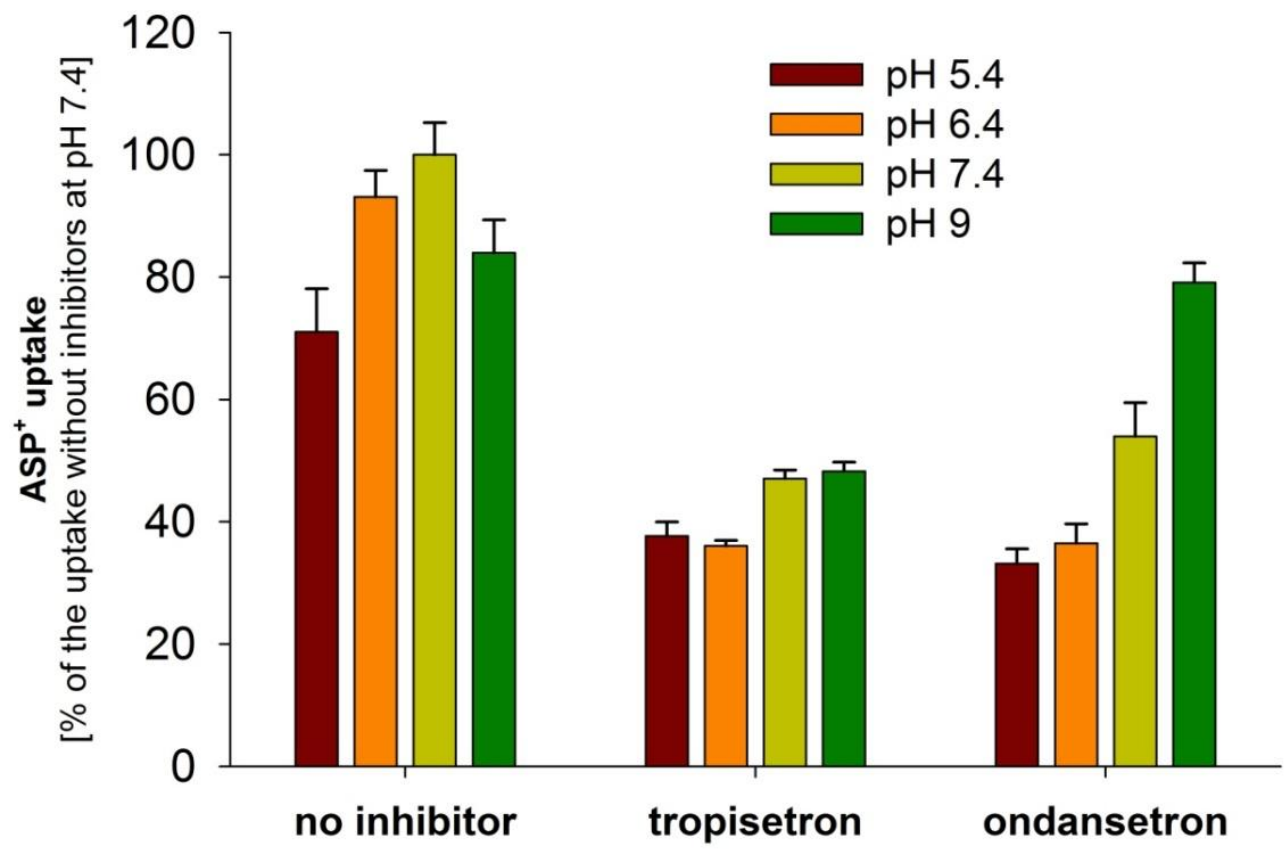

Fig.3. $26 \mathrm{pH}$ dependence of the OCT1 inhibition of tropisetron and ondansetron. $\mathrm{ASP}^{+}$uptake was measured after incubating the OCT1-overexpressing HEK293-TRex in the presence and in the absence of tropisetron or ondansetron. The intracellulary accumulated $\mathrm{ASP}^{+}$was measured using TECAN ultra plate photometer and normalized to the total protein amounts in the cells. The graph shows mean value of three independent experiments.

\subsubsection{Direct measurements of tropisetron and ondansetron cellular uptake by OCT1. Effects of the genetic polymorphisms in OCT1.}

To identify whether tropisetron and ondansetron are substrates and not only inhibitors of OCT1, the intracellular uptake of both drugs was measured in cells overexpressing the wild type OCT1 and compared to the control cells transfected with pcDNA5.1 empty vector. The cells were exposed to the drugs for $1 \mathrm{~min}$ and then the cells were lysed, and to the intracellular concentrations of tropisetron and ondansetron were measured using HPLC. Compared with cells transfected with empty vector, the OCT1overexpressing HEK293-TRex cells (wild type) showed a 2.3-fold increase in the intracellular accumulation of tropisetron ( $\mathrm{P}<0.001$, Student's t-test; Fig $3.27 \mathrm{~A}$ ). This increase was completely reversible by $\mathrm{MPP}^{+}$(1-methyl-4-phenylpyridinium), a specific model substrate and competitive inhibitor of OCT1. This experiment demonstrated that 
tropisetron is a substrate for OCT1. In the same transport assay for ondansetron, the control cells showed high uptake of ondansetron and the overexpression of OCT1 led only to a marginal $28 \%$ increase in the ondansetron uptake that was not significant ( $\mathrm{P}=0.59$, Mann-Whitney-U test; Fig.3.27 B).

Next we analyzed how common polymorphisms in the OCT1 gene may influence tropisetron uptake. The uptake of tropisetron was measured in the HEK293-TRex cells overexpressing variant OCT1 isoforms carrying the five common polymorphisms. In all variants, the uptake of tropisetron was reduced to the levels of the OCT1 nonexpressing cells ( $\mathrm{P}<0.001$, one-way ANO-VA; Fig.3.27 A).
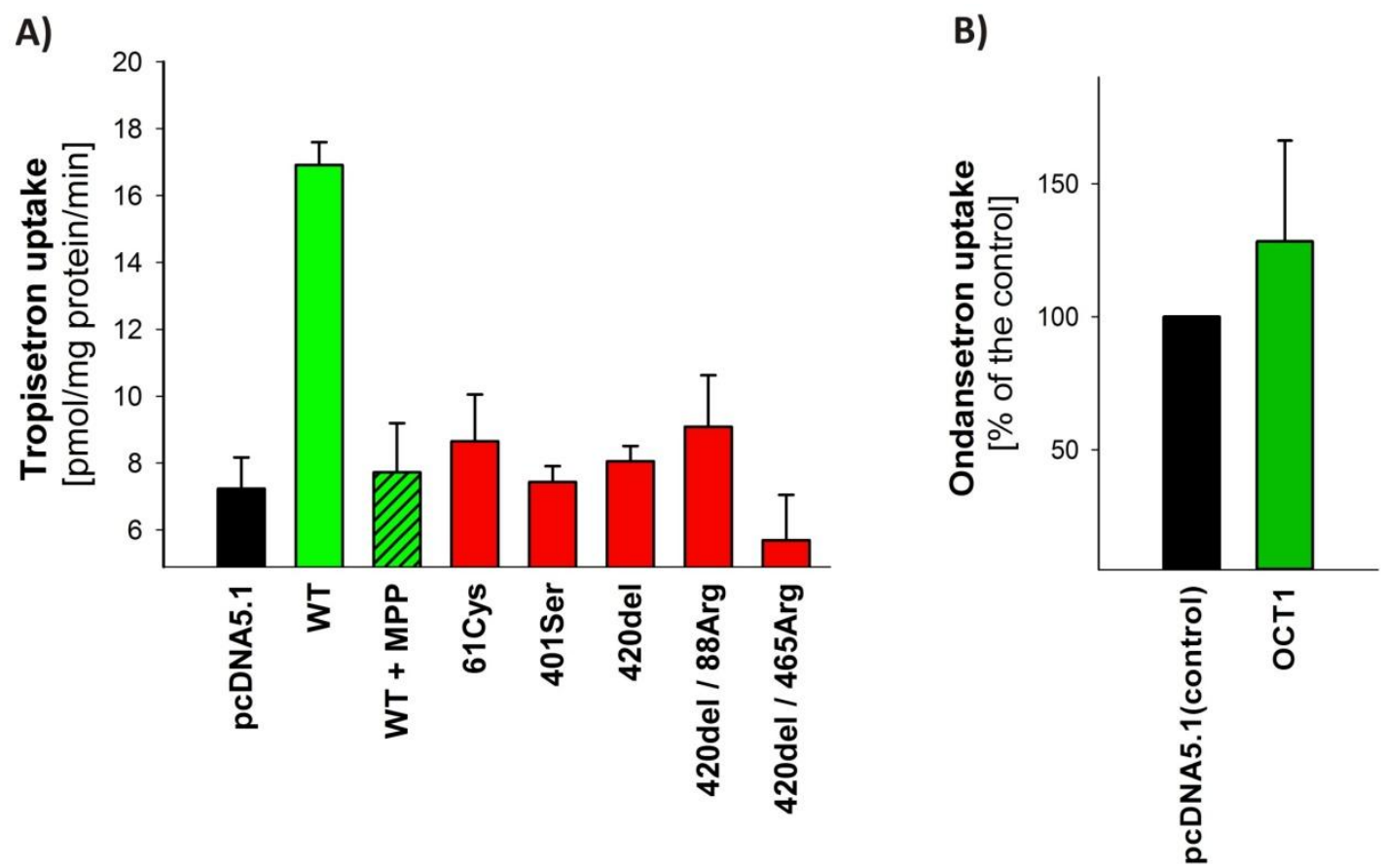

Fig.3. 27 Direct measurements for cellular uptake of tropisetron (A) and ondansetron (B) in OCT1 overexpressing HEK293-TRex cells. A) Control cells (pcDNA5.1, black bar) and cells overexpressing OCT1 wild-type (WT, green bar) or polymorphic OCT1 forms (red bars) were incubated with $1 \mu \mathrm{M}$ tropisetron for $3 \mathrm{~min}$. The intracellular accumulation of tropisetron was measured by high-performance liquid chromatography (HPLC). The cellular uptake of tropisetron was blocked in the cells expressing OCT1 wild-type using $100 \mu \mathrm{M} \mathrm{MPP}^{+}$(green hatched bars). B) The cellular uptake of ondansetron in control cell (pcDNA5.1, black bar) and cells overexpressing OCT1 wild-type (OCT1, green bar). As it indicated there is no significant difference between the cells overexpressing OCT1wild type and control. The graphs show mean value and standard errors of three independent experiments. 
It could be concluded that tropisetron is transported by OCT1 and that the common loss-of function polymorphisms in OCT1 abolished tropisetron transport. Although ondansetron inhibited the OCT1 transport (see section 3.3.1), a direct OCT1-mediated uptake of ondansetron did not show any significant difference between OCT1transfected cells compared to control cells.

\subsection{OCT1 as a cellular uptake transporter of the analgesic drugs tramadol and O-desmethyltramadol}

\subsubsection{PAMPA assay for tramadol and O-desmethyltramadol}

The ability of tramadol and O-desmethyltramadol to penetrate cell membranes by carrier-independent diffusion was evaluated using a parallel artificial membrane permeability assay (PAMPA) as described in section 2.2.12. Tramadol showed high carrier-independent membrane permeability $\left(\mathrm{P}_{\mathrm{e}}\right.$ of $\left.12.6 \times 10^{-6} \pm 0.12 \times 10^{-6} \mathrm{~cm} / \mathrm{s}\right)$, whereas O-desmethyltramadol showed low permeability $\left(\mathrm{P}_{\mathrm{e}}\right.$ of $1.46 \times 10^{-6} \pm 0.08 \times 10^{-6}$ $\mathrm{cm} / \mathrm{s}$ ). These findings suggest that tramadol, but not O-desmethyltramadol, may penetrate cell membranes by means of carrier-independent diffusion (Fig.3.28).

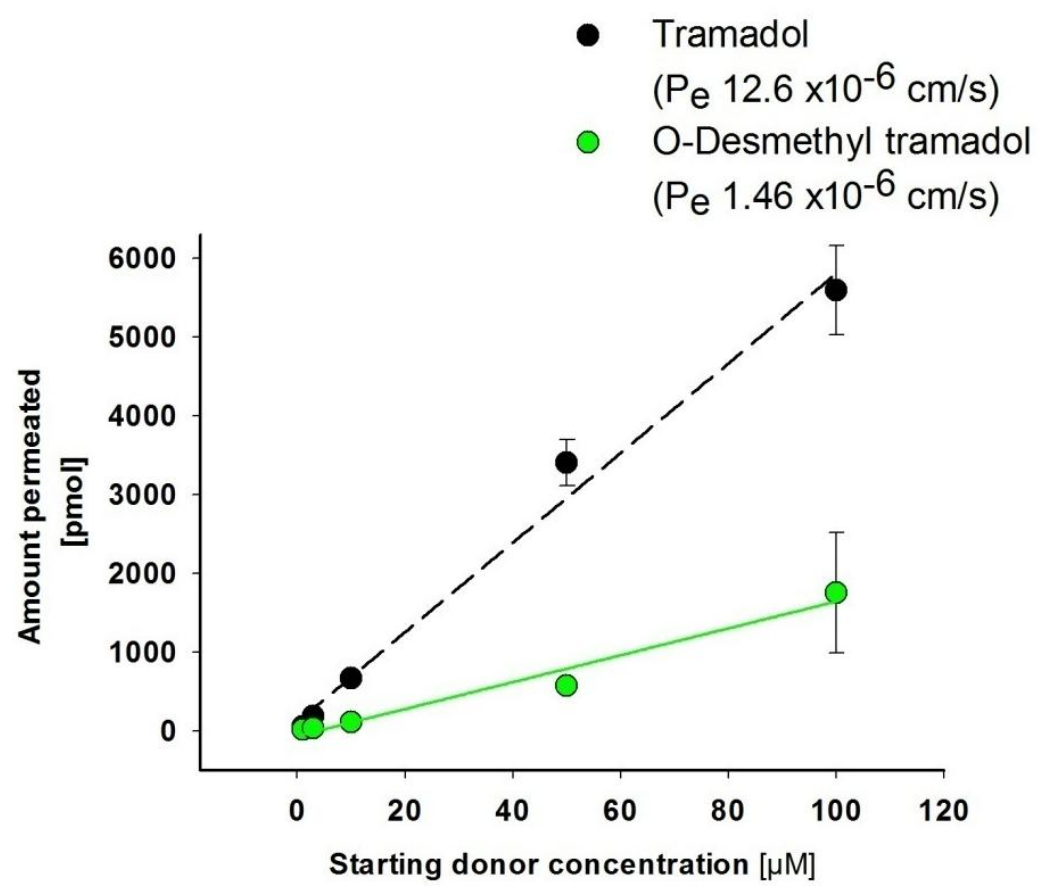


Fig.3. 28 Carrier-independent membrane permeability of tramadol and $O$ desmethyltramadol as measured using the parallel artificial membrane permeability assay (PAMPA). Mean permeability $\left(\mathrm{P}_{\mathrm{e}}\right)$ values of all five different concentrations $(0,1,10,50$ and 100 $\mu \mathrm{M})$ are given. The graph shows mean values and standard errors of three independent experiments performed in duplicate.

\subsubsection{Inhibition of OCT1-mediated $\mathrm{ASP}^{+}$uptake by tramadol and O- desmethyltramadol}

To determine if tramadol and O-desmethyltramadol are the substrates for OCT1, the ability of these two drugs to inhibit the OCT1-mediated uptake was measured. Both tramadol and O-desmethyltramadol inhibited with $\mathrm{ASP}^{+}$uptake in HEK293-TRex cells overexpressing OCT1 (Fig. 3.29). Tramadol strongly inhibited $\mathrm{ASP}^{+}$uptake, with a halfmaximal inhibitory concentration $\left(\mathrm{IC}_{50}\right)$ of $30.3 \pm 3.1 \mu \mathrm{M}$, whereas $\mathrm{O}$ desmethyltramadol inhibited the uptake less strongly, with an $\mathrm{IC}_{50}$ of $172 \pm 73 \mu \mathrm{mol} / \mathrm{l}$. This data indicated that both tramadol and O-desmethyltramadol may be substrates of OCT1.

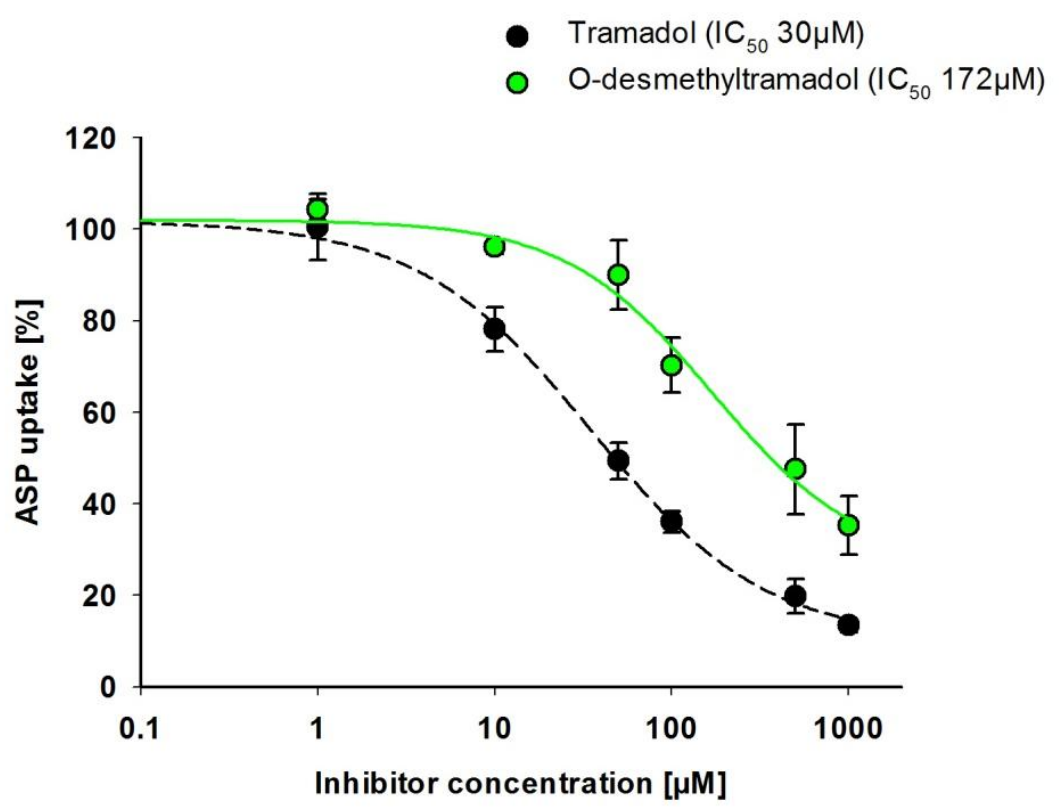

Fig.3. 29 Inhibition of the cellular uptake of the OCT1 substrate $\mathrm{ASP}^{+}$by tramadol and $O$ desmethyltramadol. OCT1-overexpressing HEK293 cells were incubated with $1 \mu \mathrm{M} \mathrm{ASP}^{+}$for 3 min in the presence of increasing concentrations of tramadol and $O$-desmethyltramadol. The graph shows mean values and standard errors of three independent experiments and illustrates that both substances do inhibit OCT1. However, tramadol inhibits OCT1 more strongly than $O$ desmethyltramadol. 


\subsubsection{Tramadol and O-desmethyltramadol cellular uptake by OCT1 and effects of the OCT1 polymorphisms.}

To determine whether tramadol and O-desmethyltramadol are substrates and not only inhibitors of OCT1, direct measurements of the cellular uptake of the both drugs by OCT1 were performed. The measurement of intracellular uptake by HPLC showed no differences in the uptake of tramadol between the OCT1 overexpressing cells and the control cells transfected with an empty plasmid (Fig. 3.30 A). In contrast, the cellular uptake of O-desmethyltramadol was 2.4-fold higher in the OCT1-overexpressing cells than in the control cells $(\mathrm{P}<0.001$, Student's t-test; Fig. $3.30 \mathrm{~B})$. This increase in the $\mathrm{O}-$ desmethyltramadol uptake was completely reversible by the addition of $100 \mu \mathrm{mol} / \mathrm{l}$ $\mathrm{MPP}^{+}$and was reversed to an extent of $>85 \%$ by the addition of $100 \mu \mathrm{mol} / \mathrm{l} \mathrm{ASP}^{+}$(Fig. $3.30 \mathrm{~B})$.

Next the effect of OCT1 polymorphisms on the uptake of O-desmethyltramadol was analyzed. The uptake of O-desmethyltramadol was significantly lower as compared with uptake by wild-type OCT1 ( $\mathrm{P}<0.05$, Student's t-test; Fig. $3.30 \mathrm{~B}$ ). The uptake in the cells overexpressing OCT1 variants did not differ significantly from the uptake in control cells transfected with the empty plasmid (one-way analysis of variance with Tukey's honestly significant difference post hoc comparison). 


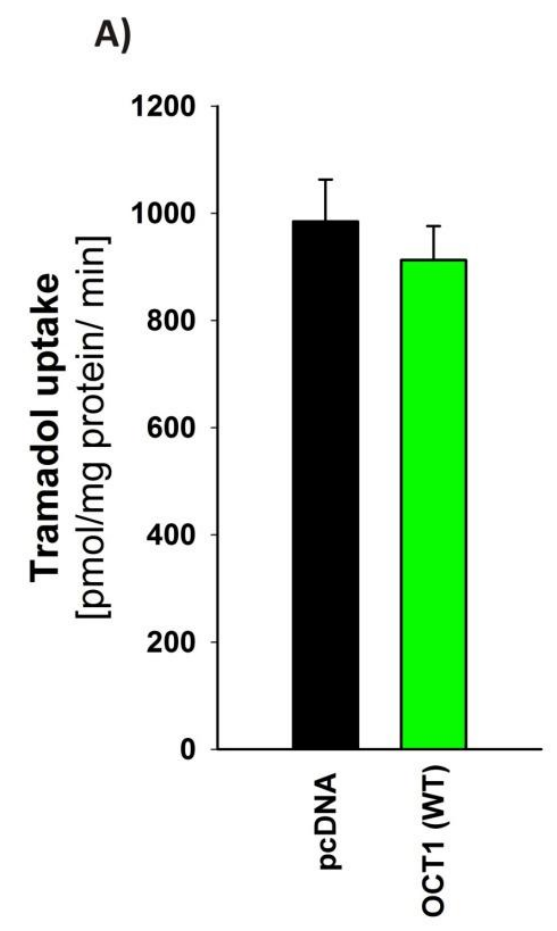

B)

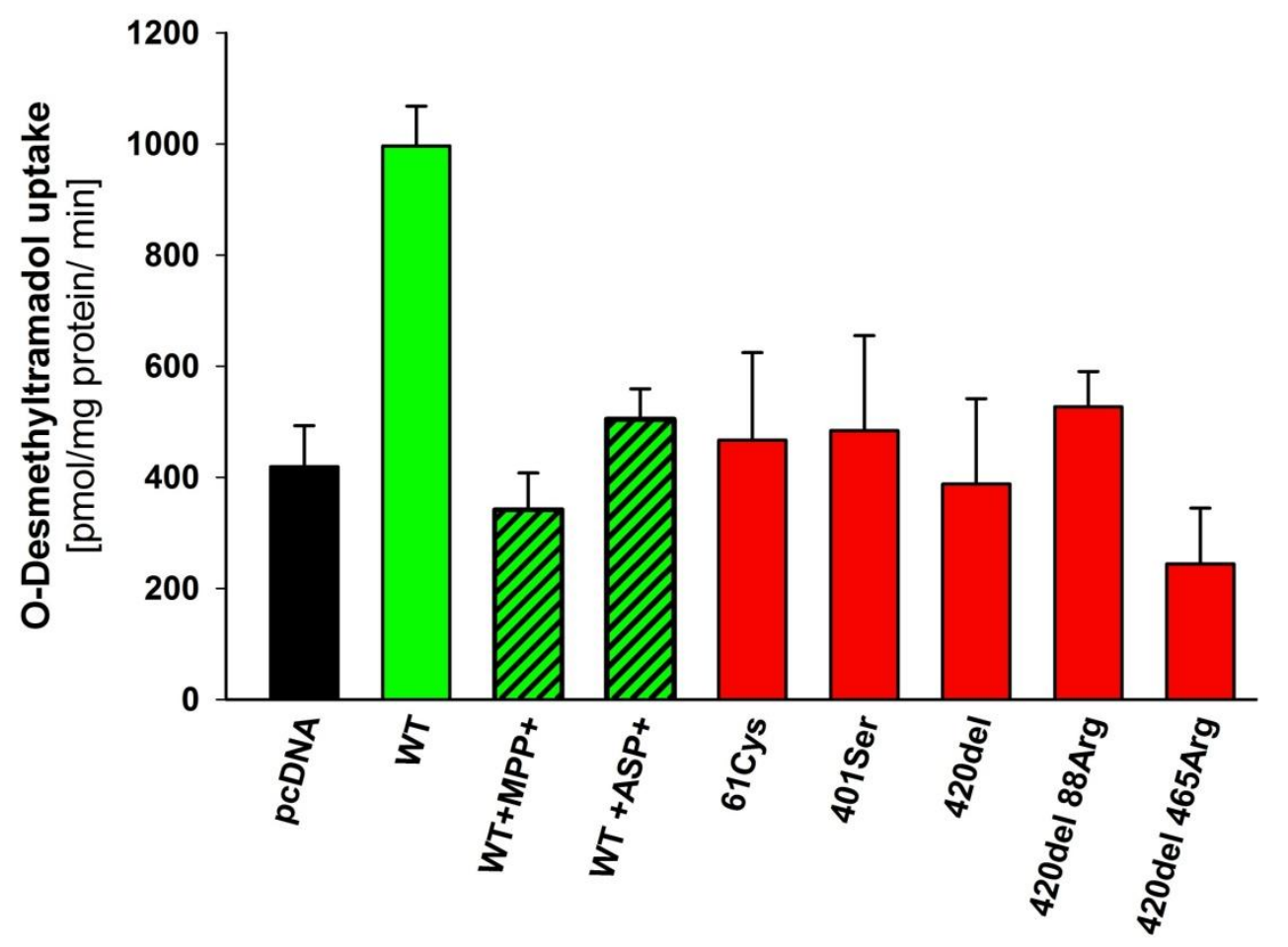

Fig.3. 30 The cellular uptake of (A) tramadol and (B) O-desmethyltramadol in OCT1 overexpressing HEK293 cells. The OCT1 overexpressing HEK cells and the control cells transfected with pcDNA5.1 empty vector were incubated with $1 \mu \mathrm{M}$ tramadol or $1 \mu \mathrm{M} \mathrm{O}$ desmethyltramadol for $1 \mathrm{~min}$, and the intracellular concentrations of both substances were measured. A) No differences were detected for tramadol uptake in OCT1 overexpressing OCT1 wild-type (WT) (green bar) compared to the control cells (pcDNA5.1, black bar). B) 
Overexpression of the wild type OCT1 increased the O-desmethyltramadol uptake by 2.5-fold (WT) (green bar), but not the overexpression of the loss-of-function OCT1 variants (red bars). The cellular uptake of O-desmethyltramadol was blocked by $100 \mu \mathrm{M} \mathrm{MPP}{ }^{+}$in the cells that expressed wild-type OCT1 (green hatched bar). The graph shows mean values and standard errors from three independent experiments.

Based on the artificial membrane permeability assays, on the inhibition and direct uptake assays, it could be concluded that O-desmethylramadol is a substrate of OCT1 and O-desmethyltramadol uptake depends on OCT1 polymorphisms. In contrast tramadol have high carrier-independent membrane permeability and do not depend on OCT1 for its cellular uptake.

\subsection{OCT1 as a cellular uptake transporter of the model drug debrisoquine}

\subsubsection{PAMPA assay for debrisoquine}

In order to assess the ability of debrisoquine to penetrate cellular membranes in a carrier-independent manner, we measured debrisoquine diffusion through artificial PAMPA membranes after 5 hours incubation at room temperature as described previously (See section 2.2.12). Debrisoquine displayed very low artificial membrane permeability $\left(\mathrm{P}_{\mathrm{e}} 0.01 \times 10^{-6} \mathrm{~cm} / \mathrm{s}\right)$, suggesting that debrisoquine is not able to penetrate cellular membranes in a carrier-independent manner (Fig.3.31). This observation is in concordance with the low calculated lipophilicity value for debrisoquine (octanol/water distribution coefficients as $\log \mathrm{D}_{7.4}$ of 1.0; calculated using ADMED PredictorTM Software Version 5.0, Simulations Plus Inc., Lancaster, CA, USA). 


$$
P_{e}=0.01 \times 10^{-6} \mathrm{~cm} / \mathrm{s}
$$

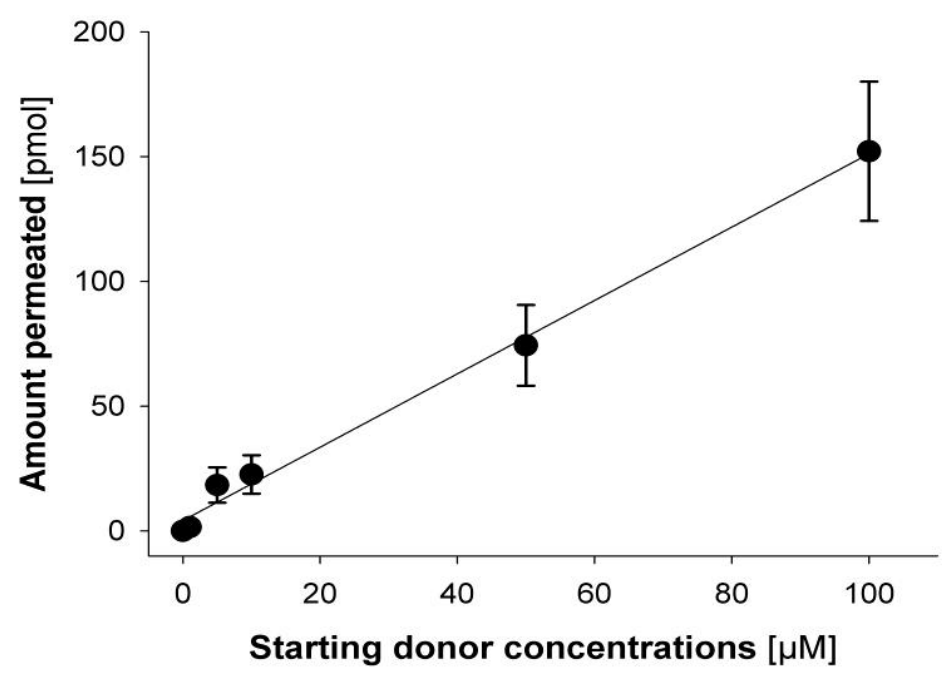

Fig.3. 31Carrier-independent membrane permeability of debrisoquine measured by PAMPA. The mean permeability $\left(\mathrm{P}_{\mathrm{e}}\right)$ value of all five different concentrations of debrisoquine $(0$, $1,10,50$ and $100 \mu \mathrm{M})$ are given. The graph shows mean values and standard errors of three independent experiments.

\subsubsection{Inhibition of OCT1-mediated MPP ${ }^{+}$uptake by debrisoquine}

First we investigate whether debrisoquine may inhibit OCT1- mediated uptake. For that purpose, OCT1 overexpressing HEK293-TRex cells as well as control cells transfected with an empty pcDNA5.1 vector were used. The cells were incubated with $\mathrm{MPP}^{+}$(1methyl-4-phenyl- pyridinium), a model substrate of OCT1, in the presence of increasing concentrations of debrisoquine. Without inhibition, $\mathrm{MPP}^{+}$uptake was 13.6-fold higher in the cells overexpressing OCT1 compared to the control cells (Fig. 3.32). Debrisoquine strongly inhibited the $\mathrm{MPP}^{+}$uptake. The difference in the $\mathrm{MPP}^{+}$uptake between the OCT1 overexpressing and the control cells was completely reversed at 500 $\mu \mathrm{M}$ debrisoquine and half-maximal inhibitory concentration $\left(\mathrm{IC}_{50}\right)$ of debrisoquine was $6.2 \pm 0.8 \mu \mathrm{M}$ (Fig. 3.32). 


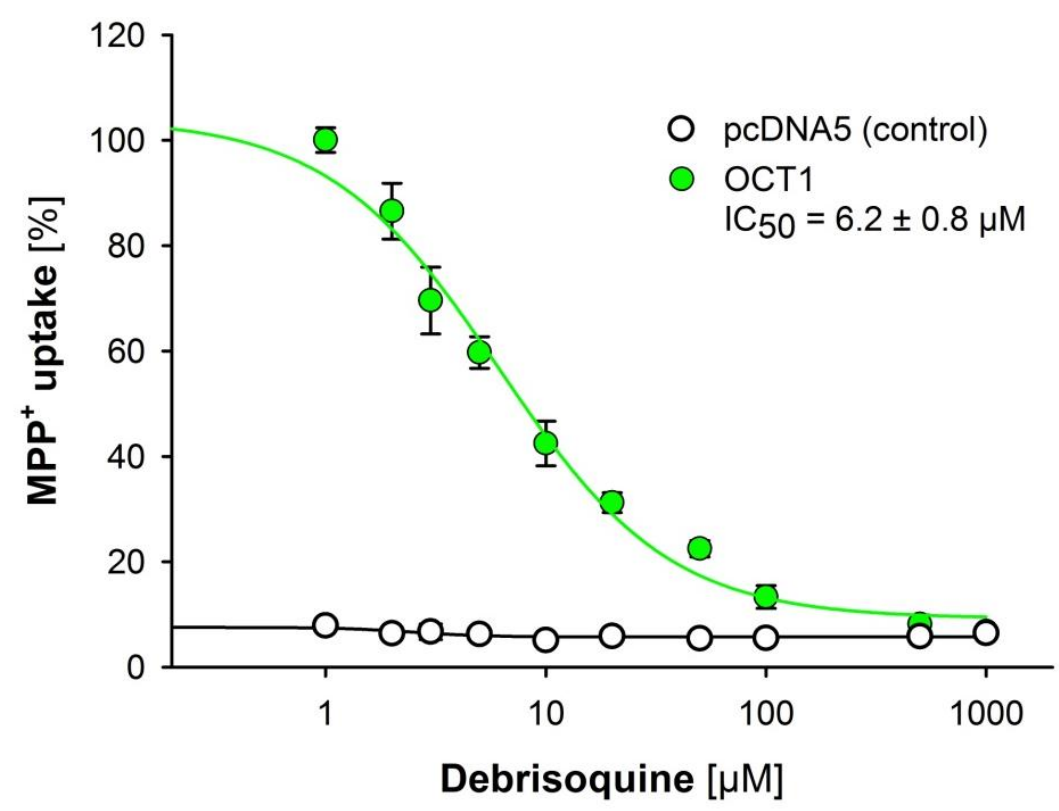

Fig.3. 32 Debrisoquine inhibits the uptake of the OCT1 model substrate MPP ${ }^{+\cdot}$ The cellular accumulation of $1 \mu \mathrm{M} \mathrm{MPP}^{+}$for $3 \mathrm{~min}$ in the presence of increasing concentration of debrisoquine was measured in cells overexpressing OCT1 and in control cells transfected with the empty plasmid pcDNA5.1. The graph shows mean values and standard errors from three independent experiments.

\subsubsection{Direct measurements of debrisoquine cellular uptake by OCT1.}

First we measured time dependence of the OCT1-mediated debrisoquine uptake. Thereto we incubated the cells overexpressing OCT1 wild type and control cells with a constant concentration of $1 \mu \mathrm{M}$ debrisoquine and different incubation time (30 sec, 1 min, $5 \mathrm{~min}, 15 \mathrm{~min}$ and $30 \mathrm{~min}$ ). Intracellular concentration increased in a time dependent manner in the wild-type, whereas no similar effect was observed in the control cells (Fig.3.33). 


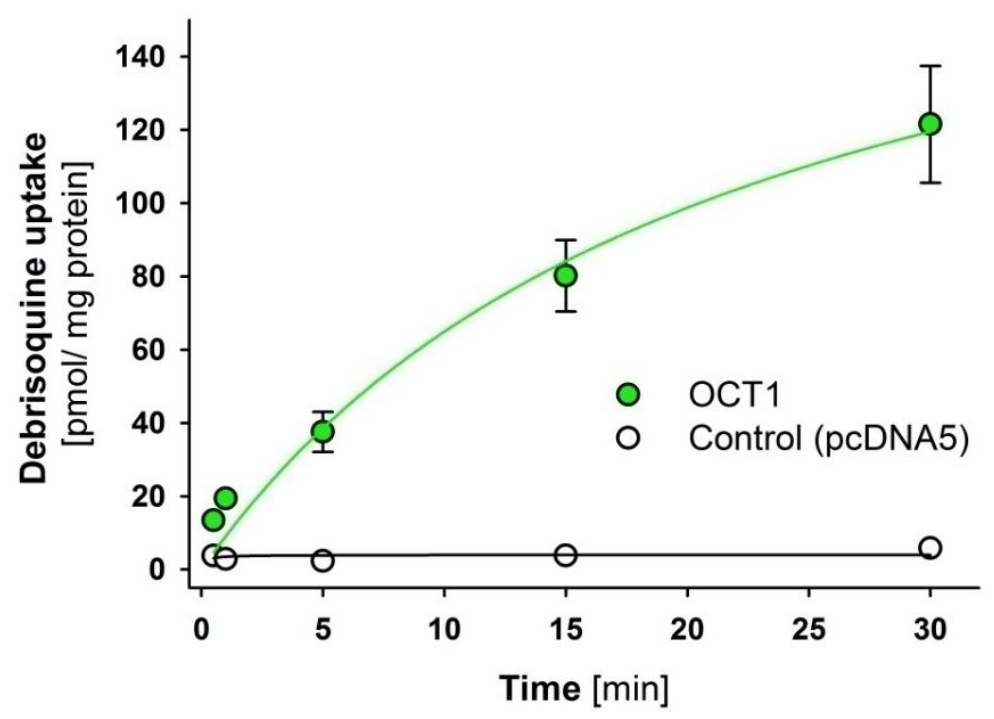

Fig.3. 33 Time dependence of debrisoquine accumulation. HEK cells overexpressing OCT1 (green line) and control cells (transfected with the empty pcDNA5.1 vector, black line) were incubated with $1 \mu \mathrm{M}$ debrisoquine for $30 \mathrm{sec}, 1,5,15$, or $30 \mathrm{~min}$ and the amount of intracellular debrisoquine was determined by means of HPLC. The graphs show mean values and standard errors from three independent experiments.

Next, the OCT1-mediated uptake of debrisoquine was measured by comparing the intracellular accumulation of debrisoquine between the OCT1-overexpressing and control cells at different concentrations of debrisoquine $(0,1,5,10,20$, and $40 \mu \mathrm{M})$. OCT1overexpressing cells showed strong concentration-dependent uptake of debrisoquine that was absent in the control cells (Fig. 3.34 A). To distinguish between the OCT1specific and carrier-independent uptake of debrisoquine, the uptake of the control cells was subtracted from the uptake of the OCT1-overexpressing cells. The OCT1-specific debrisoquine uptake showed typical Michaelis-Menten kinetics with a $\mathrm{K}_{\mathrm{M}}$ of $5.9 \pm 1.5$ $\mu \mathrm{M}$ and $\mathrm{V}_{\max }$ of $41.9 \pm 4.5 \mathrm{pmol} / \mathrm{min} / \mathrm{mg}$ of protein (Fig. $3.34 \mathrm{~B}$ ). From this data, we can conclude that debrisoquine is a high affinity substrate of OCT1. 
A)

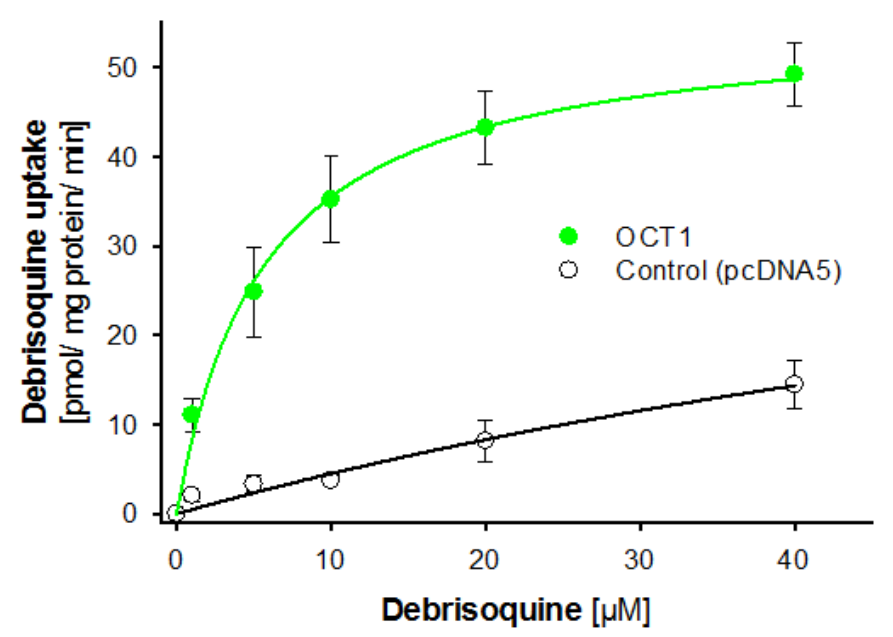

B)

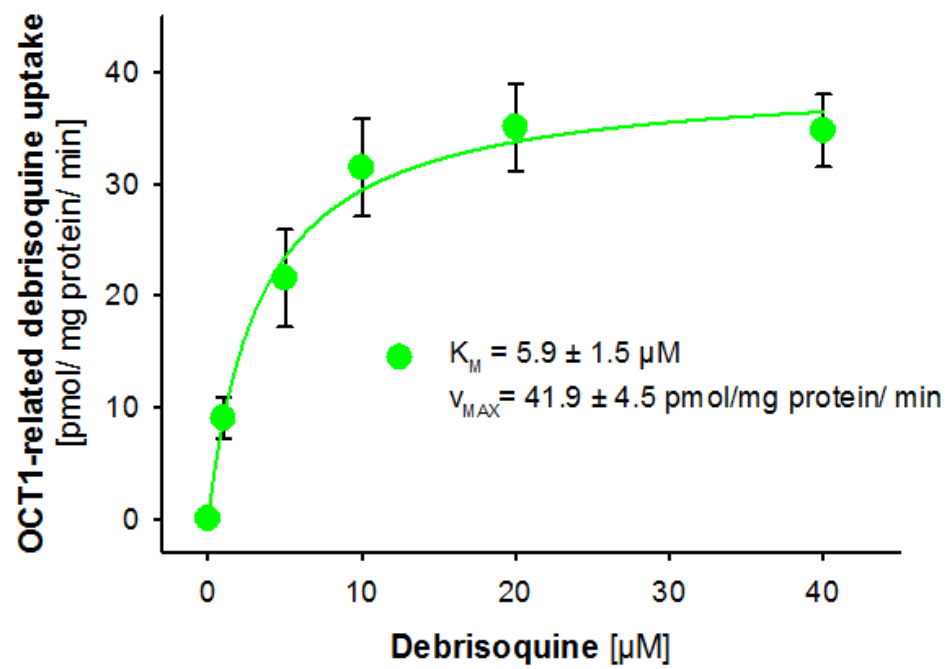

Fig.3. 34 Concentration dependence of the OCT1-mediated cellular uptake of debrisoquine.

(A) Concentration dependence of debrisoquine uptake. OCT1-overexpressing (OCT1) and control cells (pcDNA5.1) were incubated for $1 \mathrm{~min}$ with increasing concentrations of debrisoquine. (B) The OCT1 specific debrisoquine uptake calculated by subtracting the uptake in the control cells from the uptake in the OCT1-overexpressing cells using the dataset shown in (A). Intracellular accumulation of debrisoquine was measured by means of high-performance liquid chromatography and normalized to the total protein amounts in the cells. The graphs show mean values and standard errors from three independent experiments. 


\subsubsection{Effects of OCT1 genetic polymorphisms on debrisoquine uptake}

We analyzed how common coding polymorphisms in OCT1 affect debrisoquine uptake. For this reason, we compared the intracellular accumulation of debrisoquine in HEK293-TRex cells overexpressing the wild type or the five variant OCT1s as well as control cells transfected with pcDNA5.1 empty vector. In the presence of $1 \mu \mathrm{M}$ extracellular debrisoquine, all OCT1 variants tested showed lower debrisoquine uptake compared to the wild-type OCT1 (Fig. 3.35). However, the observed reduction in the uptake varied among the isoforms carrying different polymorphisms. We were unable to demonstrate a significant decrease in debrisoquine uptake when the Met420 deletion variant was present. In contrast, the Cys88Arg and Gly465Arg substitutions led to complete lack of OCT1-mediated uptake.

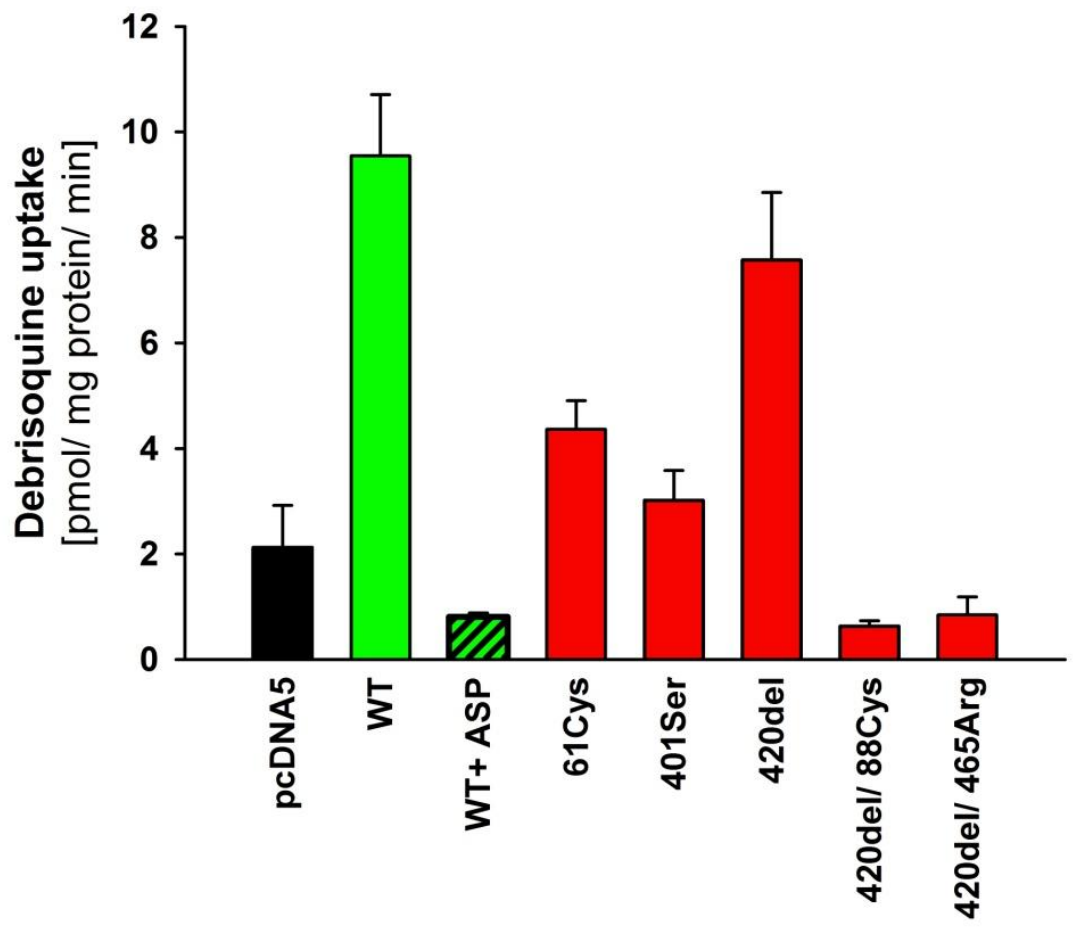

Fig.3. 35 Effects of common loss-of-function polymorphism on the debrisoquine cellular uptake. The OCT1 wild type (green bar) carrying OCT1 variants (red bars) and the control HEK293 cells transfected with the empty pcDNA5.1 plasmid (black bar) were incubated with 1 $\mu \mathrm{M}$ debrisoquine for $1 \mathrm{~min}$. The graphs show mean values and standard errors from three independent experiments 
Analyses of the concentration dependence of the debrisoquine uptake showed that the $\mathrm{V}_{\max }$ of OCT1 was affected by all of the polymorphisms tested $(\mathrm{P}<0.003$, ANOVA with Tukey-HSD post hoc test, Fig.3.36). In contrast, the $\mathrm{K}_{\mathrm{M}}$ values were not significantly affected by any of the polymorphisms ( $\mathrm{P}=0.73$, ANOVA; Table.3.6).

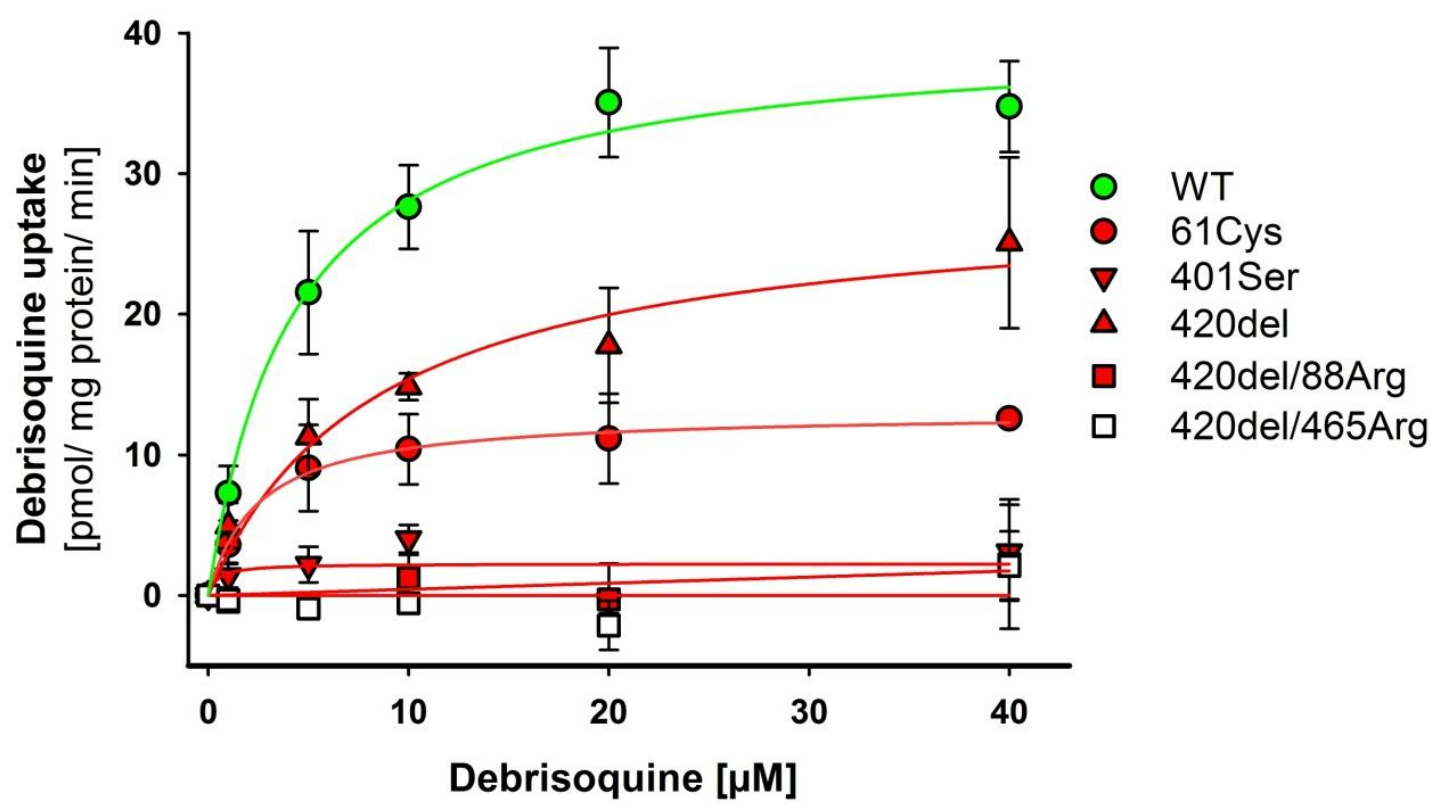

Fig.3. 36 Concentration dependence of OCT1-mediated debrisoquine uptake in the wild-type and loss-of-function OCT1 isoforms after incubation with increasing concentrations of debrisoquine $(0,1,5,10,20$ and $40 \mu \mathrm{mol} / \mathrm{l})$. The cellular uptake of debrisoquine was measured by means of high-performance liquid chromatography and normalized to the total protein amount of the cells. The graphs show mean values and standard errors from three independent experiments. 
Table 3. 6 Effects of the common loss-of-function amino acid substitutions in OCT1 on the kinetic of debrisoquine.

\begin{tabular}{lcccccc}
\hline \multirow{2}{*}{ SNP } & \multicolumn{2}{c}{$\mathbf{V}_{\text {max }}$} & \multicolumn{2}{c}{$\mathbf{K}_{\mathbf{m}}$} & \multirow{2}{*}{$\mathbf{C l}_{\text {int }}$} \\
\cline { 2 - 5 } & Mean & SEM & Mean & SEM & Mean \\
\hline Reference (WT) & 41.9 & 4.5 & 5.9 & 1.5 & 7.1 \\
61Cys & $15.6^{*}$ & 0.5 & 6.2 & 3.5 & 2.5 \\
401Ser & $3.6^{*}$ & 2.1 & 2.6 & 2.5 & 1.4 \\
420del & $21.7 *$ & 1.1 & 4.8 & 1.5 & 4.5 \\
420del/88Arg & na & na & na & na & na \\
420del/465Arg & na & na & na & na & na \\
\hline na., not applicable. * P $<0.01$ compared to the WT reference in a Tukey's HSD post hoc analysis \\
following one-way ANOVA $\left(\mathrm{P}<10^{-4}\right)$.
\end{tabular}

\subsubsection{Effects of drug-drug interactions on the OCT1-mediated debrisoquine uptake}

In this experiment we analyzed whether known model OCT1 substrates or clinically relevant drugs may inhibit the OCT1-mediated cellular uptake of debrisoquine (Fig.3.37). For this reason, we used the well known OCT1 model substrates MPP ${ }^{+}$and $\mathrm{ASP}^{+}$, the inhibitor $\mathrm{TBA}^{+}$(tetra-N-butylammonium) and the clinically relevant drugs tropisetron, ondansetron, tramadol and paroxetine (all known as OCT1 substrates or inhibitors from earlier data). All substances tested led to significant inhibition of the OCT1-mediated uptake ( $\mathrm{P}<0.003$, ANOVA with Tukey-HSD post hoc test). Of all the tested substances, the least inhibition was observed with tramadol (66\% reduction of the OCT1-mediated uptake, $\mathrm{P}=0.003$ ). This result was expected given that tramadol has a higher $\mathrm{IC}_{50}$ value for OCT1 than do tropisetron and ondansetron (Tzvetkov et al., 2010; 2011). Paroxetine had higher inhibitory effect on debrisoquine uptake among the clinically relevant drugs. The highest inhibitory effect of all tested compounds was observed for $\mathrm{ASP}^{+}$(Fig.3.37). 
It could be concluded that debrisoquine is a low membrane permeability drug and depends for its cellular uptake on OCT1-mediated uptake. Furthermore, known OCT1 inhibitors reduced or completely abolished the ability of OCT1 to mediate debrisoquine uptake.

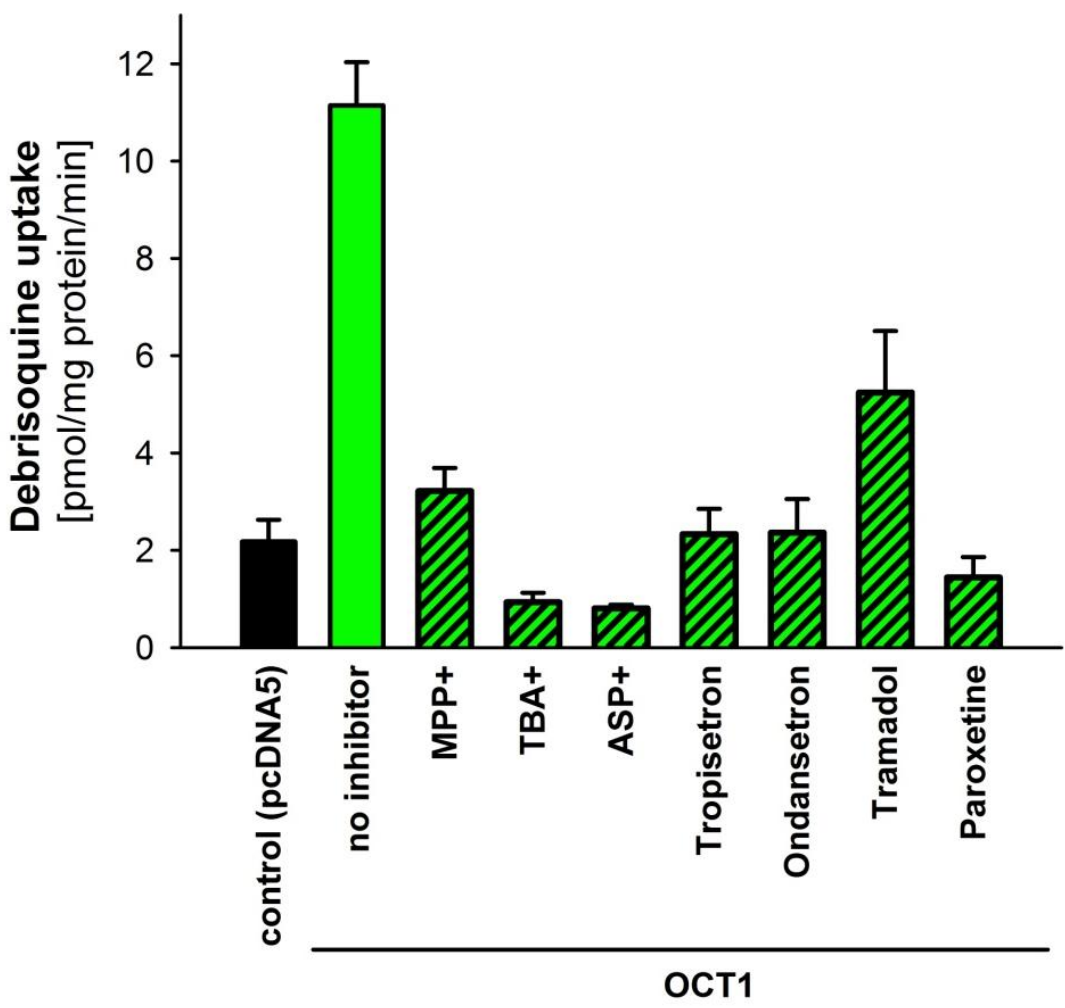

Fig.3. 37 Inhibition of the OCT1-mediated uptake debrisoquine by OCT1 inhibitors and weakly basic drugs. HEK293-TRex cells overexpressing OCT1 were incubated for 1 min with 1 $\mu \mathrm{M}$ debrisoquine in the absence of any inhibitors (green bar) or in the presence of $200 \mu \mathrm{M}$ model OCT1 substrates or drugs known to be substrates or inhibitors of OCT1 (hatched green bars). As a control, HEK293-TRex cells transfected with the empty pcDNA5.1 plasmid were incubated with debrisoquine in the absence of inhibitors (black bar). The cellular uptake of debrisoquine was measured by means of high-performance liquid chromatography and normalized to the total protein amounts in the cells. The graph shows mean values and standard errors from three independent experiments.

\subsubsection{Interaction between OCT1 and CYP2D6 during metabolism of debrisoquine}

To analyze the interactions between cellular uptake and intracellular metabolism of debrisoquine, cells overexpressing OCT1 alone, CYP2D6 alone and a combination of 
OCT1 and CYP2D6 were used. The cells were incubated with the same concentration of debrisoquine $(10 \mu \mathrm{M})$ for different incubation time $(1,3,20,60,90$ and $120 \mathrm{~min})$. The intracellular amount of debrisoquine and 4-OH debrisoquine was measured by HPLC (Fig. 3.38).

The debrisoquine uptake was increased by increasing incubation time for OCT1 overexpressing cells, whereas the maximum uptake was obtained in 1 hour incubation for HEK cells overexpressing OCT1::CYP2D6::IRES::POR. No clear trend was observed for HEK cells overexpressing CYP2D6::IRES::POR or control cells (Fig. $3.38 \mathrm{~A})$. On the other hand, the maximum amount of 4-hydroxy debrisoquine was reached after 1 hour incubation for the cells overexpressing only CYP2D6, whereas the maximum amount of 4-hydroxy debrisoquine was reached already after 3 minutes incubation for the cells overexpressing OCT1 and CYP2D6 (Fig. 3.38B). As expected no 4-hydroxy debrisoquine was detected in the cells overexpressing OCT1 only or in the control cells. 
A)
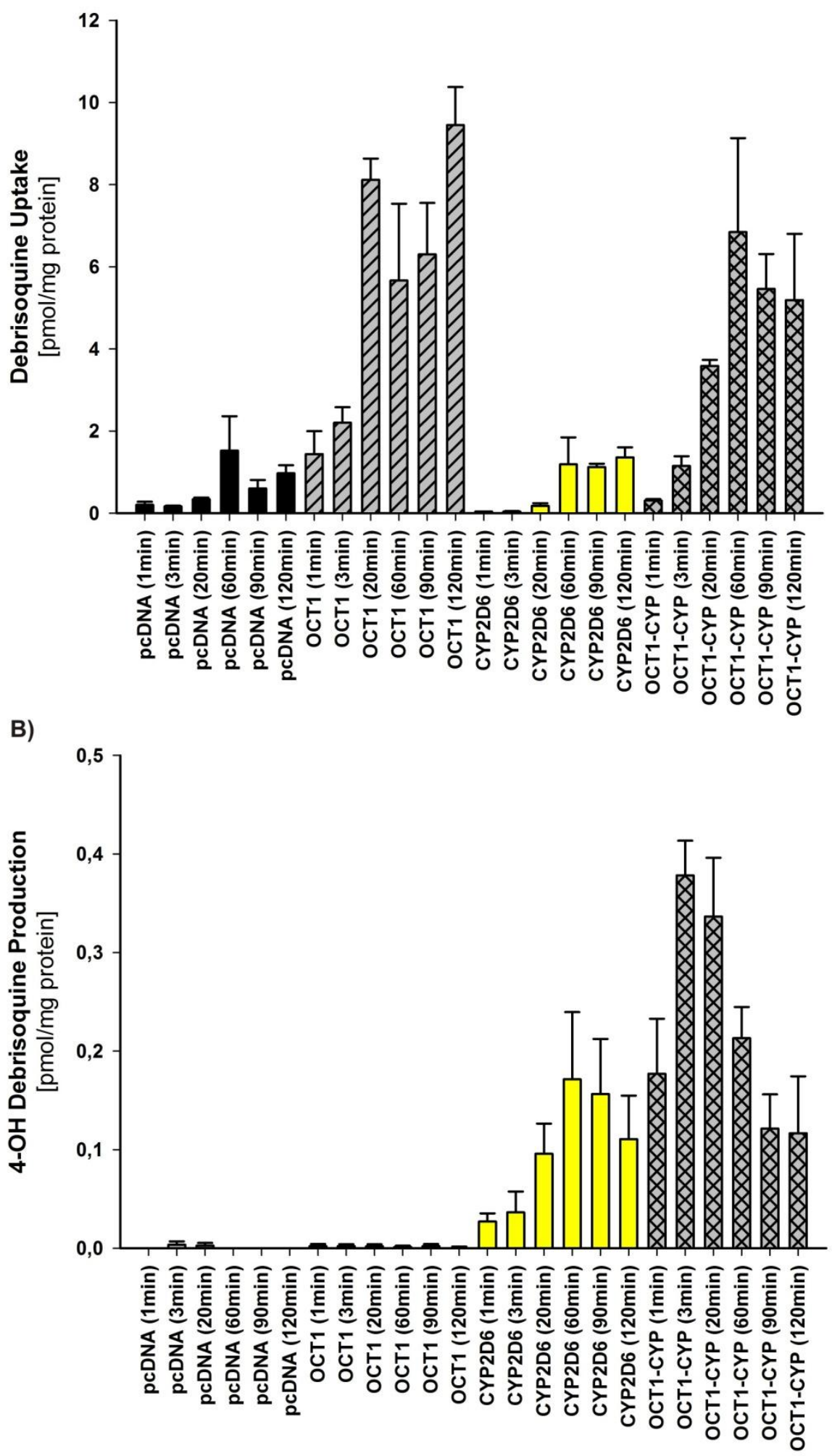

Fig.3. 38 Time dependence of debrisoquine uptake (A) and 4- hydroxy debrisoquine production (B) in the cells overexpressing OCT1 (single hatched bars), CYP2D6 (yellow bars) and combination of OCT1 and CYP2D6 (double hatched bars). The control cells transfected with the 
empty pcDNA5.1 vector are depicted as black bars. The cells were incubated with $10 \mu \mathrm{M}$ debrisoquine, washed, lysed and the intracellular accumulation of debrisoquine and 4-hydroxy debrisoquine was quantified by HPLC The graphs show mean values and standard errors from three independent experiments.

\subsubsection{Effects of loss of function polymorphisms in OCT1 on uptake and metabolism of debrisoquine}

In this experiment to evaluate the interactive effect of polymorphisms in OCT1 with CYP2D6 enzyme on production of 4-OH debrisoquine, the cells overexpressing OCT1::CYP2D6::IRES::POR wild type and the variant of OCT1 420del88R as well as the HEK cells transfected with empty vector pcDNA5 as control were treated with the same concentration of debrisoquine $(10 \mu \mathrm{M})$ and incubated for $3 \mathrm{~min}$. Then the intracellular amount of debrisoquine and 4-OH debrisoquine was measured by HPLC (Fig.3.39 A and B). As illustrated in the graphs, the amount of debrisoquine uptake and consequently intracellular production of 4-OH debrisoquine was significantly higher in wild type compared to loss of function 420del88R variant or control cells.

A)

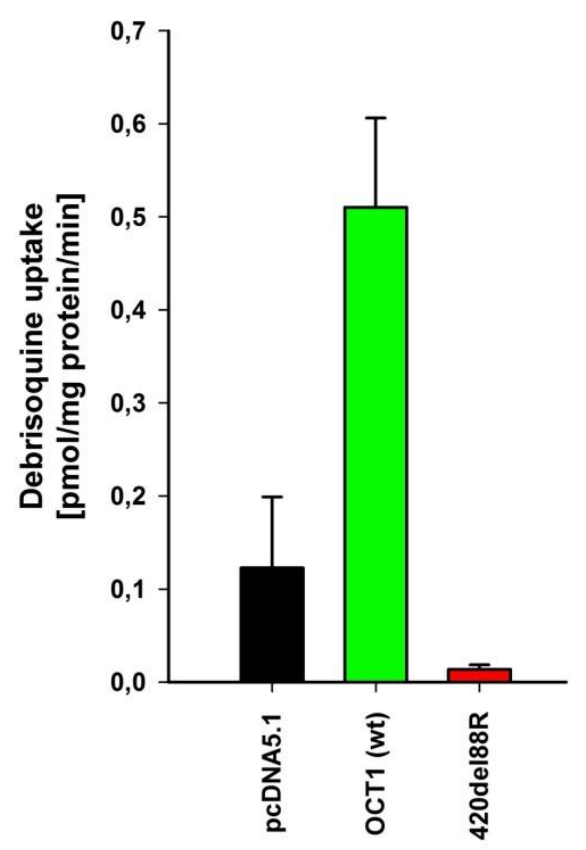

B)

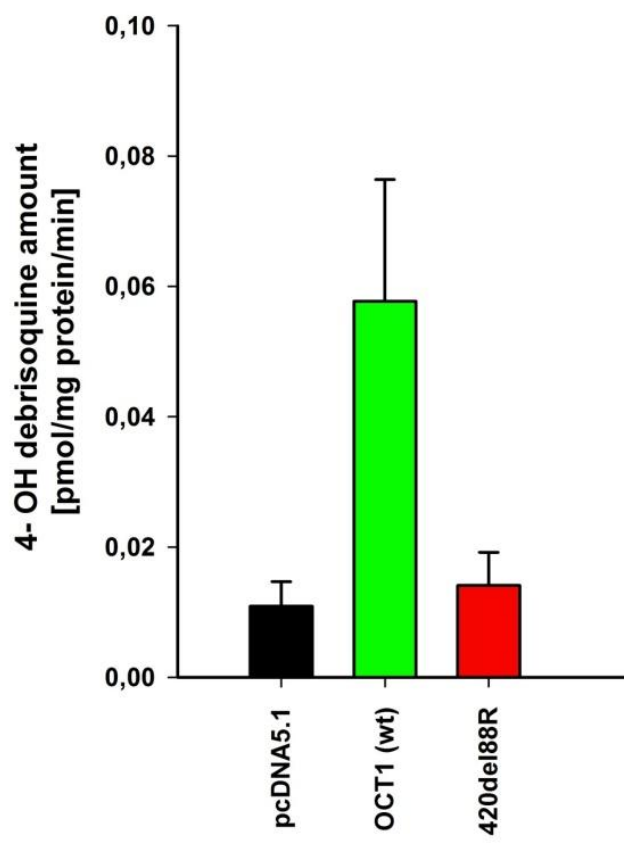

Fig.3. 39 Interactive effects of polymorphisms in the OCT1 transporter with CYP2D6 metabolizing enzyme on debrisoquine uptake (A) and 4-OH debrisoquine production (B) in the HEK cells overexpressing OCT1::CYP2D6::POR wild type (green bar) and 420del88R variant 
of OCT1 (red bar) in compare with the HEK cells transfected with empty vector pcDNA5.1 as control (black bar). The graphs show mean values and standard errors from three independent experiments.

\subsubsection{Effects of CYP2D6 inhibitors on debrisoquine metabolism in the triple transfected system}

In this experiment we analyzed whether paroxetine known as an inhibitor of CYP2D6 may inhibit the OCT1-mediated debrisoquine uptake and subsequently CYP2D6mediated metabolism of debrisoquine to 4-hydroxy debrisoquine at the same fashion (Fig.3.40 A and B). For this reason, we used increasing concentration of paroxetine ( 0 , $0.1,0.2,0.5,1,5,10$ and $50 \mu \mathrm{M})$ with the same concentration of debrisoquine $(10 \mu \mathrm{M})$. The results showed that the amount of intracellular debrisoquine declined deramatically after using paroxetine, however this trend was different for 4-hydroxy debrisoquine. As we can see, at low concentrations, paroxetine acted predominantly as an inhibitor of OCT1, whereas at higher concentrations, the inhibitory effects of paroxetine on metabolism of 4-hydroxy debrisoquine predominated. The highest concentrations of paroxetine $(50 \mu \mathrm{M})$ can completely blocked activity of CYP2D6 enzyme. This experiment impressively demonstrates that paroxetine at the low concentrations is predominantly an inhibitor of OCT1 and not of CYP2D6. 
A)

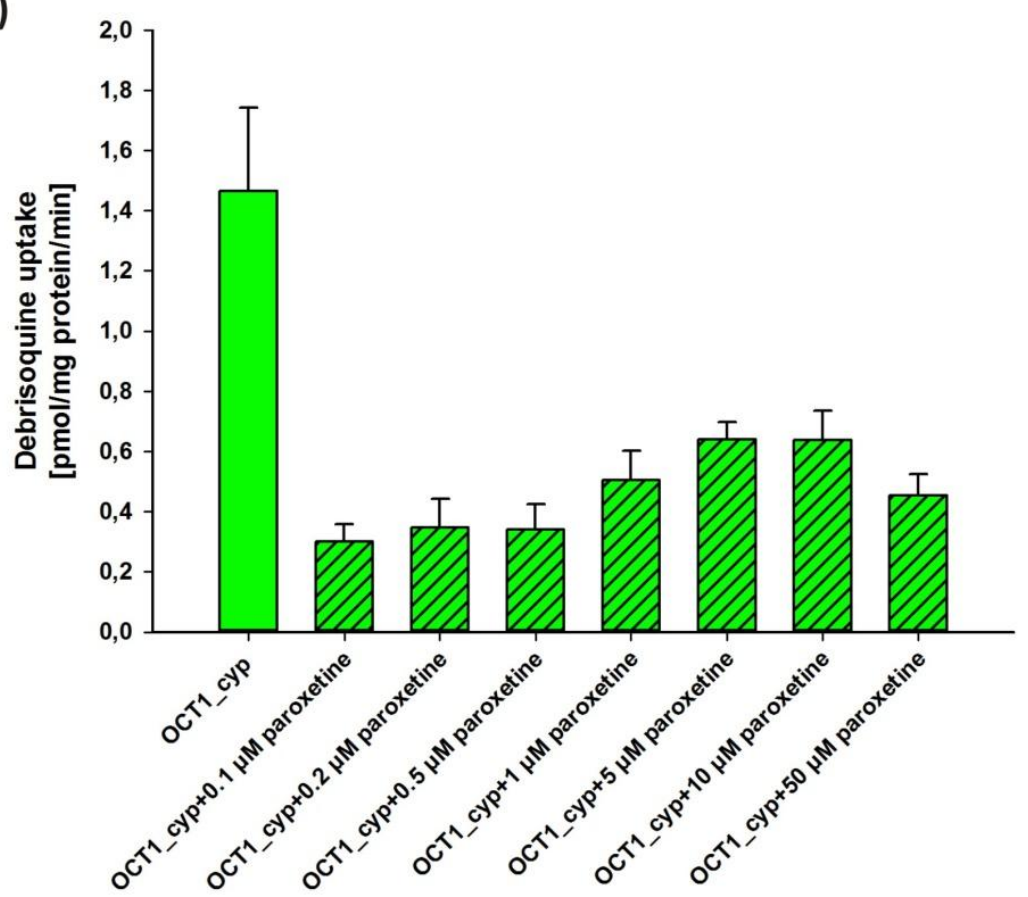

B)

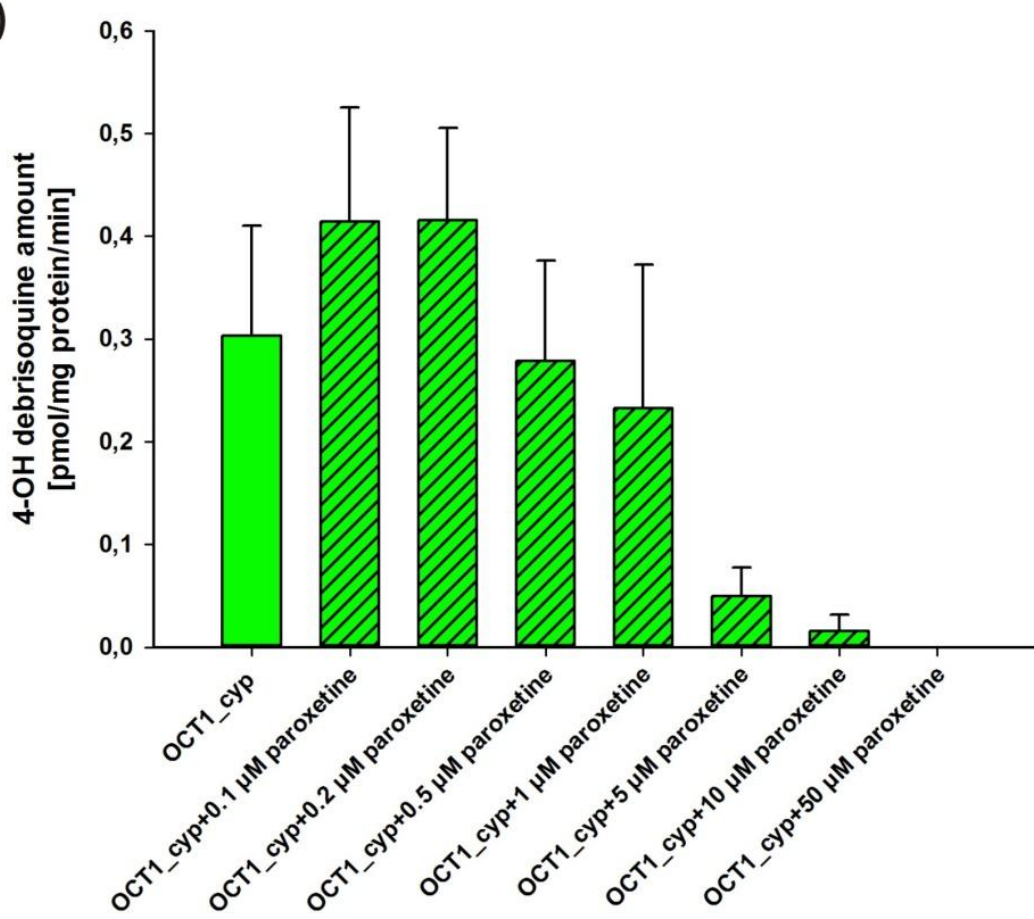

Fig.3. 40 Inhibitory effect of paroxetine on debrisoquine uptake (A) and 4- hydroxy debrisoquine production (B) in the HEK cells overexpressing OCT1 and CYP2D6. The HEK cells overexpressing OCT1 and CYP2D6 were treated with $10 \mu \mathrm{M}$ debrisoquine and increasing concentration of paroxetine $(0,0.1,0.2,0.5,1,5,10$ and $50 \mu \mathrm{M})$ for 3 min and consequently intracellular accumulation of debrisoquine and 4-hydroxy debrisoquine in the cells was quantified by HPLC. The graphs show mean values and standard error from three independent experiments. 


\subsection{OCT1 as a possible uptake transporter of the cytotoxic drugs irinotecan and doxorubicin}

\subsubsection{Inhibition of OCT1-mediated uptake by irinotecan and its active metabolite SN38}

Irinotecan and its active metabolite SN38 were tested as potential substrates of OCT1. Thereto first we measured the ability of irinotecan and SN38 to inhibit OCT1-mediated $\mathrm{ASP}^{+}$uptake. HEK293-TRex cells overexpressing wild type OCT1 were incubated with $1 \mu \mathrm{M} \mathrm{ASP}{ }^{+}$for $3 \mathrm{~min}$ in the presence of increasing concentrations of irinotecan or SN38 $(0,1,10,100$ and $500 \mu \mathrm{M})$. Only irinotecan, but not SN38, inhibited the OCT1mediated $\mathrm{ASP}^{+}$uptake (Fig.3.41). The half-maximal inhibitory concentration ( $\left.\mathrm{IC}_{50}\right)$ of irinotecan was $3 \pm 0.54 \mu \mathrm{M}$.

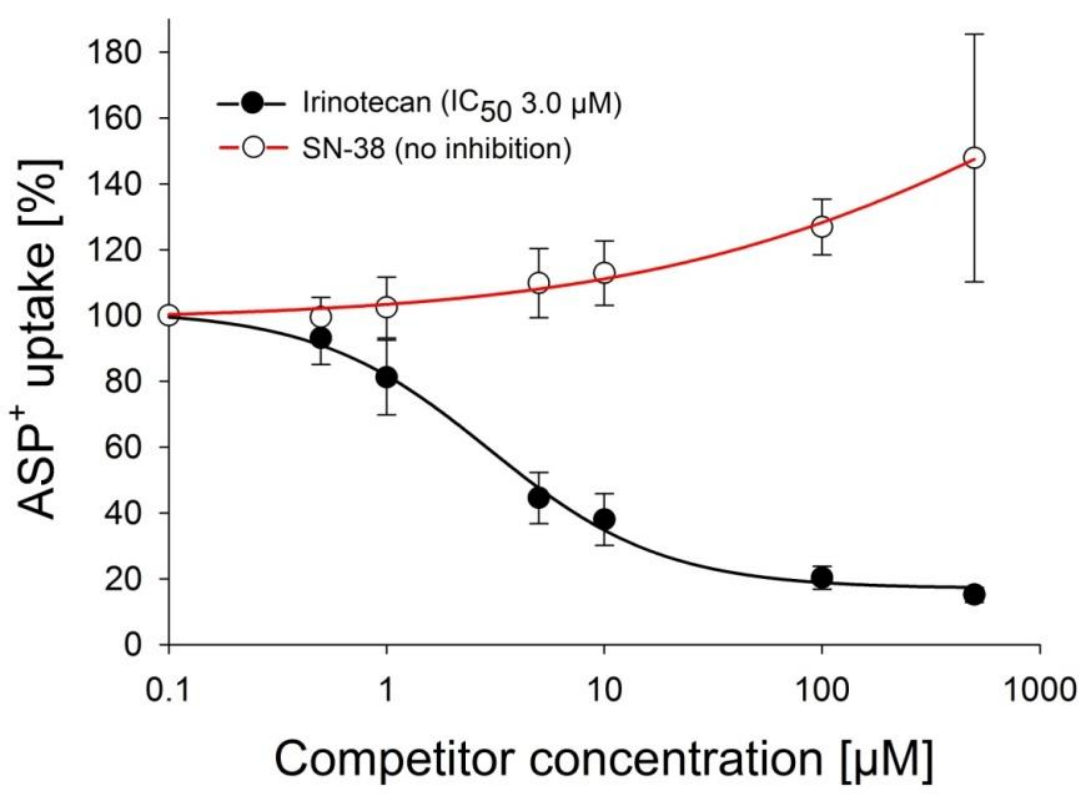

Fig.3. 41 Inhibition of the OCT1 by irinotecan and SN38. OCT1-overexpressing HEK293TRex cells were incubated with $1 \mu \mathrm{M} \mathrm{ASP}^{+}$for $3 \mathrm{~min}$ in the presence of increasing concentrations of irinotecan or $\operatorname{SN} 38(0,1,10,100$ and $500 \mu \mathrm{M})$. The graph shows mean values and standard errors of three independent experiments. 


\subsection{2 $\mathrm{pH}$-dependance of the inhibitory effect of irinotecan and its metabolite SN38}

Next we investigate whether the changes in $\mathrm{pH}$ medium affect the inhibitory effect of irinotecan and SN38 on OCT1-mediated $\mathrm{ASP}^{+}$uptake. Thereto HEK293-TRex cells overexpressing wild type OCT1 was incubated with $1 \mu \mathrm{M} \mathrm{ASP}^{+}$for 3 min in the presence or in the absence of $100 \mu \mathrm{M}$ irinotecan or SN38 in HBSS medium adjusted at different $\mathrm{pH}$. Four different $\mathrm{pH}$ were analyzed (pH of 5.4, 6.4, 7.4 and 9). Similary as shown before (section 3.3.2), the highest $\mathrm{ASP}^{+}$uptake was observed at $\mathrm{pH}$ of 7,4 . Irinotecan significantly inhibited the $\mathrm{ASP}^{+}$uptake at all $\mathrm{pH}$ tested except $\mathrm{pH} 9$ which no significant suppression was seen (Fig.3.42). In contrast, SN38 inhibited the $\mathrm{ASP}^{+}$ uptake only at $\mathrm{pH} 9$.

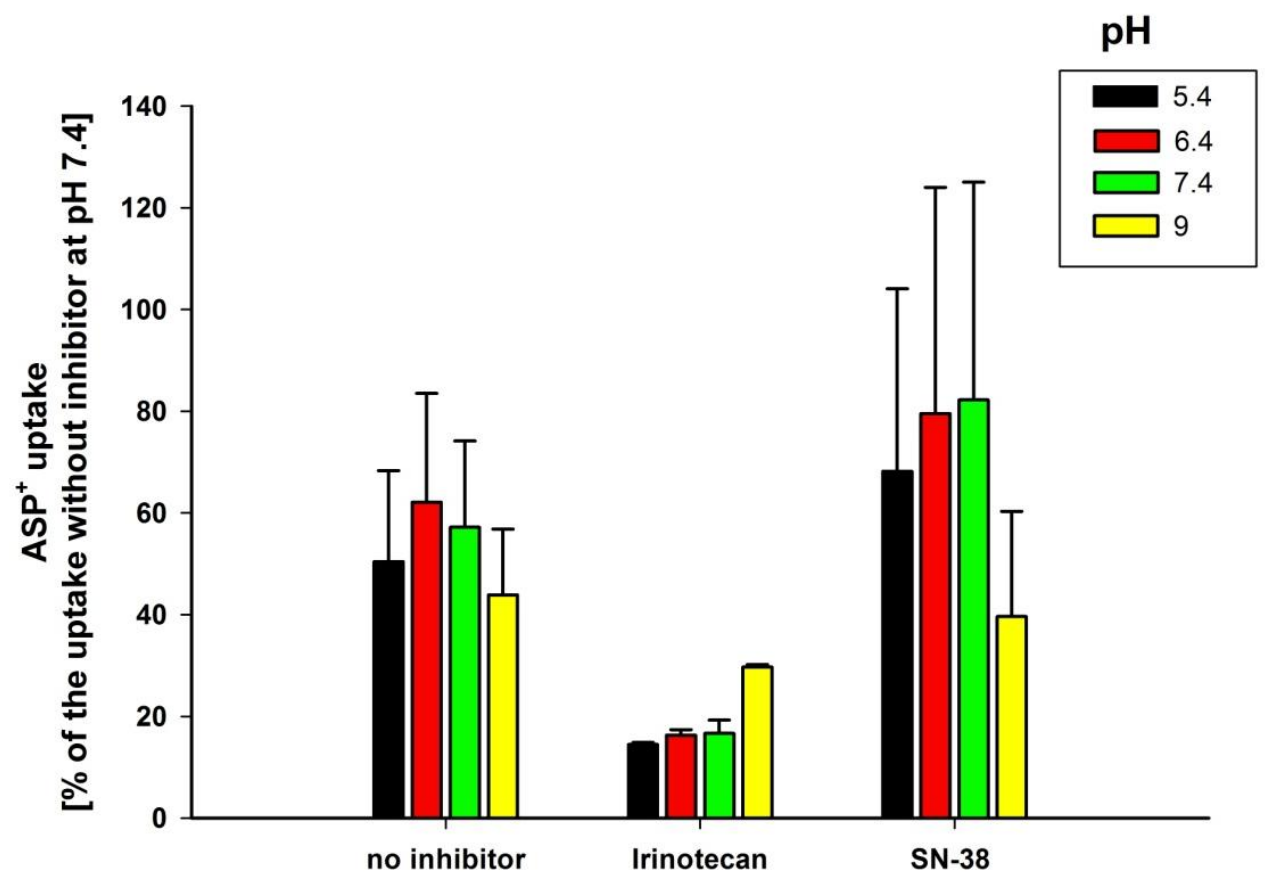

Fig.3. 42 pH-dependant effects of irinotecan and SN38 on the OCT1-mediated cellular uptake of $\mathbf{A S P}^{+}$. HEK293-TRex cells overexpressing OCT1 were incubated for 3 min with $1 \mu \mathrm{M}$ $\mathrm{ASP}^{+}$in the presence and in the absence of irinotecan or SN38. The intracellulary accumulated $\mathrm{ASP}^{+}$was measured using TECAN ultra plate photometer and normalized to the total protein amounts in the cells. The graph shows mean values and standard errors of three independent experiments. 


\subsubsection{Effects of OCT1 overexpression on irinotecan cytotoxicity}

Irniotecan is not a fluorescent substrate and we did not had access to radiolabeled irinotecan. Therefore, instead of going the tedious way of developing an HPLC method for intracellular drug and metabolite concentrations, we analyzed the differences in the amount of cellular irinotecan indirectly by differences in its cytotoxicity. In this experiment irinotecan was used as a cytotoxic drug to measure and compare the cell viability between control cells and cells overexpressing wild type and variant OCT1s. To exclude cell line specific differences in the irinotecan cytotoxicity the experiment was done both in HEK and CHO cell lines. The number of vital cells after the treatment was assessed using MTT cell proliferation assay. Incubation of the control cells with irinotecan resulted in $14 \%$ decrease in the vitality of the HEK293 cells (Fig.3.43A) or even $8 \%$ increase in the vitality of the CHO cells (Fig.3.43B). The OCT1 overexpression did not result in an increase of irinotecan cytotoxicity and there were no significant differences between the variant and wild-type OCT1. 
A)

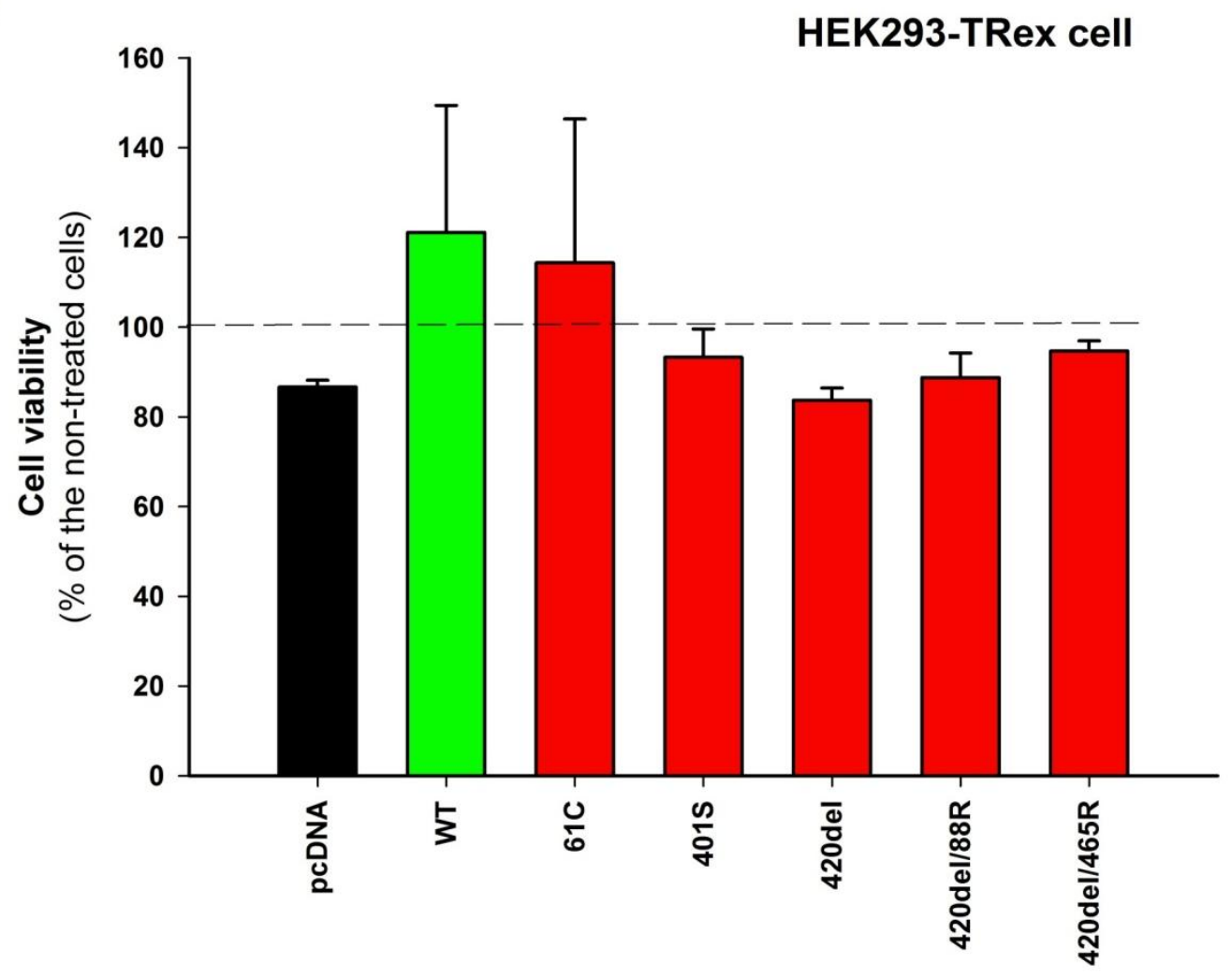

B)

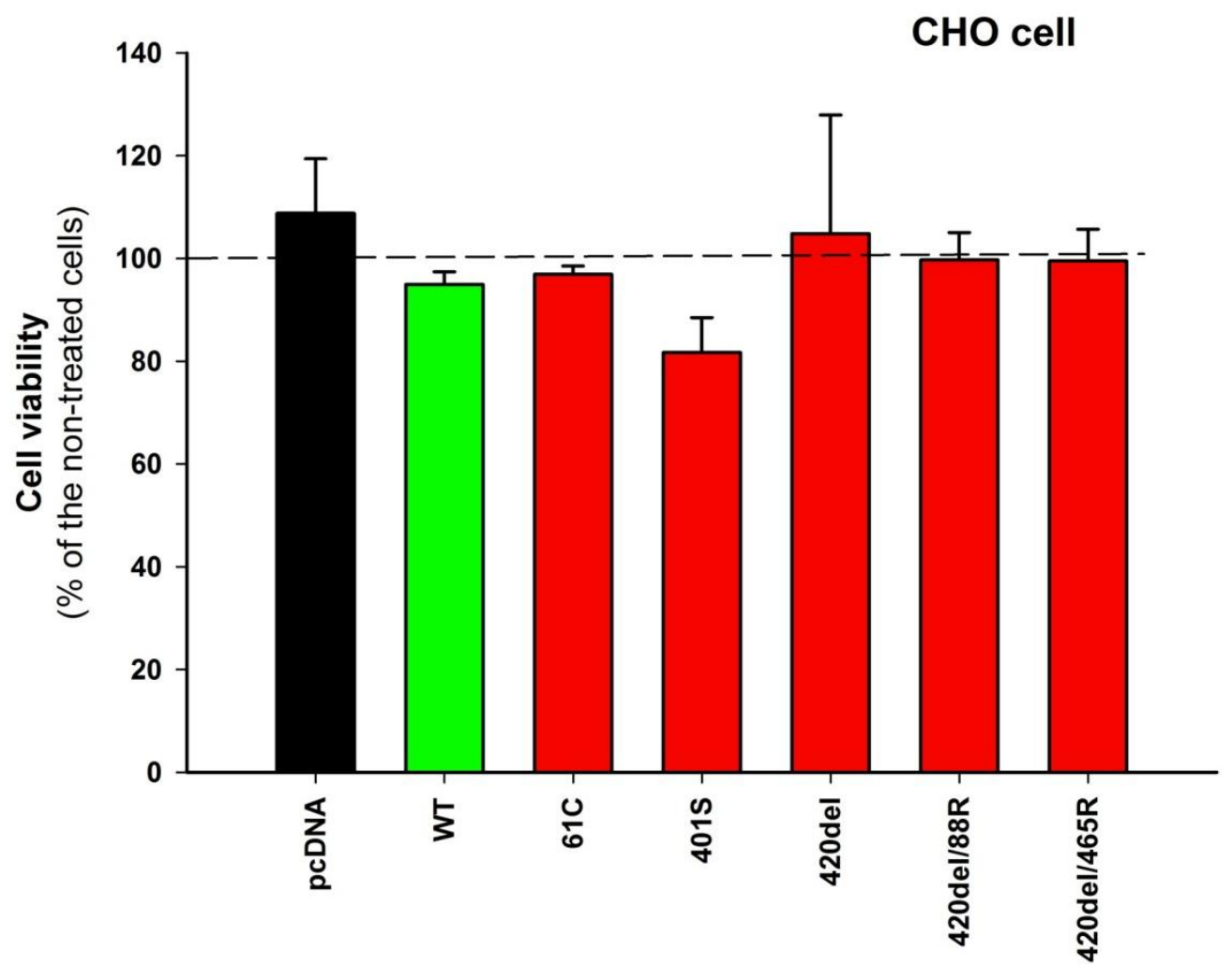

Fig.3. 43 Effects of OCT1 on irinotecan cytotoxicity in HEK (A) and CHO cells (B). The cells were treated with $100 \mu \mathrm{M}$ concentration of irinotecan for $15 \mathrm{~min}$ and then after overnight incubation the cell viability was determined by adding $1 \mathrm{ml} 750 \mu \mathrm{g} / \mathrm{ml}$ MTT to each well and 
incubated for 2 hours at $37^{\circ} \mathrm{C}$. The absorbance of the produced formazan was measured at $570 \mathrm{~nm}$.

The graph shows mean values and standard errors of three independent experiments.

As can be seen from both cell constructs, there was no relevant modification of cell toxicity depending on the expression of active or mutant OCT1. Thus, OCT1 may not be a relevant transporter for irinotecan or its active metabolite SN38.

\subsubsection{OCT1-mediated cellular uptake of doxorubicin}

In another experiment we analyzed whether OCT1 may transport doxorubicin. Doxorubicin has endogenous fluorescence that enabled us to measure doxorubicin uptake fluorometricaly. The OCT1 overexpressing HEK293-TRex cells as well as the control cells transfected with empty pcDNA5.1 plasmid were treated with increasing concentrations of doxorubicin $(0,1,10,100$ and $500 \mu \mathrm{M})$ for $3 \mathrm{~min}$. The intracellular accumulated doxorubicin was measured by TECAN ultra plate photometer. There were no significant differences in doxorubicin uptake between the OCT1 overexpressing and the control cells (Fig. 3.44), suggesting that OCT1 is not involved in the cellular uptake of doxorubicin.

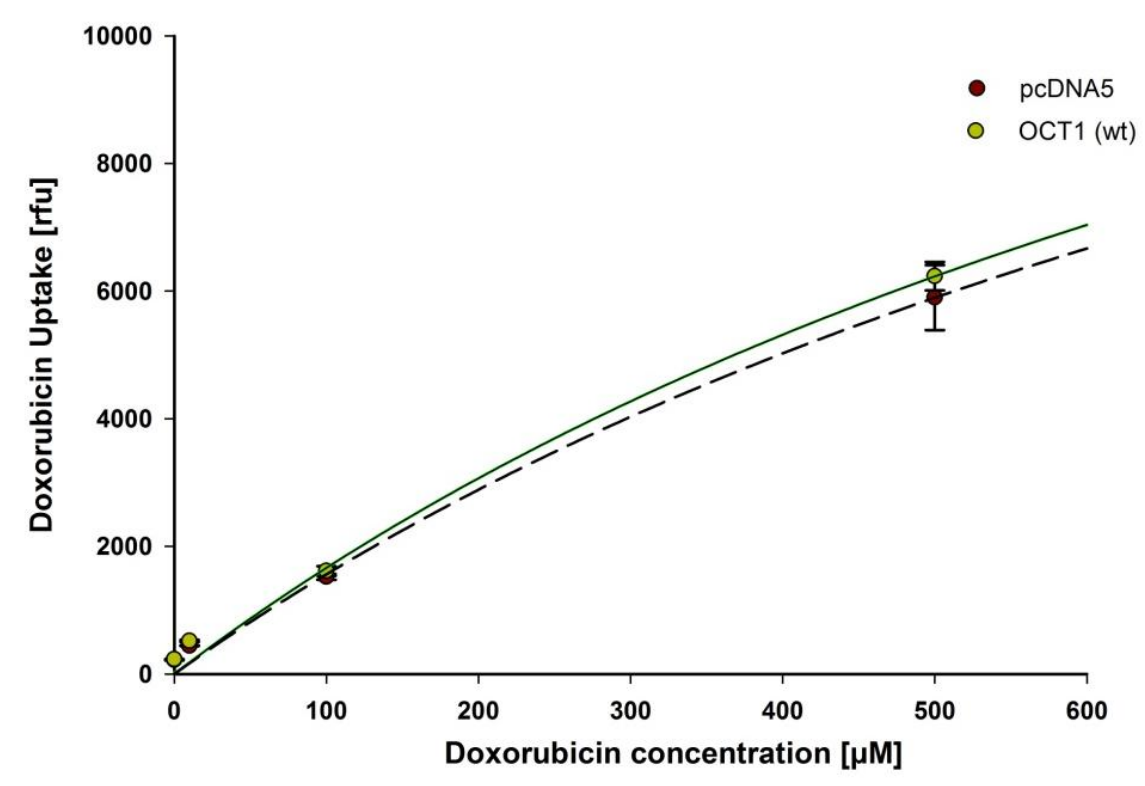

Fig.3. 44 Doxorubicin uptake is not dependent on OCT1 transporter. OCT1-overexpressing HEK cells as well as HEK cells transfected with empty vector pcDNA5 were exposed with increasing concentrations of doxorubicin $(0,1,10,100$ and $500 \mu \mathrm{M})$ for $3 \mathrm{~min}$. Doxorubicin has a native fluorescence that was used to determine the intracellular doxorubicin accumulation. 
Doxorubicin fluorescence was measured at an excitation wave length of $485 \mathrm{~nm}$ and an emission wave length of $612 \mathrm{~nm}$ using a TECAN Ultra plate ${ }^{\mathrm{TM}}$ photometer and normalized to the total protein amounts in the cells. The graphs show mean values and standard errors from three independent experiments.

\subsection{Analyzing potential dominant negative effect of the OCT1 protein variants}

\subsubsection{Generation of pcDNA5.1::OCT1_GFP construct}

We generated a fusion construct between OCT1 and GFP in order to monitor the subcellular localization of OCT1 more precisely as compared with immuno $\neg$ histochemistry. Therefore we fused EGFR to the C-terminus of the OCT1 protein. The pcDNA5.1 plasmid containing OCT1 wild type or two variants A61C and 420del-C88A, and also the pIRES2-EGFP plasmid (Addgene, Cambridge, MA) containing a 719 bp fragment of green flourescence protein (GFP). To amplify OCT1 and GFP by PCR, the primers were designed to have homologous for both genes (Table3.7). For this reason, the reverse primer of OCT1 had a homology with the forward primer of GFP which in turn caused GFP to tag in the downstream of OCT1 open reading frame and then the experiment was performed according to DNA assembling procedure as described previously (see section 2.2.1.10).

Table 3. 7 The lists of primers used for amplification of OCT1 and GFP.

\begin{tabular}{ll}
\hline Primer & Primer sequence \\
\hline Fussion_OCT1_f & 5'-GTTTAAACTTAAGCTTGCATGCTGAG-3' \\
Fussion_oCT1_r & 5'-CAGCTCCTCGCCCTTGCTCACCATGGTGCCCGAGGGTTGTGAGGT-3' \\
Fussion_eGFP_f & 5'-AACCTCAGAACCCTCGGGCACCATGGTGAGCAAGGGCGAGGAGCT-3' \\
Fussion_eGFP_r & 5'-ATCGCTCTAGAGCGGCCGCTTTACTT-3' \\
\hline
\end{tabular}

Then the assembled product (OCT1_GFP) was amplified with the forward primer, Fussion_OCT1_f and the reverse primer. Fussion_OCT1_f and Fussion_eGFP_r primers introduced the restriction sites for HindIII and NotI respectively (Fig.3.45). 

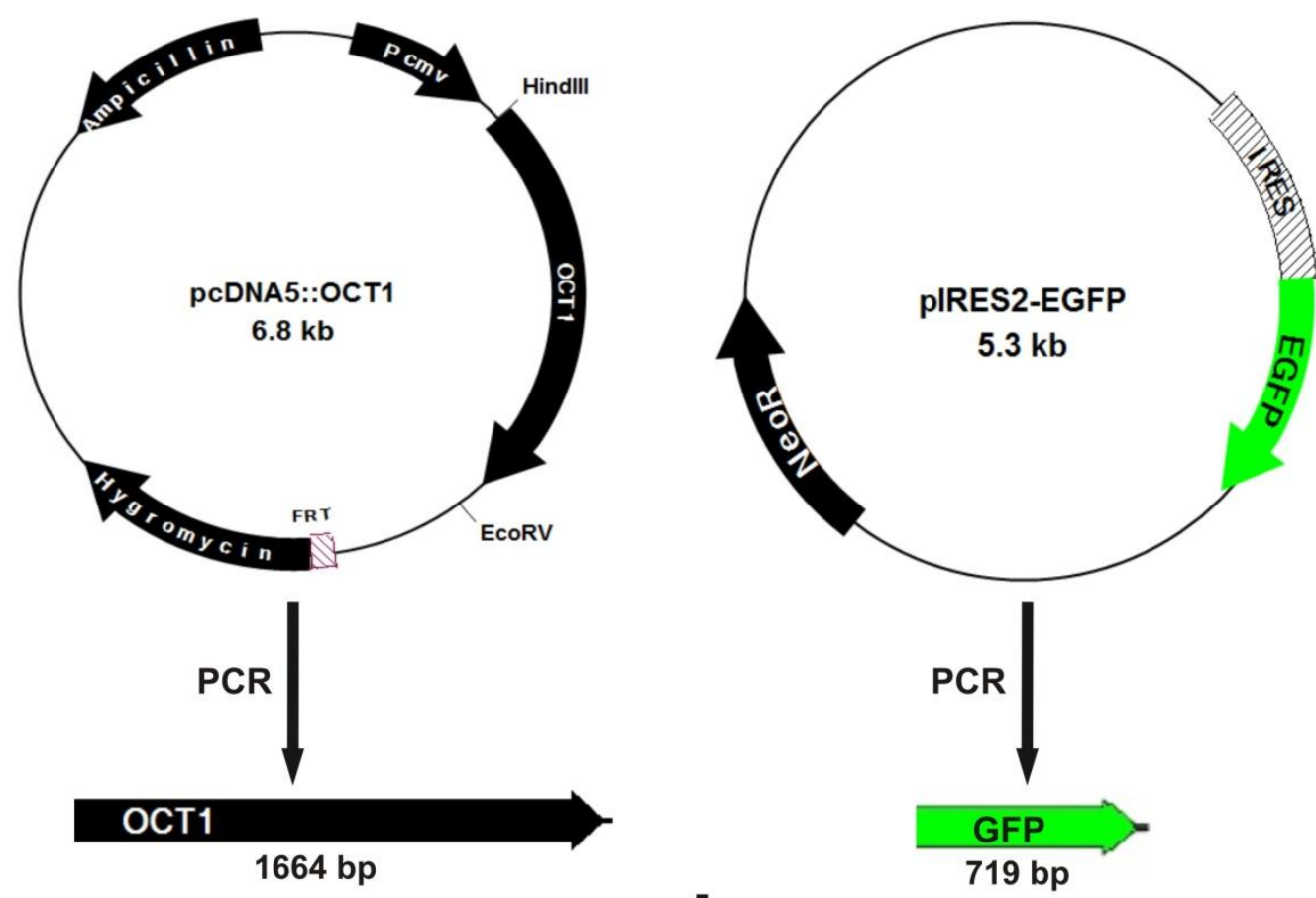

DNA assembling

Primer wth HindIII

\section{OCT1}

\section{GFP}

Primer wth Notl

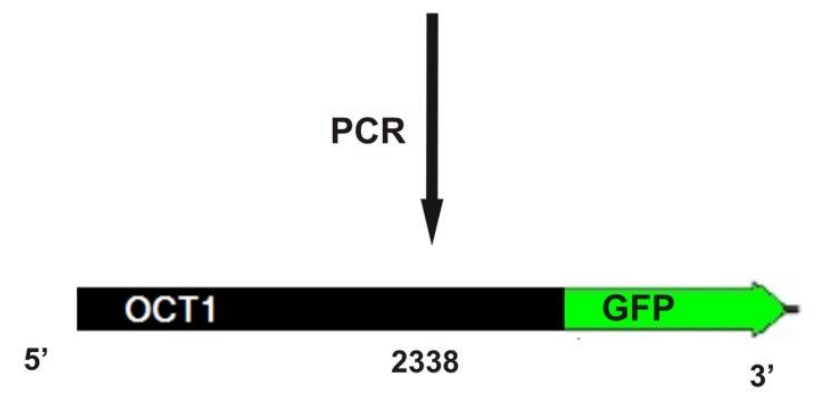

Fig.3. 45 Scheme of assembling of the OCT1_GFP fusion construct. GFP fragment was used to the C-terminal end of OCT1 cDNA according to DNA assembling method.

The PCR product was cloned into pCR-XL-TOPO plasmid and sequenced. The OCT1_GFP fragments was digested with HindIII and NotI restriction enzymes from pCR-XL-TOPO, purified from a 1\% agarose gel and cloned into pcDNA 5.1 plasmid that was linearized with the same restriction enzymes and purified from agarose gel 
(Fig.3.46). The resulting construct pcDNA5.1::OCT1_GFP carries the OCT1wild-type and two variants A61C and 420del- C88A fused to EGFP.
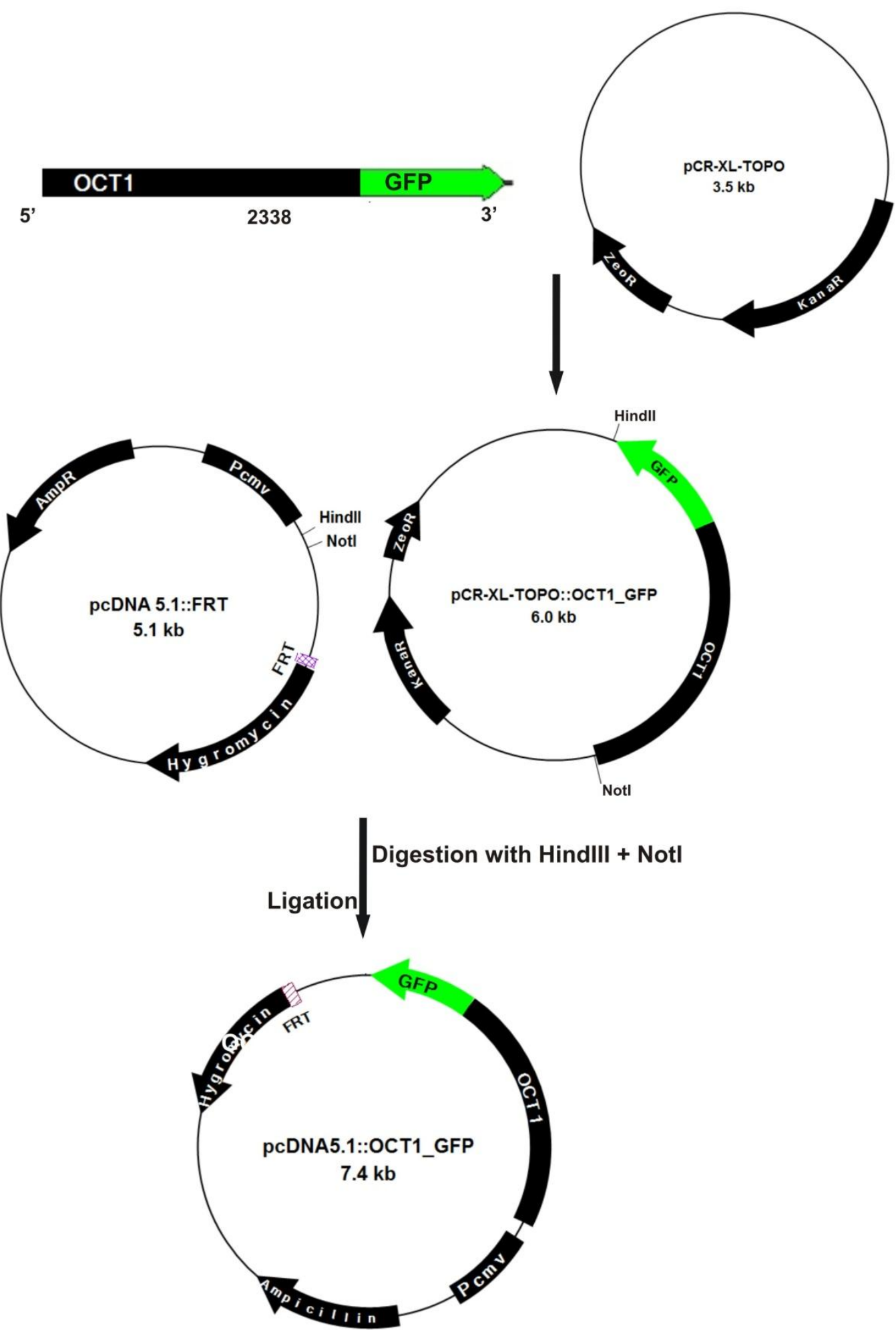

Fig.3. 46 Scheme of cloning of the OCT1-GFP fusion construct into the expression vector pcDNA5.1. 


\subsubsection{Generation of HEK293 cell lines transiently expressing OCT1- GFP}

This cell line was produced in order to investigate localization of OCT1 transporter in the cell. For this purpose, after generation of pcDNA5.1::OCT1-GFP constructs for OCT1 wild type and two variants (61C and 420del88R), these constructs were transiently transfected to HEK293T-Rex cells as described before for transient transfection (see section 2.2.5.4.1) and then the transfected cells were analyzed by $\mathrm{ASP}^{+}$ uptake measurement.

\subsubsection{Quantitative measurement of OCT1 activity}

Recent report suggested that OCT1 protein exist as oligomers and that disulfide bridges in the N-terminal extracellular loop are essential for the oligomerization and the correct cellular localization of OCT1 (KOEPSELL, 2011). Two of the common polymorphisms in the OCT1, which were also analyzed in this work, result in either a gain (R61C) or a loss of cysteine amino acid (C88R). Both cysteine amino acids are located in the Ntermina extracellular loop and may change the ability of oligomerization and correct cellular localization of OCT1. Incorrect cellular localization of the $61 \mathrm{C}$ variant has been shown previously (SHU et al., 2009). In this experiment we analyzed whether the presence of one polymorphic allele carrying either $61 \mathrm{C}$ or $88 \mathrm{R}$ may lead to incorrect oligomerization and cellular localization not only of the polymorphic, but also of the wild-type allele; to lead to so called dominant negative effect.

To do this, we transiently transfected HEK293-TRex cells with an equimolar mixture of pcDNA5.1 plasmid carrying OCT1 wild type and carrying one of the variants allele $61 \mathrm{C}$ or $420 \mathrm{del}-88 \mathrm{R}$. The resulting OCT1 activity was compared to the OCT1 activity in cells transfected with wild type only and with the variant only (simulating the homozygous carriers of this variants). To measure OCT1 activity, the transfected cells were incubated with four different concentrations of $\operatorname{ASP}^{+}(5,20,50$ and $150 \mu \mathrm{M})$ for 3 min. The maximal activity $\mathrm{V}_{\max }$ of cells transfected with the combination of the wild type and variant allels (heterozygous) exhibited exactly average $\mathrm{V}_{\max }$ activity between the wild type alone (homozygous wild type) or OCT1 variants alone (homozygous variant carrier) (Fig.3.47, Table 3.8). Identical effects were observed when the 61C 
variant and the $420 \mathrm{del}-88 \mathrm{R}$ variants were analyzed. This result suggested that there are no dominant negative effects of the $61 \mathrm{C}$ and $88 \mathrm{R}$ polymorphisms on the OCT1 activity.

A)

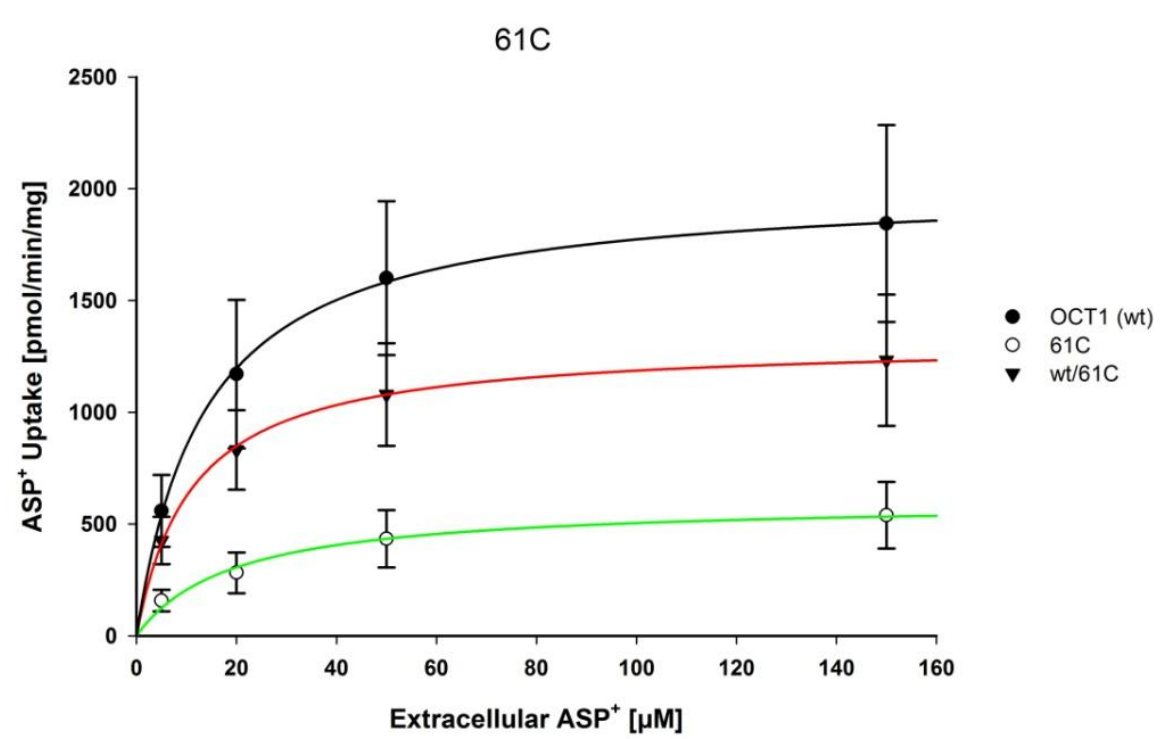

B) 420del88R

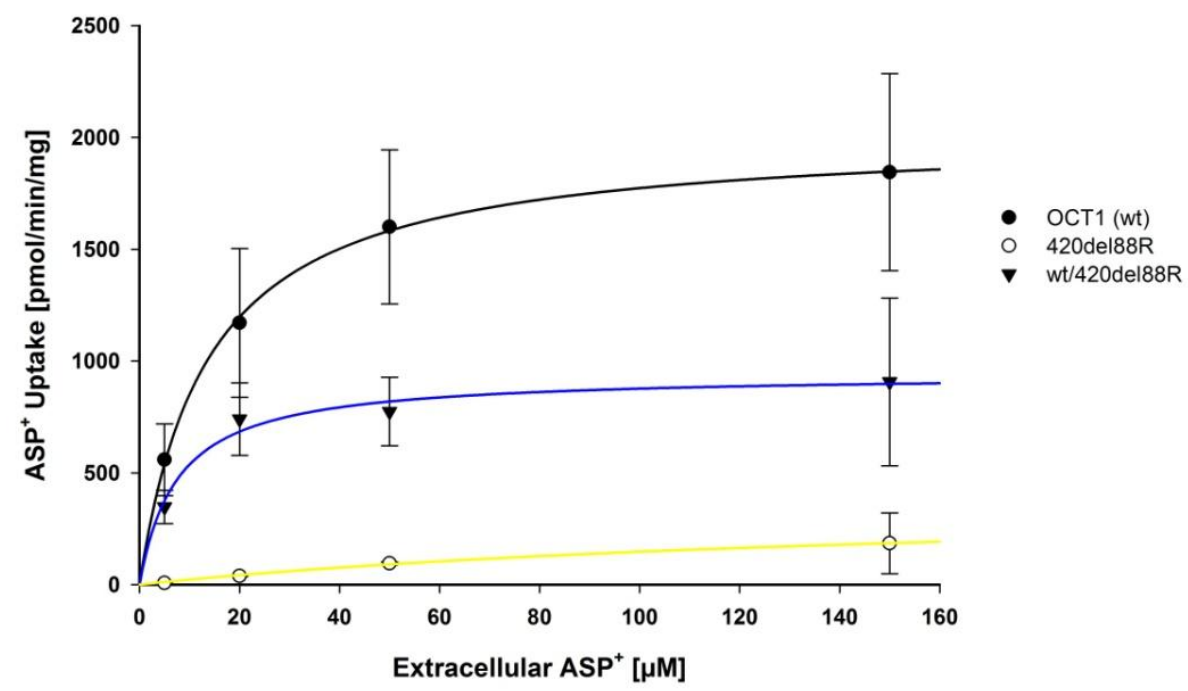

Fig.3. $47 \mathrm{ASP}^{+}$kinetics in HEK cells overexpressing OCT1 wild type alone (homozygous) or in combination of wild type and a loss of function variants (heterozygous). The $\mathrm{ASP}^{+}$uptake at four different concentrations of $\mathrm{ASP}^{+}$were measured by means of TECAN ultra plate photometer and normalized to the total protein amounts in the cells. The graph shows mean values of three independent experiments. 
Table 3. 8 Effects of the combined allels in OCT1 on the kinetics of $\mathrm{ASP}^{+}$uptake.

\begin{tabular}{lcccc}
\hline \multicolumn{1}{c}{ SNP } & \multicolumn{2}{c}{$\mathbf{V}_{\text {max }}$ * } & \multicolumn{2}{c}{$\mathbf{K}_{\mathbf{m}}[\boldsymbol{\mu M}]$} \\
\multicolumn{1}{c}{ Mean } & SEM & Mean & SEM \\
\hline OCT1(wt) /OCT1 (wt) & 2015.9 & 31.94 & 13.69 & 0.8 \\
wt /61C & 1317,09 & 19.18 & 11,06 & 0.65 \\
61C/61C & 601,51 & 42.45 & 19,34 & 4.62 \\
& & & & \\
OCT1(wt) /OCT1 (wt) & 2015.9 & 31.94 & 13.69 & 0.8 \\
wt /420del88R & 942.83 & 53.94 & 7.57 & 1.98 \\
420del88R/420del88R & 387.36 & 47.93 & 163.45 & 34.04 \\
\hline * $<$ < 0.05 in Jonckheere-Terpstra trend test. & & &
\end{tabular}

\subsubsection{Analysis of the subcellular localization}

Next, we analyzed whether the presence of OCT1 variant alleles carrying 61C or 420del88R affect the correct cellular localization of the transporter in the membrane. For this reason, the HEK cells overexpressing OCT1 wild type and 61C or 420del88R variants were used to investigate the subcellular localization of OCT1 using immunocytochemical staining (see section 2.2.7). After reaching the cells to $80 \%$ confluency, the cells were stained by indirect immunofluorescence using primary antibody SLC22A1 (2c5, Novus Biologicals, Cambridge, UK) and flourochrome conjugated secondary antibody (Goat anti mouse Alexa 488, Invitrogen) and then visualized by confocal microscopy (Carl Zeiss, Jena). The results showed while the OCT1wild type was localized on the membrane, the mentioned variants showed a notorious change where most of the OCT1 protein was intracellular (Fig.3.48). These observations were validated by $\mathrm{ASP}^{+}$uptake studies as described previously (see section 3.7.3). 
A)

B)

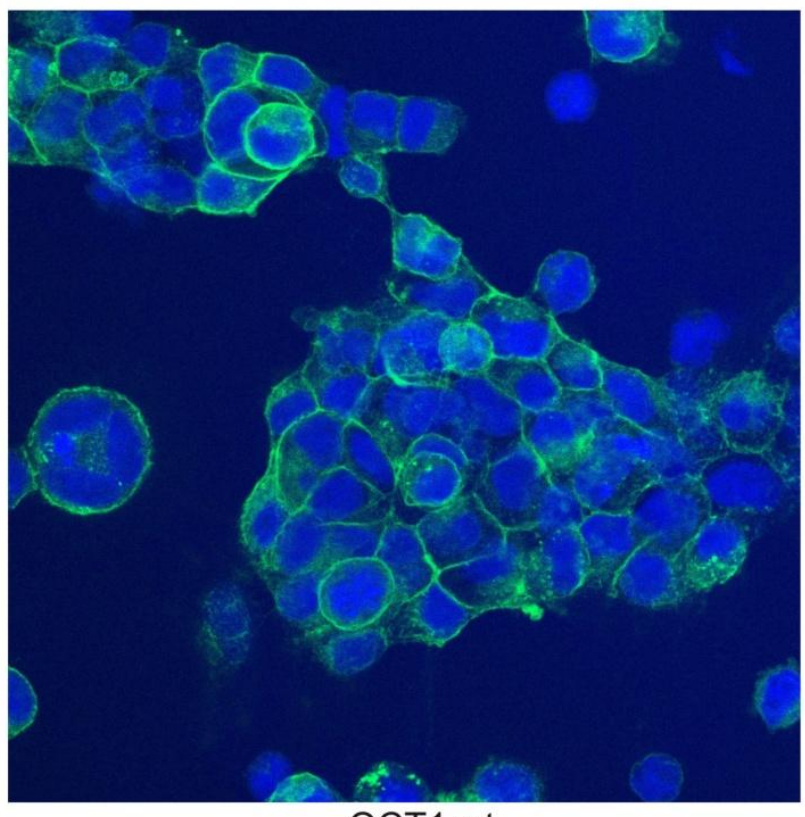

OCT1 wt

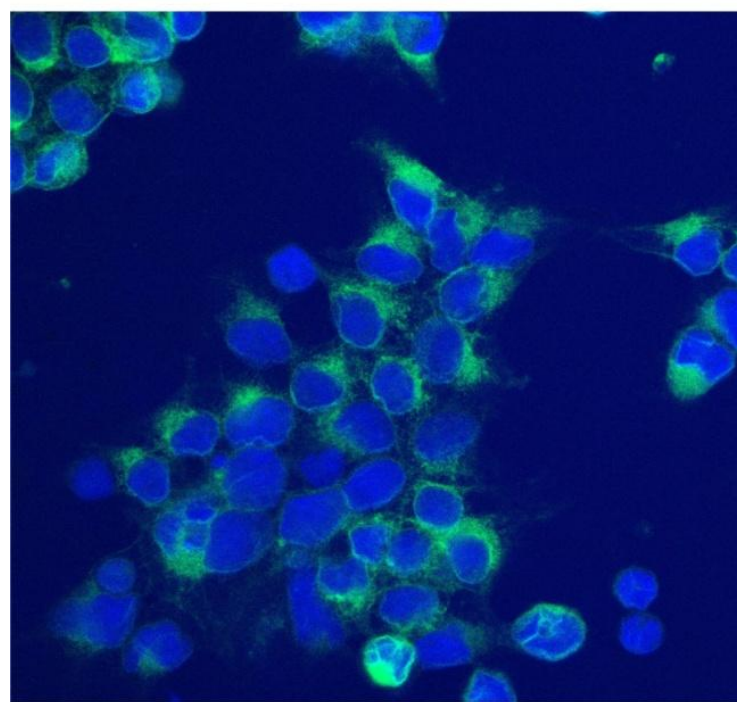

61C

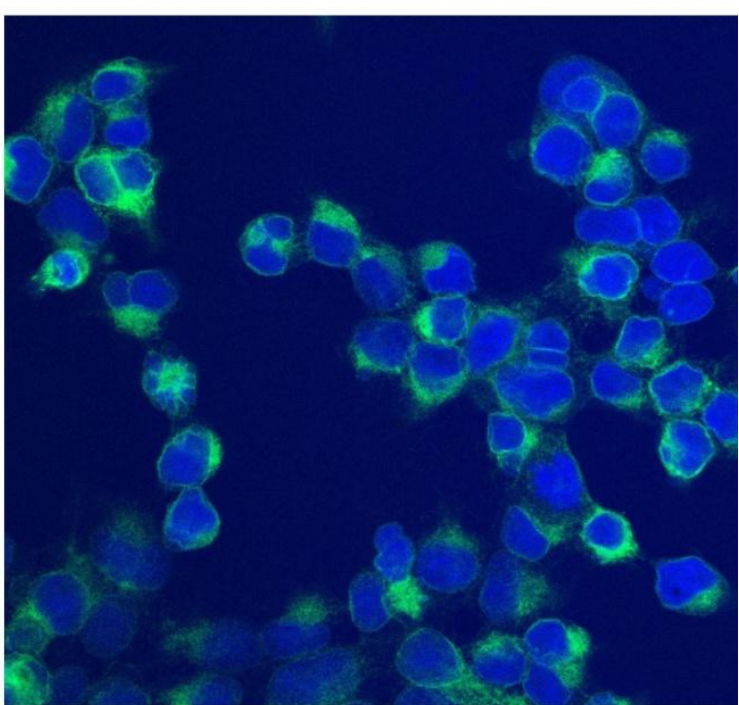

420del88R

Fig.3. 48 Subcellular localization of OCT1 wild type and two genetic variants. The HEK293 cells overexpressing OCT1-wild type and $61 \mathrm{C}$ or $420 \mathrm{del} 88 \mathrm{R}$ variants were treated with mouse anti-(human) primary antibody SLC22A1 (2c5, Novus Biologicals, Cambridge, UK) for OCT1 and visualized using goat anti-mouse conjugated to fluorochrome Alexa 488 secondary antibody (Invitrogen). The green particles depict localization of OCT1 protein, while the blue spots are nucleus stained by DAPI. A) The HEK293 cells overexpressing OCT1 wild type show membrane localization. B) The HEK293 cells overexpressing OCT1 variants exhibit reduced membrane and enhanced cytoplasmic localization. 


\section{Discussion}

\subsection{Effects of loss of function polymorphisms of OCT1 transporter on the uptake and kinetics of $\mathrm{ASP}^{+}$}

In the current study, we generated HEK293 cells overexpressing OCT1 as wild-type or five of its common SNPs. These loss-of-function $O C T 1$ forms carrying the single amino acid substitutions Arg61Cys, Gly401Ser, and Met420del, or the combinations Met420del-with-Cys88Arg and Met420del with Gly465Arg, represent all the common and functionally relevant $O C T 1$ alleles in Caucasians (TzVETKOV et al. 2009; SHU et al. 2003; KUHNE et al. 2009). Our data showed that the OCT1 variants and wild type have similar levels of mRNA transcripts in the OCT1 stably transfected HEK cell lines (Fig. 3.6), suggesting that posttranscriptional changes account for the reduced function of the OCT1variants observed for $\mathrm{ASP}^{+}$uptake (Fig. 3.11). Regarding the effects of wild-type and common loss-of-function polymorphisms in OCT1 on the uptake and kinetics of $\mathrm{ASP}^{+}$, our data showed significant differences in $\mathrm{ASP}^{+}$uptake activity and kinetic between OCT1 wild type and variants (Table 3.4). All variants had lower maximal transport rates $\left(\mathrm{V}_{\max }\right)$ than the wild type OCT1, while $\mathrm{K}_{\mathrm{m}}$ value did not show any significant differences between OCT1 wild type and variants, except for variant 401Ser that the $K_{m}$ value was significantly higher. With respect to intrinsic CL value, maximum clearance rate of $\mathrm{ASP}^{+}$was seen for the HEK cells overexpressing OCT1 wild type compared to all variants. Taken together these data suggested that $\mathrm{ASP}^{+}$uptake activity and kinetic in the HEK cells overexpressing OCT1 wild type was significantly higher than those in variants. These results were confirmed by comparison the amount of $\mathrm{ASP}^{+}$ uptake visualized by fluorescence microscopy which showed OCT1 wild type can uptake higher amount of $\mathrm{ASP}^{+}$than the variants (Fig.3.10). The OCT1 only contain one substrate binding region that changes between an outwardly directed and an inwardly directed orientation during the transport cycle. The change in orientation of the substrate binding region during transport is supposed to be accompanied by structural changes that alter the affinity for substrates or inhibitors. Therefore it may conclude that different structural changes between OCT1 wild type and these variants lead to changing in affinity for $\mathrm{ASP}^{+}$or other cationic drugs. 


\subsection{Effects of loss of function polymorphisms of OCT1 transporter on the uptake of tropisetron and ondansetron}

Although previous studies showed the impact of polymorphisms in cytochrome P450 enzymes on the pharmacokinetics and clinical effects of many drugs (BROCKMOLLER et al. 2000; Ingelman-SundBerg 2004; LYNCH and PRICE 2007). However, before a drug can be metabolized, it must enter the cell, therefore polymorphisms in a transporter mediating the cellular uptake of a drug may modify pharmacokinetics and clinical effects. Indeed genetic polymorphisms in drug transporter genes have been increasingly recognized as an additional mechanism accounting for the pharmacokinetic variability of many drugs (Ho and KIM 2005; KoEPSELl et al. 2007; SEITHEL et al. 2008; VORMFELDE et al. 2008).

The human organic cation transporter 1 (hOCT1, SLC22A1) is a multispecific transporter of organic cations, including many clinically used drugs. It has been identified that organic cation transporters are not only critical for the intestinal absorption, distribution and hepatic and renal excretion of endogenous compounds and a wide array of drugs, but also play important roles for the function of various physiological systems and various diseases (JONKER and SCHINKEL 2004; KOEPSELL et al. 2007). In this study, we investigated the activity of the wild type and five nonsynonymous variants of OCT1 in uptake of tropisetron, ondansetron and palonosetron.

According to our data, HEK cells overexpressing OCT1 wild type resulted in an increased uptake of tropisetron that was completely blocked by addition of the typical OCT1 substrate $\mathrm{MPP}^{+}$acting as a competitive inhibitor of tropisetron transport (Fig.3.27 A). Also regarding to the impact of polymorphisms in OCT1 gene on tropisetron uptake, our data showed the HEK cells overexpressing all these five polymorphisms of OCT1 reduced tropisetron uptake compared to the cells overexpressing wild type (Fig. 3.27 A). These data were confirmed by clinically data which suggested that patients lacking fully active OCT1 have impaired cellular uptake, reduced inactivation and consequently a prolonged residence of the drug in the circulation, resulting in better efficacy (TzVETKOV et al. 2010). On the other hand, carriers of three and more active CYP2D6 alleles, are at higher risk of antiemetic therapy failure (CANDIOTTI et al. 2005; JANICKI et al. 2006; KAISER et al. 2002). These carriers may indeed be particularly prone to antiemetic treatment failure if they carry in 
addition two fully active OCT1 alleles. This rare group of patients may profit from both OCT1 and CYP2D6 genotyping. In this rare group, a combined genotyping of OCT1 and CYP2D6 may have clinical consequences like dose escalation or selection of other 5-HT3 antagonists that are not dependent on polymorphic CYP2D6.

The results for ondansetron showed although ondansetron inhibited the OCT1 transport (Fig.3.25), no significant difference in the ondansetron uptake is present between HEK cells overexpressing OCT1wild type and the control cells transfected with empty vector (Fig.3.27 B). This results is in contrast with the clinical data which showed the patients lacking any fully active OCT1 allele had a significant decrease in vomiting incidence in compare to patients with one or two fully active OCT1 alleles (TzVETKOV et al. 2010). This variability in OCT1-mediated uptake of tropisetron and ondansetron can be due to differences in physiochemical properties of these two drugs that may affect the membrane permeability of tropisetron and ondansetron. As it can be seen in table 4.1, ondansetron has lower $\mathrm{pKa}$ value that causes lower protonated fraction in blood in compare to tropisetron which protonates about 96.6 percent in physiological $\mathrm{pH}$ condition. In addition, ondansetron is more lypophilic with $\log \mathrm{D}$ of 2.28 in compared to 1.36 for tropisetron which means ondansetron can penetrate to the cells by passive diffusion in contrast to tropisetron which needs transporter to enter the cells (Table 4.1). Taken together, these data suggest that ondansetron may be more prone to enter cells by passive diffusion than tropisetron, and may be less dependent on OCT1.

Table 4. 1 Comparison of physicochemical properties for tropisetron and ondansetron

\begin{tabular}{l|c|c|c|c|}
\hline Drug & pKa & $\begin{array}{c}\text { \% charged } \\
\text { at pH 7.4 }\end{array}$ & $\begin{array}{c}\text { \% un charged } \\
\text { at pH 7.4 }\end{array}$ & $\begin{array}{c}\text { Lipophilicity } \\
\operatorname{logD} \text { at pH 7.4 }\end{array}$ \\
\hline Tropisetron & 8.9 & 96.6 & 3.4 & 1.36 \\
\hline Ondasetron & 7.4 & 50.0 & 50.0 & 2.28 \\
\hline
\end{tabular}

The pKa value of ondansetron is according to Mashru et al., 2005. All other physiochemical properties were calculated using ADMET Predictor Software 4.0 (Simulations Plus, Lancaster, CA, USA). 


\subsection{Effects of loss of function polymorphisms of OCT1 transporter on the uptake of tramadol and 0 - desmethyltramadol}

Tramadol is a prodrug that requires bioactivation to $O$-desmethyltramadol for its analgesic activity. This bioactivation is catalyzed almost exclusively by the genetically polymorphic enzyme CYP2D6, and poor metabolizers of CYP2D6 substrates experience little, if any, analgesic effect from tramadol (PAAR et al. 1997; PEDERSEN et al. 2005; POULSEN et al. 1996; WANG et al. 2006). After bioactivation, $O$ desmethyltramadol is released into systemic circulation to reach its target sites and exert its influence and then to eliminate as glucuronide from body it needs to reuptake into the hepatocytes via OCT1-mediated manner (TZVETKOV et al. 2011).

Our data showed both tramadol and its metabolite O-desmethyltramadol can inhibit $\mathrm{ASP}^{+}$uptake in the HEK cells overexpressing OCT1 (Fig.3.29). Although this inhibition experiment indicated that both tramadol and $O$-desmethyltramadol may be substrates of OCT1, it did not prove that the cellular uptake of tramadol and $O$-desmethyltramadol depends on OCT1. For this reason, we measured the cellular uptake of tramadol and $O$ desmethyltramadol by HPLC. As has been shown in figure 3.30A, direct measurements of intracellular uptake of tramadol by HPLC showed no increasing in the OCT1 overexpressing HEK293 cells in compared to the control cells that were transfected with empty vector. However the uptake of $O$-desmethyltramadol was 2.5 -fold higher in the OCT1 overexpressing cells than in the control cells (Fig.3.30 B). To explain these results, both tramadol and desmethyltramadol are organic bases with nearly identical pKa values of 9.13 and 9.12, respectively and have similar structures. However, tramadol has a fivefold higher octanol/water solubility coefficient than $O$ desmethyltramadol $\left(\log \mathrm{D}_{7.4}\right.$ of 1.13 and 0.4 , respectively). This may explain the higher permeability of tramadol through artificial membranes (Fig. 3.28) and its higher uptake rates in mock-transfected HEK293 cells. In contrast, $O$-desmethyltramadol is highly dependent on OCT1 for its cellular uptake.

We also analyzed how OCT1 polymorphisms influence the uptake of $O$ desmethyltramadol. We induced overexpression of OCT1 variants carrying the five most common functional amino acid substitutions in Caucasians (Arg61Cys, Cys88Arg, Gly401Ser, Met420del, and Gly465Arg) and compared their activity with the activity of the wild-type OCT1. In all variants, the uptake of $O$-desmethyltramadol was 
significantly lower as compared with uptake by wild-type OCT1 (Fig.3.30 B). However, no significant difference was found for the $O$-desmethyltramadol uptake in the cells overexpressing OCT1 variants in comparison to the control cells transfected with the empty plasmid.

In a clinical study performed by our group, volunteers carrying variant OCT1 alleles had higher plasma concentration of O-desmethyltramadol than patients carrying the wild type OCT1 (TzVeTKOV et al. 2011). The same patients had also stronger and prolonged miosis. It can be also due to high concentration of tramadol in the central nervous system and higher stimulation of the $\mu$-opioid receptor in OCT1-deficient volunteers.

The apparent dependence of $O$-desmethyltramadol on carrier-mediated membrane transport may have two additional consequences beyond the pharmacokinetically relevant hepatic uptake. First, the release of $O$-desmethyltramadol after formation by CYP2D6 in the liver back into the blood may be critically dependent on specific membrane transporters (TZVETKOV et al. 2011). However, the efflux transporter(s) involved remain to be identified. Second, $O$-desmethyltramadol may require carriermediated transport to cross the blood-brain barrier. Recently, it was suggested that OCT1 and OCT2 are expressed on the luminal side of the brain capillaries and may thereby mediate the passage of $O$-desmethyltramadol across the blood-brain barrier (LIN et al. 2010). In another experiment, a high correlation between the plasma concentration of $O$-desmethyltramadol and opioidergic activity was observed, suggesting that the absence of OCT1 does not limit the transport across the blood-brain barrier and that OCT2 or other transporters may supplement it. The requirement for carrier-mediated transport of the more hydrophilic metabolite, but not of the parent drug, may be relevant for numerous other drugs as well. In drug development, active substances are often selected for their high lipophilicity to increase their bioavailability. However, drug metabolizing reactions lead to a decrease in the lipophilicity of the parent drug, potentially decreasing its ability to diffuse through biological membranes. If the metabolite is biologically active, membrane transporters that enable it to re-enter systemic circulation, to reach its target, or to be biotransformed may be of therapeutic relevance (TZVETKOV et al. 2011).

Individual response to tramadol is apparently not dependent on a single factor, but rather on multiple clinical and genetic factors (STAMER et al. 2010). Combined CYP2D6-OCT1 pharmacogenetic analyses may be added to other methods of therapy 
individualization in order to help optimize tramadol dosing. Carriers of two or more active $C Y P 2 D 6$ alleles who also lack or have reduced OCT1 activity may require lower dosages of tramadol and therefore be at risk of overdosing (TZVETKOV et al. 2011). One may also speculate that slow-intermediate metabolizers (carriers of only one lowactivity CYP2D6 allele) who have full OCT1 activity will be at high risk of receiving sub therapeutic doses.

Our findings that tramadol is a relevant inhibitor of OCT1 and that OCT1 is an important transporter of $O$-desmethyltramadol may also help us understand and predict some drug-drug interactions. For instance, interaction at OCT1 sites may be another explanation (in addition to synergistic serotoninergic effects) for the severe adverse effects observed in a patient receiving a tramadol-citalopram drug combination (MAHLBERG et al. 2004). Also, some effects of prototypical CYP2D6 inhibitors used in human pharmacology studies, such as quinine or quinidine, may be mediated not only by CYP2D6 enzyme inhibition but also by inhibition of OCT1-mediated liver uptake of $O$-desmethyltramadol.

\subsection{Effects of loss of function polymorphisms in OCT1 transporter on the uptake of debrisoquine}

Although debrisoquine has been extensively described in the literature as a marker drug of the oxidative phenotype of patients to investigate drug pharmacokinetics and elimination depending on the polymorphic isoform CYP2D6, there were no previous studies on the dependence of debrisoquine uptake on carrier-mediated membrane transport. According to the results taken from inhibitory experiment, debrisoquine can function as an inhibitor of OCT1-mediated transporter with half maximal inhibitory concentration $\left(\mathrm{IC}_{50}\right)$ of $6.2 \mu \mathrm{M}$ (Fig. 3.32). One hypothesis could be because debrisoquine has positively charge structure and can compete with $\mathrm{ASP}^{+}$to bind to OCT1. We have also shown such competition between tropisetrone, ondansetrone, tramadol and O-desmethyltramadol with $\mathrm{ASP}^{+}$to bind to this transporter in previous chapters. Such inhibition could be clinically relevant to drug-drug interactions and would be an indication that debrisoquine may also be transported through OCT1. In this study we showed that debrisoquine has very low carrier-independent membrane permeability (Pe $0.01 \times 10^{-6} \mathrm{~cm} / \mathrm{s}$, Fig. 3.31), which means it needs transporter to enter 
the cells. Debrisoquine is a high affinity substrate of OCT1, this could be explained by the presence of a highly hydrophobic aromatic tetrahydroisoquinoline ring in the debrisoquine molecule. As all available pharmacophores for OCT1 substrates or inhibitors contain at least one hydrophobic moiety of the molecule next to a positive charge (Ahlin et al. 2008; BEDNARCZYK et al. 2003; MOADDEL et al. 2007), debrisoquine fits much better in the structural requirements for OCT1 substrates. Taken together, our data suggests that OCT1 may mediate the cellular uptake of debrisoquine in the liver and thus may modulate the hepatic metabolism of debrisoquine.

Genetic polymorphisms in drug transporters have been increasingly recognized as possible sources of variation in drug disposition and response (GIACOMINI et al. 2007). In previous studies has been shown that functional amino acid substitutions in the OCT1 gene which leading to a reduction in OCT1 activity may reduce hepatic uptake of metformin and consequently decrease the efficacy of metformin (SHU et al. 2007; TzVETKOv et al. 2009). Our data illustrated that the cellular uptake of debrisoquine depends on genetic variants in OCT1. As has been shown in figure 3.35, maximum intracellular uptake was obtained for the HEK cells overexpressing OCT1 wild type compared to cells overexpressing variants. However, no similar pattern in uptake was seen between variants (Fig.3.35). For example, the high amount of absorption was detected for Met420del and Arg61Cys variants in comparison to other variants or control, implying that these two variants might have substrate selectivity to bind to debrisoquine. Further examination of the functional effects of the variants on debrisoquine transport will raise our understanding regarding the amino acid residues which determine OCT1 activity. Also kinetic studies indicated that OCT1 is a high affinity transporter of debrisoquine $\left(\mathrm{K}_{\mathrm{M}} 5.9 \mu \mathrm{M}\right.$, Table 3.6), while all OCT1 variants have an increased $\mathrm{K}_{\mathrm{m}}$ or reduced $\mathrm{V}_{\max }$ values in compare with wild-type. These fluctuations in $\mathrm{K}_{\mathrm{m}}$ or $\mathrm{V}_{\max }$ values could be caused by a structural change in OCT1 and might suggest that these residues involved the substrate binding affinity. This finding supported the idea that all these OCT1-variants have low activity than the wild-type to uptake debrisoquine into the cells. These results are consistent with previous results taken for tropisetron and O-desmethyltramadol.

On the other hand, drug-drug interaction at OCT1 has also been shown that inhibited debrisoquine uptake (Fig.3.37). A number of factors beyond the known loss-of-function amino acid polymorphisms may affect the OCT1 ability to take up drugs on the liver, i.e. unknown amino acid substitutions, drug- drug interactions and suggested high 
variable expression of OCT1 (NIES et al. 2009). OCT1 is genetically highly polymorphic and in this study we presented evidence that common genetic polymorphisms and commonly used drugs affect the OCT1-mediated cellular uptake of debrisoquine. These findings have at least two direct consequences. First, OCT1 polymorphisms and drug-drug interactions at OCT1 may contribute to the high and thus far unexplained inter-individual variability in debrisoquine hydroxylation. In addition, next to CYP2D6 phenotyping, debrisoquine may have the potential to be developed as probe drug for phenotyping OCT1 activity in vivo. In vivo phenotyping in humans using model drugs will be a powerful tool to study these effects. A number of in vitro model OCT1 substrates like $\mathrm{MPP}^{+}, \mathrm{TEA}^{+}$and $\mathrm{ASP}^{+}$exist. However, all these model substrates are highly toxic and cannot be given directly to humans (MARKEY et al. 1984). In contrast, small amounts of debrisoquine are safe to be administered to humans, and debrisoquine is a well established in vivo probe drug (TANAKA et al. 2003; ZGHEIB et al. 2006; FUHR et al. 2007). However, clinical studies are required to evaluate to what extent the dependence of debrisoquine cellular uptake on OCT1, which was demonstrated here in vitro, will manifest as inter-individual variations in vivo.

\subsection{Interactions between OCT1-mediated transporter and CYP2D6-mediated metabolism on debrisoquine metabolism}

Debrisoquine is a unique drug as a substrate that we can use to investigate interaction between polymorphisms in OCT1 and metabolizing enzyme CYP2D6. Debrisoquine metabolism is highly variable and debrisoquine has been extensively studied as a probe drug for the variable CYP2D6 oxidative phenotype in humans. To investigate the interactive effects between OCT1 drug transporter and CYP2D6 metabolizing enzyme on the metabolism of drugs, we established HEK cells which overexpressed both the genes of OCT1 transporter and CYP2D6 drug metabolizing enzyme. For this purpose, to have the correct evaluation of CYP2D6 activity, this cell lines were modified to overexpress cytochrome P450 reductase (POR enzyme) which supply electron for CYP2D6 enzyme function, and we used debrisoquine which is a well-known substrate for CYP2D6 (GonZALEZ et al. 1988; KIMURA et al. 1989) and recently reported by us as a model substrate for OCT1 transporter (SAADATMAND et al. 2012). Overexpression of OCT1 in combination with CYP2D6 and POR in HEK cells significantly increased 
the production of 4-OH debrisoquine, the metabolite of debrisoquine, in comparison with the HEK cells overexpressed CYP2D6::POR alone (Fig.3.38). These data illustrate that the OCT1 may be a rate limiting factor for the metabolism of organic cationic drugs and may help for more rapid metabolism.

Our data suggest that debrisoquine may have the potential to be used as a probe drug for in vivo phenotyping of OCT1 activity in humans.

\subsection{Effects of loss of function polymorphisms of OCT1 transporter on the metabolism of debrisoquine}

Interindividual variations in the pharmacokinetics of drugs may be caused by genetic variations in biotransformation and transmembrane transport (Ho and KIM 2005; KOEPSELL et al. 2007; VORMFELDE et al. 2008). In previous studies, haplotype analysis has been explored the independently impact of CYP2C9 metabolizing enzyme and polymorphisms in OATP1B1 transporter on the pharmacokinetics of torsemide (VORMFELDE et al. 2008). To evaluate the effects of polymorphisms in drug transporter on the metabolism of organic cationic drugs, we generated the HEK cells which overexpressed OCT1 wild type and 420del88R variant in combination with CYP2D6 drug metabolizing enzyme and then after treating the cells with debrisoquine the produced metabolite of debrisoquine was measured by HPLC. As has been shown in the results, the amount of debrisoquine uptake and consequent produced metabolite in 420del88R variant were reduced to the level of control cells. According to our data, the metabolism of debrisoquine to 4-OH debrisoquine depends on genetic variants in OCT1. As has been shown, maximum debrisoquine hydroxylation occurred in the HEK cell overexpressing OCT1::CYP2D6::POR wild type compared to the tested variant (Fig.3.39). From these data we can conclude that polymorphisms in OCT1 gene can modulate the entrance and access of debrisoquine to its target sites (CYP2D6 enzyme) in the liver cell. Therefore low amounts of intracellular debrisoquine leads to low amount of its metabolite by CYP2D6. These results are in concordance with the previous results corresponding to the effects of genetic polymorphisms in OATP1B1 on the metabolism of some organic anionic drugs (ROMAINE et al. 2010; VoRMFELDE et al. 2008). 
The debrisoquine hydroxylation capacity, measured as the ratio of debrisoquine over its major metabolite 4-hydroxydebrisoquine in urine, varies by more than 100 -fold among individuals (EvANS et al. 1980; LLERENA et al. 2009; SACHSE et al. 1997). This high inter-individual variation in debrisoquine hydroxylation capacity may represent variation not only in CYP2D6, but also in OCT1 activity. Our data suggest that beyond the previously suggested effects of environmental factors (LLERENA et al. 1996) or downstream metabolism reactions (ZHEN et al. 2006), the variations in debrisoquine hydroxylation may also be due to variations OCT1-mediated hepatocellular uptake. The existence of genetic polymorphisms of OCT1 with different function in cellular assays suggests that the combination of genetic polymorphism in OCT1 in relation to genetic variability in CYP2D6 metabolizing enzyme may contribute to interindividual variability in drug metabolism.

\subsection{Drug-drug interactions on the CYP2D6-madiated debrisoquine metabolism}

In our study we evaluated the effect of drug-drug interaction on OCT1 transporter alone, on CYP2D6 enzyme alone or combination of OCT1with CYP2D6 enzyme. As our results showed all known OCT1 inhibitors in this study inhibited OCT1-mediated debrisoquine uptake (Fig. 3.37).

To evaluate drug-drug interaction exclusively on CYP2D6 enzyme, we extracted microsome from the HEK cells overexpressing CYP2D6::POR. First to examine the microsome activity, we used AMMC kit which no difference was detected between the microsomes extracted from HEK cells overexpressing CYP2D6::IRES::POR, while microsome from the commercial kit showed more activity compared to those extracted from the cells (Fig. 3.17). One possible explanation might be that the amount of CYP2D6 enzyme in the microsomes originated from human liver may differ from those extracted from HEK cells. This difference may be due to different processing in extraction and/or purification of the microsomes. In our experiment, the procedure used to extract the microsome from the cells was similar to those usually utilize for extraction from tissues. Analyzing the data by western blot also showed very intensive signal detected for CYP2D6 in the human liver microsome from the commercial kit in compare to faint signal taken for the microsome extracted from the cells. Another 
possibility for these results may correspond to the substrate (AMMC) that we used or detection of the produced metabolite (AHMC) measured by TECAN photometer. Therefore, we used debrisoquine which is also a model substrate for CYP2D6 enzyme and detected 4-OH debrisoquine, a metabolite compound of debrisoquine, by HPLC. The amount of 4-OH debrisoquine depends on debrisoquine concentration and hydroxylation of debrisoquine was inhibited significantly in the presence of a CYP2D6 inhibitory drug, paroxetine (Fig. 3.18). The production of 4-OH debrisoquine was specific for the HEK cells overexpressing CYP2D6::POR and was not present in the HEK cells overexpressing OCT1 or control cells transfected with empty plasmid. Our results imply that debrisoquine can be a good substrate to measure microsome activity and interaction between debrisoquine and paroxetine can inhibit metabolism of debrisoquine mediated by CYP2D6 enzyme.

Regarding to the effect of drug-drug interaction on the CYP2D6-mediated debrisoquine metabolism, we used HEK cells overexpressing OCT1::CYP2D6::POR as a model cell and we used paroxetine as an inhibitor on the levels of drug uptake and drug metabolism. The results showed that the inhibitory effect of paroxetine on the OCT1madiated debrisoquine uptake is stronger than those depicted for CYP2D6-madiated debrisoquine metabolism, because the OCT1 transporter was blocked using lowest amount of paroxetine, while in the range of $0.1-1 \mu \mathrm{M}$ concentration of paroxetine the activity of enzyme slightly decreased (Fig.3.40). However, the potential clinical relevance of this result remains to be tested.

Inhibition of CYP-mediated metabolism, often the mechanism for drug-drug interactions, can limit the use of a drug because of adverse clinical effects. For example, inhibition of CYP3A4 enzyme by coadministered drugs has been shown to result in adverse clinical drug-drug interactions, including fatalities (HONIG et al. 1993). Therefore, it is important to determine the inhibition potential of each new chemical drug for cytochrome P450 enzymes early in the discovery stage as to predict, anticipate, and ultimately manage potential drug-drug interactions. 


\subsection{Effects of OCT1 transporter on the uptake of cytotoxic drugs irinotecan and doxorubicin}

In this study cytostatic drugs, doxorubicin, irinotecan and SN38, the active metabolite of irinotecan, were tested to evaluate whether they are substrates or only inhibitors for OCT1. As demonstrated in the results, only irinotecan can act as an inhibitor for OCT1, whereas no inhibitory effect was seen for SN38 (Fig.3.41).

Also regarding to the effects of polymorphisms in OCT1 on the cytotoxicity of irinotecan using MTT assay, our data showed small differences between the HEK or CHO cells overexpressing OCT1 wild type and five common polymorphisms treated with irrinotecan compared to untreated cells (Fig.3.43). This test is used to measure the activity and viability of cells, one explanation for this result can be, in these measured cells no reductase enzyme has been produced, because active reductase enzymes are needed for this reduction of MTT to formazan, so OCT1 and CYP2D6 overexpressing cells may be useful for this assay. For the therapy of cancers expressing OCT1, it might be useful to use a cytostatic, which is taken up by OCT1 at high rates and is not a prodrug. Future research might reveal a drug suitable for such a cause. However the recent data published by Gupt et al, 2012 showed OCT1 may contribute to the susceptibility of cancer cells to selected antineoplastic drugs. They showed that the OCT1-positive cell lines and transfectants exhibit significantly higher susceptibilities to the cytotoxic effects of irinotecan and paclitaxel compared with those of OCT1-negative controls (GUPTA et al. 2012).

The cytostatic drug doxorubicin showed very high levels of fluorescence at the same wavelength where $\mathrm{ASP}^{+}$fluorescence was measured, therefore this drug was exposed alone to the cells to check how much of the drug was taken up by the cells and then after lysing the cells the amount of drug absorption was measured. As has been shown, no significant difference was found in doxorubicin uptake by HEK cells overexpressing OCT1 wild type compared to control cells transfected with empty vector (Fig.3.44). 


\subsection{Effects of different $\mathrm{pH}$ on interaction of organic cations with OCT1}

In our study changes in the $\mathrm{pH}$ value from 5.4 to 9 had no significant effect on the inhibitory effect of tropisetron on $\mathrm{ASP}^{+}$uptake. The results showed tropisetron can inhibit OCT1-mediated $\mathrm{ASP}^{+}$uptake in all these $\mathrm{pH}$ ranges, however the inhibitory effects of ondansetron on $\mathrm{ASP}^{+}$uptake was decreased by increasing in $\mathrm{pH}$ (Fig.3.26). In other hand it can be concluded that only charged form of ondansetron interacts with OCT1. It may be related to pKa value of these drugs. Ondansetron has pKa value 7.4 which means it is mostly charged in lower than $\mathrm{pH}$ 7.4. One explanation could be the decreasing in fractional protonation (positively charged form) of ondansetron at high $\mathrm{pH}$ which results in decreasing to bind to the OCT1 transporter and act as inhibitor for $\mathrm{ASP}^{+}$uptake. Also regarding the effects of irinotecan and SN38 on OCT1-mediated cellular uptake of $\mathrm{ASP}^{+}$in different environmental $\mathrm{pH}$, our data showed that the inhibitory effect of irinotecan on $\mathrm{ASP}^{+}$uptake was decreased by increasing $\mathrm{pH}$ value from 5.4 to 9, while SN38 did not suppresse $\mathrm{ASP}^{+}$uptake in these $\mathrm{pH}$ ranges (Fig. 3.42). This might be relevant to pKa values of these two compounds. The pKa value for irrinotecan is 8.48 which is a weak basic in physiological $\mathrm{pH}$. At $\mathrm{pH}$ values of 7.4 and below, irinotecan is protonated and this causes to bind to OCT1 and consequently inhibits $\mathrm{ASP}^{+}$uptake, while $\mathrm{SN} 38$ is a weak acid and is negatively charged under these examined $\mathrm{pH}$ and in turn could not bind to transporter and exert an inhibitory influence on $\mathrm{ASP}^{+}$uptake. Other studies have also indicated that transport of organic cations via OCT2 is sensitive to environmental pH (FUJITA et al. 2006). They concluded that environmental $\mathrm{pH}$ may influence OCT2 activity by modulating the fractional protonation of OCT2 amino acid residues or of OCT2 substrates, although translocation of organic cations by OCT2 does not appear to be directly coupled to $\mathrm{H}^{+}$influx or efflux. Urakami et al., 2002 indicated a decrease in the influx of TEA by OCT2 with lowering the extracellular $\mathrm{pH}$ from 8.4 to 5.4, demonstrating that the transport function of OCT2 is influenced by extracellular $\mathrm{pH}$. In another study, changing the $\mathrm{pH}$ value from 7.0 to 8.0 had no effect on the rate of transport of TEA, whereas the interaction of the weak bases cimetidine and trimethoprim with OCT2 was decreased by changing the $\mathrm{pH}$ value from 7.0 to 8.0. It was concluded that the change in fractional protonation of the compounds is the basis for their decreased interaction with the transporter at higher pH (BARENDT and WRIGHT 2002). 


\subsection{Analysis of dominant negative effect between OCT1 variants}

Examination of the functional effects of the OCT1 wild type and variants on drug transport has implications on our understanding of the amino acids that determine OCT1 activity and trafficking. Chen et al., 2010 demonstrated that in comparison to the OCT1 wild type, variant $\mathrm{P} 117 \mathrm{~L}$ exhibited a reduced uptake activity and $V_{\max }$ for metformin with a similar localization to the plasma membrane. They concluded that the reduced $V_{\max }$ of metformin in cells expressing P117L could be caused by a structural change in OCT1. However, the change in $K_{\mathrm{m}}$ value of variant Q97K might suggest that this residue involved the substrate binding affinity (CHEN et al. 2010). According to the secondary structure of OCT1 transporter, both R61C and OCT1-420del88R variants are substitutions which are located in the large extracellular loop of OCT1, which is generally considered as containing substrate recognition domains (Jonker and Schinkel 2004; Koepsell and Endou 2004) and to be important for the oligomerization and the correct cellular localization of OCT1. As has been shown in figure 3.48 visualized by confocal microscopy, the HEK cells transfected with OCT1 wild type construct showed the expression of OCT1 protein in membrane, while most of the OCT1 protein was localized in the cytoplasm for the HEK cells transfected with variants of OCT1, 61C and 420del88. These results showed these two variants resulted in a disruption of transporter subcellular localization. One experiment indicated that the reduced activity of the OCT1 variant R206C seemed to be explained by a much reduced surface expression level of the transporter (CHEN et al. 2010). The reduced total GFP-tagged signal in cells expressing GFP-R206C or GFP-R206E may be caused by accelerated protein degradation in the endoplasmic reticulum (ER) with the misfolded immature protein. R206C reduced the export of OCT1 from the endoplasmic reticulum to the plasma membrane. Therefore, we hypothesize that the OCT1 variants 61C or 420del88R may have dominant negative effects by impairing the correct membrane localization of the wild type OCT1 in case on co-existence of both forms, i.e. in heterozygous carriers of this two polymorphisms. To determine whether there is a dominant negative effect between OCT1 wild type and variants, the HEK cells were transiently transfected with combination of plasmid constructs containing OCT1 wild 
type and two common variants $61 \mathrm{C}$ and $420 \mathrm{del} 88 \mathrm{R}$. The results obtained for $\mathrm{ASP}^{+}$ uptake showed that $\mathrm{ASP}^{+}$uptake was reduced in the cells overexpressing OCT1 variants R61C and OCT1-420del88 compared to wild type (Fig. 3.47). It is noteworthy that the $\mathrm{V}_{\max }$ values for $\mathrm{ASP}^{+}$uptake in the cells transfected with the combination of wild type and variants were almost exactly the half of the $V_{\max }$ values in the cells transfected with OCT1 wild type alone. From this result, we can conclude that there is no dominant negative effect between wild type and variants in OCT1. However, analyses of the exact subcellular localization of wild type OCT1 in the presence and absence of both OCT1 variants are still necessary to confirm these preliminary results.

\section{Summary and conclusion}

The major result and conclusion of this work may be summarized as follows:

- In this work HEK293 cell lines were generated that overexpress wild type organic cation transporter 1 (OCT1) and the five common loss-of-function OCT1 polymorphic variants. The cell lines were generated by targeted chromosomal integration using the Flp-In system.

We characterized these cell models using integration-specific polymerase chain reaction (PCR) to evaluate the correct genome integration, quantitative PCR to evaluate mRNA expression rate, western blot and flow cytometry to evaluate protein expression and immunocytochemistry staining to evaluate localization of the OCT1 proteins. OCT1 activity was measured using the model OCT1 substrate 4-(-4-(dimethylamino) styryl-N-methylpyridinium $\left(\mathrm{ASP}^{+}\right)$.

- Using the cell line model we showed that the antiemetic drugs tropisetron and ondansetron inhibited OCT1-mediated $\mathrm{ASP}^{+}$uptake. Tropisetron uptake was 2.3-fold higher in the cells overexpressing wild type OCT1 compared to the control cells. There was no increase in the tropisetron uptake in the cells overexpressing the common loss-of-function OCT1 variants.

In conclusion, tropisetron was proven to be a substrate of OCT1 and common loss-of-function polymorphisms affect tropisetron uptake in cell culture. Studies of tropisetron pharmacokinetic and efficacy in humans (performed in our group but not part of this thesis) showed that OCT1 is a medically relevant transporter of tropisetron in vivo. 
- Using the same model we showed that the opioid pro-drug tramadol and its active metabolite O-desmethyltramadol inhibited OCT1-mediated $\mathrm{ASP}^{+}$uptake. The cellular uptake of O-desmethyltramadol, but not that of tramadol, was increased in cells overexpressing wild type OCT1 compare to the control cells. There was no increase in the O-desmethyltramadol uptake in the cells overexpression the common loss-of-function variants of OCT1.

In conclusion, O-desmethyltramadol, but not tramadol is a substrate of OCT1 and common loss-of-function polymorphisms affect O-desmethyltramadol uptake. Studies of O-desmethyltramadol pharmacokinetic and efficacy in humans (performed in our group but not part of this thesis) showed that OCT1 is a medically relevant transporter of O-desmethyltramadol in vivo.

- Using the OCT1-overexpressing model we showed that the prototypic CYP2D6 drug debrisoquine inhibited OCT1-mediated $\mathrm{ASP}^{+}$uptake. Debrisoquine uptake was significantly increased in HEK293 cells overexpressing OCT1 compared to control cells and followed Michaelis-Menten kinetics $\left(\mathrm{K}_{\mathrm{M}}\right.$ of $5.9 \pm 1.5 \mathrm{mM}$ and $\mathrm{V}_{\max }$ of $41.9 \pm 4.5 \mathrm{pmol} / \mathrm{min} / \mathrm{mg}$ protein). There was significant decrease in the debrisoquine uptake in the cells overexpression the common loss-of-function variants compared to cells overexpressing wild type OCT1.

- An additional cell line model was generated co-overexpressing OCT1 transporter and CYP2D6 metabolizing enzyme. Initially, the genes for CYP2D6 and its helper enzyme POR were stably transfected in HEK293 cells using random chromosomal integration. In the next step, using Flp-In system wild type or the 420del/465R loss-of-function OCT1 variant was stably transfected. The chromosomal integration and co-overexpression of OCT1, CYP2D6 and POR were confirmed using integration-specific PCR, qPCR, western blot, flow cytometry and immunocytochemistry.

- Using this second cell model we showed that the presence of OCT1 leads to higher production of 4-OH debrisoquine, the main CYP2D6 metabolite of debrisoquine. The effect was present when the wild-type OCT1, but not when variant OCT1 was co-expressed with CYP2D6 and POR. 
Using the same model we analyzed drug-drug interaction. The well known CYP2D6 inhibitor paroxetine inhibited both OCT1-mediated uptake and CYP2D6-mediated metabolism.

It could be concluded that OCT1 may limit debrisoquine metabolism and that OCT1 variants and drug-drug interactions at OCT1 can result in decreased metabolism providing a new view on the "old" CYP2D6 substrate debrisoquine and the "old" CYP2D6 inhibitor paroxetin.

- The effects of OCT1 transporter on cytotoxic drugs were minor in this study. Irinotecan, but not its active metabolite SN38 can inhibit OCT1-mediated $\mathrm{ASP}^{+}$ uptake, but more extensive experiments would have been required to fully rule out a role of OCT in this drug. No effects of OCT1 on doxorubicin could be measured.

In general, it could be concluded that OCT1 play an important role in the cellular uptake of clinically relevant weak basic drugs as tropisetron and tramadol. Common loss-offunction genetic variants lead to reduced hepatocellular uptake and thus limit the metabolism and modulate the efficacy of these drugs. The cell lines developed in this work are a valid model for evaluating the role of OCT1 in drug metabolism. This model may be used for identification of drugs beyond those described in this work, which metabolism may be affected by the common loss-of-function polymorphisms in OCT1 gene or be subjected to drug-drug interaction at OCT1. 


\section{References}

AAPRO, M., 2005 5-HT(3)-receptor antagonists in the management of nausea and vomiting in cancer and cancer treatment. Oncology 69: 97-109.

ABU-Zahra, T. N., and K. S. PANG, 2000 Effect of zonal transport and metabolism on hepatic removal: enalapril hydrolysis in zonal, isolated rat hepatocytes in vitro and correlation with perfusion data. Drug Metab Dispos 28: 807-813.

Ahlin, G., J. Karlsson, J. M. Pedersen, L. Gustavsson, R. Larsson et al., 2008 Structural requirements for drug inhibition of the liver specific human organic cation transport protein 1. J Med Chem 51: 5932-5942.

ANDO, Y., H. SAKA, M. ANDO, T. SAWA, K. Muro et al., 2000 Polymorphisms of UDPglucuronosyltransferase gene and irinotecan toxicity: a pharmacogenetic analysis. Cancer Res 60: 6921-6926.

Ballestero, M. R., M. J. Monte, O. Briz, F. Jimenez, F. Gonzalez-San Martin et al., 2006 Expression of transporters potentially involved in the targeting of cytostatic bile acid derivatives to colon cancer and polyps. Biochem Pharmacol 72: 729-738.

BARENDT, W. M., and S. H. WRIGHT, 2002 The human organic cation transporter (hOCT2) recognizes the degree of substrate ionization. J Biol Chem 277: 2249122496.

Bauer, S., E. Stormer, R. Kaiser, P. B. Tremblay, J. Brockmoller et al., 2002 Simultaneous determination of ondansetron and tropisetron in human plasma using HPLC with UV detection. Biomed Chromatogr 16: 187-190.

BednarczyK, D., S. Ekins, J. H. Wikel and S. H. Wright, 2003 Influence of molecular structure on substrate binding to the human organic cation transporter, hOCT1. Mol Pharmacol 63: 489-498.

Bochkov, Y. A., and A. C. PAlmenberg, 2006 Translational efficiency of EMCV IRES in bicistronic vectors is dependent upon IRES sequence and gene location. Biotechniques 41: 283-284, 286, 288 passim.

Bourdet, D. L., J. B. PRITCHARD and D. R. THAKKER, 2005 Differential substrate and inhibitory activities of ranitidine and famotidine toward human organic cation transporter 1 (hOCT1; SLC22A1), hOCT2 (SLC22A2), and hOCT3 (SLC22A3). J Pharmacol Exp Ther 315: 1288-1297.

Brockmoller, J., J. KirchHeINER, C. Meisel and I. RoOts, 2000 Pharmacogenetic diagnostics of cytochrome P450 polymorphisms in clinical drug development and in drug treatment. Pharmacogenomics 1: 125-151.

Brockmoller, J., and M. V. TZVetKov, 2008 Pharmacogenetics: data, concepts and tools to improve drug discovery and drug treatment. Eur J Clin Pharmacol 64: 133-157.

Candiotti, K. A., D. J. Birnbach, D. A. Lubarsky, F. Nhuch, A. Kamat et al., 2005 The impact of pharmacogenomics on postoperative nausea and vomiting: do CYP2D6 allele copy number and polymorphisms affect the success or failure of ondansetron prophylaxis? Anesthesiology 102: 543-549.

Cerqueira, P. M., F. H. Mateus, E. J. Cesarino, P. S. Bonato and V. L. Lanchote, 2000 Enantioselectivity of debrisoquine 4-hydroxylation in Brazilian Caucasian hypertensive patients phenotyped as extensive metabolizers. J Chromatogr B Biomed Sci Appl 749: 153-161.

Chen, J. J., Z. Li, H. PAN, D. L. MurPhy, H. TAMIR et al., 2001 Maintenance of serotonin in the intestinal mucosa and ganglia of mice that lack the high-affinity 
serotonin transporter: Abnormal intestinal motility and the expression of cation transporters. J Neurosci 21: 6348-6361.

Chen, L., M. Takizawa, E. Chen, A. Schlessinger, J. Segenthelar et al., 2010.Genetic polymorphisms in organic cation transporter 1 (OCT1) in Chinese and Japanese populations exhibit altered function. J Pharmacol Exp Ther 335: 42-50.

Ciarimboli, G., D. Deuster, A. Knief, M. Sperling, M. HoltKamp et al., 2010. Organic cation transporter 2 mediates cisplatin-induced oto- and nephrotoxicity and is a target for protective interventions. Am J Pathol 176: 1169-1180.

Ciarimboli, G., H. Koepsell, M. Iordanova, V. Gorboulev, B. Durner et al., 2005 Individual PKC-phosphorylation sites in organic cation transporter 1 determine substrate selectivity and transport regulation. J Am Soc Nephrol 16: 1562-1570.

DALY, A. K., and B. P. KING, 2003 Pharmacogenetics of oral anticoagulants. Pharmacogenetics 13: 247-252.

Davies, S. J., S. EAYRs, P. Pratt and M. S. Lennard, 2004 Potential for drug interactions involving cytochromes P450 2D6 and 3A4 on general adult psychiatric and functional elderly psychiatric wards. Br J Clin Pharmacol 57: 464-472.

DE LeON, A., 2006 Palonosetron (Aloxi): a second-generation 5-HT(3) receptor antagonist for chemotherapy-induced nausea and vomiting. Proc (Bayl Univ Med Cent) 19: 413-416.

Dixon, C. M., P. V. Colthup, C. J. Serabjit-Singh, B. M. Kerr, C. C. Boehlert et al., 1995 Multiple forms of cytochrome $\mathrm{P} 450$ are involved in the metabolism of ondansetron in humans. Drug Metab Dispos 23: 1225-1230.

DRIESSEN, B., and W. REIMANN, 1992 Interaction of the central analgesic, tramadol, with the uptake and release of 5-hydroxytryptamine in the rat brain in vitro. $\mathrm{Br} \mathrm{J}$ Pharmacol 105: 147-151.

Egenberger, B., V. Gorboulev, T. Keller, D. Gorbunov, N. Gottlieb et al., 2012. A Substrate Binding Hinge Domain is Critical for Transport-Related Structural Changes of Organic Cation Transporter 1. J Biol Chem.

Eichelbaum, M., M. Ingelman-Sundberg and W. E. Evans, 2006 Pharmacogenomics and individualized drug therapy. Annu Rev Med 57: 119137.

Evans, D. A., A. Mahgoub, T. P. Sloan, J. R. Idle and R. L. Smith, 1980 A family and population study of the genetic polymorphism of debrisoquine oxidation in a white British population. J Med Genet 17: 102-105.

Evans, W. E., and H. L. MCLEOD, 2003 Pharmacogenomics--drug disposition, drug targets, and side effects. N Engl J Med 348: 538-549.

Evans, W. E., and M. V. Relling, 1999 Pharmacogenomics: translating functional genomics into rational therapeutics. Science 286: 487-491.

Fischer, V., A. E. Vickers, F. Heitz, S. MAhadeVAn, J. P. BALdeCK et al., 1994 The polymorphic cytochrome P-4502D6 is involved in the metabolism of both 5hydroxytryptamine antagonists, tropisetron and ondansetron. Drug Metab Dispos 22: 269-274.

FUHR, U., A. JETTER and J. KIRCHHEINER, 2007 Appropriate phenotyping procedures for drug metabolizing enzymes and transporters in humans and their simultaneous use in the "cocktail" approach. Clin Pharmacol Ther 81: 270-283.

Fujita, T., T. J. Urban, M. K. Leabman, K. Fujita and K. M. Giacomini, 2006 Transport of drugs in the kidney by the human organic cation transporter, OCT2 and its genetic variants. J Pharm Sci 95: 25-36. 
Giacomini, K. M., C. M. Brett, R. B. Altman, N. L. Benowitz, M. E. Dolan et al., 2007 The pharmacogenetics research network: from SNP discovery to clinical drug response. Clin Pharmacol Ther 81: 328-345.

Gonzalez, F. J., R. C. Skoda, S. Kimura, M. Umeno, U. M. ZAnger et al., 1988 Characterization of the common genetic defect in humans deficient in debrisoquine metabolism. Nature 331: 442-446.

Gorboulev, V., J. C. Ulzheimer, A. Akhoundova, I. Ulzheimer-Teuber, U. KARBACH et al., 1997 Cloning and characterization of two human polyspecific organic cation transporters. DNA Cell Biol 16: 871-881.

Gorboulev, V., C. VolK, P. Arndt, A. Akhoundova and H. Koepsell, 1999 Selectivity of the polyspecific cation transporter rOCT1 is changed by mutation of aspartate 475 to glutamate. Mol Pharmacol 56: 1254-1261.

Guengerich, F. P., 2008 Cytochrome p450 and chemical toxicology. Chem Res Toxicol 21: 70-83.

GUPTA, S., G. BURCKHARDT and Y. HAGOS, 2012. SLC22 transporter family proteins as targets for cytostatic uptake into tumor cells. Biol Chem 392: 117-124.

HalfPenNy, D. M., L. F. CAllado and J. A. StAmFord, 1999 Is tramadol an antidepressant? Br J Anaesth 82: 480-481.

HeSKETH, P. J., 2008 Chemotherapy-induced nausea and vomiting. N Engl J Med 358: 2482-2494.

Higuchi, R., C. FockleR, G. Dollinger and R. WATSON, 1993 Kinetic PCR analysis: real-time monitoring of DNA amplification reactions. Biotechnology (N Y) 11: 1026-1030.

Ho, R. H., and R. B. KIM, 2005 Transporters and drug therapy: implications for drug disposition and disease. Clin Pharmacol Ther 78: 260-277.

Honig, P. K., D. C. Wortham, K. Zamani, D. P. Conner, J. C. Mullin et al., 1993 Terfenadine-ketoconazole interaction. Pharmacokinetic and electrocardiographic consequences. Jama 269: 1513-1518.

INGELMAN-SunDBERG, M., 2004 Pharmacogenetics of cytochrome P450 and its applications in drug therapy: the past, present and future. Trends Pharmacol Sci 25: 193-200.

INGELMAN-SUNDBERG, M., 2005 Genetic polymorphisms of cytochrome P450 2D6 (CYP2D6): clinical consequences, evolutionary aspects and functional diversity. Pharmacogenomics J 5: 6-13.

InNocenti, F., S. D. Undevia, L. IYeR, P. X. Chen, S. DAS et al., 2004 Genetic variants in the UDP-glucuronosyltransferase $1 \mathrm{~A} 1$ gene predict the risk of severe neutropenia of irinotecan. J Clin Oncol 22: 1382-1388.

JANicki, P. K., H. G. Schuler, T. M. JARZEMBOWSKI and M. Rossi, 2ND, 2006 Prevention of postoperative nausea and vomiting with granisetron and dolasetron in relation to CYP2D6 genotype. Anesth Analg 102: 1127-1133.

JOHANSSON, I., and M. INGELMAN-SUNDBERG, Genetic polymorphism and toxicology-with emphasis on cytochrome p450. Toxicol Sci 120: 1-13.

Johansson, I., E. LundQvist, L. Bertilsson, M. L. DAhl, F. SJoQvist et al., 1993 Inherited amplification of an active gene in the cytochrome P450 CYP2D locus as a cause of ultrarapid metabolism of debrisoquine. Proc Natl Acad Sci U S A 90: $11825-11829$.

JONKER, J. W., and A. H. SCHINKEL, 2004 Pharmacological and physiological functions of the polyspecific organic cation transporters: OCT1, 2, and 3 (SLC22A1-3). J Pharmacol Exp Ther 308: 2-9. 
Kaiser, R., O. Sezer, A. PAPIES, S. BAuer, C. Schelenz et al., 2002 Patient-tailored antiemetic treatment with 5-hydroxytryptamine type 3 receptor antagonists according to cytochrome P-450 2D6 genotypes. J Clin Oncol 20: 2805-2811.

Kanebratt, K. P., U. Diczfalusy, T. Backstrom, E. Sparve, E. Bredberg et al., 2008 Cytochrome $\mathrm{P} 450$ induction by rifampicin in healthy subjects: determination using the Karolinska cocktail and the endogenous CYP3A4 marker 4beta-hydroxycholesterol. Clin Pharmacol Ther 84: 589-594.

Karbach, U., J. Kricke, F. Meyer-Wentrup, V. GorbouleV, C. VolK et al., 2000 Localization of organic cation transporters OCT1 and OCT2 in rat kidney. Am J Physiol Renal Physiol 279: F679-687.

Keller, T., B. Egenberger, V. Gorboulev, F. Bernhard, Z. UzelaC et al., 2011. The large extracellular loop of organic cation transporter 1 influences substrate affinity and is pivotal for oligomerization. J Biol Chem 286: 37874-37886.

Kerb, R., U. Brinkmann, N. Chatskaia, D. Gorbunov, V. Gorboulev et al., 2002 Identification of genetic variations of the human organic cation transporter hOCT1 and their functional consequences. Pharmacogenetics 12: 591-595.

KidO, Y., P. MATSSON and K. M. GiACOMINI, 2011. Profiling of a prescription drug library for potential renal drug-drug interactions mediated by the organic cation transporter 2. J Med Chem 54: 4548-4558.

Kimura, S., M. Umeno, R. C. Skoda, U. A. Meyer and F. J. Gonzalez, 1989 The human debrisoquine 4-hydroxylase (CYP2D) locus: sequence and identification of the polymorphic CYP2D6 gene, a related gene, and a pseudogene. Am J Hum Genet 45: 889-904.

KiRChHEINER, J., J. T. KeUlen, S. BAUER, I. RoOTS and J. BROCKMOLLER, 2008 Effects of the CYP2D6 gene duplication on the pharmacokinetics and pharmacodynamics of tramadol. J Clin Psychopharmacol 28: 78-83.

KoEPSELL, H., 2011. Substrate recognition and translocation by polyspecific organic cation transporters. Biol Chem 392: 95-101.

KoEPSELl, H., 2004 Polyspecific organic cation transporters: their functions and interactions with drugs. Trends Pharmacol Sci 25: 375-381.

KoEPSELl, H., and H. ENDOU, 2004 The SLC22 drug transporter family. Pflugers Arch 447: 666-676.

KoePSELl, H., K. LiPS and C. VoLK, 2007 Polyspecific organic cation transporters: structure, function, physiological roles, and biopharmaceutical implications. Pharm Res 24: 1227-1251.

Koepsell, H., B. M. Schmitt and V. Gorboulev, 2003 Organic cation transporters. Rev Physiol Biochem Pharmacol 150: 36-90.

Kuhne, A., M. V. Tzvetkov, Y. Hagos, H. Lage, G. Burckhardt et al., 2009 Influx and efflux transport as determinants of melphalan cytotoxicity: Resistance to melphalan in MDR1 overexpressing tumor cell lines. Biochem Pharmacol 78: 45-53.

Kummer, W., S. Wiegand, S. Akinci, A. H. Schinkel, J. Wess et al., 2006 Role of acetylcholine and muscarinic receptors in serotonin-induced bronchoconstriction in the mouse. J Mol Neurosci 30: 67-68.

LAI, J., S. W. MA, F. PORRECA and R. B. RAFFA, 1996 Tramadol, M1 metabolite and enantiomer affinities for cloned human opioid receptors expressed in transfected HN9.10 neuroblastoma cells. Eur J Pharmacol 316: 369-372.

Ledesma, M. C., and J. A. AgundeZ, 2005 Identification of subtypes of CYP2D gene rearrangements among carriers of CYP2D6 gene deletion and duplication. Clin Chem 51: 939-943. 
Lin, C. J., Y. TAI, M. T. HuAnG, Y. F. TsaI, H. J. Hsu et al., 2010. Cellular localization of the organic cation transporters, OCT1 and OCT2, in brain microvessel endothelial cells and its implication for MPTP transport across the blood-brain barrier and MPTP-induced dopaminergic toxicity in rodents. J Neurochem 114: 717-727.

Link, E., S. Parish, J. Armitage, L. Bowman, S. Heath et al., 2008 SLCO1B1 variants and statin-induced myopathy--a genomewide study. N Engl J Med 359: 789-799.

LiPS, K. S., C. Volk, B. M. Schmitt, U. Pfeil, P. Arndt et al., 2005 Polyspecific cation transporters mediate luminal release of acetylcholine from bronchial epithelium. Am J Respir Cell Mol Biol 33: 79-88.

Llerena, A., J. CobaledA, C. MartineZ and J. BeniteZ, 1996 Interethnic differences in drug metabolism: influence of genetic and environmental factors on debrisoquine hydroxylation phenotype. Eur J Drug Metab Pharmacokinet 21: 129-138.

Llerena, A., P. Dorado and E. M. Penas-Lledo, 2009 Pharmacogenetics of debrisoquine and its use as a marker for CYP2D6 hydroxylation capacity. Pharmacogenomics 10: 17-28.

LYNCH, T., and A. PRICE, 2007 The effect of cytochrome P450 metabolism on drug response, interactions, and adverse effects. Am Fam Physician 76: 391-396.

Mahgoub, A., J. R. Idle, L. G. Dring, R. LAnCASter and R. L. SMith, 1977 Polymorphic hydroxylation of Debrisoquine in man. Lancet 2: 584-586.

MAHLBERG, R., D. KUNZ, J. SASSE and J. KIRCHHEINER, 2004 Serotonin syndrome with tramadol and citalopram. Am J Psychiatry 161: 1129.

Markey, S. P., J. N. Johannessen, C. C. Chiueh, R. S. Burns and M. A. Herkenham, 1984 Intraneuronal generation of a pyridinium metabolite may cause druginduced parkinsonism. Nature 311: 464-467.

Mashru, R.C., Sutariya, V.B., Sankalia, M.G., Sankalia, J.M. 2005 Effect of pH on in vitro permeation of ondansetron hydrochloride across porcine buccal mucosa.

Pharm Dev Technol; 10: 241-247.

Meyer-Wentrup, F., U. Karbach, V. Gorboulev, P. ARndt and H. Koepsell, 1998 Membrane localization of the electrogenic cation transporter rOCT1 in rat liver. Biochem Biophys Res Commun 248: 673-678.

MeYer, U. A., 2000 Pharmacogenetics and adverse drug reactions. Lancet 356: 16671671.

Meyer, U. A., 2004 Pharmacogenetics - five decades of therapeutic lessons from genetic diversity. Nat Rev Genet 5: 669-676.

MichaleTS, E. L., 1998 Update: clinically significant cytochrome P-450 drug interactions. Pharmacotherapy 18: 84-112.

MoAdDEl, R., S. RAVichandran, F. Bighi, R. YAMAGUChI and I. W. WAiner, 2007 Pharmacophore modelling of stereoselective binding to the human organic cation transporter (hOCT1). Br J Pharmacol 151: 1305-1314.

Nies, A. T., U. Hofmann, C. Resch, E. Schaeffeler, M. Rius et al., Proton pump inhibitors inhibit metformin uptake by organic cation transporters (OCTs). PLoS One 6: e22163.

NiEs, A. T., H. KoePsell, S. Winter, O. BurK, K. Klein et al., 2009 Expression of organic cation transporters OCT1 (SLC22A1) and OCT3 (SLC22A3) is affected by genetic factors and cholestasis in human liver. Hepatology 50: 1227-1240.

PaAR, W. D., P. Frankus and H. J. Dengler, 1992 The metabolism of tramadol by human liver microsomes. Clin Investig 70: 708-710. 
PAar, W. D., S. Poche, J. Gerloff and H. J. Dengler, 1997 Polymorphic CYP2D6 mediates O-demethylation of the opioid analgesic tramadol. Eur J Clin Pharmacol 53: 235-239.

Pedersen, R. S., P. DAMkier and K. Brosen, 2005 Tramadol as a new probe for cytochrome P450 2D6 phenotyping: a population study. Clin Pharmacol Ther 77: 458-467.

Popp, C., V. Gorboulev, T. D. Muller, D. Gorbunov, N. Shatskaya et al., 2005 Amino acids critical for substrate affinity of rat organic cation transporter 1 line the substrate binding region in a model derived from the tertiary structure of lactose permease. Mol Pharmacol 67: 1600-1611.

Poulsen, L., L. Arendt-Nielsen, K. Brosen and S. H. Sindrup, 1996 The hypoalgesic effect of tramadol in relation to CYP2D6. Clin Pharmacol Ther 60: 636-644.

Ravid, A., D. Rocker, A. Machlenkin, C. Rotem, A. Hochman et al., 1999 1,25Dihydroxyvitamin D3 enhances the susceptibility of breast cancer cells to doxorubicin-induced oxidative damage. Cancer Res 59: 862-867.

Roberts, B. J., B. J. Song, Y. SoH, S. S. PARK and S. E. ShOAF, 1995 Ethanol induces CYP2E1 by protein stabilization. Role of ubiquitin conjugation in the rapid degradation of CYP2E1. J Biol Chem 270: 29632-29635.

Romaine, S. P., K. M. Bailey, A. S. Hall and A. J. BAlmforth, 2010. The influence of SLCO1B1 (OATP1B1) gene polymorphisms on response to statin therapy. Pharmacogenomics J 10: 1-11.

SAadAtmand, A. R., S. TAdjerpisheh, J. Brockmoller and M. V. TzVetKov, 2012. The prototypic pharmacogenetic drug debrisoquine is a substrate of the genetically polymorphic organic cation transporter OCT1. Biochem Pharmacol 83: $1427-1434$.

Sachse, C., J. Brockmoller, S. BAuer and I. Roots, 1997 Cytochrome P450 2D6 variants in a Caucasian population: allele frequencies and phenotypic consequences. Am J Hum Genet 60: 284-295.

Seithel, A., H. Glaeser, M. F. Fromm and J. Konig, 2008 The functional consequences of genetic variations in transporter genes encoding human organic anion-transporting polypeptide family members. Expert Opin Drug Metab Toxicol 4: 51-64.

Shikata, E., R. Yamamoto, H. Takane, C. Shigemasa, T. IKeda et al., 2007 Human organic cation transporter (OCT1 and OCT2) gene polymorphisms and therapeutic effects of metformin. J Hum Genet 52: 117-122.

Shnitsar, V., R. Eckardt, S. Gupta, J. Grottker, G. A. Muller et al., 2009 Expression of human organic cation transporter 3 in kidney carcinoma cell lines increases chemosensitivity to melphalan, irinotecan, and vincristine. Cancer Res 69: 1494-1501.

Shu, Y., M. K. Leabman, B. Feng, L. M. Mangravite, C. C. Huang et al., 2003 Evolutionary conservation predicts function of variants of the human organic cation transporter, OCT1. Proc Natl Acad Sci U S A 100: 5902-5907.

Shu, Y., S. A. SheArdown, C. Brown, R. P. Owen, S. Zhang et al., 2007 Effect of genetic variation in the organic cation transporter 1 (OCT1) on metformin action. J Clin Invest 117: 1422-1431.

Soderback, E., A. L. ZaCKrisson, B. Lindblom and A. Alderborn, 2005 Determination of CYP2D6 gene copy number by pyrosequencing. Clin Chem 51: $522-531$. 
Sproule, B. A., S. V. Otton, S. W. Cheung, X. H. Zhong, M. K. Romach et al., 1997 CYP2D6 inhibition in patients treated with sertraline. J Clin Psychopharmacol 17: $102-106$.

StAmer, U. M., K. LeHnen, F. HothKer, B. BAYERER, S. Wolf et al., 2003 Impact of CYP2D6 genotype on postoperative tramadol analgesia. Pain 105: 231-238.

Stamer, U. M., F. Musshoff, M. Kobilay, B. MadeA, A. Hoeft et al., 2007 Concentrations of tramadol and O-desmethyltramadol enantiomers in different CYP2D6 genotypes. Clin Pharmacol Ther 82: 41-47.

Stamer, U. M., L. Zhang and F. Stuber, 2010. Personalized therapy in pain management: where do we stand? Pharmacogenomics 11: 843-864.

Sugawara-Yokoo, M., Y. Urakami, H. Koyama, K. Fujikura, S. Masuda et al., 2000 Differential localization of organic cation transporters rOCT1 and rOCT2 in the basolateral membrane of rat kidney proximal tubules. Histochem Cell Biol 114: $175-180$.

TAKedA, M., S. Khamdang, S. NARIKAwa, H. KimUra, Y. Kobayashi et al., 2002 Human organic anion transporters and human organic cation transporters mediate renal antiviral transport. J Pharmacol Exp Ther 300: 918-924.

Takeuchi, A., H. Motohashi, M. OKUda and K. InUi, 2003 Decreased function of genetic variants, Pro283Leu and Arg287Gly, in human organic cation transporter hOCT1. Drug Metab Pharmacokinet 18: 409-412.

TANAKA, E., N. KuRATA and H. YASUHARA, 2003 How useful is the "cocktail approach" for evaluating human hepatic drug metabolizing capacity using cytochrome P450 phenotyping probes in vivo? J Clin Pharm Ther 28: 157-165.

TIRONA, R. G., and K. S. PANG, 1999 Bimolecular glutathione conjugation kinetics of ethacrynic acid in rat liver: in vitro and perfusion studies. J Pharmacol Exp Ther 290: $1230-1241$.

Tucker, G. T., J. B. Houston and S. M. HuAng, 2001 EUFEPS conference report. Optimising drug development: strategies to assess drug metabolism/transporter interaction potential - towards a consensus. European Federation of Pharmaceutical Sciences. Eur J Pharm Sci 13: 417-428.

Tzvetkov, M. V., A. R. SaAdatmand, K. Bokelmann, I. Meineke, R. Kaiser et al., 2010. Effects of OCT1 polymorphisms on the cellular uptake, plasma concentrations and efficacy of the 5-HT(3) antagonists tropisetron and ondansetron. Pharmacogenomics J 12: 22-29.

Tzvetkov, M. V., A. R. SaAdatmand, J. Lotsch, I. Tegeder, J. C. Stingl et al., 2011. Genetically polymorphic OCT1: another piece in the puzzle of the variable pharmacokinetics and pharmacodynamics of the opioidergic drug tramadol. Clin Pharmacol Ther 90: 143-150.

TzvetKov, M. V., S. V. Vormfelde, D. Balen, I. Meineke, T. Schmidt et al., 2009 The effects of genetic polymorphisms in the organic cation transporters OCT1, OCT2, and OCT3 on the renal clearance of metformin. Clin Pharmacol Ther 86: 299-306.

Vormfelde, S. V., M. R. ToliAt, M. Schirmer, I. MEINEKe, P. NuRnBerg et al., 2008 The polymorphisms Asn130Asp and Val174Ala in OATP1B1 and the CYP2C9 allele *3 independently affect torsemide pharmacokinetics and pharmacodynamics. Clin Pharmacol Ther 83: 815-817.

WANG, G., H. ZHANG, F. HE and X. FANG, 2006 Effect of the CYP2D6*10 C188T polymorphism on postoperative tramadol analgesia in a Chinese population. Eur J Clin Pharmacol 62: 927-931.

WeInShILbOUM, R., 2003 Inheritance and drug response. N Engl J Med 348: 529-537. 
WiLKINSON, G. R., 2005 Drug metabolism and variability among patients in drug response. N Engl J Med 352: 2211-2221.

YASUKOCHI, Y., and Y. SATTA, 2011. Evolution of the CYP2D gene cluster in humans and four non-human primates. Genes Genet Syst 86: 109-116.

Yonezawa, A., S. Masuda, S. Yokoo, T. Katsura and K. Inui, 2006 Cisplatin and oxaliplatin, but not carboplatin and nedaplatin, are substrates for human organic cation transporters (SLC22A1-3 and multidrug and toxin extrusion family). J Pharmacol Exp Ther 319: 879-886.

ZameK-Gliszczynski, M. J., K. A. Hoffmaster, K. NeZAsa, M. N. TAllman and K. L. BROUWER, 2006 Integration of hepatic drug transporters and phase II metabolizing enzymes: mechanisms of hepatic excretion of sulfate, glucuronide, and glutathione metabolites. Eur J Pharm Sci 27: 447-486.

ZANGer, U. M., S. RAimundo and M. EichelbauM, 2004 Cytochrome P450 2D6: overview and update on pharmacology, genetics, biochemistry. Naunyn Schmiedebergs Arch Pharmacol 369: 23-37.

Zgheib, N. K., R. F. Frye, T. S. Tracy, M. Romkes and R. A. Branch, 2006 Validation of incorporating flurbiprofen into the Pittsburgh cocktail. Clin Pharmacol Ther 80: 257-263.

Zhang, L., M. J. Dresser, A. T. Gray, S. C. Yost, S. Terashita et al., 1997 Cloning and functional expression of a human liver organic cation transporter. Mol Pharmacol 51: 913-921.

ZHANG, L., M. E. SCHANER and K. M. GIACOMINI, 1998 Functional characterization of an organic cation transporter (hOCT1) in a transiently transfected human cell line (HeLa). J Pharmacol Exp Ther 286: 354-361.

Zhang, S., K. S. Lovejoy, J. E. Shima, L. L. LagPaCAN, Y. Shu et al., 2006 Organic cation transporters are determinants of oxaliplatin cytotoxicity. Cancer Res 66: 8847-8857.

Zhen, Y., O. Slanar, K. W. Krausz, C. Chen, J. SlaviK et al., 2006 3,4Dehydrodebrisoquine, a novel debrisoquine metabolite formed from 4hydroxydebrisoquine that affects the CYP2D6 metabolic ratio. Drug Metab Dispos 34: 1563-1574. 


\section{CURRICULUM VITAE}

\section{PERSONAL INFORMATION}

Name: Ali Reza Saadatmand

Date of birth: 18 September 1977

Place of birth: Shiraz, Iran

\section{EDUCATION AND QUALIFICATIONS}

$\begin{array}{ll}2009-2012 & \begin{array}{l}\text { University Medical Center of the George August } \\ \text { University, Göttingen, Germany }\end{array} \\ \text { PhD student in the Molecular Medicine Study Program } \\ 2001-2004 & \begin{array}{l}\text { College of Agriculture, Shiraz University, Iran } \\ \text { MSc. Plant Pathology (Mycology) }\end{array} \\ 1996-2000 & \begin{array}{l}\text { College of Agriculture, Shiraz University, Iran } \\ \text { BSc. Plant Protection }\end{array} \\ 1991-1995 & \begin{array}{l}\text { Towhid High School, Shiraz, Iran } \\ \text { Diploma in Science }\end{array}\end{array}$

\section{HONORS AND AWARDS:}

2009 - 2012 Scholarship from German Research Foundation (DFG)

2004 Diploma of honors in MSc. From Shiraz University, Shiraz, Iran

1996-2004 Free education at governmental university in B.Sc and M.Sc periods 